\title{
CONDENSED MILK
}

\author{
AND \\ MILK POWDER \\ BY \\ 0. F. HUNZIKER
}




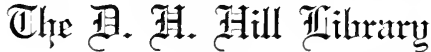

978

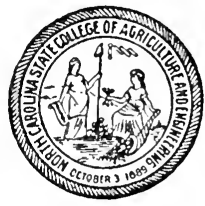

X̃orth Uaralina State Uallege

SF259

$\mathrm{H} 8$ 
Date Due

$$
\text { L7.2A }
$$

$$
\begin{aligned}
& 23 \mathrm{Aug} \\
& 18 \mathrm{Nav} 50
\end{aligned}
$$

TSUL 131993 

• 

TO THE

MEMORY

OF

MY FATHER

THIS VOLUME IS DEDICATED 
COPYRIGHT, 1914

O. F. HUNZIKER

ERRATA: Page 186, Figure 57, “The Passburg Milk Dryer" should read "The Buflovak Milk Dryer."

Page 195: "The Machine used was of the Passburg type" should read "The Machine used was of the Buflovak type." 


\section{GONDENSED MILK AND MILK POWDER}

Prepared for the use of

\section{Milk Gondenseries, Dairy Students and Pure Food Departments}

By

otTo F. HUNZIKER, B. S. A., M. S. A.

Professor of Dairy IInsbandry, Purdue University

and

Chief of the Dairy Department of the

Indiana Agricultural Experiment Station

LaFayette, Indiana

U. S. A.

Pablished by the Author

LaFayette, Indiana 


\section{PREFACE}

This book treats of the various phases of the condensed milk and powdered milk industry. It discusses every step in the process of manufacture, following the milk from the farmer's door to the finished product in the pantry of the consumer. The processes of condensing and desiccating milk, skim milk, buttermilk and whey are given special attention and the defects of the product, their causes and prevention are explained in detail.

The inception of this publication is the result of innumerable and persistent calls for definite and reliable information on the subject of condensed milk and milk powder, from manufacturers in this country and in foreign lands; from parties contemplating embarking in the business; from national and state experiment stations which are oftentimes called upon to investigate condensed milk defects; from dairy schools desiring to give instruction on the subject; from national and state pure food departments, seeking information concerning the possibilities and linitations of manufacture, in their efforts to formulate and enforce standards and laws; and from comme"cial chemists in need of reliable methods of analyses of these iial dairy products.

The information contained in this volume represents the author's experience, covering a period of twelve years, in the prac1 - al manufacture of condensed milk, as expert advisor to milk 1 ndensing concerns in the United States, Canada and Australia, and as visitor of condensed milk and milk powder factories in this country and in Europe.

It is the author's hope that the information contained herein may serve as a guide to manufacturers, investigators, teachers and food authorities, alike; that it may assist in a better understanding and wider dissemination of the principles, phenomena and facts involved in the processes of manufacture; and that it may lift the obstructing veil of unnecessary secrecy which has hovered over these industries since their beginning, curtailing their development and depriving them of much of the light of advanced science to which they are justly entitled and which they need for their greatest development for the lasting benefit of the producer, manufaçturer and consumer alike.

O. F. Hunziker.

Purdue University, March, I9I4. 


\title{
CONTENTS
}

\author{
PART I \\ CONDENSED MILK
}

Definition

Chapter I

History and Development of Industry-Invention of process; development of industry; output of condensed milk in the United States.

Pages 1-16

\section{Chapter II}

Essentials of Suitable Locations for Milk Condensing Factories-Milk supply; water supply; transportation facilities; other conditions.

Building and Equipment-Material of construction; drainage; general plan of factory; list of equipment; economic arrangement of machinery; sanitary arrangement of machinery............. Pages 16-27

\section{Chapter III}

Milk Supply-Basis of buying milk; quality; control of quality; inspection of milk at the condensery; tests for purity of milk.

Factory Sanitation-Effect on patrons; effect on wholesomeness of product; effect on marketable property of product; how to keep factory in sanitary condition $\ldots \ldots \ldots \ldots \ldots \ldots \ldots \ldots \ldots$. $\ldots \ldots \ldots$ ages $27-36$

\section{PART II}

\section{MANUFACTURE OF SWEETENED CONDENSED MILK}

Definition

\section{Chapter IV}

Heating-Purpose; temperature; manner; advantages and disadvantages of different methods.

Addition of Sugar-Kinds; quality; amount; mixing the sugar. Pages 37-45

\section{Chapter V}

Condensing-Description of the vacuum pan.

The Condenser-Surface condenser; barometric condenser; wet-vacuum spray condenser; care of the condenser.

The Expansion Tank, Catch-All, or Milk Trap.

The Vacuum Pump.

Science and Practice of Condensing in Vacuo-Object; relation of pressure to boiling point; relation of altitude to atmospheric pressure; relation of steam pressure in jacket and coils, water in condenser, temperature in pan, and vacuum, to rapidity of evaporation.

Starting the Pan.

Operating the Pan.

Prevention of Accidents ............................... 45-66 


\title{
Chapter VI
}

Striking or Finishing the Batch-Definition; ratio of concentration; methods of striking.

Use of the Beaume hydrometer; correction of Beaume reading for temperature variations; specific gravity of sweetened condensed milk of different Beaume degrees; sampling the batch.

Drawing off the condensed milk.

Cooling the Condensed Milk................................ 66-73

\section{Chapter VII}

Filling- Filling in barrels; filling in cans.

Sealing-Kinds of seals; soldering devices and machinery; solder; soldering flux; gas supply, gas generators................... $73-80$

\section{PART III}

\section{MANUFACTURE OF UNSWEETENED CONDENSED MILK}

\author{
EVAPORATED MILK
}

Definition.

Chapter VIII

Quality of Fresh Milk.

Heating the Milk

. Pages $80-83$

Condensing.

\section{Chapter IX}

Striking-Use of the Beaume hydrometer; correction of Beaume reading at temperatures other than $60^{\circ} \mathrm{F}$; calculation of specific gravity from Beaume reading $\ldots \ldots \ldots \ldots \ldots \ldots \ldots \ldots \ldots \ldots \ldots \ldots \ldots \ldots$. $8 \ldots \ldots \ldots$

\section{Chapter X}

Homogenizing-Purpose; principle of the homogenizer; kinds of homogenizers; operation of the homogenizer; effect on casein. .Pages 86-89

Cooling.

\section{Chapter XI}

Filling, Filling Machines.

Sealing, Sealing Machines

Pages $89-93$

\section{Chapter XII}

Sterilizing-Purpose of sterilization; sterilizers; loading the sterilizer; uniform distribution of heat; temperature and time of exposure; qualifications of processor; rapid and uniform cooling; fractional sterilization.

Shaking--Methods of shaking; speed of the shaker; efficiency of different types of shakers; formation of curd not desirable nor necessary.

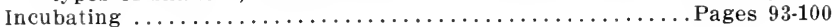




\section{Chapter XIII}

Plain Condensed Bulk Milk-Definition; quality of fresh milk; heating of fresh milk; condensing; superheating; striking; ratio of concentration; cooling .................................. 100 102

\section{Chapter XIV}

Concentrated Milk-Definition; apparatus needed; operation of Campbell Process; advantages and disadvantages of Campbell process.

Chapter XV

Condensed Buttermilk-Manufacture; chemical composition; uses.

Condensed Whey, Myseost, or Primost...................... 104-106

\section{PART IV}

\section{FROM FACTORY TO CONSUMER}

Stamping.

\section{Chapter XVI}

Inspecting-Checking the work of the sealers; disposition of leaky cans; importance of inspection.

Labeling-Labeling machines; principle of labeling machines; wrinkles and rust spots on labels.

Packing-Marking the cases; packing condensed milk for export.

Pages 107-112

Chapter XVII

Storage-Purpose of storing; effect of storage temperature; advisability of storing.

Transportation Pages 112-115

\section{Chapter XVIII}

Markets-Market prices of condensed milk; exports and imports.

Pages 115-119

Chapter XIX

Chemical Composition of Condensed Milk-Sweetened condensed milk; evaporated milk; plain condensed bulk milk; concentrated milk.

Pages 119-127

Chapter XX

Sanitary Purity and Dietetic Value of Condensed Milk.....Pages 127-132

\section{Chapter XXI}

Condensed Milk Standards and Laws-Federal standards for: Sweetened condensed milk; evaporated milk.

Modified standard; difficulties of meeting standard; putting composition of evaporated milk on label.

Condensed Skim Milk ............................. 132-136 


\section{Chapter XXII}

Cost of Manufacture-General Discussion.

Cost of sweetened condensed milk per case.

Cost of evaporated milk per case.................. Pages 136-139

\section{PART V}

\section{CONDENSED MILK DEFECTS, THEIR CAUSES AND PREVENTIONS}

Classification of Defects.

\section{Chapter XXIII}

Defective Sweetened Condensed Milk-Sandy, rough or gritty; settled; thickened and cheesy; lumpy; blown or fermented; rancid; putrid;

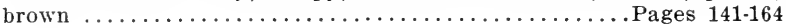

\section{Chapter XXIV}

Defective Evaporated Milk and Plain Condensed Bulk Milk-Curdy; grainy; separated and churned; fermented, acid curd, bitter curd, gassy fermentation.

Swelled cans due to freezing; swelled cans due to chemical action; brown; gritty ........................................ 164-177

\section{Chapter XXV}

Adulterations of Condensed Milk-Skimming; addition of artificial fats; addition of commercial glucose; addition of bi-carbonate of soda, ammonium hydroxide, lime water and other alkali; addition of cream of tartar; addition of starch..................... Pages 177-180

\section{PART VI}

\section{MANUFACTURE OF MILK POWDER}

Definition.

Chapter XXVI

Kinds.

History and Development of Industry.

Quality of Fresh Milk.

Description of Principal Processes; Wimmer process; Just-Hatmaker process; Eckenburg process; Passburg process; Campbell process;

Merrell-Gare process . ................... Pages 181-190

Packing for Market.

\section{Chapter XXVII}

Composition.

Defects of Milk Powders-High water content; insoluble milk powders; non-miscible milk powders; rancid milk powders.

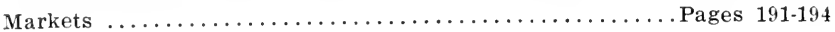

\section{Chapter XXVIII}

Dried Buttermilk and Dried Whey-Manufacture of; composition of buttermilk powders ............................. 194-197 


\section{PART VII}

\section{TESTS AND ANALYSES OF MILK, CONDENSED MILK AND MILK POWDERS}

\section{Chapter XXIX}

Practical Methods of Systematic Examination of Product for Marketable Properties-Number of samples needed; frequency of examination; technique of examination; interpretation of results; systematic examination a necessary factor of economic manufacture. Pages 197-200

\section{Chapter XXX}

Chemical Tests and Analyses-Milk-specific gravity-total solids-ashtotal nitrogen-casein and albumin-lactose-butter fat.

Sweetened Condensed Milk-Preparation of sample-specific gravity - total solids-ash-proteids-lactose-butter fat-sucrose-milk solids.

Evaporated Milk-preparation of sample-specific gravity-total solids-tables showing total solids, when Beaume reading and per cent. fat are known-ash-proteids-lactose-butter fat.

Milk Powders-total solids-ash-proteids-lactose-sucrose-butter fat ............................................. 200-224

\section{Chapter XXXI}

Detection of Adulterants and Preservatives-Extraneous water; skimming; extraneous water and skimming; artificial coloring; sucrose of lime; lime; gelatin; formaldehyde; boric acid; benzoic acid; salicylic acid; hydrogen peroxide ....................... 224-231

\section{Chapter XXXII}

Bacteriological Analysis.

Table Showing Legal Standards of Dairy Products by States.Pages 231-233 


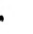




\section{ACKNOWLEDGMENTS}

It is my pleasure to express my high appreciation and gratitude to Messrs. George Spitzer, Associate in Dairy Chemistry, and W. F. Epple, Assistant Dairy Chemist, Purdue University Agricultural Experiment Station, for much valuable assistance in the preparation of the chapter on "Chemical Analysis"; to Professors E. S. Ferry, Chief of the Department of Physics, G. A. Young, Chief of the Department of Mechanical Engineering, and Mr. Arthur Dufty, Superintendent of Buildings, Purdue University, for timely suggestions on the scientific relation to the subject of physics and mechanics; to Messrs. Ed. B. Gage. Superintendent of the Missouri Condensed Milk Co.. Kohoka, Mo., Frank A. Page, Manager of Hires Condensed Milk Co., Lake Odessa, Mich., and IV. T. Wilson, President of the Indiana Condensed Milk Co., Sheridan, Ind., for valuable data connected with practical manufacture; to Mr. F. F. Taylor, President of Borden's Condensed Milk Co., for biographic data relating to Gail Borden and for cuts for illustrations of Gail Borden and of the first milk condensing factory in the United States; to Niss Nellie Tracy, Secretary of the Purdue Agricultural Experiment Station, for most valuable services in proof-reading; and to the following manufacturers of machinery and supplies related to the manufacture of condensed milk and milk powder, for valuable cuts for illustration in the text and for their generous contributions of advertisements as shown at the conclusion of this volume, whose kindly and active cooperation made possible the issuance of this publication: American Can Co., A. H. Barber Creamery Supply Co., Bausch and Lomb Optical Co., Bessire and Co., Burt Machine Co., Dairy Machinery and Construction Co., DeLaval Separator Co., F. G. Dickerson, Eimer and Amend, J. B. Ford and Co., Emil Greiner Co., William Grelck, Arthur Harris and Co., F. K. Higbie Co., Howe Scale Co., Ernst Leitz, Louis F. Nafis, E. H. Sargent and Co., Schaefer Manufacturing Co., Spencer Lens Co., Sprague Canning Machinery Co., Stevenson Company, Herman Stier Manufacturing and Engineering Co., Sturges and Burn Manufacturing Co., C. J. Tagliabue Manufacturing Co., Taylor Instrument Co., The Engineering Co., The Preservaline Manufacturing Co., The Torsion Balance Co., Union Fibre Co., and Wagner Glass Works. 


\section{Dairy Building \\ Purdue University \\ LaFayette, Indiana}

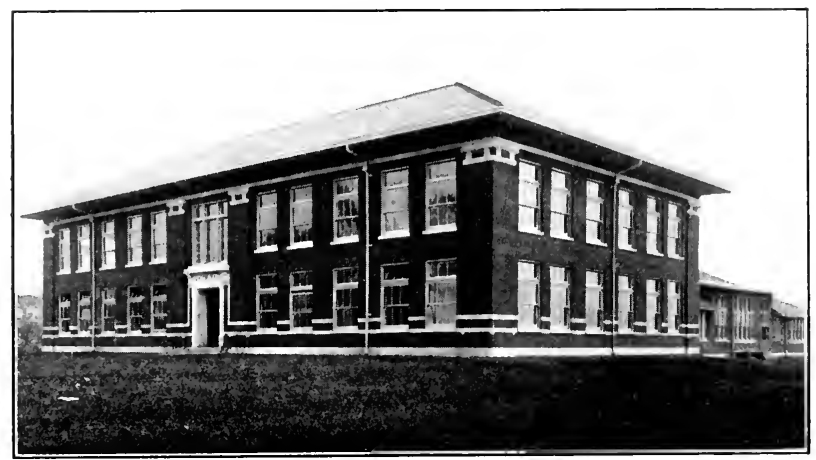

Fig. 1.

The dairy school is the manufactory of dairy knowledge, the clearing house of dairy thought, and the distributory of the dairy gospel.-Hunziker. 


\title{
PART I \\ CONDENSED MILK
}

\author{
CHAPTER I \\ DEFINITION
}

Condensed milk is cow's fresh milk from which a considerable portion of the water has been evaporated and to which sucrose may or may not have been added.

There are chiefly two classes of condensed milk, namely, sweetened and unsweetened. Both reach the market in hermetically sealed tin cans intended for direct consumption, and in bulk, intended for bakers, confectioners and ice cream manufacturers.

A portion of the condensed milk on the market is made from the chief by-products of milk, skim milk and buttermilk. Conclensed skim milk supplies the same markets as condensed whole milk sold in bulk. Condensed buttermilk furnishes a valuable chicken feed. It has, also, been recommended for medicinal purposes.

\section{HISTORY AND DEVELOPMENT OF INDUSTRY}

Invention of Process.-Condensed milk is the child of the nineteenth century. Its origin does not date back far, and its innovation and rapid development stand in sharp contrast to those of the manufacture of butter and cheese, industries to which reference is made in the Old Testament ${ }^{1}$ and the evolution of which has been very gradual. Notwithstanding the newness of this product, its manufacture has assumed such proportions that today it occupies a prominent place among the leading branches of clairy manufactures.

The condensed milk industry was introduced at about the same time as the factory system of the butter and cheese industry; although, for many years before the invention of a successful process of condensing milk, methods had been sought to preserve milk.

\footnotetext{
${ }^{2}$ Book of Genesis, C. 18, V. 8: "Ancl he took butter and milk and the calf he had dressed and set it before them"

Book of Jol, C. 10, V. 10: "Hast thou not poureal me out like milk and curdled me like eheese"
} 
The American, Gail Iorden, the inventor of the manufacture of condensed milk, is said to have experimented some ten years before he finally decided that a semi-fluid state, produced by evaporation in vacuo, was the best form of preservation. He first applied for a patent in 1853 , but it was not until three years later that the Patent Office appreciated the originality and value of his

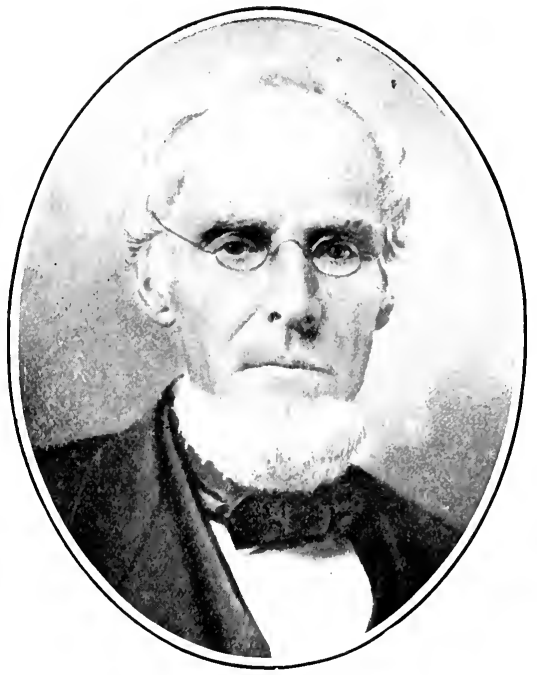

Fig. 2. Gail Borden

claim sufficiently to grant him a patent. In August, 1856, he was awarded a patent on his process both by the United States and by England.

In his application Mr. Borden says: ${ }^{1}$

"I am aware that sugar, and various extracts, have been and are now concentrated in vacuo under a low degree of heat, to prevent discoloration or burning. I do not claim concentrating milk in a vacuum pan for such a purpose, my object being to exclude the

1 "A Brief Sketch of Gail Borden" by S. L. Goodale, Secretary Maine State Board of Agriculture, 1872.-Courtesy of F. F. Taylor, President of Borden's Condensed Milk Company 
air from the beginning of the process to the end, to prevent incipient decomposition. This is important and I claim the discovery."

The claim, United States Patent, August, I 856 , is in the following words:

"Prolucing concentrated sweet milk by evaporation in a'acuo, substantially as set forth, - the same having no sugar or other foreign matter mixed with it."

Since the introduction of the process of milk condensing, invented and patented by Borden, numerous modifications of the process, as well as entirely different processes, have been inventerl in this country and abroad. The most characteristic among these are: condensation by refrigeration, by contrifugal force, by boiling under atmospheric pressure, by passing hot air through milk, etc. None of these new processes have proved commercially satisfactory, with the result that the principle of the process, originally invented by Cail Borden, and which consists of condensing the milk in vacuo to a semi-fluid liquid, is still made use of in the manufacture of the great bulk of condensed milk produced, both in this country and abrọad.

While the claim of the patent granted Cail Borden was that of "producing concentrated sweet milk by evaporation in a'ac uo without the admixture of sugar or other foreign matter," records show that Gail Borden manufactures sweetened condensed milk, sold under the famous Eagle Brand label as early as 1856 . The first advertisement by Borden of unsweetened condensed milk was recorded in Leslie's Weekly, May 22, 1858. It reads as follows:

"Borden's Condensed Milk. I'repared in Litchfield County, Comn., is the only milk ever concentrated withont the admixture of sugar or some other substance and remaining easily. soluble in water. It is simply Fresh Country Nilk, from which the water is nearly all evaporated, and nothing added. The Committee of the Academy of Medicine recommend it as 'an article, that, for purity, durability, and economy, is hitherto unequalled in the annals of the milk trade.'

"One quart, by the addition of water, makes two and a half quarts,-equal of cream, five quarts rich milk and seven quarts good milk.

"For sale at 173 Canal Street, or delivered at dwellings in New York or Brooklyn at 25 cents per quart.'

Development of Industry. - The begimning was small, the process erude and the product imperfect. Not until the 
strenuous years of the WVar of Secession did the value and useful-

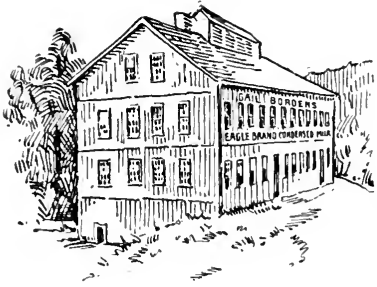

Fig. 3. The first condensed milk factory in Imerica, Wolcottville, Conn. ness of condensed milk as a commodity become fully recognized. During the Civil War there was a great demand for this product and from that time on the industry grew with great rapidity.

The first factory was operated by Gail Borden in Wolcottville, Litchfield county, Connecticut, in the summer of 1856 , but disappointed in not obtaining means, nothing was accomplished. A second attempt was made at Burrville, five miles distant, in 1857 , by a company consisting of the owners of the patent. A small quantity of milk was here successfully condensed and its introduction into New York began. Although admitted by all to be superior to any before made, it was slow in meeting with sales proportional in magnitude to the expenses incurred. Yielding to the monetary revulsion of that year the company suspended operations, leaving Mr. Borden liable for bills drawn, on which he was sued.

It was not until February, 1858 , when Mr. Borden (with the other owners of the patent) associated himself with Jeremiah Milbank, Esq., who advanced money to revive the business, that he could be said to enjoy adequate means to develop his invention and at which time the New York Condensed Milk Company was formed. Abandoning Burrville, the new company established work on a more extensive scale in Wassaic, Duchess county, New York, in 1860. In 1865, extensive works were erected at Elgin, Illinois. Borden's Condensed Milk factories today number upwards of fifty, extending from Maine to Washington State as well as into Canada. The New York Condensed Milk Company was incorporated in New Jersey in 1860 and in New York in 1870. This company was succeeded by Borden's Condensed Milk Company which was incorporated in New Jersey in 1899

In the sixties of the last century, the Anglo-Swiss Condensed Milk Company was organized in Switzerland under the leadership of Charles A. Page, then United States Consul at Zurich, Switzer- 
land, and his brother George H. Page, and with the assistance of Swiss and English capital. The first factory of that company was built and operated in I866 at Cham, Lake Zug, Switzerland, under the direction of George H. Page, who was its president until I898, when he died.

This company prospered and grew rapidly in Europe. In the eighties of the last century it invaded the United States, where it built and operated several large factories in New York, Wisconsin and Illinois. The American factories were managed by David Page and William B. Page, brothers of George H. Page. In 1902 the Anglo-Swiss Condensed Milk Company sold its entire American interests, factories and business, to Borden's Condensed Milk Company. In IgOt the Anglo-Swiss Condensed Milk Company consolidated with Henry Nestle, of Vevay, Lake Geneva, Switzerland, another successful manufacturer of condensed milk. The company which is now known as the Nestle-Cham Condensed Milk Company, is operating some twenty large condensed milk factories in European countries, with headquarters at Cham, Switzerland.

$U_{p}$ to the early eighties of the last century, sweetened condensed milk was the only condensed milk that was put on the market and sold in hermetically sealed cans, while unsweetened condensed milk was manufactured and sold open, largely direct to the consumer, in a similar way as market milk. The purity and keeping quality of this unsweetened condensed milk, however, were greatly superior to market milk.

In 1885 the Helvetia Milk Condensing Company was organized and started operation at Highland, Illinois, under the direction of Messrs. Latzer, John Wildi and others of Swiss birth. This company confined its efforts exclusively to the manufacture of evaporated milk (unsweetened condensed milk, sold in hermetically sealed cans). After several unsuccessful attempts, they finally succeeded in putting on the market a sterilized, unsweetened condensed milk. At first this unsweetened condensed milk failed to appeal to the public; but of late years the demand for, and the manufacture of this product have increased very rapidly, so that today, in this country, the output of evaporated milk exceeds that of sweetened condensed milk. Originally this unsweetened condensed milk was labelled and sold under the name of "Evaporated Cream." The 
Federal Food and Drugs Act of 1906 caused the name "evaporated cream" to be changed to "evaporated milk."

In this country, as well as in Canada and Europe, the condensed milk inchstry grew rapidly. Every succeeding decade marked the organization of new companies and the erection of new factories until today, there are milk condensing factories in nearly every civilized country within the dairy belt.

Output of Condensed Milk in the United States.-In the last ten years, from I899 to I909, the output of condensed milk in the United States nearly trebled, as shown by the United States Census figures recorded below.

United States Census Report, I9IO

\begin{tabular}{|c|c|c|c|}
\hline $\begin{array}{l}\text { Output of condensed milk } \\
\text { in the United States }\end{array}$ & I 899 & 1904 & 1909 \\
\hline $\begin{array}{l}\text { Condensed milk, total } \\
\text { Amount, pounds } \\
\text { Value, dollars }\end{array}$ & $\begin{array}{r}186,921,787 \\
\text { I 1 ,888,792 }\end{array}$ & $\begin{array}{r}308,48_{5}, 8_{2} \\
20,149,28_{2}\end{array}$ & $\begin{array}{r}494,796,544 \\
33,563,129\end{array}$ \\
\hline $\begin{array}{l}\text { Sweetened- } \\
\text { Amount, pounds } \\
\text { Value, dollars }\end{array}$ & $\begin{array}{l}\text { (I) } \\
\text { (I) }\end{array}$ & $\begin{array}{r}\text { 198, } 355,189 \\
\text { I } 3,478,376\end{array}$ & $\begin{array}{r}214,518,310 \\
17,345,278\end{array}$ \\
\hline $\begin{array}{l}\text { Unsweetened- } \\
\text { Amount, pounds } \\
\text { Value, dollars }\end{array}$ & $\begin{array}{l}\text { (I) } \\
\text { (I) }\end{array}$ & $\begin{array}{r}\text { I I O, I } 29.993 \\
6,670,906\end{array}$ & $\begin{array}{r}280,278,234 \\
16,217,851\end{array}$ \\
\hline
\end{tabular}

${ }^{1}$ Not reported separately

The above figures show that the total output of condensed milk in this country in I9o9 was $494,796,544$ pounds, estimated at a value of $\$ 33,653,129$. Calculating the ratio of concentration at $2.5: 1$, which is liberal, the total amount of fluid milk supplying our condenseries in 1909 amounted to over one billion pounds. The above figures largely represent the canned goods only. Within recent years the manufacture of condensed milk in bulk, especially for the ice cream trade, has increased enormously, so that, if this bulk milk 
were included in the above figures, the estimate of the total output would be materially increased.

In I899, there were in operation in this country about fifty factories manufacturing condensed milk, distributed over fourteen different states, New York and Illinois leading the list by over 50 per cent. In Igo4, the Government estimated the total number of condenseries in operation at eighty-seven. Today there are in the United States over two hundred milk condensing factories, distributed over twenty-three different states as shown below.

Distribution of Milk Condensing Factories in Uniten States

\begin{tabular}{|c|c|}
\hline States & Number of Factories \\
\hline Arizona & I \\
\hline California & 7 \\
\hline Colorado & I \\
\hline Illinois & 39 \\
\hline Indiana & 9 \\
\hline Iowa & 3 \\
\hline Kansas & 4 \\
\hline Kentucky & I \\
\hline Maine & I \\
\hline Marỵland & 3 \\
\hline Nassachusetts & I \\
\hline Michigan & $\mathrm{I} 2$ \\
\hline Missouri & 2 \\
\hline New Jersey & 6 \\
\hline New York & 54 \\
\hline North Dakota & I \\
\hline Ohio & Io \\
\hline Oregon & 6 \\
\hline Pennsylvania & 20 \\
\hline Utah & 6 \\
\hline Vermont & 4 \\
\hline Mashington & I 4 \\
\hline Wisconsin & 26 \\
\hline Total $=3$ & 240 \\
\hline
\end{tabular}


Other countries in which the condensed milk industry has made rapid progress are: Canada, Australia, New Zealand, Switzerland, Germany, England, Ireland, Holland, Sweden, Norway, Austria, Russia, Japan and India.

\section{CHAPTER II}

\section{ESSENTIALS OF SUITABLE LOCATIONS FOR MILK CONDENSING FACTORIES}

Unlike the establishment of creameries and cheese factories, the building of condenseries and the installing of the necessary machinery involve the investment of large capital. There is need of a substantial building and of expensive machinery. The supplies are numerous and must be purchased in larger quantities before the returns from the sale of the manufactured product are available. It is estimated that it takes from three to six months before the condensed milk reaches the consumer. This holds true especially in the case of canned goods. The fixed expenses also, are comparatively heavy, and do not materially change with a decrease or increase in the milk supply.

All of these facts emphasize the importance of locating the factory in a territory most suitable for economic manufacture, to guard against heavy loss which would naturally result in localities unfavorable to the industry.

The chief factors to be considered in this connection are

Milk supply
Water supply
Transportation facilities
Other conditions

Milk Supply.-A large supply of milk with possibilities for extending the milk supply territory is the first essential. The condensery must have milk to do business. The locality in which it is located must be adapted for the production of large quantities of milk; it must be a dairy country where reasonably large herds are kept. Other things being equal, the larger the milk supply, the lower the cost of manufacture. Where the milk supply drops below fifteen thousand pounds of milk daily, profitable manufacture becomes difficult. Territories of gathered cream creameries are us- 
ually not very desirable. The farmers generally have small herds and are not inclined to haul their milk daily. They prefer to take their cream to the creamery once or twice per week, or whenever it is convenient for them to do so. Again, they appreciate the feeding value of the skim milk, and depend on the skim milk to raist their young stock and pigs. When they take their milk to the condensery, there is no skim milk nor buttermilk left for feeding purposes.

The presence of whole milk creameries and cheese factories does not disqualify a locality for milk condensing. On the contrary, it is a strong point in favor of a condensery site. The farmers usually have reasonably large herds, they are accustomed to take reasonable care of their milk and to haul it to the factory daily, and the condensery prices are generally high enough above the creamery or cheese factory prices to induce the farmers to patronize the condensing factory.

Territories in close proximity of large consuming centers, though dairying may have reached a high state of development, are not desirable, owing to the continuous and growing demand for fresh milk. Competition of this kind means high prices, which no business tactics are capable of modifying.

Water Supply.-The value to the milk condensing plant of a generous and never-failing supply of clean, cool water cannot be over-estimated. The folly of erecting condenseries without first ascertaining the water supply has frequently compelled milk condensing companies to abandon new plants, merely because of lack of water.

In addition to the water used in the boilers and for washing purposes, large amounts of water are necessary for condensing and for cooling the condensed milk. It is estimated that the condensation of one pound of fresh milk requires about three gallons of water.

The water must be pure. In spite of all precautions, it will come in contact, more or less, with the milk. Though all apparatus and utensils holding and conveying milk and condensed milk may be thoroughly steamed after rinsing with water, there are untold channels through which the milk may become contaminated with 
polluted water. Frequently, while the milk is condensing, the vacuum pump accidentally stops. If the processer fails to immediately shut off the water supplying the condenser, water will pour back from the condenser into the milk in the vacumm pan. In the case of filthy, polluted water, the entire batch may be ruined. Again, the pan is usually rinsed between batches, and, if the water used is unclean, it will contaminate the milk of the succeeding batch. Finally, when the heary fo-quart cans filled with condensed milk are set into the cooling tank. water frequently splashes over into the cans. Here again, the quality of the condensed milk is jeopardized, unless the water used is pure.

The water must be cold. The colder the water, the more satisfactory is the operation of the vacuum pan. If the temperature of the water used in the condenser rises much above 65 degrees $F$. the process of condensing becomes difficult. Cold water is essential, also, for the prompt and proper cooling of the unsweetened condensed milk.

Transportation Facilities.-It is essential that the factory have access to one or more railway lines.

While, for reasons discussed under "Milk Supply," it is not advisable to erect a factory in too close proximity to large consuming or railway centers, it is equally undesirable to choose a condensery site where transportation facilities are poor.

Where access to one railroad only can be hadl, the factory is at the mercy of that road. Experience has shown that monopoly of transportation usually means a low standard of efficiency of service and high freight rates. On the other hand, competition involves a struggle for the survival of the fittest, and it offers the public all the inducements that business ingenuity and enterprise can produce. Where two or more transportation companies are after the business of the same nanufacturing concern, they will generally leave nothing undone in the way of accommodations and low rates to please the manufacturer. The result is that the manufacturer enjoys the advantages of efficient service, good accommodations and reasonable freight rates. 
This is a factor which the condensery cannot afford to overlook, as the freight charges are a very conspicuous item in the expense account of the milk condensing business. A part of the fresh milk may have to be shipped to the factory by rail, all the finished product must leave the factory by rail and the condensery is dependent on the railway for its raw materials and supplies, such as sugar, tinplate, solder, box shooks, barrels, labels, oil, rosin, gasoline, coal, etc. Prompt and efficient transportation is essential. Undue delays may cause the condensery serious inconvenience and loss, and may result in the cancelling of important orders.

Other Conditions.--The removal of the sewage of the factory is important. It may be possible for the factory to connect with the town or city sewer, in which case the problem is easily solved. Where this is not possible, a site along a creek, river, pond or lake may offer effective means to take care of the condensery sewage. Where no such natural depository is available, the elevation of the site should be sufficient to carry off the sewage far enough from the factory to insure the plant against foul odors and unsanitary conditions. In the absence of all of these avenues for the disposal of the sewage, a properly laid-out system of septic tanks with efficient filter beds may serve the purpose.

Where possible, it is advisable to take advantage of hillsides, affording natural means to arrange and operate the factory on the gravity plan.

\section{BUILDING AND EQUIPMENT}

Material of Construction.--Since the establishment of a milk condensing factory involves the investment of considerable capital, those willing to invest must have faith in the permanency of the business. For a permanent business, a building substantially constructed is the most economical. Most of the factories belonging to the most reputable concerns are built very substantially. However, there are in this country condensing factories, in the construction of which, cheapness was the governing factor. Nany of these cheap factories are the work of unscrupulous promoters whose ambition it is, to convince men of wealth or farming communities of the "enormous" profits possible in the manufacture of condensed milk, and to induce them to invest large sums of money in the condensed milk 
industry. By skillful manipulation these promoters frequently secure "fat rake-offs" on every purchase of machinery and on every contract of labor. Their victims pay exorbitant prices for a first class building and most up-to-date equipment, and often receive a shack barely strong enough to stand up under its own weight, and equipment of inadequate capacity.

Stone, brick and concrete, according to availability, are most desirable materials of which to construct a condensery. In the case of wooden walls or partitions, they should rest on cement, brick or stone, built up at least two feet from the floor, or the lower two feet of such walls and partitions should be wainscoated with good cement plaster. All floors of the main building should be of cement, with at least three and one-half inches of concrete on a good foundation, and one-half to three-fourths inch cement surfacing. If the walls, partitions and ceilings are of wood, they should be lathed and plastered with damp-proof plaster on the inside. Matched lumber is unsatisfactory. It generally soon warps and peals off, owing to exposure to free steam and dampness. Plenty of ventilators should be provided in the boiler room, receiving platform, vat room and well room to afford a ready escape of steam and foul air, facilitate the regulation of the temperature and prevent the walls and ceilings from "sweating."

Drainage.-All floors of the manufacturing rooms should slope to facilitate rapid drainage. A fall of one-eighth inch per foot is usually sufficient. Large water-sealed floor drains should be sufficiently numerous and well placed in all rooms to rapidly carry off water. The surface of these floor drains should be about onehalf inch below that of the adjoining floor, so as to catch the water, readily. In the larger rooms open drain-ditches in the cement floor six to eight inches wide, and covered with perforated iron plates, are preferable to bell-traps. They may be placed along the walls or elsewhere. They should be not more than forty feet apart and have a fall of one-eighth inch to the foot, with the floor sloping toward them. It is generally most convenient to have all the drain pipes enter into one large sewer pipe not less than ten inches in diameter, for a condensery receiving about fifty thousand pounds of milk daily, which should dispose of all the factory sewerage. 


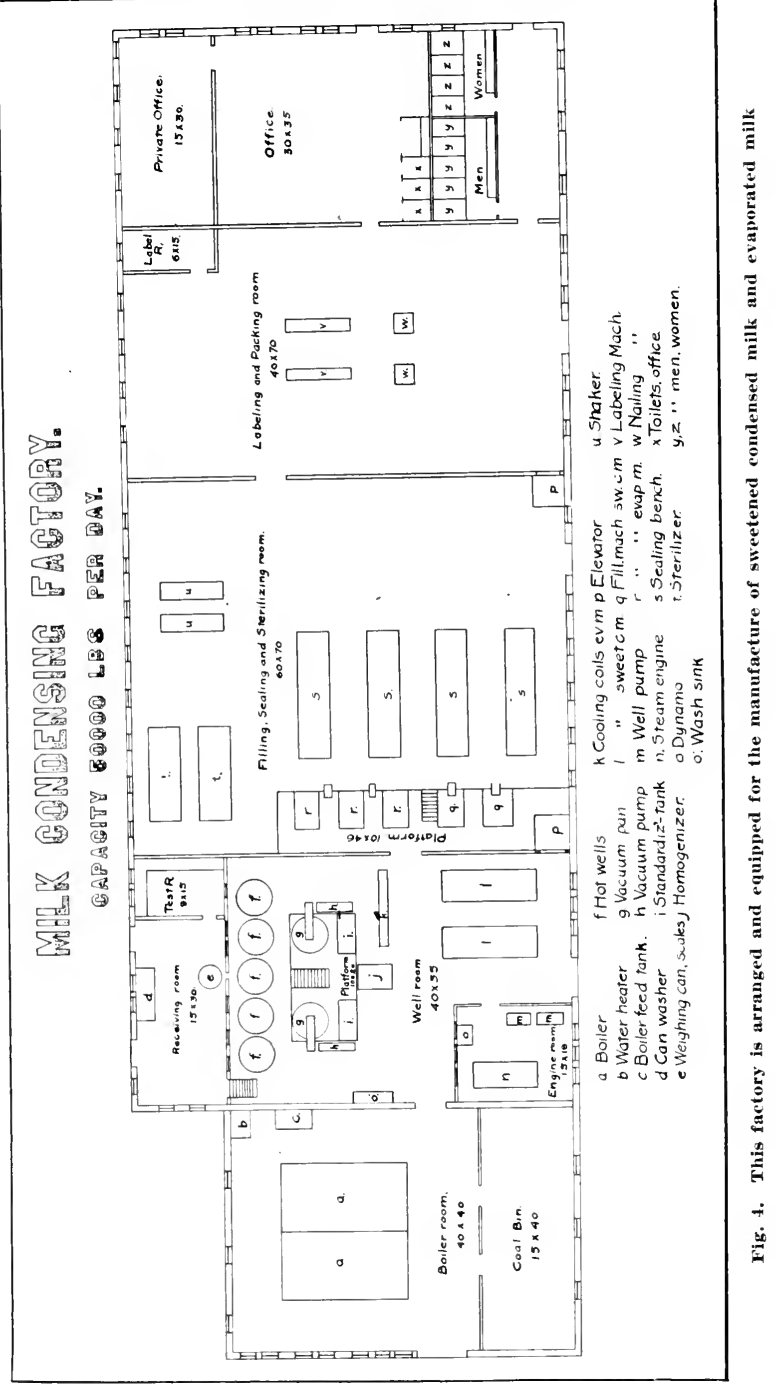


General Plan of Factory.-Most of the condensing factories are either one or two story buildings. In the case of two-story buildings the first floor is usually devoted to the boiler and engine rooms, vat room, well room, filling, sealing and packing rooms. On the second floor are installed the pan room, store room for sugar and box shooks, the tinshop and possibly the offices. A basement is sometimes provided and used for the storing of condensed milk.

Fig. 4 illustrates a floor plan of a milk condensing factory with a capacity of fifty thousand pounds of milk daily. All operating rooms are located on one floor. The arrangement of machinery permits of the handling of the milk on the gravity plan or with pumps, according to the topography of the site and the elevation of the rooms. The receiving room floor and the platform which accommodates the vacuum pans, should be seven to eight feet above the main floor. In order to take care of storage of water, sugar, tin cans, barrels and box shooks, there should be a second floor over the well room and the filling, sealing and sterilizing room. The ceiling of these rooms should be not less than sixteen feet above the floor.

The rooms are so arranged as to necessitate the minimum expenditure of machinery, conveyors and labor. All work rooms open on the railway switch, and the storage room is accessible by two elevators. The well room, where most of the steam is needed, is next to the boiler room, so as to minimize condensation in the steam pipes. If the main steam pipes are properly insulated, this arrangement should furnish the vacuum pans with dry steam. The floor in the boiler room should be two feet below the main floor, in order to give additional fall for the condensation water from jacket and coils of the vacuum pans to the boiler feed tank.

The partition between the receiving room and testing room is equipped with a cabinet, opening on both sides so that the sample bottles can be placed on the shelves in the receiving room, and taken off the shelves in the test room.

From the weigh cans on the receiving platform the milk runs direct into the hot wells, which are sufficient in number to conveniently divide the milk into batches and to heat the milk with the least possible delay. The capacity of the vacuum pumps is augmented by their close proximity to the vacuum pans and the hot- 
wells and by the fact that the water supply tanks are overhead. The space to be evacuated is confined very largely to the vacuum pan only, the milk has to be lifted by the vacuum pump but a few feet and the water runs into the condenser by gravity.

From the well room the condensed milk is transferred to the tanks on the platform over the filling machines. The evaporated milk is pumped from the cooling coils through the wall and the sweetened condensed milk is raised to the platform in ten gallon cans on the elevator. 'The sealing benches are equipped with selfheating soldering coppers. In the place of the soldering benches and hand coppers, an automatic sealing machine may be installed. The sterilizers and shakers are conveniently placed to take care of the sealed evaporated milk. The tin cans for the sealing room and the box shooks for the packing room are brought down from the storage room overhead on the elevator. The labeling and packing room, equipped with the labeling and box nailing machines, provides for considerable storage of the finished product. Additional storage at a moderate and uniform temperature might be provided for by a basement under the packing room. A label stock room furnishes satisfactory storage for the labels.

In case the factory manufactures its own tin cans, a tin shop, equipped with the necessary machinery, (see list of machinery and equipment) should be located in as close and convenient proximity to the filling and sealing room as possible. A suitable place is directly opposite the filling room with the railway track separating the latter from the tin shop. The tin shop should have two outside doors and its machinery should be so arranged that the tin plate can be unloaded from the car at one door, is moved back through the machinery and appears again in the form of finished cans at the other door, directly opposite the filling room and ready for the reception of the condensed milk. Instead of erecting a separate building for the tin shop, the latter may also be conveniently installed in the second story directly over the filling room.

Where natural gas and gas from municipal corporations is not available one or more gasoline gas generators should be installed. These gas generators contain inflammable material and should, therefore, be located at a reasonable distance from the main building. 
List of Equipment.-The following is a list of the principal machinery and equipment needed in an up-to-date condensery with a capacity of fifty thousand pounds of milk daily:

\section{BOILER ROOM}

Boilers with a total capacity of $400 \mathrm{H}$. P.

I boiler feed tank

I boiler feed pump

I boiler water heater

\section{ENGINE ROOM}

I $40 \mathrm{H}$. P. engine

2 well pumps, I 50 gallon per minute each

I 80 light dynamo

Pipe and thread cutting tools, anvil and forge

\section{RECEIVING ROOM}

2 Iooo pound weigh cans, "low down" style

26 beam milk scales

I can washing machine with steam and water jets and air blower for drying the cans

I milk sample bottle rack

\section{WELL ROOM}

65000 pound capacity jacketed kettles with revolving agitators and superheating device

I 6 foot vacuum pan

I 7 foot vacuum pan

2 vacuum pumps

2500 gallon standardizing vats

I 6 cylinder homogenizer

I internal tube cooler, capacity 5000 to 8000 pounds per hour

236 can cooling vats with cans, cross bars and paddles, complete

I wash tank

I elevator

I sugar chute 
I 2 beam platform scale

I truck

\section{FILLING, SEALING AND STERILIZING ROOM}

4200 gallon condensed and evaporated milk vats

2 filling machines for sweetened condensed milk

2 filling machines for evaporated milk

4 soldering benches, $5 \times 20$ feet, with Io self-heating soldering coppers each, or

I or more sealing machines, the number depending on type and capacity of machine used

2000 wooden trays holding 24 sixteen-ounce cans each

2 sterilizers, capacity 75 to Ioo cases each, complete with iron trays

I double shaker

2 trucks

\section{LAEELING AND PACKING ROOM}

2 labeling machines

2 nailing machines

2 trucks

\section{TESTING ROOM}

2 24-bottle Babcock testers, with one gross of standard milk test bottles and accessories, complete

Equipment for chemical and bacteriological analyses of milk and sugar

\section{OFFICES}

Usual equipment

\section{TOILET ROOMS}

Usual equipment

\section{OVERHEAD STORAGE ROOM}

I 50,000 gallon water tank

This tank is preferably located outside of factory

I 4 beam platform scale for sugar 


\section{ADDITIONAL, EQUIPMENT}

I gasoline gas generator (complete), needed in absence of access to natural gas or municipal gas

\section{TIN SHOP}

Needed in case cans are manufactured at the factory

2 squaring shears

2 body cutting machines

2 lock seamers

6 presses

2 crimping machines

2 soldering floats

I can tester with vacuum pump

I can wiper

I lathe with tools

I gasoline gas generator, complete

I $25 \mathrm{H}$. P. engine or motor

200 can crates

Economic Arrangement of Machinery.-In the arrangement and connection of the machinery, economy of manufacture and sanitation of the product should receive serious consideration. The machinery should be so arranged as to reduce to the minimum the space, pumps, pipes and conveyors needed. Pumps, conveyors, pipes and fittings are expensive, and the space saved by judicious arrangement of the stationary machinery may be used to advantage for other purposes.

Human muscle is the most expensive form of motive power. Wherever muscle can be replaced by machinery and where, by intelligent arrangement of the machinery, unnecessary steps and handling can be avoided, the cost of manufacture is reduced.

Sanitary Arrangement of Machinery.-Milk pumps, milk pipes, milk troughs and other milk conveyors are, at best, enemies of sanitation. They should be avoided wherever possible. The gravity system of conveying milk:should be used in preference to the pumping system. Milk pipes should be short and accessible; all vats should be of sanitary construction; wooden jackets should not be tolerated; all seams in the vats and kettles should be well 
flushed with solder; milk pumps should be brass lined; no black iron pipes should be used for transferring milk; all milk pipes should be of galvanized iron or copper, heavily tinned over on the inside; long lines of milk pipes should be equipped with unions at short distances; crosses or sanitary couplings should be used in place of elbows, in order to render all sections of the milk pipes easily accessible to flue brushes.

\section{CIIAPTER III}

\section{MILK SUPPLY}

Basis of Buying Milk. - The prices which the condensery pays the patrons are not usually governed by any board of trade. They do not even necessarily follow the quotations of the butter and cheese market. They are generally announced from three to six months in advance. They average, in most cases, from twenty to fifty cents higher per hundred pounds of milk than those paid by the creameries and cheese factories.

Most condenseries pay for the milk on the one hundred pound basis. Some factories are still clinging to the Mediaeval custom of buying milk by the quart, using the yard stick for the remmant cans. Other factories are paying a stated price for all milk testing say + per cent. fat and over, and make corresponding reductions for milk containing less than + per cent. Still others pay a premium for milk testing over + per cent. fat. A few concerns only are buying their milk on the butter fat basis.

As far as the condensery is concerned it would be entirely feasible to pay for all milk strictly on the butter fat basis. Milk rich in fat, and therefore rich in solids, yields more condensed milk than milk poor in fat. To pay by the hundred weight, regardless of quality is a practice which discriminates in favor of breeds of low-testing milk and against breeds of high-testing milk. For the sake of justice to the milk producer, it is to be hoped that the milk condensing companies may soon break away from old traditions and antiquated practices, and adopt the only fair and up-to-date method of buying milk on the butter fat basis.

Quality.-The quality of the fresh milk is the first and most important factor to be considered. The milk condensing factory, 
ignoring this fact and accepting milk from unsanitary dairies and careless dairymen, is bound to pay the penalty for such neglect sooner or later.

Polluted milk and milk that has not been cooled promptly and to a reasonably low temperature on the farm, may pass through the process successfully, if it is not too sour. 'The condensed milk made from it, though, is inferior in flavor and keeping quality, and usually shows signs of deterioration and decay before it reaches the consumer. The risk of handling such milk is very great; it often results in total loss to the manufacturer. The trouble may and often does begin before the process is completed. Unclean, abnormal, or partly fermented milk, when subjected to the process, is prone to curdle and whey off; the condensed milk becomes lumpy and shows other defects. This is especially true where superheating is practiced and where evaporated milk is made.

Milk that has received the best of care on the farm may be detrimental to the interests of the condensery, if it comes from cows less than thirty days before their parturition, or from fresh cows within the first seven days after calving. Such milk is often abnormal in its chemical properties, and, when subjected to high temperatures, undergoes changes that make its manufacture into a marketable condensed milk difficult.

Control of Quality.-Every well managed milk condensing factory plays the part of an educator in the production of sanitary milk. The condensery usually issues a set of rules, setting forth specifically the conditions under which the milk coming to the factory shall, or shall not be produced. Copies of these rules, which are generally a part of the contract, are placed in the hands of all patrons. The condensery employs one or more dairy inspectors whose business it is to see that the rules are rigidly enforced. These rules cover, in general, the following principal points:

I. Cows.-The milk must come from healthy cows. Milk from cows that are diseased, or that have a discased udder, or that are otherwise in poor physical condition, will be rejected.

2. FEED AND MATER.-Do not feed weeds, roots, or other feed stuffs possessing strong and obnoxious odors, such as onions, garlic, turnips, cabbage, wet distillery slops, decayed, musty or sour 
silage, or other fermented feed. (Some condenseries prohibit the use of all silage. This restriction betrays prejudice and ignorance on the part of the management concerning the great value and absolute harmlessness of good silage as a dairy feed. It is an injury to the dairy interests of the country. Corn silage or other silage, in good condition, and fed in reasonable quantities, does in no way injure the milk for condensing purposes). The cows must be supplied with clean, fresh water.

3. Lactation Period.-Reject all milk from cows less than thirty days before, and of the first seven days after calving.

4. Milkers ANd Milking.--Nilk with clean, dry hands into clean utensils and remove the milk to the milk room immediately after drawn.

5. Strainag.-Strain the milk in the milk room through a fine wire mesh strainer (So to 100 meshes to the inch). Do not use cloth strainers.

6. Cooling.-Cool the milk to 60 degrees F. or below and keep it at that temperature until it reaches the factory. Do not mix the warm morning's milk with the cold night's milk; cool the morning's milk before mixing, or send it to the factory in separate cans.

7. CARE OF UTEXSILS.-Rinse with cold water, wash with warm water and washing powder, and rinse with boiling water all milk utensils thoroughly after use; keep them in a clean place between milkings. Do not store the milk on the farm in cans that have not been washed by the factory.

8. STABLfs.-Whitewash the stable twice every year and remove manure daily. (Some condenseries furnish spray pumps for applying whitewash).

Inspection of Milk at the Condensery.-At the condensery the milk is subjected to rigid inspection by a man who is, or should be, an expert on milk inspection; every can is examined. Warm milk and milk that is tainted, or smells slightly sour should be rejected.

Inspection of Milk bi Sexse of Salell and Taste.-In most cases the milk is inspected with reference to odor. The inspector quickly raises the cover of each can to his nostrils. The odor in the cover is typical of that in the can. If it is "off," the can is rejected. An experienced man on the platform can, by the use of 
this method, tell with much accuracy, whether the milk should pass or not.

INSPECTION OF MILK ACCORDING TO ITS TFMPER.TTLRE.-The temperature is also noted. This need not be done with the thermometer in each case. By placing his hand on the body of the can, or by noting the warmth of the air and odor in the cover immediately after remoring it, or by the presence or absence of small particles of butter floating on the surface of the milk, the inspector can readily tell if the milk has or has not been properly cooled. A correct thermometer should always be on the platform for guidance.

Inspection of MhL BL THE Lse of Acid Tests.- Since the degree of acidity, or the sweetness of the milk, is one of the chief factors that determines its fitness for condensing purposes, tests that rapidly and accurately determine the per cent. of lactic acid in the fresh milk, are of great service.

Some concerns have adopted a definite standard of milk, rejecting all milk containing more than the maximum per cent. of acid of their standard, and they test every can of milk received with an acid test. This method insures sweet milk in the factory, provided that the alkaline solutions used are correct. This work involves considerable expense, however, and unless the solution is carefully prepared and made up fresh often, its use may yield misleading results. Again, when the acid test is performed on the milk of each can, the acceptance or rejection of the milk depends altogether on the per cent. of acid it contains. Although milk may be otherwise unfit for use, it will pass, as long as it is low in acidity. Experience has shown that, while it is necessary for the condensery to decide on a maximum acidity of milk above which all milk be rejected, the nose and the palate of the experienced inspector are better criterions than the acid tests alone, as to the fitness of milk for condensing. Acid tests are valuable in the case of uncertainty and suspicion as to the quality of any given can of milk. All milk containing .2 per cent. lactic acid or more is dangerous for condensing purposes and should be rejected.

Acid Test for Daily Use, Where Each Can of Milk is Tested.Stock Solution.-W Weigl out two hundred grams of sodium hydrate C. P. and add distilled water to make up one liter. Keep tightly stoppered. 
Solution for Daily Use.-Mix + c.c. of stock solution with 991 c.c. of distilled water, and add 5 c.c. of phenolphthalein indicator. The indicator is prepared as follows: dissolve one gram of dry phenolphthalein in IOO c.c. of 50 per cent. alcohol. Each cubic centimeter of the prepared alkaline solution neutralizes. OI per cent. lactic acid, 20 c.c. of the prepared solution, therefore, neutralize .2 per cent. lactic acid, when a 17.6 c.c. pipette is used for measuring out the milk.

Making the Test.-With the Babcock pipette, measure 17.6 c.c. into a white cup. With a small dipper, holding exactly 20 c.c., pour 20 c.c. of the prepared solution into the cup; stir or shake. If the mixture remains faintly pink, it contains less than .2 per cent. acid and will pass; if it turns white, it contains more than .2 per cent. acid and should be rejected.

The stock solution should be standardized by a chemist. The prepared solution should be made up daily. Both solutions should be kept in glass bottles, tightly corked. The bottle containing the stock solution should be glass-stoppered.

Acicl T'est for Use on Suspicions Cans Only.-The Farrington Alkaline Tablet 'l'est. Use an eight ounce, wide-mouth bottle, place in it sixteen Farrington alkaline tablets, add eight ounces of distilled water or rain water, or any pure water relatively free from carbonates. Stopper tightly and let stand for six hours, or until the tablets are completely dissolved. This solution neutralizes .2 per cent. of lactic acid in equal parts of milk.

Making the 'Test.-Use small dipers of the same size for milk and for test solution. Pour into a white cup one dipperful of milk and one dipperful of solution. If the mixture turns white, it contains more than .2 per cent. lactic acid and should be rejected. If it remains pink, the milk contains less than .2 per cent acid.

TH: Borlng 'Tist. Inspection by Heating.-The heating to the boiling point of samples of suspicious milk furnishes a most reliable means to determine the fitness of such milk for condensing. In many instances milk may satisfactorily pass the other tests and yet it may not be in condition to stand the heat to which it will be subjected in the process. If it curdles, when boiled, it is obviously unfit for use. This test shows more than the acid test above. By its use the operator is able to detect milk otherwise abnormal, such 
as milk containing colostrum, etc., or the proteids of which are unstable for other reasons.

Making the Test.--The boiling test is simple and can be manipulated rapidly. A sample of the questionable milk is taken into a small dipper. The dipper is held up against a steam jet turned down into the milk. Direct steam is turned into the milk until it comes to a boil. If flakes or specks of curd cling to the sides of the dipper, the milk is unfit for use.

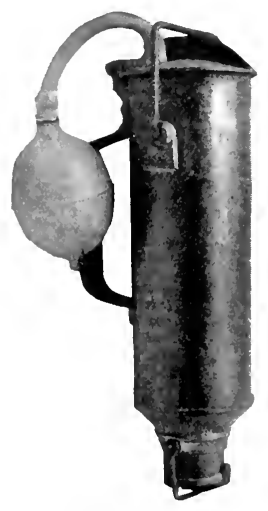

Fig. 5.

An alcohol lamp or gas burner on the platform may be used for heating the sample. In this case a few cubic centimeters of the milk are discharged with an ordinary pipette into an ordinary test tube, such as are in common use in the chemical laboratory and can be obtained from the drug store. The tube is held over the flame and the milk comes to a boil in less than a minute. If the milk is in good condition the sides of the glass tube remain perfectly clear. If it curdles upon heating, the sides of the tube show fine specks of curd. The appearance of these specks condemns the milk.

The Sedinent Test.-This test shows the relative amount of dirt present in milk. One half pint of milk is passed through a small circle of absorbent cotton and the amount of mechanical impurities present in the milk is indicated by the color of the cotton after filtration. In order to hasten the filtration, the milk is forced through the filter under slight pressure. This is accomplished by a rubber bulb attachment to the apparatus, as shown in the accompanying figure.

If the cotton retains a white or creamy color, the milk is relatively free from filth. Milk produced under unsanitary conditions stains the cotton brown or black.

These cotton filters may be pasted on a sheet of paper similar to a milk sheet, arranged so that the circles are placed opposite the respective patron's name or number. When shown to the patrons who come to the factory, they furnish a most effective object lesson to them. When the milk reaches the factory on route wagons or 


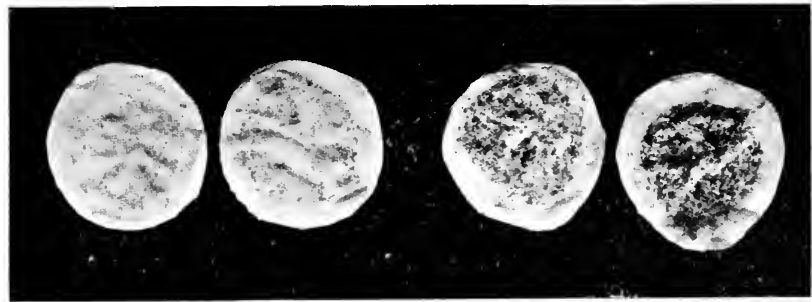

Clean milk

Fig. 6. Cotton Filters

Dirty milk

by rail, cards similar to Figure 7 may be mailed to the patrons. The evidence is so conclusive that even the most obstinate patron can not help admitting his guilt and can usually be induced to "clean up."

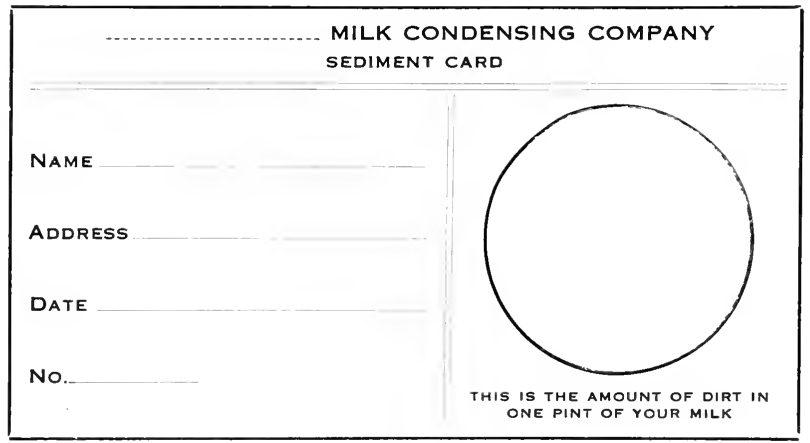

Fig. :

FERMENTATION TESTS.-These tests are of great value in the rapid determination of the kind of bacteria with which the milk from indiviclual patrons is contaminated. Glass tubes are filled one half full of milk from each patron. These tubes are set in a constant water bath at 100 degrees $\mathrm{F}$. and the changes which milk undergoes are noted after six, twelve and twenty-four hours.

A solid curd with a clear whey indicates that lactic acid bacteria are the chief organisms and that the milk has been produced under cleanly conditions. These organisms are killed when the milk 
is heated in the hot wells. Such milk therefore is safe, unless it contains excessive acid, as shown by the acid test.

A curd with gas holes, or that which is torn to pieces in the tubes, shows the presence of gas-producing germs. These come largely trom manure and other filth. Among these are Bacillus coli communis, the natural inhabitant of the colon of the animal, and butyric acid organisms which are spore bearers. The latter especially may give rise to serious milk defects, causing "swell heads." Patrons sending such milk should be looked after at once.

If the curd dissolves or no curd is formed and the milk changes into a transparent liquid, it usually is contaminated by germs from the dust of hay and bedding, or polluted water. To this class of organisms belong Bacillus subtilis, Bacillus fluorescens liquifaciens, Plectridium foetidium, Bacillus putrificus, etc. Some of these are violent gas producers and most of them are spore bearers. They are the cause of some of the most disastrous milk defects. Dairies from which such milk comes should be vigorously inspected and all milk from them should be rejected, until the patrons have learned how to furnish sanitary milk.

Milk that remains unchanged for twenty-four hours when subjected to the fermentation test, suggests that it contains some preservative. It is possible, however, for milk produced under ideally sanitary conditions to remain normal and unchanged even at these high temperatures for several days. Where milk comes to the factory in bulk as is the case in the condensery, samples showing abnormal keeping quality should be regarded with suspicion, and the respective dairies should receive immediate and thorough inspection.

Tests for Butterfat and Specific Gravity.-In the factories where the milk is not paid for on the butter fat basis, composite samples should be taken daily, to be tested for fat and specific gravity, at regular intervals of from two to four weeks, in order to detect possible adulterations by skimming or by the addition of water. For specific directions for the Babcock test, the use of the lactometer and tests for preservatives see Chapter XXIX "Chemical Tests and Analyses of Milk and Milk Products" and Chapter XXX "Detection of Adulterants and Preservatives, Etc." 


\section{FACTORY SANITATION}

In the previous paragraphs, special emphasis was placed on the great importance of a good quality of fresh milk. It is equally essential that the factory be kept in exemplary condition as to cleanliness and sanitation. This is necessary because of its effect on the patrons, on the wholesomeness and on the marketable property of the finished product.

Effect on Patrons.-It does not take the watchful eye of the intelligent patron, who daily comes to the factory, very long to learn, whether the manufacturer gives his milk as good care as he gave it on the farm. A good example set by the factory will mean much toward instilling the patron with ambition to do likewise on the farm. Shiftlessness is a contagious disease, to which the average farmer is very susceptible. It is, therefore, inconsistent for the factory to issue and enforce rules of sanitation for the dairy farmer when, within its own walls, all principles of sanitation are violated.

Effect on Wholesomeness of the Product.-Uncleanliness and filth interfere with the wholesomeness of the product. Condensed milk mare in a factory ignoring sanitation, may contain certain products of decay which are poisonous to the human system. Again, it may contain germs of infectious diseases and thus become the cause of widespread epidemics of these diseases and possibly claim many victims. As a matter of common decency and of duty to the commonwealth, the condensery should pay close attention to cleanliness in all operations.

Effect on the Marketable Property of the Product.-Again, uncleanliness in the factory is bound to bring financially disastrous results. The seriousness of the disaster is greatly augmented by the fact that the consequences of neglect are usually not apparent until after the goods have reached the market. The pollution of condensed milk with impurities and filth in the factory, shortens the life of the product. Such condensed milk is of very poor keeping quality. It may reach the market and the consumer in condition that causes it to be rejected, resulting in a complete loss to the manufacturer. The manufacturer allowing such conditions to exist, is usually the last man to realize and admit that he is at fault, which 
renders attempts to locate and stop such defects exceedingly difficult. Furthermore, instead of helping to build up the trade and to advertise the brand, he demoralizes it.

How to Keep Factory in Sanitary Condition.-Cleanliness in the factory is absolutely essential. The milk vats should be rinsed with plenty of water and scrubbed and steamed thoroughly, as soon as possible after use. 'The copper kettles and vacuum pans should be rinsed, then scoured with sandpaper or emery cloth, then rinsed and steamed thoroughly. The milk pipes should be scoured by running flue brushes through, flushing them with clean water and steaming them until they are scalding hot. In the case of milk pipes of excessive length, they should be well flushed with hot alkaline water. Milk pumps should be taken apart every day and freed thoroughly from all remnants of milk. The water in the cooling tanks, should be changed as often as is necessary to insure clean water in them at all times. The homogenizer should receive special attention, all its valves should be thoroughly cleaned and steamed daily. The cooling coils should be scalded before use. The filling machines for evaporated milk should be freed from all milk, rinsed and steamed thoroughly and no remnants of milk should be allowed to stick to the valves. The filling machines for sweetened condensed milk should be emptied and completely washed, at least once per week, and protected from dust and filth by covering them when not in use. The tin cans should be stored in a clean room and every precaution should be taken to guard against their defilement from dirt, dust, insects and mice. Where possible they should be sterilized before use.

All vats, kettles, milk conveyors, vacuum pans, milk pumps, and all machinery coming in contact with milk, should be flushed and steamed again in the morning, as soon as the condensery opens. The sugar chute should be kept clean, care being taken that no damp or wet sugar remains in it. Special attention should be given to the washing of the farmers' cans. After washing with brush and hot water containing some good washing powder, they should be thoroughly rinsed, then steamed until they are hot. If possible they should be dried by an air blast. 


\section{PAR'T I I \\ MANUFACTURE OF SWEETENED CONDENSED MILK}

\section{CHAPTER IV \\ DEFINITION}

Sweetened condensed milk is cow's milk, condensed at the ratio of $21 / 2$ to $23 / 4$ parts of fresh milk to I part condensed milk. It contains considerable quantities of sucrose, usually about 40 per cent., to preserve it. It is of semi-fluid consistency and reaches the market in liermetically sealed tin cans, varying in size from eight ounces to one gallon, and in barrels similar to glucose barrels, holding from three hundred to seven hundred pounds of condensed milk. When made properly, sweetened condensed milk will keep for many months, but is best when fresh.

\section{HEATING}

Purpose.-The first step in the process is to heat the milk to near the boiling point. There are three chief reasons for which the milk is heated, namely to destroy most of the bacteria, yeast, molds and other organized and unorganized ferments, to facilitate the solution of the sucrose, and to prevent the milk from burning on to the heating surface in the vacuum pan.

Destruction of Ferments.-When the fresh milk arrives at the factory it contains micro-organisms in varying numbers and of different species. In some cases disease-producing bacteria may be present, rendering the milk dangerous to the health and life of the consumer, were it not heated to temperatures high enough to destroy these germs. Again, milk may contain bacteria, yeast, molds and enzymes that cause it to undergo undesirable fermentations which, if allowed to pass into the condensed milk, may tend to shorten the life and impair the wholesomeness and marketable properties of the latter. 
Solution of Sucrose.--It is very essential that all the cane sugar which is added to the milk, be completely dissolved, in order to lessen the tendency of the sugar to crystallize in the finished product. Undissolved sugar crystals in condensed milk, act in a physical way much as bacteria in fluid milk do in a bacteriological way. They multiply rapidly, and such condensed milk usually precipitates its sugar before the product reaches the market. The presence of excessive sugar crystals makes the product gritty and causes the formation of a serliment in the bottom of the cans; this is objectionable to the consumer. When the milk is heated to the proper temperature before condensing, the solution of the cane sugar is facilitated and the tendency toward grittiness is minimized.

Prevention of Burning Milk on Heating Surface.-If cold milk comes in contact with a steam-heated surface and is not agitated vigorously, it bakes or burns onto this heating surface. The milk in the vacuum pan is heated or kept hot by means of the steam jacket and coils. These radiators are charged with steam under pressure and consequently give off a high degree of heat. If cold milk is drawn into the vacuum pan, the milk remains calm for a considerable length of time. During this time it is bound to bake or burn on the heating surface, giving the product a burnt flavor, causing it to contain brown specks and retarding the process of evaporation. If the milk is hot when it enters the pan, the reduced pressure in the pan causes it to boil violently at once, avoiding all danger of sticking to and burning on the heating surface.

Temperature.-In most factories the milk is heated to from I 80 degrees $F$. to 200 degrees $F$. This temperature is sufficient to accomplish the three purposes. Heating the milk to the boiling point tends to give it a rather pronounced cooked flavor, which is objectionable. However, in the case of danger of contamination of the milk with resistant types of undesirable bacteria, it may become necessary to practice boiling the milk.

Manner of Heating.-Thorough, efficient and rapid heating of large volumes of milk to temperatures near the boiling point is a problem that requires careful consideration. The tendency of the milk to stick to the heating surface is a permanent obstacle and efforts to overcome this frequently result in sacrificing thoroughness of heating. 
A variety of methods and numerous different types of machines are used for this purpose in the different milk condensing factories. Some use large copper kettles in which the milk is heated by turning steam direct into the milk. Others use jacketed copper kettles equipped with a revolving agitator. The milk is heated

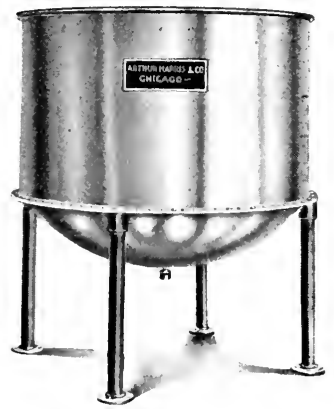

Fig. 8. The hot well or forewarmer Courtesy of Arthur Harris \& Co. by turning steam under pressure into the jacket and the burning of the milk is prevented by keeping the milk in constant motion. Still others are heating the milk by means of large continuous pasteurizers of the Miller type, in which case hot water serves as the heating medium. The milk passes in a thin layer between two water-heated surfaces, one of which is revolving. In some factories the milk is forced through a series of pipes inclosed in a hot water or steam jacket.

Finally, in some condenseries a combination of the continuous pasteurizer and the jacketed kettle is used. The milk is heated to nearly the desired temperature in the pasteurizer. From there it flows into the jacketed kettle. This kettle is so constructed that when steam is turned into the jacket, the milk rises and it flows over and off into the sugar well. This insures efficient heating and, at the same time, if operated properly, it prevents the baking of the milk on the heating surface. The disadvantage of this double system of heating is that the overflowing kettle has to be watched very closely.

\section{Advantages and Disadvantages of Different Methods of Heat-} ing.-In most factories, in this country, the first named method is used. Steam is turned direct into the milk until it boils up. This is the oldest and most primitive method. While very simple in operation, this method has serious objections. At best, much of the steam used condenses in the milk, increasing the amount of water that has to be evaporated. It, therefore, prolongs the process of condensing and increases the cost of manufacture. This is espe- 
cially true where the boilers are located at some distance from the hot wells and the steam pipes are not well insulated, causing the steam to be "wet." It is estimated that the amount of extraneous water thus added to the milk, increases the bulk of the milk by onesixth of its original volume. The steam is often associated with impurities, such as cylinder oil from the engine, boiler compounds used in the boilers, scales from the inside of the pipes, etc. These various impurities cannot possibly improve, but may seriously injure the quality of the milk. It is quite probable, also, that the direct contact of live steam with milk, has no beneficial effect on its ingredicnts. It is generally conceded by those who have given this matter careful thought, that the turning of steam direct into the milk shortens the life of the product and causes it to develop a stale flavor, which may degenerate into an oily flavor. The same defect is noted also when cream is heated by turning steam into it. The prolonged exposure of the milk to the condensing process, as the result of the addition to the milk of considerable quantities of condensed stean, further may be injurious to the milk.

Any method of heating that does not require direct contact of the steam with the milk is preferable, provided that it makes possible thorough heating to the required temperature without burning the milk. Practically all of the other methods above referred to accomplish this.

\section{ADDITION OF SUGAR}

Considerable quantities of sucrose are added to the condensed milk for the purpose of preserving it.

Kinds of Sugar.-In order to convey to the milk preservative properties, that kind of sugar must be used, which does not readily undergo fermentation and which has the power of inhibiting bacterial activity when dissolved in a concentrated solution. Glucose could be purchased at a very low cost, but it is not suitable for this purpose, since it is, in itself, very unstable and fermentable. It has no preservative qualities, even in concentrated solutions. Sucrose, saccharose, or cane sugar, $\mathrm{C}_{12} \mathrm{H}_{22} \mathrm{O}_{11}$, properly refined, ferments with difficulty in concentrated solutions, and has the power of retarding the growth of bacteria and other ferments ordinarily present in sweetened condensed milk. It is, therefore, very satisfactory and useful in this connection. 
Beet sugar, which is chemically identical with cane sugar, is used in European countries very largely in the place of cane sugar. On the continent the beet sugar industry is an important factor. With the climate adapted to the growing of sugar beets and the labor relatively cheap, beet sugar can be secured by the European condenseries at lower cost than cane sugar. In America where the annual sugar cane crop is large and where the high cost of labor renders the expense of growing sugar beets relatively high, there is practically no difference between the price of cane sugar and beet sugar. When American beet sugar was used in the condenseries during the infancy of the beet sugar industry. this sugar was found undesirable, often giving rise to fermented condensed milk. It was then supposed by the condensed milk men, that beet sugar contained very resistant spore-bearing bacteria, which followed the beets from the soil into the refined sugar. This conclusion is highly improbable, as the temperatures and chemicals employed in the process of beet sugar making, are prohibitive of the pasiage of living bacteria from the soil to the finished sugar. It is possible, however, that the standard of refinement of American beet sugar, during the earlier days of its manufacture, was low and that some of the beet sugar on the market may have contained small amounts of acid, invert sugar and other impurities, ingredients of such a nature as to render the sugar prone to give rise to fermentation and, therefore, condemn its use in the milk condensery.

While the beet sugar on the market to-day appears to have reached a very high state of refinement and is, according to the best authorities, equal in purity to cane sugar, it is still shunned by the American condenseries, which insist that nothing but cane sugar will do. However, the total beet sugar production in the United States has more than trebled within the last ten years. In IgOr it amounted to one hundred eighty-four thousand tons and in IgI It was six hundred six thousand and thirty-three tons. Again, whenever a shortage occurs of the sugar cane crops in the West Indies, raw European beet sugar is imported into the [nited States and it all emerges from our seaboard refineries as "pure cane sugar." It is not improbable, therefore, that the sugar supply of many American condenseries today consists at times largely of beet sugar, though it is purchased under the name of cane sugar. 
There is no good reason why the best refined beet sugar, manufactured today in this country and elsewhere, should not give fully as good results for condensing purposes, as the same quality of cane sugar. Tests made at the California Agricultural Experiment Station $^{1}$ led to the conclusion that the two kinds of sugar, cane sugar and beet sugar, were equally valuable for canning and identical in their behavior when of the same fineness of crystallization.

Beet Slgar Caxnot be Detected From Cane Stgar.-While the raw sugar from the two different sources, the sugar cane and the sugar beet, takes on the character of the impurities from which it has not yet been freed (the raw product of the sugar cane is pleasant in flavor, the raw product from the sugar beet is acrid and disagreeable in flavor), the sucrose or so-called pure cane sugar, can be and is crystallized out, and in every case the sugar is identical in chemical composition, appearance and properties. "By no chemical test can the pure crystallized sugar from these two different sources be distinguished. ${ }_{2}$

Quality of the Sugar.-Since the sugar, sucrose, is added for the purpose of preserving the condensed milk, it is obvious that none but the best quality of refined sucrose is admissible. Low grade sucrose is a product dangerous to the condensed milk business. It is apt to contain sufficient quantities of acid and invert sugar, to give bacteria and yeast an opportunity to start fermentation. When once started. the destruction of the product is almost inevitable. In years of failure of the sugar cane crop, when the prices of sucrose soar high, condenseries yield frequently to the temptation of buying lower grades of sugar. The result invariably is an abnormally large output of condensed milk that "goes wrong."

It is very important that the sugar in the factory be stored where it will keep dry. Sucrose has hygroscopic properties. When exposed to an atmosphere saturated with moisture it absorbs water. In damp storage it is prone to become lumpy, moldy and frequently sour. When these precautions are neglected there is danger of defective condensed milk, causing the cans on the market to swell, due to gaseous fermentation.

\footnotetext{
1 California Agricultural Experiment Station, Cireular No. 33

2 United States Department of Agriculture, Farmers' Bulletin No. 535, 1913
} 
When the sugar reaches the milk through a chute from the floor above, the sugar chute and similar conveyors must be kept clean and dry. The lower end of the sugar chute is usually located directly over the steaming milk in the well room. In such cases there is always more or less danger of condensation in the chute of the vapors from the milk below. This causes the sugar to stick to and form a crust on the inside of the chute. This moist crust of sugar, when contaminated with bacteria, yeast or molds, is prone to start fermenting. When portions of this sour crust peel off and are carried into the milk below, they may cause entire batches of condensed milk to spoil, as the result of gaseous fermentation.

Adulteration of sugar with foreign admixtures such as white sand, white clay, starch, or lime dust is rare, and occurs usually only in pulverized sugar. For the detection of these adulterants, add a spoonful of the suspicious sugar to a glass of hot water and stir. Pure sugar will dissolve completely, while most of the common impurities are insoluble and will settle to the bottom.

The purchase of coarsely granulated sugar is an effective safeguard. insuring freedom from these adulterants. Powdered sugar should not be used in the condensery.

Amount of Sugar.-The amount of stucrose used varies in diferent countries, with different manufacturing concerns, in differens factories of the same company and at different seasons of the year. The normal variations range between twelve and eighteen pounds of sucrose per one hundred pounds of fresh milk. Most factories use about 16 per cent.

It is not advisable to overstep the limits above indicated. Condensed milk serves as a substitute for fresh milk. The more sucrose it contains, the greater is the difference in composition and properties between the condensed milk and the fresh milk. Sucrose is not as readily digested as the other ingredients of milk; therefore, the presence of excessive anounts of cane sugar in conclensed milk, tends to reduce its digestibility and its wholesomeness as a food. Again, while normal milk is a well-balanced food in itself, the presence of large amounts of cane sugar in it, causes this equilibrium to be disturbed, the condensed milk being excessively rich in carbohydrates and relatively poor in proteids. These facts are especially signifi- 
cant where condensed milk is used for infant feeding and by persons with weak digestion.

On the other hand, sweetened condensed milk depends for its preservation on the sucrose. This class of condensed milk is not sterile and is prevented from rapid deterioration by the preservative action of the sucrose only. Therefore, the smaller the amount of sucrose it contains, the greater the danger from the activity of ferments and the less its keeping quality.

The relative prices of cane sugar and of fresh milk also govern the amount of cane sugar used in many factories. In summer, milk prices are low and sugar prices are high, while in winter the relative prices are reversed. Hence there is a tendency on the part of the manufacturer to use less sugar in summer than in winter.

Again, the amount of cane sugar uset, varies according to the kind of market for which the condensed milk is intended. Milk put on the market in hernetically sealed cans is generally exposed to more unfarorable conditions and is older by the time it reaches the consumer than milk sold in barrels. It is customary to use about sixteen pounds of cane sugar for every one hundred pounds of fresh milk for canned goods, and about twelve to fourteen pounds of cane sugar for barrel goods.

Finally, there is a strong tendency in some localities, for sweetened condensed milk made in May and June to thicken rapidly and become cheesy with age. This can easily be prevented by the use of more cane sugar in the milk manufactured during these months. (See Chapter XXIII on "Conclensed Milk Defects")

Mixing the Sugar.-The sugar is added to the hot milk before the latter enters the vacuum pan. In some factories a separate tank is provided for this purpose. Small portions of the hot milk are allowed to flow into this tank. To these the sugar is added. This tank is called the sugar well. It is usually equipped with a mechanical, reversible stirrer, moving to and fro on an eccentric, to facilitate the solution of the sugar. The milk from the heater and from the sugar well, runs into a tank sunk into the floor of the well room, the ground well, from which the mixed sweetened milk is drawn into the vacuum pan. In other factories the sugar well and ground well are one and the same tank, into which the milk runs direct from the 
heater. In this case it is advisable to set a wire mesh strainer (sixty to eighty meshes to the inch) over the sugar well. The sugar is placed into this strainer, a little at a time; the hot milk from the heater passing into and through the strainer dissolves the sugar. A paddle or stick should be used to stir the sugar in the strainer. For greater convenience and economy of labor, the sugar barrels and scales are placed on the floor over the well room. The sugar is transferred to the strainer below through a sugar chute which may be equipped at the lower end with an adjustable cut-off, to regulate the sugar coming down. Other factories dissolve their sugar in boiling water in a separate tank, and draw this syrup into the vacuum pan together with the hot milk. This is a very commendable practice as it mininizes the danger of undissolved sugar crystals to escape into the pan. Moreover, this watery syrup can be boiled without danger of giving the milk a cooked flavor.

\section{CHAPTER V}

\section{CONDENSING}

From the ground well in the well room, the sweetened milk is drawn into the vacuum pan, where it is condensed under reduced pressure. The vacuum pan is usually located on the second floor over the well room, or in the well room itself, in which case it is elevated above the floor six to eight feet. The vacuum pan is connected with the vacuum pump which should be installed near the pan.

Description of the Vacuum Pan.-The vacuum pan is a retort in which the milk is heated and evaporated in partial vacuum. The origin of the term "pan" has not been satisfactorily explained. In the early and experimental days of the manufacture of condensed milk, the milk was evaporated in open kettles, called pans. It is probable that the name of this primitive apparatus was passed on to the more perfected machinery now in use.

The vacuum pans are constructed of copper, iron, steel or bronze. Practically all of the vacuum pans used for condensing milk are made of copper throughout; they are of various styles and sizes. The predominating size used in milk condenseries is the "six-foot pan." By the term six-foot pan is meant a retort measuring six feet in diameter. 
There are two general types of vacuum pans on the market; pans that are relatively wide in diameter and shallow in depth, and pans of a relatively narrow diameter and which have a deep body. Both types are claimed to have special advantages by their respective manufacturers, such as ease of operation, uniformity of action, economy of fuel and water and rapidity of evaporation. Notwithstanding advertising claims to the contrary, the pan that is wide and shallow and has its heating surface so arranged as to take care

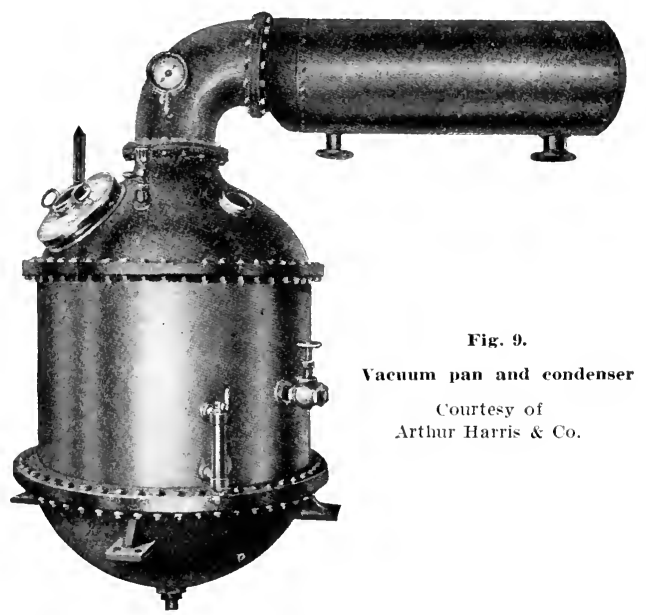

of the maximum amount of milk with the minimum depth of milk over the heating surface, is the most satisfactory. The wide, shallow pan offers a larger area of boiling surface and therefore makes possible more rapid evaporation than the narrow, deep pan. In the wide, shallow pan the milk boils more quietly, it is under better control and is less apt to be carried over into the condenser and lost, than in the natrow, deep pan.

The vacuum pan consists of four main parts, namely, the jacket, the body, the dome, and the condenser. 
THE JACKET forms the bottom of the pan. The inside wall is copper, the outside cast iron. It is concave and in the case of a six-foot pan about two and one-half feet deep. It is equipped with two steam inlets and one outlet. The outlets for the coils are also brought through the jacket. In the center of the bottom there is an opening, two to three inches in diameter, for the discharge of the condensed milk and fitted with two valves and a nipple between, to facilitate the sampling of the condensed milk.

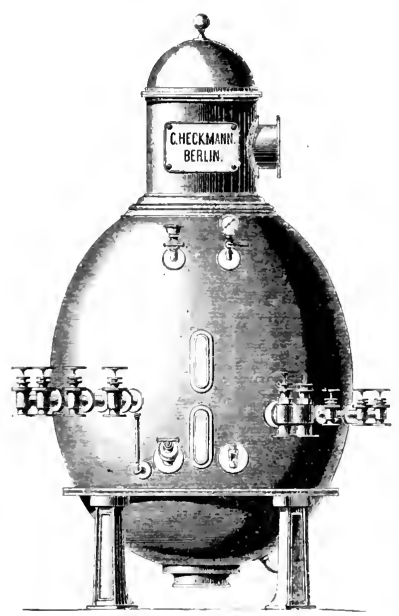

Fig. 10. Iacuum pan

THE BONY OR VAPOR BeLT represents the main part of the pan. It is cylindrical, of varying height and is equipped with copper coils which have their outlets through the jacket. Their upper ends connect, through the body of the pan, with the main stean line. Most pans are equipped with two to three coils located at different elevations. Since steam should be turned into the coils only when they are covered with the milk, it is desirable to have several short independent coils rather than but one large one. This will give a larger range of the quantity of milk that can be condensed and increases the speed of evaporation. The coils vary in diameter from about three to five inches. The upper and outer coils are the larger ones. The diameter and length of the coils necessarily vary with and are limited by the capacity of the pan. The greater the total heating surface, consistent with easy access to all parts of the jacket and coils, the better. Other things being equal, the more square feet of heating surface, the less steam pressure, by the gauge, is required to furnish the necessary heat for maximum evaporation. This is important because high stean pressure in the jacket and coils, means exposure of the milk to high temperature, which is undesirable. The heating surface should be sufficient to make possible the complete 
condensation of the steam in the jacket and coils. If the heating surface is inadequate, more steam has to be turned into the jacket and coils, in order to secure the necessary heat for rapid evaporation, than will condense; free steam will blow through and out of the

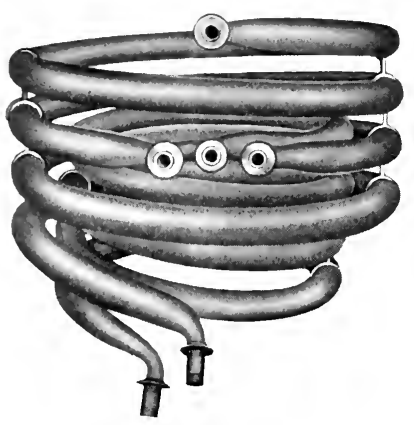

Fig. 11. Steam coils

Courtesy of Arthur Harris \& Co. coils, resulting in uneconomic and wasteful use of fuel, and jeopardizing the quality of the product. A properly constructed six-foot pan usually has not less than one hundred twenty to one hundred thirty square feet of heating surface.

Jacket and coils are connected independently with the direct steam main from the boiler. Each connection at the pan should carry a valve and a steam gauge on the pan-side of the valve. The main steam line and connections leading to pan should be properly insulated by proper pipe coverings, in order to supply the pan with as dry steam as possible.

The drips or discharge ends of the jacket and coils are connected with the boiler feed water tank. If the pan has sufficient heating surface and is operated properly, the drip ends of the jacket and coils should discharge warm water only, and not free steam. The jacket and coils should be free at the drip or discharge ends so that all condensation water may be quickly and continuously removed. This is necessary in order to make the most economical use of the steam and to secure high efficiency of evaporation. In order to guard against back pressure the drips may be equipped with suitable check valves.

Through the walls of the body of the pan also enters the milk draw pipe. This pipe connects with the hot well and through it the milk rushes into the pan. Immediately outside of the pan the milk pipe should be equipped with a valve to regulate the inflow. The size of the milk draw pipe and valve, is governed by the capacity of the pan; usually two to three inches in diameter. Inside of the pan the milk pipe should be turned down. If this provision is not made, 
the milk shoots straight across the pan atomizing into a dense spray, which is partly drawn over into the condenser, causing loss of milk.

The Dome rests on top of the body of the pan. It is equipped with a manhole, manhole cover, thermometer, vacuum gauge, eye glasses, lights and blow-down valve, or vacumm breaker. The man-

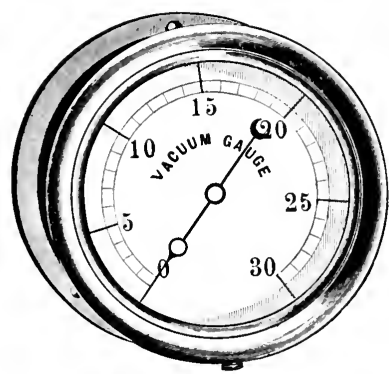

Fig. 12. Vacuum gauge Courtesy of Arthur Harris \& Co. hole measures about fourteen to eighteen inches in diameter. It is closed by a solid brass cover with a well fitting, ground-surface flange. The cover carries a five inch eye glass or sight-glass through which the operator watches the boiling milk in the pan. The stem of the thermometer is enclosed in a brass casing and reaches to near the botton of the pan. Some processors prefer a short thermometer which registers the temperature of the vapors instead of that of the milk. As both, the milk and the vapors are subjected to the same pressure, their respective temperatures are the same. The long-stem thermometer, the bulb of which is submerged in the milk, however, is more sensitive and registers changes of temperature more rapidly, because the milk is a better conductor of heat than the vapors. The vacuum gauge connects with the interior of the pan, and indicates the number of inches of vactum. A mercury colunn may be used in the place of the vacuum gauge. In the rear of the dome there are two eye glasses. Through these the interior of the pan is illuminated by means of lamps, gas or electric lights. The "blow down" valve, or vacuum breaker, serves to admit air into the pan in order to "break" the vacuum. This is necessary for readily drawing off the finished condensed milk. It is further needed to prevent the contents of the vacuum pan from being drawn over into the condenser, whenever the milk rises above a safe level.

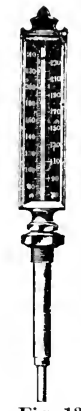

Fig. 13.

Thermometer for vacuum pan Courtesy of Taylor Instrument Co. 
The Condenser.- The condenser is that portion of the condensing apparatus in which the vapors, rising from the boiling milk in the pan, are condensed to water. The condenser is attached to the dome of the pan. There are three types of condensers in use, the surface condenser, the barometric condenser and the wet-vacuum spray condenser.

The SURFACE CONDENSER consists of a tube cylinder filled with brass tubes, mounted on a receiver. The water used for cooling circulates outside of the tubes and the vapors pass through the tubes

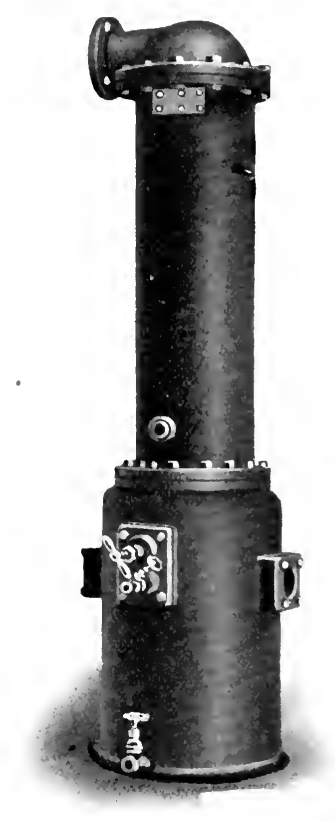

Fig. 14. The surface condenser Courtesy of Buffalo Foundry \& Machine Co. where they are chilled and condensed. This condenser las the advantage of enabling the operator to note the amount of condensation and to measure the anount of water actually condensed. 'The receiver, at the bottom of the condenser, should be so arranged that it can be drained at will and without interfering with, or retarding the operation of the pan.

The Baronetric ConDENSER consists of a vertical cylinder of iron or brass, equipped with a spray jet, through which the cooling water enters the condenser. The vapors being drawn over from the violently boiling milk in the pan. are condensed by passing through this spray of cold water. This condenser discharges its water into a tight cistern in the ground. The condenser is placed so that its bottom flange is about thirty-five feet above the water level of the cistern in which the discharge pipe from the condenser terminates. The height of the condenser depends on the barometric pressure of the location where it is installed. The lower the altitude and there- 
fore the higher the atmospheric pressure, the higher must the condenser be above the cistern. At the sea level, the atmospheric pressure sustains a water column about thirty-four feet high. This water column in the discharge pipe seals the vacuum and at the

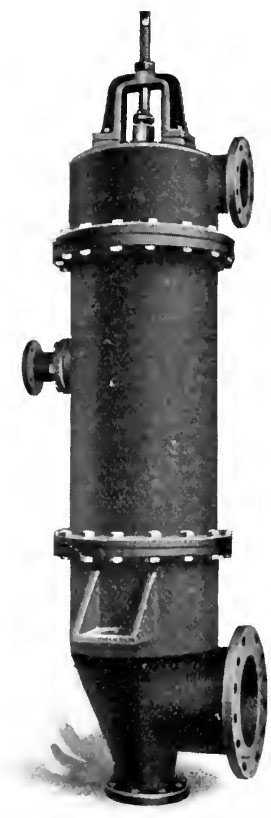

Fig. 15. Barometric condenser Courtesy of Buffalo Foundry \& Hachine Co. same time it permits the water from the spray and the condensation water to escape automatically. The cistern in which the water column terminates should be of sufficient size to hold about one-third more water than the capacity of the entire length of the discharge pipe calls for and should have a large overflow into the sewer. When the pan is in operation and a uniform vacuum is maintained, the level of the water columm remains constant and the excess water from the condenser overflows from the cistern into the sewer.

'The Wer-Vacuent Spray ConDENSER consists of a huge hollow cylinder of brass or iron, usually, but not necessarily, horizontal. It is equipped with a perforated spray-pipe placed lengthwise through the center of the cylinder. The spray pipe connects at one end with the pipe supplying the cooling water. When the pan is in operation, a shower of cold water issues forth from the perforations in the spray pipe as the result of the reduced pressure in pan and condenser. The hot vapors arising from the boiling milk in the pan are drawn over into the condenser, where they come in contact with the cold water spray and are condensed. The bottom of the condenser is connected with the suction end of the vacumm pump, through which the water in the condenser escapes.

The chief difference between the wet-vacuum condenser and the barometric condenser is that, in the wet-vacumm condenser the water from the condenser passes through the vacuum pump, while in the barometric condenser the water loes not pass through the vacuum 
pump, but goes direct into the sewer and the vacuum is sealed by the barometric water column. So far as practical experience has shown, there is no material difference in the efficiency between these two types of condensers. The water column of the barometric condenser

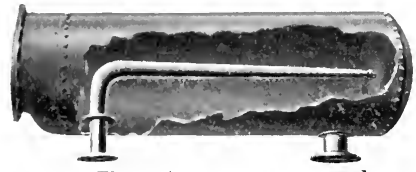

Fig. 16. The wet-vacuum spray condenser Courtesy of Arthur Harris \& Co. helps somewhat to maintain a uniform vacuum. It necessitates, however, the installing of the pan inconveniently high and requires somewhat more extensive machinery, than is the case with the wet-vacuum condenser.

The chief difference between both of these systems and the surface condenser is that, in the wet-vacuum and barometric condenser the condensed vapors mix with the cooling water, while.in the surface condenser the condensed vapors are collected and carried off separately and without mixing with the cooling water. In the case of condensing liquids, the vapors of which are of commercial value, the surface condenser must be used. The surface condenser, however, is of relatively small capacity and the cooling water cannot be utilized as economically as in the case of the other systems. Where large quantities of vapors are to be handled and the vapors have no commercial value, as is the case in condensing milk, the barometric and wet-vacuum condensers are best stited; their operation utilizes the cooling water more economically.

CARE of THE CONDENSER.-In the operation of the spray and jet condenser, special attention should be paid to the condition of the spray pipe. Especially, when the water used contains much organic matter, as is the case with water from a creek, pond or lake, there is a tendency of the spray pipe becoming filled and coated with slimy organic matter, causing the perforations to clog. This renders the distribution of the spray irregular and the control of the pan difficult. It causes great waste of water because much of the water is discharged from the condenser and lost without coming into direct contact with the vapors. The water is therefore not utilized economically and the difference between the temperature of the vapors and the discharge of the condenser is excessive. In order to avoid this the condenser should be cleaned out thoroughly at least once a week, or oftener, if necessary to keep the pores of the 
spray pipe free from obstructions. It is advisable to install condensers equipped with a manhole on top or at the end, otherwise access to the spray pipe is not sufficiently convenient to insure frequent inspection and thorough cleaning by the average operator.

The Expansion Tank, Catch-all, or Milk Trap.-This is a tank, frequently installed between the dome of the pan and the condenser. Its purpose is to collect and reclaim any milk that may be carried over from the pan and to prevent its escape and loss through the condenser.

If the pipe through which the milk enters the pan is turned down and its end is carried to near the bottom of the pan, so as to

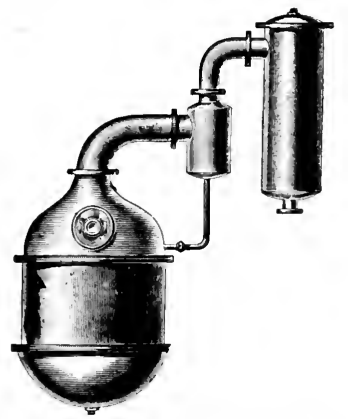

Fig. 17. Vacuum pan with milk tran and barometric conclenser trall and barometric condenser
Courtesy of Arthur Harris \& Co. avoid the formation of excessive milk spray, if the pan is operated carefully and if the milk is kept at a reasonably low level, there is very little danger of milk being carried over into the condenser in quantities sufficient to be of any consequence. Under these conditions the installation of a special milk trap between the pan and the condenser, for the purpose of collecting the escaping milk spray and carrying it back to the pan, is therefore an unnecessary expense.

If the pan is small in comparison to the amount of milk to be condensed, and if it is forced beyond its intended capacity, so that the milk boils up high, there usually is considerable loss of milk, as indicated by the foaminess and milky color of the exhaust of the vacuum pump. In such cases the mechanical loss of an average size batch, may amount to several hundred pounds of milk. In order to not lose this milk, a milk-trap or catch-all may be installed between the pan and the condenser. The vapors loaded with the milk spray enter the trap near the top. The spray Irops to the bottom of the trap, while the vapors are drawn over into the condenser, where they are condensed as usual. This trap may be constructed of sufficient size so as to serve as a reservoir to collect all the milk that is carried over, and at the conclusion of the process, the con- 
tents of the trap are drawn from the bottom and are condensed with the next batch; or the bottom of the trap may be connected with the pan so that the milk thus carried over flows back into the pan automatically. In this case a small trap only is necessary.

It should be understood that the milk trap is only a remedy and not a preventive. Where the capacity of the pan is in proportion to the amount of milk to be condensed, as it should be, and where the pan is operated properly, the trap is unnecessary. The trap is an additional piece of apparatus to be kept clean. Unless it is so constructed that access can be had to all parts of its interior and unless it really is kept clean at all times, it may become a serious source of contamination.

The Vacuum Pump.-The vacuum pump is, strictly speaking; not a part of the vacuum pan, but its intimate connection with the

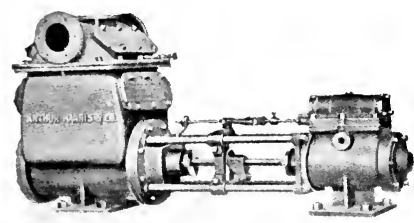

Fig. 18. Vacuum pump Courtesy of Arthur Harris \& Co. pan makes it necessary to briefly consider it at this point. The suction end of the vacuum pump is connected with the end of the condenser farthest of rom the pan. The vacuum pump exhausts the pan, forming a partial vacuum. There are principally two types of vacuum pumps used in the milk condensery, the dry-vacuum pump and the wet-vacuum pump. The dry-vacuum pump is used in the factories with the dry-vacuum system, i. e., where the cooling water and the condensation water escape to the sewer direct and without passing through the vacuum pump, as is the case with the surface condenser and the barometric condenser. The wet-vacuum pumps are used with the wet-vacuum system, where the cooling water and the condensation water pass through the cylinder of the pump. The dry-vacuum pumps have the advantage of permitting the operation of the machine at a higher piston speed than the wet-vacuum pumps in which the water must be displaced at the end of each stroke. The cylinders of the dry-vacuum pump are cooled by water jackets. The initial cost of the dry-vacuum pumps, however, is greater than that of the wetvacuum pumps. 
The efficiency of the vacuum apparatus depends very largely on the vacuum pump. Rapid evaporation at a relatively low temperature necessitates the maintenance of a high vacuum. The type, material, construction, workmanship, installation and operation of the vacuum pump should be such as to insure the maximum efficiency.

The pump should be placed on a good foundation and as near the vacuum pan as practicable, in order that the full benefit of the vacuum may be realized. The suction pipe and all connections must be tight. The suction pipe must be of the size directed by the manufacturer, as short as possible and with few and easy bends. The grade of the suction pipe should be uniform in order to avoid air pockets.

The water should be turned into the condenser before the vacuum pump is started. The pump should not run at a higher speed than is necessary to secure the required vacuum. Excessive speed means high steam consumption and heary wear and tear on the pump. The amount of water supplied to the condenser should be regulated to suit the requirements. Ordinarily, and with a vacuum of twenty-five to twenty-six inches, the temperature of the condenser discharge should be about i ro degrees F. A lower temperature would cause excessive and uneconomic use of water. The basin on the vacuum cylinder should be kept filled with water to prevent admission of air to the cylinder through the stuffing box, and the spray pipe or jet in the condenser should be inspected often to make sure that the perforations are not clogged. The stuffing box of the cylinder should be well packed with a good quality of packing and the steam cylinder well oiled. Start the pump slowly. Belt driven pumps, especially those equipped with a fly-wheel, insure greater uniformity of speed than direct-acting, steam-driven pumps. Steam-driven pumps should be furnished with a high grade governor. The vacuum pump should have a capacity, proportionate to the size of the vacuum pan, amount of heating surface, steam pressure for boiling and temperature of condensing water.

Science and Practice of Evaporating in Vacuo.-Purpose OF Condersing in TACuO.-The important adrantages gained by evaporating milk under reduced pressure, or in vacuo, are: economy of evaporation, rapidity of evaporation, low temperature and large ca- 
pacity of apparatus. All of these features are essential in the successful condensing of milk.

Rapid evaporation cannot take place until the milk is brought to the boiling point and is kept there until evaporation is completed. Under atmospheric pressure and at the sea level, the boiling point of water is 212 degrees $F$, the boiling point of milk is very slightly higher, abnut 2I4 degrees F. Evaporating of milk under atmospheric pressure, however, is a relatively slow process, requiring a long time, much fuel and large apparatus. Furthermore, exposure of the milk to 2 I 2 to $2 \mathrm{I} 4$ degrees F. long enough to complete evaporation would render the product unsuitable for market. The properties of some of its ingredients are altered, the product would asassume a dark color and a marked cooked flavor, as the result of the effect of heat. All of these objections are minimized and partly avoided by lowering the boiling point of milk.

Relation of Pressure to Boiling Point.-The temperature at which milk boils depends on the pressure to which it is exposed. 
The table below shows the boiling point of water at pressures ranging from atmospheric pressure at the sea level ( 14.72 pounds per square inch) to a complete vacuum.

\section{Boiling Points of Water at Different Vacua}

\begin{tabular}{|c|c|c|c|c|}
\hline $\begin{array}{c}\text { Absolute pressure } \\
\text { per square inch }\end{array}$ & $\begin{array}{l}\text { Vacuum inches of } \\
\text { mercury column }\end{array}$ & \begin{tabular}{|} 
Vaeuum milli- \\
meters of \\
mercury column
\end{tabular} & $\begin{array}{l}\text { Temperatures } \\
\text { of boiling point } \\
\text { of water, F. }\end{array}$ & $\begin{array}{l}\text { Temperatures } \\
\text { of boiling point } \\
\text { of water, C. }\end{array}$ \\
\hline $1+.720$ & 0.00 & OO & 212.00 & 100.00 \\
\hline $\mathrm{I}_{4} . \mathrm{OIO}$ & I. 42 & $3^{6}$ & $209 \cdot 55$ & 98.5 \\
\hline I 3.015 & $3 \cdot 45$ & 88 & 205.87 & 96.8 \\
\hline $\mathrm{I} 2 . \mathrm{OI} 5$ & $5 \cdot 49$ & I 39 & $201 \cdot 96$ & $94 \cdot 3$ \\
\hline I I . O2O & $7 \cdot 52$ & I9I & I97.75 & $91 \cdot 9$ \\
\hline 10.020 & $9 \cdot 5^{6}$ & 243 & 193.22 & $89 \cdot 5$ \\
\hline 9.020 & I I . 60 & 295 & IS8. 27 & 86.75 \\
\hline 8.024 & I 3.63 & 346 & $\mathrm{IS}_{2} .86$ & $8_{3} \cdot 7$ \\
\hline 7.024 & 15.67 & 398 & 176.85 & So. 5 \\
\hline 6.024 & $\mathrm{I} 7.7 \mathrm{O}$ & $45^{\circ}$ & I70.06 & 76.8 \\
\hline 5.029 & 19.74 & $5 \mathrm{O} 2$ & I 62.28 & 72.5 \\
\hline 4.029 & $2 \mathrm{I} .78$ & 553 & I $53.0 \mathrm{I}$ & $67 \cdot 2$ \\
\hline 3.034 & $23.8 \mathrm{I}$ & 605 & $\mathrm{I} 4 \mathrm{I} \cdot 5^{2}$ & 60.8 \\
\hline 2.034 & 25.85 & $65 \pi$ & I $26 . \mathrm{I} 5$ & $52 \cdot 3$ \\
\hline I. O4O & 27.88 & 708 & IOI .83 & $3^{8.7}$ \\
\hline .980 & 28.00 & 712 & IOO.OO & 37.8 \\
\hline .735 & $28.5^{\circ}$ & 724 & 90.00 & 32.2 \\
\hline $.54 t$ & 28.89 & 734 & So. 00 & 26.7 \\
\hline .402 & 29.18 & $7+\mathrm{I}$ & 70.00 & 2 I. I \\
\hline .294 & $29 \cdot 4^{0}$ & $7+7$ & 60.00 & I 5.6 \\
\hline .216 & $29 \cdot 56$ & $75 !$ & 50.00 & 10.0 \\
\hline .162 & 29.67 & 754 & 40.00 & $4 \cdot 4$ \\
\hline .127 & 29.74 & $75^{6}$ & 32.00 & \\
\hline
\end{tabular}

1 By courtesy of the Buffalo Foundry and Machine Company 
The pressure, or correctly speaking, the vacuum is expressed in terms of inches of mercury which the atmospheric pressure sustains. The mercury column is not a direct measure of the pressure, but it shows the difference between the atmospheric pressure and the absolute pressure in the vacuum chamber. The atmospheric pressure at the sea-level is 14.7 pounds per square inch. It sustains a mercury column in an absolute vacuum of thirty inches at 62 degrees $F$. and of 29.922 inches at 32 degrees $F$. The absolute vacuum may be calculated by multiplying the atmospheric pressure by the factor 2.04. In case there is only a partial vacuum the mercury column sustained is lowered to the extent of the absolute pressure in the vacuum pan. The absolute pressure may be calculated as follows:

$A V=$ Absolute vacuum which is thirty inches at the sea-level

$\mathrm{V}=$ Actual vacuum

$\mathrm{P}=$ Atmospheric pressure which is $\mathrm{I}+.7$ pounds at the sea-level

$\mathrm{AP}=$ Absolute pressure

Example: The actual vacuum in the pan is 25 inches at the sea-level. What is the absolute pressure?

$\frac{\mathrm{I}_{4} .7 \times(30-25)}{30}=2.45$ pounds of absolute pressure per sq. inch

Relation of Altitude to Atmospheric Pressure.-At altitudes higher than the sea-level, the atmospheric pressure is reduced and the mercury column is lowered, though the absolute pressure in the vacuum pan may be the same. Therefore, in factories located at high altitudes the mercury column will show fewer inches of vacuum at a given temperature and with a given absolute pressure.

The following tables show the barometric reading in inches of mercury and the atmospheric pressure in pounds per square inch at different altitudes, and the altitudes of various cities in the United States. 
${ }^{1}$ Barometric Reading Corresponding with Different Altitudes

\begin{tabular}{|c|c|c|c|c|c|}
\hline $\begin{array}{l}\text { Barometric } \\
\text { reading in } \\
\text { inches of } \\
\text { mercury }\end{array}$ & $\begin{array}{l}\text { Atmospheric } \\
\text { pressure in } \\
\text { pounds per } \\
\text { square ineh }\end{array}$ & $\begin{array}{l}\text { Altitude } \\
\text { above sea } \\
\text { level in feet }\end{array}$ & $\begin{array}{l}\text { Barometrie } \\
\text { reading in } \\
\text { inehes of } \\
\text { mereury }\end{array}$ & $\begin{array}{l}\text { Atmospherie } \\
\text { pressure in } \\
\text { pounds per } \\
\text { square inch }\end{array}$ & $\begin{array}{c}\text { Altitude } \\
\text { above sea } \\
\text { level in feet }\end{array}$ \\
\hline 30.0 & $1+.72$ & $\mathrm{O}$ & $23 \cdot 5$ & 11.54 & $6+12$ \\
\hline 29.7 & $1+.60$ & 264 & 23.0 & $1 \mathrm{I} \cdot 3 \mathrm{O}$ & 6977 \\
\hline 29.5 & $1+4.47$ & +41 & 22.5 & 11.05 & 7554 \\
\hline 29.2 & $1+.35$ & $7 \mathrm{IO}$ & 22.0 & 10.80 & 8144 \\
\hline 29.0 & $1+.23$ & 800 & $2 \mathrm{I} \cdot 5$ & $10.5^{6}$ & $87+7$ \\
\hline 28.7 & $\mathrm{I}+\mathrm{II}$ & 1163 & 21.0 & 10.31 & 9366 \\
\hline 28.5 & 13.98 & $13+7$ & 20.0 & $9.8 \mathrm{I}$ & 10648 \\
\hline 28.2 & 1.3 .86 & 1625 & 19.0 & $9 \cdot 32$ & I 1994 \\
\hline 28.0 & 13.74 & 1812 & 18.0 & 8.82 & ${ }^{1} 3+13$ \\
\hline 27.5 & 13.50 & $22 S_{5}$ & 17.0 & 8.33 & 14914 \\
\hline 27.0 & 13.26 & 2767 & 16.0 & 7.84 & I 6506 \\
\hline 26.5 & 13.02 & 3257 & 15.0 & $7 \cdot 35$ & 18201 \\
\hline 26.0 & 12.77 & 3758 & $1+.0$ & 6.86 & 19996 \\
\hline $25 \cdot 5$ & I 2.53 & +268 & 13.0 & 6.37 & 2I89I \\
\hline 25.0 & 12.27 & $47 \mathfrak{~}$ & 12.0 & 5.8 & $23 \times 86$ \\
\hline $24 \cdot 5$ & 12.03 & $53 \mathrm{IS}$ & I I.O & $5 \cdot 39$ & 25991 \\
\hline 24.0 & I I.7S & 5859 & & & \\
\hline
\end{tabular}

${ }^{1}$ By courtesy of the Buffalo Foundry and Machine Company 


\section{${ }^{1}$ ALTITUDE IN FEE'T OF VARIOUS CITIES IN THE UNITED STATES}

\section{By Courtesy of United States Department of Agrictulture}

Akron, O.............9940

Albany, N. Y. ........ 22

Atlanta, Ga. ............. 1032

Baltimore, Mld. ....... 92

Birmingham, Ala. .....6 600

Boston, Mass. ....... I6

Buffalo, N. Y. ....... 583

Burlington, Vt. ....... I I 2

Butte, Mont. .............. 5555

Charleston, S. C. ..... I2

Chattanooga, Tenn. ..... 672

Chester, Pa. ......... 22

Chicago, Ill. ........ 590

Cincinnati, O. ........ 490

Cleveland, O. ................... $5^{82}$

Dayton, O. ...........740

Denver, Colo. ........5 5 I83

Dallas, Tex. ........ 430

Des Moines, Ia. ........ 805

Detroit, Mich. ........ $5^{88}$

Dutluth, Minn. ........609

Houston, Tex. ........ $4^{6}$

Indianapolis, Ind. ...... 708

Ithaca, N. Y. ....... 4I I

Kansas City, Mo. ...... 750

Knoxville, Tenn. ...... 890

Lexington, Ky. ........ 955

Little Rock, Ark. ...... 264
Los Angeles, Cal. ....... 267

Louisville, Ky. ....... 453

Memphis, Tenn. ...... 256

Milwaukee, Wis. ...... 593

Minneapolis, Minn. ..... 8 I 2

New Iaven, Conn. ..... Io

New Orleans, La. ....... 6

New York City ........ 54

Oklahoma City, Okla. .... II97

Omaha, Neb............ Iоा6

Philatlelphia, Pa. ...... 42

Phoenix, Ariz. ........ $\operatorname{IO}_{2}$

Pittsburg, Pa. ....... 743

Providence, R. I. ....... I I

Richmond, Va. ........ 5 I

Rochester, N. Y. ...... 510

St. Louis, Mo. . . ...... 455

Salt Lake City, Utah....423

San Francisco, Cal. ..... I5

Santa Fe, New Mex. . . . .6952

Seattle, Wash. ........ Io

South Bend, Ind. ...... 7I7

Spokane, Wash. ........ I908

Tampa, Fla. ......... 15

Washington, D. C. .... 25

Wichita, Kan. .......... 294

Vicksburg, Miss. ...... $19^{6}$ 
According to Kent ${ }^{1}$ the relation of altitude to atmospheric pressure per square inch is as follows:

\section{Altitude}

At sea level

$1 / 4$ mile above sea level

$1 / 2$ mile above sea level

$3 / 4$ mile above sea level

I mile above sea level

I $1 / 4$ miles above sea level

I $1 / 2$ miles above sea level

2 miles above sea level
Pounds Pressure Per Square Inch

$$
\begin{aligned}
& \text { I } 4.7 \\
& \text { I } 4.02 \\
& \text { I } 3.33 \\
& \text { I } 2.66 \\
& \text { I } 2.02 \\
& \text { I } 1.42 \\
& \text { IO.88 } \\
& 9.80
\end{aligned}
$$

"For a rough approximation we may assume that the pressure decreases.one-half pound per square inch for every one thousand feet of ascent."

The absolute pressure in the pan of a factory located at Omaha, Nebraska, with an altitude of ten hundred sixteen feet above sea level, and condensing in an actual vacuum of twenty-five inches, would then be as follows:

Atmospheric pressure $=\mathrm{I}+.7-.5=\mathrm{I} 4.2$ pounds per square inch.

Absolute vacuum $=14.2 \times 2.04=28.97$ inches.

Absolute pressure $=\frac{1+.2 \times(28.97-25)}{28.97}=\mathrm{I} .95$ pounds per square inch.

Relition of Steam Pressure in Jacket and Colls, IVAter in Condenser, Temperature in Pan and Vacuum, to Raphity or Evaporatron.-The temperature of the vapors in the vacuum pan depends directly upon the pressure or vacum under which they are generated. The more nearly complete the vacuum and therefore the lower the pressure, the lower the temperature, and, other conditions being the same, the more rapid the evaporation. The pressure in turn is governed by the capacity of the vacuum pump, the tightness of the joints, the steam pressure in jacket and coils and the amount and temperature of the water in the condenser.

\footnotetext{
1 Mechanical Engineer's Pocket-book p. 581
} 
With a low capacity vacuum pump, or a pump running irregularly, or too slow, or too fast, and with leaky joints, the vacuum will ahways be low, and the pressure and temperature relatively high. Under these conditions the pan is difficult to operate and evaporation is slow.

With the above conditions under control and properly adjusted, the temperature and the rapidity of evaporation depend on the steam pressure in the jacket and coils and on the amount and temperature of the water used in the condenser.

Twenty-five pounds of steam pressure in the jacket and coils has been found to be about the maximum that can safely be used. With this steam pressure the milk coming in direct contact with the heating surface is exposed to about 267 degrees $\mathrm{F}$. and there is a tentency for some of it to bake or burn on, which is undesirable. The walls of the jacket and coils are also subjected to considerable strain, since they are surrounded by an almost complete vacuum. Then again, if the pan has the proper amount of heating surface the capacity of the condenser and the water supply are in most cases insufficient to take care of and condense the vapors, arising from the boiling milk in the pan, when the stean pressure in jacket and coils approaches or exceeds twenty-five pouncls. In many instances twenty pounds of steam pressure is the maximum which can be used to advantage and most condenseries operate their pans with twelve to twenty pounds of steam pressure in jacket and coils. In the operation of some pans not more than about five pounds steam pressure can be used in jacket and coils economically, because the use of more steam causes the steam to blow through and out of the coils. This may be due to relatively large heating surface, or small evaporating capacity due to a small capacity pump or limited water supply to condenser.

The capacity of the condenser used in milk condenseries is very largely dependent on the water supply. Whenever the condenser is forced beyond its capacity, by using excessive steam in jacket and coils, the vacuum drops, the temperature rises and the process of evaporation is retarded.

The higher the vacuum the more rapid the evaporation. A rise in the steam pressure in the jacket and coils increases the rapidity of evaporation only as long as enough water passes through the con- 
denser to maintain a high vacutum. As soon as the steam pressure in the jacket and coils reaches the point where the water in the condenser fails to promptly reduce the vapors, the vacuum drops, the temperature in the pan rises and evaporation is checked.

If the water supply were unlinited and the water available were cool (about 50 degrees $\mathrm{F}$. or below), condensing with twenty to twenty-five pounds of steam pressure in the jacket and coils would result in the maximum rate of evaporation consistent with good quality of the product.

The condensing of milk requires immense quantities of water; experience has shown that it takes from two to three gallons of water to condense one pound of fresh milk. The water supply is one of the weakest points in most condenseries, so that economy of water is one of the important factors to be considered. The steam pressure in the jacket and coils should therefore be so regulated, as to make it possible to maintain the maximum vacuum consistent with reasonably economic use of water. The experience of the best pan operators is that about fifteen pounds of steam pressure in the jacket and coils and a racuum of twenty-five inches is practically the maximum that can be maintained under average conditions without taxing the ustral water supply beyond its capacity. With a vacuum of twenty-five inches the temperature in the pan is about I 35 degrees $\mathrm{F}$, the temperature varying somewhat with the altitude of the factory. In some condenseries the temperature of the pan is kept at I50 degrees F. This practice may economize the water a trifle better, but the rapidity of evaporation is considerably lower.

Condensing at temperatures lower than I zo degrees F., without reducing the steam pressure in the jacket and coils, increases the rapidity of evaporation, but taxes the water supply beyond the reach of most condenseries. So much water has to be used in the condenser that it is not used economically, as is shown by the relatively low temperature of the water discharging from the condenser. The temperature of the condenser discharge bears a direct relation to the temperature of the rapors in the pan. Observations made in various factories and under different conditions by Hunziker and others showed that the condenser discharge was any where from 5 to 25 degrees $\mathrm{F}$. lower in temperature than the vapors in the pan, the difference averaging about $\mathrm{I}_{5}$ degrees $\mathrm{F}$. 
The smaller the difference in temperature between the condenser discharge and the vapors in the pan, the more economic is the use of the water and vice versa. It is not advisable under average conditions, to so operate the pan that the temperature of the condenser discharge drops below i io degrees F., because of the wasteful use of water under such conditions.

The condensing of one pound of milk requires about one pound of steam and eighteen to twenty-five pounds of water. The quantity of heating steam used for condensing in vacuum is practically the same as that required by evaporating in open pans. In order to use the steam economically the pan should be so operated as to make possible its complete condensation by the time it leaves the jacket and coils. Whenever so much steam is used that it blows through and out of the jacket and coils without being conclensed, there is great waste of fuel. For further details on this point see Chapter $\checkmark$, on the "Deseription of the Vacum Pan."

Starting the Pan.-Before drawing the milk into the pan, the pan should be thoroughly rinsed with water, then steamed until the temperature rises to about $\mathrm{I} 8 \mathrm{So}$ degrees $\mathrm{F}$. Then the manhole cover is put in place, all the air valves are closed, water is turned into the condenser and the vacuum pump is started. When the vacuum gauge shows over twenty inches of vacuum, the pan is reacly for the milk.

Operating the Pan.--The valve of the milk pipe leading to the pan is now partly opened. The milk enters the pan automatically as the result of the reduced pressure in the pan. W'hen the milk covers the jacket, steam is gradually turned into the jacker. As each coil becomes submerged in milk, the coils are charged with steam. At no time should steam be turned on the jacket and coils when they are not completely covered with milk, as such action would cause the milk to stick to and burn on the heating surface, the milk would assume a burnt flavor, it would become permeated with black specks and the evaporation would be retarded. (On the start, but a few pounds of steam pressure should be used in the jacket and coils, to avoid burning, owing to the presence in the milk of considerable air. As the milk becomes more concentrated and settles down to uniform boiling, the steam pressure may be gradually increased until it reaches the maximum. The maximum pressure permissible must 
be governed by the amount of heating surface, the capacity of the vacuum pump and the temperature and amount of water available for use in the condenser. Under average conditions about fifteen to twenty pounds of steam pressure may be safely used.

During the early stages of the process, when the milk is of low density, the evaporative duty is high, probably about twenty-five to thirty-five pounds per square foot of heating surface with ten pounds of steam pressure. This gradually decreases and is lowest toward the end of the process.

When enough milk is in the pan to completely cover the jacket and coils, the milk intake should be reduced and regulated in accordance with the rate of evaporation. The milk is drawn into the pan continuously, but only as fast as it evaporates. It should be kept as much as possible at a constant level, and this level is preferably as low as is consistent with complete covering of the upper coil.

In order to secure maximum rapiclity of evaporation, the vacuum pump should run at the proper speed and its operation should be uniform, a uniform vacuum and temperature should be maintained, and the milk should be prevented from rising to an abnormally high level in the pan.

Prevention of Accidents. - The operator should pay strict attention to the pan in order to avoid loss of milk due to accidents. He should watch the water supply and govern its use accordingly. If the water supply becomes exhausted, air is liable to be drawn into the pant through the condenser. This will cause the milk to drop suddenly and then rise in a body threatening to escape through the condenser. Whenever air in considerable quantities is allowed to enter the pan while in operation, be it as the result of lack of water, or through any other cause, the escape of milk may be avoided by immediately shutting the steam inlet to the jacket and coils, by closing the milk intake and by slightly opening the blow-down valve, whenever the milk rises dangerously high. Iy careful manipulation until the milk again settles down to uniform boiling, loss can be avoided and the process can be continued in the normal way.

By the time all the milk is in the pan, condensation is nearly completed, and from ten to twenty minutes further boiling usually gives the milk the desired density. Toward the end of the process 
the steam pressure in jacket and coils should be reduced to about five pounds or less. When the milk approaches the desired density, it is comparatively heavy and viscous and boils less vigorously. It therefore is nore directly exposed to the heating surface. In the case of excessive steam pressure, its quality is jeopardized. If the batch is small so that the level of the milk drops below sone of the coils, steam to the exposed coils should be turned off entirely.

\section{CHAP'TER V'I}

\section{STRIKING OR FINISHING THE BATCH}

Definition.- When the boiling milk in the vacuum pan approaches the desired degree of concentration, the batch is "struck." 'The term "striking" is applied to the operation of sampling the condensed milk and testing the sample for density. This term very probably referred, originally, to the meaning of " "striking the batch right," that is, stopping the process at the proper time, or when the milk is neither too thick nor too thin. It then expressed the result of the operation, while now it is used to mean the operation itself.

Ratio of Concentration.-Sweetened condensed milk intended for canned goods has a specific gravity of 1.28 to 1.30 . This density is reached usually when the ratio of concentration is about $2.5: \mathrm{I}$, i. e., 2.5 parts of fresh milk are condensed to one part of condensed milk, assuming that about sixteen pounds of sucrose have been added to every one hundred pounds of fresh milk.

Methods.-To know just when the proper degree of concentration has been reached, is difficult and requires experience. It is here where the processor can easily make or lose his wages. There are various indications reminding the observant processor that the milk in the retort is nearly "done," viz., time consumed for condensing, time elapsed since all the milk has been "drawn up," amount of condensed milk left in the pan, and, most of all, the appearance and behavior of the boiling milk itself. Milk that has been sufficiently condensed assumes a glossy, glistening luster, it boils over from the periphery towards the center, forming a small nucleus or puddle of foam in the center of the pan. An experienced and ob- 
servant operator knows within a few minutes, when the milk is condensed enough. This does not mean, however, that he should wait until the last minute before he "strikes" the batch, for even the most skillful and experienced processors are easily deceived by the mere appearance of the condensed milk through the eye-glass.

The degree of concentration may be more accurately determined by taking a sample from the pan and testing it by varions methods. such as by weighing a definite quantity of condensed milk on a sensitive scale, by the use of a resistance apparatus, or by the use of a specially constructed hydrometer. ()f these the Iieaumé hydrometer has been found the most suitable to use.

Mechanical devices and methods, stuch as the above, can be depended on, when all the conditions influencing the specific gravity of the liquid are under control, and when there is plenty of time for their manipulation. When the boiling and rapilly craporating milk in the retort is approaching the proper density, however, quick action is essential. One minute over or under condensing, may cause the milk to be either too thick or too thin for the market and may necessitate the "re-running" of the entire batch. These instruments are, therefore, practically worthless at the time they are needed most. There is not time to carefully measure and weigh out a sample of sweetened conflensed milk, nor can the processor always wait until the hyctrometer has found its equilibrium in as viscous a fluid as sweetened condensed milk. Again, the lensity or specific gravity of the finished product depends, outside of the degree of concentration, on many and fluctuating conditions, such as amount of heat applied toward the end of the process, the temperature of the sample when drawn, and the per cent. of fat and cane sugar in the condensed milk. It is for these reasons that arbitrary mechanical instruments and methods are not uniformly satisfactory, and are prone to yield misleading results. The experienced eye and goor judgment of the processor are all essential. The following are satisfactory and reliable methods of "striking," which, with a little experience, enable the operator to determine the proper degree of condensation :

Draw a sample from the pan into a tin dipper, lower the dipper into a pail of ice water or snow. Stir the condensed milk with a metal-back thermometer until the condensed milk is cooled to zo 
degrees F. Note the thickness of it ; or, finich the batch at a constant temperature, say i 20 degrees F. Draw a sample into a tin cup and note the thickness by examining the milk when pouring from a teaspoon. The transparency of the milk when thus held against the light is a good indication of its density. The last method is preferable because of its greater rapidity.

USE OF BEAUMÉ HYDROMFTER.-lieginners and inexperienced operators do well to take numerous samples from the batch in the operating pan and to start sampling early, so as to avoid over-condensing. 'The use of a Beaumé hydrometer, especially constructed for sweetened condensed milk, graduated from 30 to 37 degrees $B$. and with subdivisions of one-tenth degrees, is an additional safeguard to insure accuracy and uniformity of thickness. No definite figure at which the beaumé hydrometer should be read can be stated, that would show the proper density under all conditions. 'The Beaumé reading of sweetened condensed milk of the proper concentration varies with such factors as per cent. of fat, per cent. of sucrose and per cent. solids, ratio of concentration, and temperature of the condensed milk when the reading is taken. However, for general guidance, it may be stated that condensed milk of proper density, made from fresh miik of average richness, and containing sucrose at the ratio of sixteen pounds of sugar per one hundred pounds of fresh milk, will show a Beaumé reading of about 33.5 degrees $\mathrm{B}$. at 60 degrees $\mathrm{F}$., or about 32 degrees $\mathrm{B}$. at i 20 degrees F. Sweetened condensed skim milk, containing approximately to per cent. sucrose will show a lieaumé reading at 60 degrees $\mathrm{F}$. of about 37 degrees B., or about 35.5 degrees B. at 120 degrees $\vec{F}$.

CORRECTION OF HYDROMETER READING FOR TEMFig. 19. Beaume PERATURF. - The Beaumé hydrometers used in Amerihyilrometerfor
sweetened

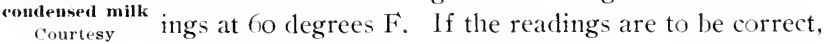

C. J. Tagliabue or if it is desirable to convert the!n into specific grav-
ufg. Co. 
ity, the condensed milk should have a temperature of 60 degrees $\mathrm{F}$. Where this is not convenient, the observation may be made at any temperature convenient and the reading corrected as follows:

When the temperature is above 60 degrees F. multiply the difference between the observed temperature and 60 degrees $F$. by the factor .025 and add the product to the observed reading of the Beaumé hydrometer. When the temperature of the observed reading is below 60 degrees $\mathrm{F}$. the corresponding product is deducted:

Exámple: Beaumé reading at $\mathrm{I} 2 \mathrm{O}$ degrees $\mathrm{F}$. is $3 \mathrm{I} .2$. Corrected reading is $3 \mathrm{I} .2+[.025 \times(120-60)]=32.7$. The specific gravity may be calculated, when the Beaumé reading is known, by using the following formula:

$$
\text { Specific gravity }=\frac{1+4 \cdot 3}{\mathrm{I}+4.3-\mathrm{B} .} ; \mathrm{B} .=\text { Beaumè reading }
$$

Example: Beaumé reading at 60 degrees F. is 33.I.

$$
\text { Specific gravity }=\frac{1+4 \cdot 3}{1+4 \cdot 3-33 \cdot 1}=1.2976
$$

In the following table are assembled figures showing the specific gravity of sweetened condensed milk of different Beaumé degrees, varying from 28 degrees B. to 37.8 degrees $B$. 
SPECIFIC CRAVIYY OF SWEE'LENED CONDENSED MILK UF DIFFEREN'T BEALME DEGREES

\begin{tabular}{|c|c|c|c|}
\hline $\begin{array}{l}\text { Beaume at } \\
\text { to degrees } \mathrm{F} \text {. }\end{array}$ & $\begin{array}{l}\text { specifie } \\
\text { Giravity }\end{array}$ & $\begin{array}{l}\text { Beaume at } \\
\text { 6il degrees } \mathrm{F} \text {. }\end{array}$ & $\begin{array}{l}\text { Mpectice } \\
\text { firavity }\end{array}$ \\
\hline 28.0 & 1.2407 & 33.0 & I. 2065 \\
\hline .2 & $1.2+28$ & .2 & $1.20,88$ \\
\hline$\cdot+$ & I. $2+49$ & $\cdot+$ & I $\cdot 3$ O I I \\
\hline .6 & I . $2+7 \mathrm{I}$ & .6 & I. 3034 \\
\hline .8 & $1.2+93$ & .8 & 1.3058 \\
\hline 29). 0 & I. 2515 & $3+.0$ & $\mathrm{I} \cdot 30 \mathrm{~S}_{2}$ \\
\hline .2 & I. 25,36 & .2 & I. 3106 \\
\hline+4 & $1.255^{\circ}$ & $\cdot 4$ & I. 31,30 \\
\hline .6 & 1.2580 & .6 & $1 \cdot 3154$ \\
\hline .8 & 1.2602 & .8 & 1.3178 \\
\hline 30.0 & 1.2624 & 35.0 & 1.3202 \\
\hline .2 & $1.26+6$ & .2 & 1.3226 \\
\hline$\cdot 4$ & 1.2068 & $\cdot+$ & 1.3250 \\
\hline .6 & $1.26) 0$ & .6 & I. 3274 \\
\hline .8 & $1.27 \mathrm{I} 3$ & .8 & 1.3209 \\
\hline 31.0 & I. 27.36 & 36.0 & 3.3324 \\
\hline .2 & I. $275^{8}$ & .2 & $1 \cdot 3.34^{8}$ \\
\hline$\cdot t$ & 1. 2780 & $\cdot+$ & $1 \cdot 3.372$ \\
\hline .6 & I . $2 \mathrm{SO}_{3}$ & .6 & I. 3397 \\
\hline .8 & 1.2826 & .8 & I. $3+22$ \\
\hline 32.0 & $1.28+9$ & 37.0 & $1 \cdot 3+47$ \\
\hline .2 & I. .2872 & .2 & I. 3472 \\
\hline$\cdot+$ & 1. 2895 & $\cdot+$ & $1 \cdot 3+97$ \\
\hline .6 & 1.2918 & .6 & I. 3522 \\
\hline .8 & $1.29+\mathrm{I}$ & .8 & I. $354^{8}$ \\
\hline
\end{tabular}


Sampling of Batch.-The samples can be drawn from the pan by operating the two valves at the bottom. While the milk is condensing, the partial vacuum in the pan makes impossible the draw-

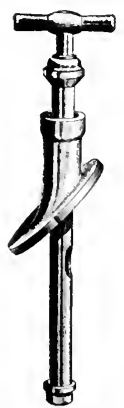

Fig. 20. I convenient device for sampling

the contensed

milk in the pai
Courtesy of

Arthur Harris \& Co.

ing off of the sample by simply ppening the outlet. Instead of causing the milk to come out, air would rush in with violent force and would cause the milk in the pan to be thrown over into the condenser, besides dangerously jolting the machinery. For this reason, the outlet is equipped with two valves, both of which are closed during the condensing process. For taking samples, open the upper valve. This allows the condensed milk to run into the nipple between the two valves. Now close the upper valve and open the lower one. The milk will run out freely. The first

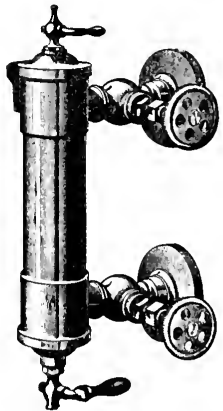

Fig. 21. A convenient device for sampling comblensed milk in the pan Courtesy of Arthur Harris \& Co.

sample should be rejected, as it may contain water caught in the nipple. For greater convenience, specially constructed sample testers attached to the sicle of body of the pan may be used.

Drawing off the Condensed Milk.-As soon as the evaporation is completed, the steam is shut off from the jacket and coils, the water valve is closed, the vacuum pump stopped and the vacuum broken by opening the "blow-down" valve. The manhole cover is then removed and the vacuum pump started again in order to remove the hot air over the milk. The milk is drawn into fo-quart cans. The condensed milk should be drawn from the pan as rapidly as possible to prevent its superheating while in the pan. In some factories a wire mesh or cloth strainer is attached to the outlet of the pan, so that the condensed milk is strained before it runs into the cans. This practice is unnecessary and objectionable, as it tends to retard the removal of the milk from the pan.

\section{COOLING}

The condensed milk in the fo-quart cans has now a temperature of about i 5 degrees F. to IzO degrees F. If it were allowed 
to cool naturally, i. e., if no effort were made to cool it promptly, it would become thick and cheesy in texture in a short time. It is, therefore, essential that it be cooled at once. Formerly, this was done by setting the cans in tanks containing ice water and stirring the milk with a stick. This was a very crude method, it involved much hard work and time, and the quality of the product was poor. It was soon found that the imperfect hand stirring caused excessive sugar crystallization, which made the milk sandy. The sudden chilling and irregular stirring of a saturated sugar solution like sweetened condensed milk are favorable to the formation of sugar crystals. Where the stirring is imperfect and irregular, all the milk is not kept in sufficient motion to insure uniform and gradual cooling. The milk next to the side of the cans is chilled too abruptly, favoring the formation of crystals. Vigorous stirring in itself is conducive of sugar crystallization.

The hand stirring has been completely superseded by mechanical stirring. Paddles closely scraping the sides of the cans are now used. Instead of setting the paddles in motion, they are stationary and the cans revolve. The principle is similar to that of the vertical ice cream freezer. Heavy iron tanks, with a capacity of twelve to forty-eight to-quart cans, are used for this purpose. The bottoms of these tanks are equipped with a system of $\operatorname{cog}$ wheels, set in motion by means of a gear at one end of the tank. The wheels have a diameter large enough to carry one can each. The cans are set on these wheels, the paddles are inserted and fastened to cross-bars and the power started. The cans should be heavily constructed to stand rough usage, without suffering indentations. Cans with irregular, depressed, or bulged sides cause the paddles to do poor work. Such cans should be slipped over a wooden horn, or other contrivance, and the indentations hammered out with a mallet. The paddles are held stationary by cross-bars and are forced against the periphery of the cans by springs. Attention should also be paid to the pivots on which the $\operatorname{cog}$ wheels rest. If they are warped, the wheels do not run true, so that it is not possible for the paddles to scrape the sides of the cans properly.

The sweetened condensed milk should be cooled gradually. Sudden chilling should be avoided. This is best accomplished by warming the water in the cooling tank to about 90 degrees $F$., before the cans are set in. The cans are then allowed to revolve for fifteen 
to twenty minutes before any cold water is turned into the tank. After that, cold water is turned in slowly until the temperature of the milk has fallen to about 70 degrees $\mathrm{F}$. The entire time of cooling should last about two hours. The cans should revolve slowly, rapid stirring enhances the precipitation of sugar crystals. In order to scrape the sides of the cans efficiently, when the cans revolve slowly, (about five revolutions per minute) it is advisable to use two paddles in each can, scraping the cans at opposite sides. When the milk is sufficiently cooled the cans are stopped, the paddles lifted out, scraped and removed, and the cans taken out of the tank.

In some factories, the condensed milk is transferred from the pan direct into large tanks and is subsequently

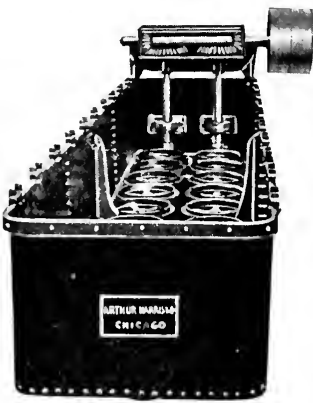

Fig. 22. Cooling tank for sweetened condensed milk Courtesy of Arthur Harris \& Co. cooled by pumping it through a series of coils submerged in cold water. This method is labor and time-saving and the objectional,e features of agitation are avoided. On the other hand, there is danger of too rapid chilling which tends toward excessive sugar crystallization and the production of rough, sandy and settled milk.

\section{CHAP'TER VII}

\section{FILLING:}

The sweetened condensed milk is put on the market in barrels and in hermetically sealed tin cans.

In Barrels.-Barrels, similar to glucose barrels, are generally used. They hold from three hundred to seven hundred pounds of condensed milk. New barrels should be used for this purpose. Barrels paraffined on the inside are most satisfactory, as they are more apt to be free from mold spores. Old glucose barrels are dangerous to use, as they often contain decaying remnants of glucose, which cause the condensed milk to ferment. The new barrels are steamed out and drained thoroughly. The filling is facilitated by the use of a large galvanized iron funnel with a discharge one 
and one-half inches in diameter, or an ordinary milk pail with a nipple one and one-half inches in diameter in the bottom of the pail. When filled, a clouble layer of cheese cloth is placed over the bunghole, and the bung is driven in level with the staves. T'he harrel goods are sold to bakeries and candy factories.

In Cans.-The canned goods are intended for the retail market. The cans used hold from eight to sixteen ounces of condensed milk. Most makes of tin cans for sweetened condensed milk have a small

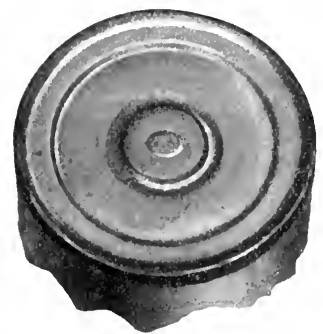

Fig. 23. The solder seal 1

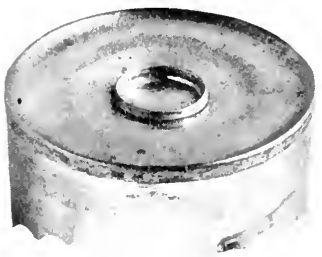

Fig. 24. The liebere seal

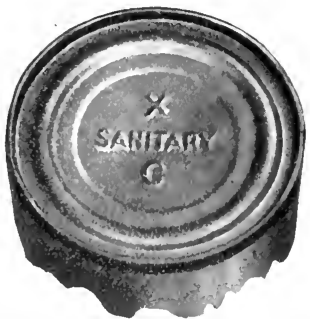

Fig. 25. The Sanitary can 1

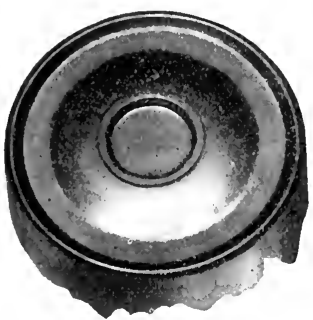

Fig. 26. The Mclonald seal

opening, three-eighths to three-fourths inch in diameter, through which they are filled. The cans made by the Sanitary Can Company are filled before the top is erimperl on. Sweetened condensed nilk is of a semi-fluid, viscous and sticky consistency. The successful and rapid filling of the cans without spilling the milk over the top of the can is, therefore, somewhat difficult. If done by hand the work is very slow. For this reason many ingenious machines

\footnotetext{
1 Courtesy of The Sprague Canning Machinery Co.
} 
have been devised which are more or less efficient in "cutting off" the milk without "slobbering." The filling machines now in use

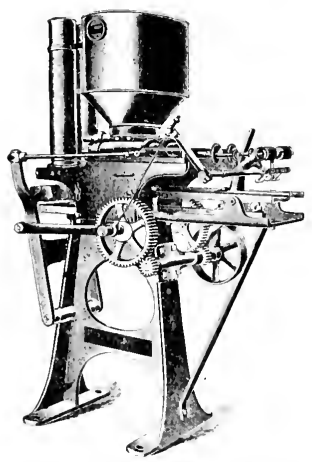

Fig. 27. The Nibluey siller courtasy of The sprague canning Machinery Co. vary from the primitive hand filler, in which the condensed milk is "ground out" by the turning of a crank by hand. to the most perfect forms of automatic filling machines. In these filling machines, all parts coming in contact with the condensed milk are constructed of brass. They are equipped with a reservoir, receiving tank, or hopper, which has an automatic feed, usually a loating device attached to a valve, which regulates the inflow according to the discharge. the discharge is adjustable to fill any size can with a remarkable degree of accuracy. Machines of this type will fill from twenty-five thousand to thirty thousand cans per day (ten hours).

These machines are of complex construction and must receive proper care. It is best to clean them thoroughly after each day's work. But, since their inlet and discharge are closed hermetically, the complete washing may be done once per week only. without seriously disturbing their efficiency or impairing the product. For thorough cleaning, the filler should be dissected, removing all detachable parts, such as valyes, pistons, tubes, etc. When freed from all rem-

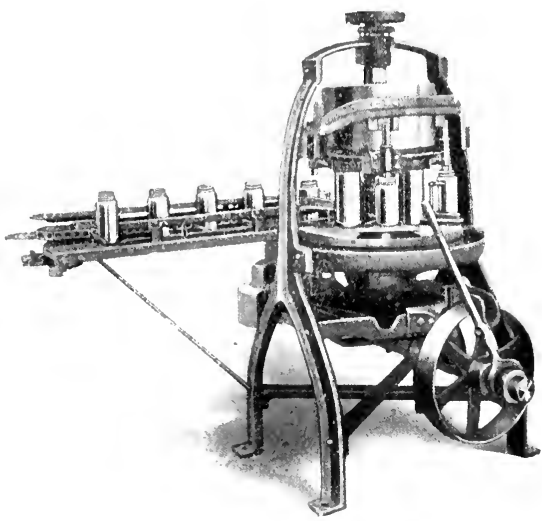

Fig. 28. The Merrell-soule filler Courtesy of The sprague ('anning Machinery ('o. 
nants of condensed milk, the parts should be scalded, dried and replaced in the machine. In order to guard against all possible contamination by remmants of wash water, it is advisable to reject the first few cans of milk of the next filling. When not in use, the filling machine should be covered with clean cloth, or oil cloth, to protect it from dust and flies, etc.

As soon as the cans are filled, they should be "capped." If allowed to stand open, dust, dirt and flies, or other insects are prone to reach their interior, and the prolonged exposure of the condensed milk to the air causes the surface to crust over.

\section{SEALING}

Kinds of Seals.- The seal must be air-tight and firm enough to prevent its breaking during the rough treatment to which the cans are exposed in transportation. There are several methods of sealing the cans, depending largely on the construction of the can. Most of the cans used are sealed with solder. There is a groove around the opening, the cap fits into this groove and the latter is filled with soller. In the case of cans which are sealed without solder, the cap or the entire end of the can is crimped onto the can so as to make a hermetical seal. The $\mathrm{McD}$ Donald seal with the friction cap, the Gebee seal with the burr cap, and the Sanitary can seal with the top of the can crimped on after filling, are the chief types of solderless seals. In the case of the McDonald seal, a tightly fitting cap with a wide flange is pressed into the opening. The "capped" can passes under a series of steel rollers pressing the flange firmly against the top of the can. This seal is very simple, but is not very strong and not hermetically tight. In the case of the Gebee seal, a rim projects around the opening of the can. After the cap is inserted, it is crimped over this rim by means of a series of revolving dies. This seal is reasonably strong but not hermetically tight. The Sanitary can is entirely open at one end when filled. The cover or end is crimped around the periphery of the body of the can by means of revolving dies. This seal is reasonably strong and usually hermetically tight.

The chief advantages of the seals without solder lie in the saving of labor, and the reduction of the cost due to the omission of solder. The principal reason for which they are not used more gen- 
erally by milk condensing companies, lies in the fact that these solderless seals are all patented. In most cases the inventors or patent holders are condensel milk manufacturers. They refuse to sell their patents at a reasonable price to other condenseries and they charge exorbitant royalties for the use of their patents by their competitors. With the possible exception of the "Sanitary can," solderless seals are not as reliable as solder seals.

Soldering Devices and Machinery.-The sealing of all solderless seals is done by specially constructed sealing machines.

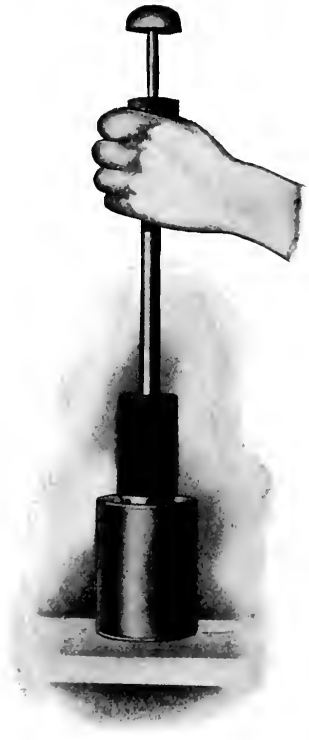

Fig. 30. A convenient device for soldering by hand Courtesy of The Sprague canning Machinery co.

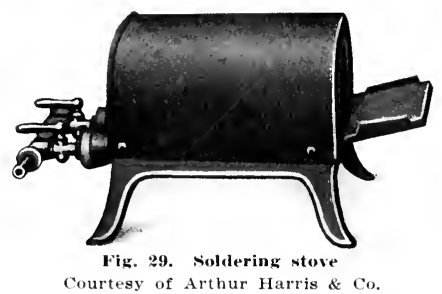

For seals with solder there are several machines on the market but most of this work is as yet done by hand. For this, different types of soldering coppers are in use and the copper tips are heated in soldering stoves or pots. Some soldering coppers have hollow circular tips with a diameter equal to that of the cap used. The hollow tip is telescoped by a rod which holds the cap in place and the periphery of the tip fits into the groove of the opening of the can, where it melts the solder, completing the seal. A rapid, neat and leakless seal can be made with this instrument.

Ordinary solkering coppers with a blunt point, such as are in general use by the tin smith, are not very satisfactory. Unless they are drawn out and filed down into a fine point, their use is not conducive of neat work, progress is comparatively slow and leakers are often numerous. When gas is available the automatic soldering 
copper may be usesl to advantage. In this tool the copper tip, which is long and slender, is automatically heated by a current of gas passjng through the handle and burning at the copper tip. The handle of the device is connected with the gas and air pipes by means of flexible rubber tubing. No time is lost waiting for the coppers to heat and the flame can be so regulated that the temperature of the copper tip is right and uniform. 'This is important, because perfect work is impossible unless the coppers have the proper temperature.

Nachine-soldering is now gradually replacing hand-soldering. The principle of the older types of soldering machines consisted of revolving discs on which the tin cans were placed. The cap was held in place by a vertical rod pressing on it. The solder was applied by hand, the hot soldering copper was held over the groove in the can while the cans revolverl. This method had no particular advantage over the hand soldering. There was little, if any, saving of time and the quality of the work was not much, if any, better.

There are now on the market newer types of solkering machines, most ingeniously constructed and their operation in factories with large outputs economize labor and time. When operated by a skillful mechanic they do very creditable work.

Solder.-The solder used for sealing should be of standard composition. In this country, canning establishments are prone to use a very poor quality of solder. It contains from 45 to 5.5 per cent. lead. Lead is a poisonous metal; its use in the canning industry should, therefore, be regulated by law. In Germany, the law requires that solder used in tin cans for food products must not contain over io per cent. of lead.

Where the sealing is done by hand the solder is most conveniently used in the form of thin hars or wire. The wire is usually bought already cut up in segments, each segment furnishing solder enough to seal one can. In the newer types of soldering machines the solder wire is automatically fed from spools. The smaller the opening of the can, the less solder is necessary to complete the seal. An opening smaller than three-eighths of an inch in diameter, however, cannot conveniently be used, owing to the difficulty of filling the can with this viscous product. The essential points of satisfactory sealing are: no "leakers," neat work, rapid work, small amount of solder. Aside from the size of the opening of the cant, the amount of solker used depends on the experience of the sealer. Beginners usually 


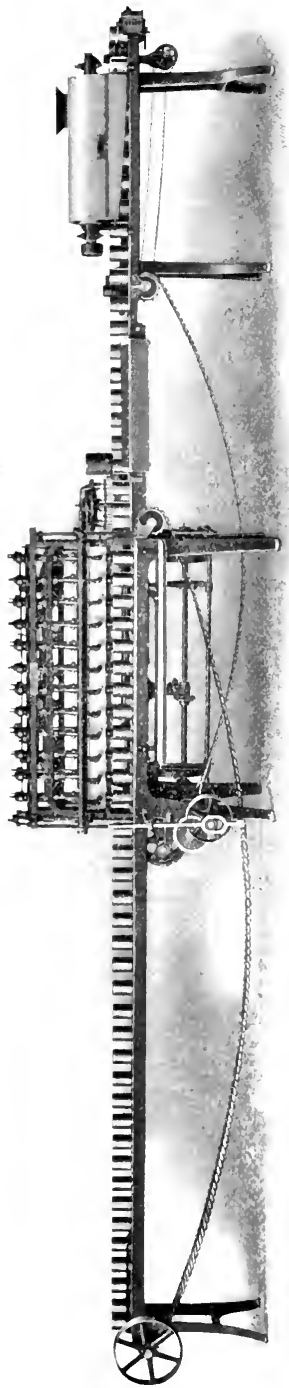

make an uneven seal, waste nuch solder, and have many "leakers." 'This is largely due to their ignorance of the proper soldering temperature of the coppers. An experienced sealer will use from two to three pounds of solder per thousand tin cans with moderate-sized openings. He will seal from fifteen hundred to twenty-five hundred cans per day.

Soldering Flux.-The use of solder requires the application of soldering flux, to prepare the surface of the tin for the solder. The flux always precedes the solder. When the hot solder is applied, some of the flux is bound to sweat through, between cap and can, gaining access to the interios of the can. 'llhe common practice of using zinc chloride or other similar acid fluxes, which are highly poisonous, therefore, cannot le too strongly condemned. 'Their presence in the can may jeopardize the health and life of the consumer, as well as the marketable properties of the product. There are other fluxes which are absolutely harmless, and which, if properly used, give satisfactory results. Dry, powdered resin, or resin dissolved in alcohol or gasoline, are of this class. Anmonium chloride, while used in most tin shops, is not as well suited for this purpose.

Gas Supply. - A plentiful and steady supply of gas is very essen-

tial. Where natural gas or gas from * a municipal corporation is not avail- 
able, the factory must rely on its own generator. For the needs of the condensery a gasoline gas plant seems suitable. Gasoline gas is produced by forcing atmospheric air over or through a body of gasoline. The mixture of air and gasoline vapors forms the gasoline gas. The gas generators in use consist chiefly of carburetor, air pump or blower, and regulator. The carburetor usually has a series of cells, connected with one another by means of a system of syphon tubes. The interior of each cell is partitioned off with heavy cotton wicking. This wicking absorbs the gasoline by capillary attraction. The air, passing through the fine meshes of wicking, comes in contact with a large surface of gasoline.

The following are some of the essential points to be observed in the installation and operation of gas generators of this type: Sink the carburetor low enough ( three to five feet below the surface of the ground, if necessary) to permit the gas pipe to slant from the factory to the carburetor. If the gas pipe is horizontal, or inclined toward the factory, condensation water may collect in the pipe, obstructing the free passage of gas. This causes the gas either not to be available at all, or to reach the stoves in irregular gusts, which is equally unsatisfactory. Where the gas pipe slants toward the carburetor. the condensation water flows back into the carburetor, causing no obstruction. Use gasoline of the best quality only. Cheap grades form a residue and $\operatorname{clog}$ the generator. The gasoline is best bought in iron barrels; this prevents unnecessary loss by evaporation, which occurs in wooden barrels, especially in summer. The cells should not be filled more than two-thirds full; too much gasoline reduces the gasgenerating capacity of the carburetor. If, during extremely cold weather, the carburetor refuses to generate gas, the injection of a pint of wood alcohol through the blow pipe into the cells, usually remedies the trouble. The gas plant and gasoline storage should be located in a separate building and at a reasonable distance from the main building, in order to minimize danger from fire. 


\title{
PART III
}

\section{MANUFACTURE OF UNSWEETENED CONDENSED MILK}

EVAPORATED MILK

\author{
CHAP'TER VIII
}

\section{DEFINITION}

There are three kinds of unsweetened condensed milk on the market, namely, evaporated milk, formerly called evaporated cream, plain condensed bulk milk and concentrated milk.

Evaporated milk is cow's milk condensed in vacuo at the ratio of about two to two and one-half parts of fresh milk to one part of condensed milk. It is of the consistency of thin cream and reaches the market in hermetically sealed cans varying in size from eight ounces to one gallon. Evaporated milk is preserved by sterilization in steam under pressure. When properly made, it will keep indefinitely, but is best when fresh.

\section{QUALITY OF FRESH MILK}

In the manufacture of evaporated milk the psysiological normality and the chemical purity and sweetness of the freshmilk are factors even more important than in the case of sweetened condensed milk. A uniformly satisfactory and marketable product cannot be manufactured, unless the milk is normal and pure in every respect. The reason for this largely lies in the fact, that defects the fresh milk may have, are greatly magnified and intensified by the high sterilizing temperature to which the evaporated milk is subjected. While, from the biological point of view, contaminations of this milk are largely rendered harmless by sterilization, defective fresh milk cannot be made into a marketable product, because such milk does not survive the process.

It should be understood that any condition or factor that, in the slightest degree, increases the tendency or ability of the casein to 
curdle, tends toward the formation of a hard, unshakable coagulum during sterilization, and makes the manufacture of a marketable product difficult. Abnormal milk of this type may come from cows approaching parturition, or too soon after calving, or milk from cows suffering from disease, generalized or local, or from cows in poor and abnormal physical condition, which may be brought about by poor care, over feeding, feeding the wrong kinds of feed, or feed in poor condition, exposure to abnormally hot weather and fiies, or any other condition which disturbs the physiological functions of the animal and thereby affects the physical, chemical, and physiological properties of the milk; or it may be due to improper care of the milk, causing it to be excessively contaminated with germ life, or to be relatively high in acid. All such milk renders the quality of the finished product uncertain and may result in heavy loss.

In view of these facts it is obvious that the greatest care should be exercised on the receiving platform, inspecting every can of milk, using the most reliable means, as recommended in Chapter III on "Control of Quality," 1. 28, to detect suspicious milk, and rejecting all milk that fails to reach the sanitary standard adopted by the factory.

\section{HEATING THE MILK}

The equipment for heating the milk should be such as to enable the factory to heat the milk with the least possible delay, so as to avoid the development of acid. In the manufacture of evaporated milk, the batches of condensed milk in the vacuum pan must be relatively small. This milk foams more in the pan than the heavier sweetened condensed milk. Also, it is not condensed to as high a degree of concentration. These factors reduce, therefore, the capacity of the pan. If the milk is heated in the hot wells, either by steam jackets or by turning steam direct into the milk, it is advisable to use numerous small wells, rather than but one or a few large ones. These small wells fill rapidly and the milk can be heated without delay. This system makes it possible to render the bacteria inactive and harmless practically as soon as the milk arrives, minimizing the danger of acid formation.

Steam may be saved if the milk is forewarmed by running it through coils inclosed in a chamber of exhaust steam, but the coils 
increase the labor and difficulty of cleaning. It is best to heat the milk to as near the boiling point as possible and hold it there for five to ten minutes, provided that the capacity of the factory warrants this delay. In this heating the casein of the milk is somewhat clanged. There occurs partial, though invisible, precipitation, and the higher the temperature to which the milk is heated, the more pronounced is this change. This change is desirable, because the casein thereby surrenders, to a limited extent, its power and tendency to form a firm curd in the sterilizer.

\section{CHAP'TER IX}

\section{CONDENSING}

The same apparatus, the vacum pan and pump, are used for condensing the milk, and the process of condensing is principally the same as in the case of sweetened condensed milk. The fresh milk is condensed at the ratio of two to two and one-half parts of fresh milk to one part of condensed milk. In some factories it is customary to superheat the milk in the pan before it is drawn off, i. e., the steam to the jacket and coils is shut off, the water valve is closed, the vacumm pump is stopped and "live" steam is passed into the condensed milk. This is done to swell or thicken the milk and partly precipitate the curd, in order to prevent the formation of too hard a curd in subsequent sterilization. When the vacuum has dropped to about six or eight inches and the temperature has risen to I 80 or 200 degrees $F$., the super-heating is stopped, the vacuum pump is started again and the condensing completed. In other factories the superheating is omitted.

\section{STRIKING}

The striking, or sampling and testing for density, of evaporated milk, is more easily accomplished than that of the sweetened condensed milk. When this product has nearly reached the proper density, it is not viscous and syrupy, containing no cane sugar. It resembles in consistency rich milk or thin cream and has a specific gravity of 1.05 to 1.075 at 15.5 degrees C. or 60 degrees F.

Samples are drawn from the vacum pan as described under 
sweetened condensed milk and the density can be readily determined by means of a hydrometer. Beaumé hydrometers, registering from I to 15 degrees B., are generally used. As it is important that the determinations be accurate, the hydrometer should be sensitive and its scale should be subdivided into tenth degrees. The batch should be "struck" at a uniform temperature, say 120 degrees F., so as to avoid misleading readings of the hydrometer. A difference of a few tenths degrees Beaumé affects the behavior of the evaporated milk in the sterilizer very appreciably. If the density is too great the product may badly curdle during sterilization. If the density is too low the evaporated milk may be below the legal standard. It is advisable for the operator to use a pail of water of the proper temperature, when he strikes the batch, so that he can adjust the temperature of the milk in the hydrometer jar readily and quickly, and need not depend entirely on the temperature of the milk in the pan, which may change several degrees while he is engaged in the operation of striking.

While the lieaume hydrometers should be used at the temperature for which they are graduated, which is 60 degrees $F$., they answer all practical purposes at any other temperature; at I 20 degrees $F$. for instance. The chief essential is to take the reading at some uniform and definite temperature and read the Beaumé at that same temperature in the case of every batch. In that way the results are comparable. The operator soon learns that at a given temperature the evaporated milk of proper density shows a certain Beaumé reading. When the reading is higher or lower, the milk has either been condensed too much or not enough.

The same formula, however, cannot be used under all conditions. No rule-of-thumb method of determining the density can therefore be established. Aside from the degree of condensation, the specific gravity of the milk varies with locality, season of year, quality of milk, etc. This means that what is the proper Beatmé reading in one locality, or at one season in the same locality, may be entirely wrong in another locality or at other seasons in the same locality. If uniformity in the density and behavior of the batches of evaporated milk is to be secured throughout the year, the operator must watch the behavior of his milk from day to day and from season to season and he must modify the Peaumé reading in ac- 
cordance with the changing conditions. This is one of the all important stages of manufacture, where relentless and careful study and watchfulness are indispensable.

In order to make absolutely sure that the density of the evaporated milk is right, it is advisable to get it just as near right as possible in the pan and then draw the milk from the pan into a standardizing vat large enough to accommodate the entire batch. The operator then tests the milk again and this second estimation he can perform more carefully, because he is then relieved of the responsibility of attending to the operation of the vacum pan. If the evaporated milk happens to be a trifle too heavy he can dilute it with distilled water mutil the Beaume reading is just right.

\section{Correction of Beaumé Reading at Temperatures} Other than 60 Degrees F.-At a temperature of I 20 degrees $\mathrm{F}$. the Beaume reading of the finished batch of standard evaporated milk may vary between about 6 and 8 degrees 13 ., according to season of year and locality. At fo degrees $F$. the Beaumé reading is approximately 1.88 degrees $\mathrm{B}$. higher.

If it is desired to record the Beaume reading at the correct temperature, i. e., 60 degrees F., and it is not convenient to cool the evaporated milk to that temperature, the reading at any temperature may be corrected as follows: when the temperature at which the Beaumé reading is taken is above 60 degrees F., multiply the difference between the temperature of the observd reading and 60 by the factor .03 I 3 and add the product to the observed reading.

Example: Peaumé at 120 degrees $F$. is 6.8 ; what is the reading at 60 degrees $F$. ?

Answer: $6.8+(60 \times .0313)=8.68$ degrees $\mathrm{B}$.

Fiz. 3\%. Beaume $\mathrm{Nfg} . \mathrm{Co}$

The corrected Beaumé reading is 8.68 degrees $\mathrm{B}$. When the temperature at which the reading is made is below 60 degrees $F$., multiply the difference be- 
tween the temperature of the observed reading and 60 by the factor .0313 and subtract the product from the observed reading.

Calculation of Specific Gravity from Beaume Reading.-In order to record the density of the evaporated milk in terms of specific gravity, instead of Beaumé degrees, the following formula may be used:

Specific gravity $=\frac{1+5 \cdot \overline{0}}{1+5 \cdot 5-\mathrm{B}} ; \mathrm{B}=$ Beaumé reading at 60 degrees $\mathrm{F}$.

Example: Leaumé reading at 60 degrees $F$. is 8 degrees $B$. What is the specific gravity?

$$
\text { specific gravity }=\frac{1+5 \cdot 5}{1+5 \cdot 5-8}=1.058_{2}
$$

\section{CHAPTER X}

\section{HOMOGENIZING}

Purpose.-The introduction of the homogenizer in milk condensing factories is a comparatively recent innovation. The object of its use is to avoid the separation of the butter fat in the evaporated milk after manufacture.

The butter fat is present in milk in the form of minute globules. These fat globules are lighter than the rest of the ingredients of the milk. They, therefore, show a strong tendency to rise to the surface and to form a layer of thick cream in the cans. When these cans are subsequently subjected to agitation, as is the case in transportation, this cream churns, forming lumps of butter. This tendency of evaporated milk to separate in storage and churn in transportation is especially noticeable with milk rich in fat and in which the large fat globules predominate. In Jersey and Guemsey localities, it is more difficult, therefore, to manufacture evaporated milk that does not separate, than in Holstein and Ayrshire localities. While separated and churned evaporated milk is perfectly sound and in every way as valuable as a food, as it would be without this separation, it does not sell in this condition. It is rejected on the market.

This tendency toward fat separation can be minimized and frequently entirely prevented by increasing the viscosity of the evapo- 
rated milk. This can be accomplished by superheating the milk in the pan and by prolonging the sterilizing process, raising the heat very slowly. However, there are conditions when even this precaution does not permanently avoid separation of the fat. In such cases, the proper use of the homogenizer furnishes a reliable means: to guard against this difficulty.

Principle of the Homogenizer.-The principle of the homogenizer is to force the milk muler high pressure through exceedingly small, microscopic openings. By so doing the fat globules are broken up so finely that they fail to respond to the gravity force, they cannot rise to the surface and therefore remain in homogeneous emulsion. The value of the homogenizer lies in removing the funclamental canse of this separation. It reluces the fat globules to such small size that their buoyancy, or gravity force, is not great enough to overcome the resistance of the surrounding liquicl.

Kinds of Homogenizers. - There are at this time two makes of homogenizers in use in this country, namely, the "Ganlin" and the "Progress" homogenizer.

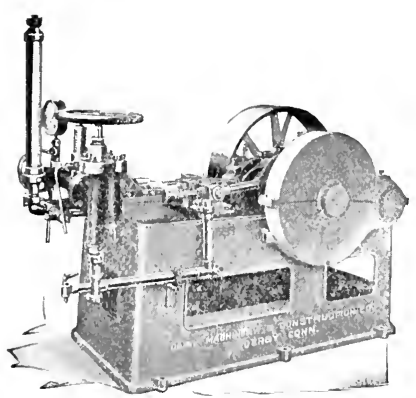

Fig. 33. The I'rogrens homogenizer Courtesy of

Dairy Iachinery \& Construction $\mathrm{Co}$.

In the Gaulin homogenizer, the milk is forced, by means of single-acting punips, against an agate valve which presses against a ground valve seat. The milk has to pass between the ground surfaces of this valve and valve seat. This causes the fat glolules to he divided very minutely. This type of homogenizer has not been used much as yet in the manufacture of evaporated milk and but little is known concerning its effect on this product.

In the Progress homogenizer the lomogenizing principle consists of forcing the milk, by means of single acting pumps, between a series of discs with ground surfaces. The discs lay flat one upon the other, they are enclosed in a cylinder and are hele in place by a rod running through their center. The discs are pressed against each other by a heary spiral screw, which regulates the pressure to 
which the milk is subjected. The milk passes from the center to the periphery of the discs. While being forced through the discs the fat globules are split up very finely. The discs used in this machine are of two types. One type has very fine irregular grooves. The milk shoots through these grooves against hard shoulders. The other type of dises has smooth surfaces but their area of contact is narrow. The milk passes through between these smooth surfaces.

The Progress homogenizer is used in numerous evaporated milk factories in this country and, where operated properly, it overcomes fat separation very satisfactorily, without damaging the other ingredients of milk.

Operation of the Homogenizer.-In order to avoid fat separation it is necessary to reduce the fat globules to about one-third their original size. If enough pressure is applied to divide the fat globules much smaller, there is a tendency to also change the properties of the casein, causing it to give rise to copious precipitation, when the evaporated milk is sterilized, and making the finished product curdy and unnarketable. In this case the cure would be more disastrous than the original defect. Great care must, therefore, be exercised, guarding against the use of excessive pressure that would injure the casein. Experiments have shown that a pressure of between seven hundred and one thousand pounds per square inch is sufficient to prevent fat separation and is practically harmless as far as its effect on the casein in the evaporated milk is concerned.

The evaporated milk is run through the homogenizer hot, just as it comes from the vacuum pan or standardizing tank. The first pailful of milk passing through the machine should be returned to the supply tank, as on the start, the pressure is not uniform and homogenization is incomplete.

The pistons, cylinders, valves and pipes of the homogenizer should be kept in sanitary condition. They are difficult to clean. After homogenizing, the machine should be kept in operation, running water through it, until most of the remnants of evaporated milk are rinsed out; then hot water containing some active alkali should be pumper through: this should be followed by clean hot water and steam. Unless this machine is kept scrupulously clean, it may become a dangerous source of contamination, infecting the evaporated milk with spore forms that are exceedingly resistant and 
which are liable to pass into the finished product alive, in spite of the sterilizing process, causing the goods to be a complete loss, due to subsequent fermentation.

\section{CHAP'TER XI}

\section{COOLING}

In the cooling of the eraporated milk, no attention need be paid to sugar crystallization. In this class of goods there is plenty of water to keep the milk sugar in ready solution. The evaporated milk can, therefore, be cooled as rapidly as facilities permit. The cooling may be accomplished in similar ways as are used for cooling fresh milk. From the homogenizer the evaporated milk is run over a surface cooler, or cooling coil. It is advisable to cover the coils with

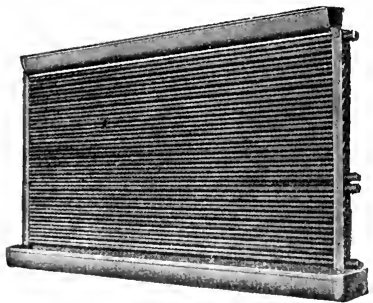

Fig. 34.

surface cooler for evaporated milk

Courtesy of Arthur Harris \& Co.

a jacket of galvanized iron, tin or copper, so as to avoid undue contamination of the milk from dust, flies, and other undesirable agents. In some condenseries, the hot evaporated milk is forced through double pipes, cold water passing between the inner and outer pipe, or the coils through which the milk passes are submerged in a tank of cold water. The only objection to this system is that the pipes are more difficult to clean than in the case of an open surface cooler. Where this system is used, the pipes should be equipped with sanitary fittings so that they can be readily swabbed out from both ends. In other factories, the same cooling equipment is used as for sweetened condensed milk, with the exception that cold water is run into the cooling tank at once. If the evaporated milk is not homogenized it should be cooled as soon as it leaves the vacuum pan.

The evaporated milk should be cooled to as low a temperature as the available water permits. If the condensery is not in position to fill the avaporated milk into tin cans immediately after cooling, it is advisable to place the covers on the fo-quart cans and submerge them in cold or ice water. Condenseries which are provided with 
artificial refrigeration may store the evaporated milk, before filling, in glass-lined storage tanks cooled with brine. 'This practice makes it posible to mix all the batches of one day's make together and

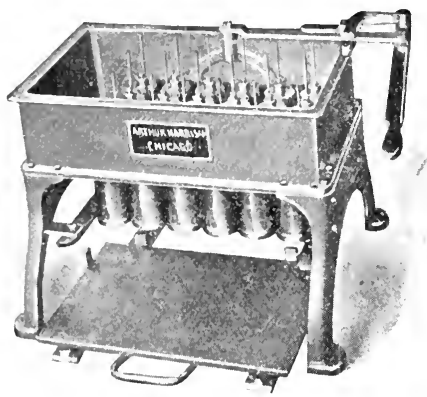

Fig. 35. Hand filling machine for evaporated milk

Courtesy of Arthur Harris \& Co. thereby increase the uniformity of the product. At this stage of the process the craporated milk is not sterile, nor does it contain any preservative, such as sucrose; it is not concentrated enough to be preserved by the absence of moisture. If exposed to warm temperatures for any length of time, therefore, its acidity will increase, thereby rendering the subsequent sterilizing process difficult.

\section{FILLING}

The cooled evaporated milk is filled into tin cans ranging in size from eight ounces to one gallon. The gallon cans are usually filled by hand. The filling of the smaller cans is done by automatic filling machines.

Of late years much progress has been made in the construction of different types of filling machines for evaporated milk. The openings in the cans through which the cans are filled range from the Sanitary can, which is filled with the top of the can entirely removed, to the venthole can with an opening of not more than one-eighth inch in diameter. The filling machines are constructed to fill by gravity, under pressure, or in vacuo.

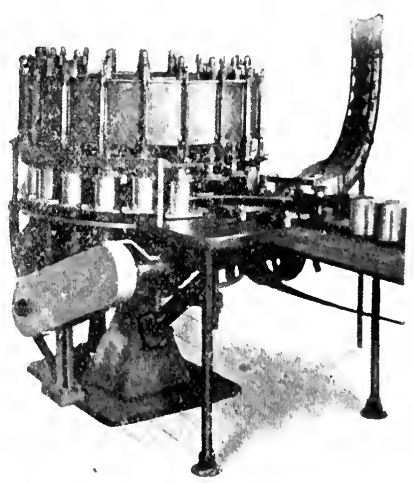

Fig. 36. Elgin filling machine for evaporated milk

Courtesy of The sprague Canning Machinery Co. 
These filling machines should be thoroughly washed and freed from all remnants of evaporated milk adlhering to the valves and other parts after each use. Remnants of milk left in any part of the

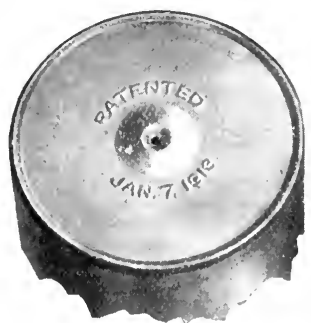

Fig. 37

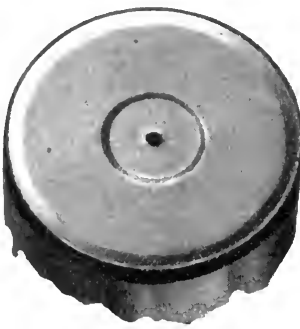

Fig. 38

Vent hole cans

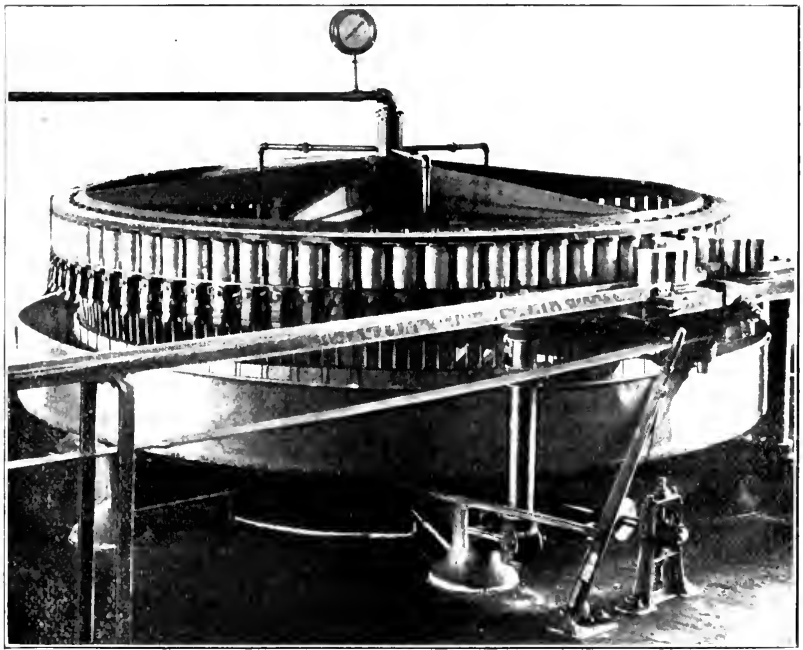

Fis. 39. The vacuum filler

Courtesy of The sprague canning Nachinery ('o.

filling machine decompose readily and impair the wholesomeness and marketable properties of the product. This is an important point 


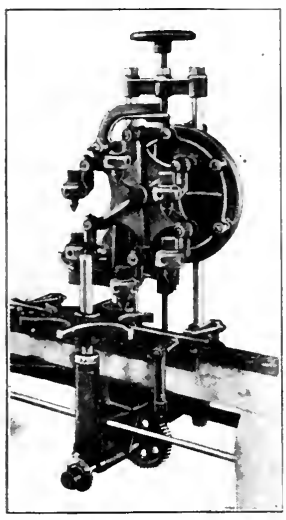

Fig. 40. The Sprague-Colbert rotary tipping machine Courtesy of The sprague Canning Machinery Co.

and one too often neglected. Much of the spoiled evaporated milk may be the result of the use of unsanitary and unclean filling machines. The fact, that the evaporated milk is sterilized after it leaves the filling machine, is no excuse for unclean filling machines. The operator should bear in mind that the milk running through an unclean filling machine becomes contaminated with millions of bacteria. The more bacteria it contains, the more difficult it is to render it perfectly sterile. Furthermore, sporeforms are prone to develop in the decaying remnants of milk; these spores are very resistant and require excessively high sterilizing temperatures to be destroyed.

\section{SEALING}

The filled cans should be capped and sealed at once. The seal must be hermetical and strong enough to withstand the strain of the subsequent sterilizing process. With the exception of the "Sanitary" can," seals without solder have so far proven unsatisfactory in the canning of evaporated milk. They are prone to weaken in the sterilizer and cause "leakers." Most of the cans on the market containing evaporated milk are, therefore, sealed with solder. Sealing eraporated milk cans with solder is by far the safest method. The sanitary can, however, has been found to furnish a satisfactory seal without solder. For details of methods of sealing see Chapter VII. 


\section{CHAP'TER XII}

\section{STERILIZING}

The sealed cans are now ready for the sterilizer. If they cannot be sterilized within an hour or two they should be submerged in ice water or placed in a refrigerating room until the sterilizer is ready for them. This precaution is especially advisable in summer.

Purpose of Sterilization.-The chief purpose of subjecting the evaporated milk to the sterilizing process is to kill all germ life and, therefore, preserve the product permanently. When the hermetically sealed cans come from the sealing room, their contents are not sterile. The only means to preserve this milk is to subject it to temperatures high enough to kill all forms of ferments, organized and unorganized, vegetative cells and spores. The success of the manufacture of this product depends to a large extent on the process of sterilization.

Aside from this, the manufacturer aims to gain another commercially important condition, namely, to prevent the separation of the butter fat. Before sterilization, there is nothing to prevent the fat from separating out in the evaporated milk and from chuming in transportation, unless the evaporated milk was homogenized. This is a highly undesirable characteristic, making the goods unmarketable. The sterilizing process helps to so change the physical properties of the milk, that this tendency of the fat to separate is greatly minimized. The sterilizing temperatures used, further lend to the evaporated milk a creamy consistency and yellowish color, giving the product a semblance of richness.

Sterilizers.-The apparatus used for sterilizing is a huge boilerlike, hollow, iron cylinder or box. It opens either at one end or on the side. Its interior is equipped with a revolving framework, steam inlet and exhaust, a water distributing pipe running the entire length of the sterilizer, and a water exhaust. The sterilizer carries on its exterior a steam gauge, a vacuum gauge, a water gauge, a blow-off valve and a

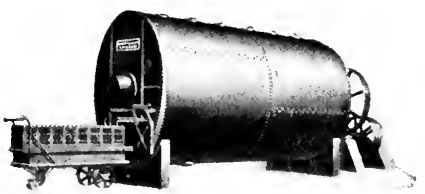

Fig. 41. Sterilizer for evaporated milk Courtesy of Arthur Harris \& Co. 
high-temperature thermometer (registering to about 280 degrees F.). In some makes of sterilizers the interior frame-work does not revolve on its axis, but moves back and forth by means of a direct-acting, steam-driven piston, attached to the back end of the sterilizer. The purpose of keeping the cans in motion while heat is applied, is to heat the contents rapidly and uniformly, and to prevent the evaporated milk from baking onto the sides of the cans.

Loading the Sterilizer.-The sealed tin cans are placed in heavy iron trays, usually holding twenty-four 16 -ounce cans or six I-gallon cans. The loaded trays are slid and locked into the framework in the interior of the sterilizer. The sterilizer is closed with heavy iron loors and the framework is put in motion. In some makes of sterilizers the interior consists of a large perforated iron box revoiving on its axis. In this case the cans are simply piled into this box, no trays being used.

Uniform Distribution of Heat.-Where no water is used in the sterilizer during the sterilizing process, it is important that there be a free air space between every two layers of cans, so as to allow the

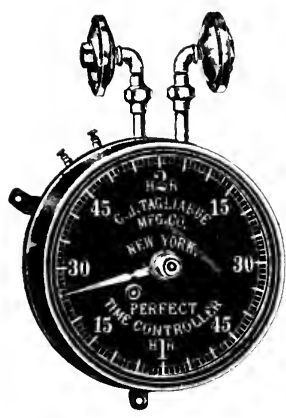

Fig. 12. Time control gauge

Courtesy of

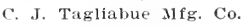

$s$ t e a m to circulate freely and to come in direct contact with every can. When the cans are piled into the sterilizer six to twelve layers deep without any free air space between layers, the cans in the center do not receive as much heat as those at the sides, ends, top and bottom. This causes irregular heating and imperfect sterilization.

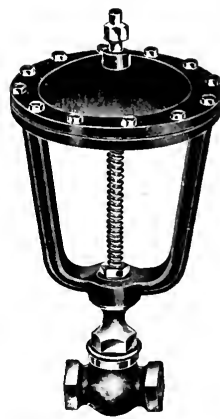

Fig. 43. Diaphraym

Courtesy of

C. J. Tagliabue $11 \mathrm{fg}$. Co.

A satisfactory means of insuring even distribution of heat is to fill the sterilizer about one-third full of water, so that, when the sterilizer is in operation, the cans pass through this water, with each revolution of the frame work. Water distributes the heat uniformly, 
rapidly and there is no langer of the formation of air pockets between the cans. Since the heat is applied by steam under pressure the temperature of the water is equal to that of the steam in the sterilizer. This precaution is especially necessary in the case of baby-size cans (eight ounces) which are ustally piled in stacks more than two deep. When sterilizing in the absence of water there is danger of lack of uniformity of the amount of heat they receive.

Temperature and Time of Exposure.-When the sterilizer is filled with the cans and closed, the frame work is set in motion and steam is turned into the sterilizer. In order to hasten the heating and expel all the air, the exhaust and safety should be left open until the temperature has risen to $2 \mathrm{I} 2$ degrees $\mathrm{F}$. This temperature is usually reached in about ten to fifteen minutes. The exhaust and safety are then closed.

From this point on, the process must depend on locality, season of year and condition, properties and concentration of the milk. No formula can be laid down which can be depended on to give uniformly

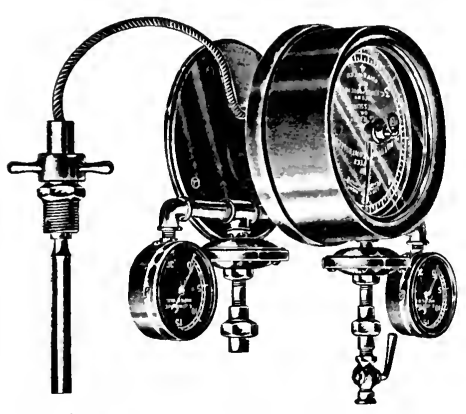

Fig. 44. Temperature control gauge Courtesy of C. J. Tagliabue Mfg. Co. satisfactory results under all conditions. The temperature should be high enough and the duration of exposure long enough to insure absolute sterility of the product and to give the milk sufficient body to prevent the separation of the butter fat in subsequent storage. The temperature should not be so high nor the duration of exposure so long, as to cause the formation of a hard, unshakable curd and dark color.

Some processors use a very short process with high temperatures, others raise the heat gradually and not to quite so high a degree. The more gradual heating is preferable, as it gives the product a better body and more viscosity, which is necessary to keep the fat from separating in storage. The author's judgment in this matter is, that it is not safe to raise the temperature to less than 230 
degrees F. and it is advisable to heat the milk to $23+$ to 236 degrees F., provided that the milk is in condition to stand this heat without the formation of too firm a curd. Where the maximum temperature to which the milk is raised in the sterilizer is 230 degrees $\mathrm{F}$. or thereabout, the raise of the last ten degrees should occupy from thirtyfive to forty-five minutes, and this time should be about evenly distributed over the ten degrees.

Qualifications of the Processer.-The operator, or the person directing the sterilizing process, should thoroughly appreciate the complexity of the product, understand the cause and effect of the many influencing factors, study the ever-changing conditions and modify the process in accordance with prevailing conditions. He should know that during the exceedingly hot summer days, when the cows suffer from heat and are pestered with flies, the milk will not stand as much heat without badly curdling in the sterilizer as under more favorable conditions. He should know that toward and during the fall months the organisms normally present in milk are more resistant and require higher heat to be destroyed, than earlier in the season.

Rapid and Uniform Cooling:-As soon as the required heat has been given the milk in the sterilizer, the steam should be turned off and the exhaust and drain should be opened. When the temperature has dropped to about 220 degrees F., cold water should be turned into the sterilizer while the cans are constantly in motion, until the cans are cool enough to handle. There should be enough cold water available to reduce the temperature to 70 or 80 degrees $F$. in twenty minutes for gallons and in ten to fifteen minutes for small size cans. The water pipe should be so arranged as to distribute the water uniformly over the entire length of the sterilizer.

If the process is to be successful, the processor must have as nearly perfect control of the heat as possible. This means especially, that there must be plenty of water available to insure rapid cooling and the water must be distributed over the cans uniformly. Insufficient water supply and uneven distribution of the water in the sterilizer, means that some of the cans are exposed to the sterilizing heat longer than others, causing lack of uniformity in the smoothness and color of the milk of different cans of the same batch. Delayed cooling owing to insufficient water supply has the 
further disadvantage of causing the cans to bulge badly, owing to the difference in pressure between the interior and exterior of the cans. This is especially noticeable in gallon-size cans, the ends of which may become badly distorted, present an unsightly appearance and their seams and seals may be weakened to the extent of producing "leakers."

Fractional Sterilization.-In some factories fractional sterilization is occasionally practicel. The milk is heated in the sterilizer to considerably lower temperatures than those stated above, and this heating is repeated on two or three successive days. The principle of this process is to kill all vegetative forms of bacteria during the first heating. This gives the spores a chance to develop into regetative forms by the second and third days, which forms are then destroyed during subsequent heating. This system of sterilization is not practical for general use. It is too great a tax on the capacity of the average factory and increases the cost of manufacture. It should, therefore, be made use of only in exceptional cases, when it is known that a certain batch of milk could not be put through the higher sterilizing temperatures without causing the product to become permanently curdy.

\section{SHAKING}

Purpose.-The purpose of shaking the evaporated milk is to mechanically break down the curd that may have been formed in the process of sterilization and to give the contents of the cans a smooth and homogeneous body.

The high temperatures to which the evaporated milk is subjected in the sterilizer have a tendency to coagulate the casein. In the case of normal, fresh milk the casein coagulates at a temperature of 269 degrees $F$. In the evaporated milk, made from perfectly normal and sweet, fresh milk the casein curdles at much lower temperatures, and the higher the ratio of concentration, the lower the temperature required to precipitate the casein. It seems that the concentration of the milk intensifies the properties of milk to coagulate when subjected to heat. This factor is probably largely, though not necessarily, wholly due to the increase of the per cent. of lactic acid in the evaporated milk, due to the concentration. If the fresh milk contains . I 7 per cent. lactic acid, a concentration of two and 
one-fourth parts of fresh milk to one part of evaporated milk causes the evaporated milk to contain .I $7 \times 2.25=.38$ per cent. lactic acid. With this amount of acid acting on the casein, it is not difficult to understand why a coagulum is often formed in the sterilizer. While the formation of this coagulum may be partly aroided, under certain conditions it appears in every factory and there are more batches, especially in summer, that come from the sterilizer coagulated than otherwise.

In this condition the product

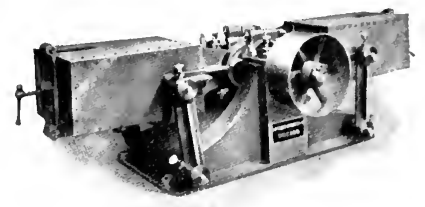

Fig. 45. Shaker Courtesy of Arthur Harris \& Co. is not marketable. Some means must be provided, therefore, to break up this curd and reduce the contents of the cans to a smooth, homogeneous and creany body. For this purpose a mechanical shaker is used.

Method of Shaking.-The shaker consists of one or more heavy iron boxes or boxes made of black iron pipes. These boxes are attached to an eccentric. The trays filled with evaporated milk cans

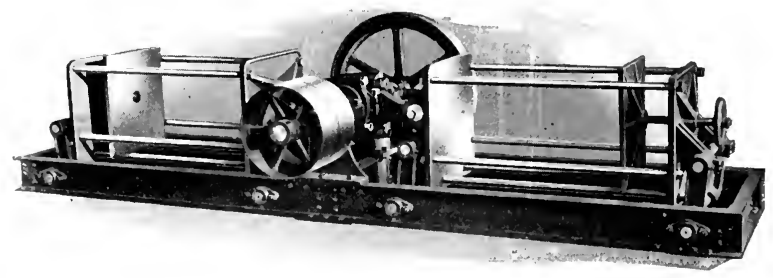

Fig. 46. Shaker

Courtesy of The Schaefer $11 \mathrm{fg}$. Co.

are firmly wedged into the shaker. When the shaker is in operation. the cans are shaken back and forth violently, causing the curd in the cans to be broken up.

Speed of the Shaker.-If the shaker is to perform its work properly, it must have long enough a stroke and run fast enough to 
cause most vigorous agitation. The stroke should be not less than two and one-half inches and the eccentric should revolve not less than three hundred to four hundred times per minute. In order to accomplish this without wrecking the machine, the shaker must be fastened securely to a solid foundation.

From one-fourth to two minutes shaking is usually sufficient to completely break down a soft curd. When shaking for five minutes does not produce a smooth milk, the product is usually hopelessly curdy and no amount of additional shaking will remedy the defect.

In some cases it has been possible, however, to improve the curdy product by shaking again after a lay or two. Under certain conditions, age seems to have a slight mellowing effect on the curd.

Efficiency of Different Types of Shakers.--Some shakers have a straight, horizontal, back and forth motion. Others have a rotary or elliptical motion; the latter are not considered as effective in their work as the former. Some of the sterilizers in which the interior frame holding the cans, moves back and fortl, are advertised to shake the milk as well as sterilize it. Experience has shown, however, that the shaking performed by these sterilizer-shakers is not sufficient and that the use of a separate shaker is necessary.

Formation of Curd not Desirable nor Necessary.-It should be understood that the processor should aim to get only a very slight and soft curd in his product, that can be shaken out in the shaker in one-fourth to one-half mimute. When the curd produced is firm, even prolonged shaking will not prevent the appearance in the finished product of specks and small lumps of curd. Such milk is rejected on the market.

The formation of curd during the sterilizing process is not desirable and is not necessary as far as the marketable properties of the evaporated milk is concerned. It is unavoidable, however, under many conditions and as long as it can be confined to a soft curcl that readily shakes out, no harm is done.

\section{INCUBATING}

From the shaker, the cans are transferred to the incubating room. This is a room with a temperature of 70 degrees to 90 degrees F. The evaporated milk remains there ten to thirty days. The pur- 
pose of incubation is to detect defective milk and defective cans before they leave the factory. If the contents of any of the cans have not been completely sterilized, or if any cans have the minutest leak, the evaporated milk therein will spoil within the time of incubation. Such milk either sours, curdles or becomes solid, or it undergoes gaseous fermentation, causing the appearance of "swell heads." The more nearly perfect the process of sterilization and the better the construction and seal of the cans, the fewer are the spoiled cans. This incubation process is strictly a preventative measure. It is omitted in many factories where the cans are labeled, packed and shipped to their destination at once, or put in ordinary storage in the factory.

\section{CHAP'TER XIII}

\section{PLAIN CONDENSED BULK MILK}

Definition,-This is an unsweetened condensed milk made from whole milk, or partly, or wholly skimmed milk, condensed in vacuo at the ratio of about three or four parts of fluid milk to one part of condensed milk. It is usually superheated to swell and thicken it, and it has the consistency of rich cream. It is sold in ro-gallon milk cans to ice cream factories and in milk bottles to the direct consumer. Plain condensed bulk milk is not sterile, nor is it preserved by sucrose. Its keeping quality is similar to that of a high quality pasteurized milk.

Quality of Fresh Milk.-The sweeter and purer the fresh milk or skim milk, the better will be the quality of this product. Old milk, or skim milk in which the acid development has made considerable headway, tends to form a lumpy, plain condensed bulk milk. However, since this milk is not subjected to sterilizing temperatures and is used up quickly after manufacture, the quality of the fresh milk from which it is made, is not of such magnitude as in the case of evaporated milk.

Heating.- In the manufacture of plain condensed bulk milk the heating is accomplished much in the same manner as in the case of sweetened condensed milk and evaporated milk. The milk is usually heated by turning steam direct into it. 
It is advisable, however, to heat this milk only to about ${ }_{50}$ to I60 degrees F. in order to secure a nice "liver" (coagulum), when it is superheated in the pan. If the milk is heated to the boiling point in the forewarmers, it does not respond to the superheating in the pan as satisfactorily.

Condensing.-The condensing of plain condensed bulk milk is done in the vacuum in a similar manner as described under evaporated milk, except that the evaporation is carried farther.

Superheating.- When the condensation is nearly completed the milk in the pan is superheated. This is accomplished by shutting off the steam to the jacket and coils, closing the valve that regulates the water supply of the condenser, stopping the vacumm pump and blowing steam direct into the milk in the pan, for the purpose of swelling and thickening it. During this process the vacuum drops to about six inclies of the mercury column and the temperature rises to between I8o and 200 degrees F. When the milk has become sufficiently thick or, in the language of the processor, has produced the "proper liver" (coagulum) the steam is shut off, water is again turned into the condenser and the vacumm pump is started up. As soon as the vacuum has risen to twenty-five to twenty-six inches and the temperature has dropped to abont I30 degrees $F$. the process is complete, the vacumm is released and the condensed milk is drawn off. The superheating occupies about twenty-five to thirty minutes.

Striking.- The striking, or sampling and testing for gravity is done with the same Beaumé hydrometer that is used for evaporated milk. The batch should be struck before and after superheating.

Ratio of Concentration.-The ratio of concentration varies largely with the fat content of the milk, although the locality and season of year are also influencing factors. Whole milk is condensed at the ratio of about three parts of milk to one part of condensed milk, while the ratio of concentration for skim milk is about 4 to $\mathrm{I}$. The proper density varies somewhat with locality and reason of year. Roughly speaking, whole milk has reached the proper density when the Beamme reading at $\mathrm{I} 2 \mathrm{O}$ degrees $\mathrm{F}$. is about 10 degrees B. and skim milk has reached abont the proper density when the Beaumé reading at I 20 degrees F. is about $\mathrm{I}+$ degrees $\mathrm{B}$. 
If the ratio of concentration exceeds $4: \mathrm{I}$ there is langer of gritty milk, (lue to the precipitation of crystals of milk sugar.

Cooling.-The plain condensed bulk milk is clrawn into fo-quart cans, placed in cooling tanks as described in Chapter VI, under "Cooling of Sweetened Condensed Milk," and cooled to as near the freezing point as facilities will permit. The product is then ready for the market. If held in the factory, it should be placed in a cold room or should be otherwise protected against souring. If transported long distances it should be shipped in refrigerator cars.

\section{CHAP'TER XIV \\ CONCENTRATED MILK}

Definition.-Concentrated milk is cow's milk, either whole milk, or partly or wholly skimmed milk, condensed at the ratio of three to four parts of fresh milk to one part of concentrated milk. It is not condensed in vacuo, but in open vats by passing currents of hot air through the milk. It is sold largely in pint and quart bottles for direct consumption. It is not sterile and therefore keeps for a limited time only. Its keeping quality is similar to that of a high grade of properly pasteurized milk. 'The process by which the concentrated milk is manufactured is known as the "Campbell Process." This process was invented by J. H. Campbell of New York City, in IgOo and patented in I9OI.

Apparatus Needed.-The principal parts are: the evaporating vat with hot water jacket and coils, and air blast registers or nozzles near the botton of the tank; an air blower which furnishes the air blast; an air heater through which the air blast passes and from which the heated air is conducted into the milk; a water pump circulating lot water through the jacket and coils; an auxiliary evaporating tank for completing the evaporation; and a spray pump which throws the spray of milk drawn from the bottom of the main evaporating vat into that tank and for transferring the partly condensed milk from tank I to tank 2.

Operation of Campbell Process.-The milk is heated to about I oo degrees F. and allowed to flow into evaporating tank I. Water at temperatures ranging from $\mathrm{IOO}$ to $\mathrm{I} 25$ degrees $\mathrm{F}$. is forced through 
the coils and jacket. Hot air is then passed into the milk. The temperature of the air is regulated so as to keep the temperature of the evaporating milk down to 120 degrees F. on the start, and to finish the evaporation between 90 and 100 degrees $F$. The air blast is so introduced as to keep the milk along the heating surface of the jacket and coils in circulation and, therefore, prevent largely the baking of the milk on the heating surface. After the milk has been evaporated to a certain degree of concentration, say $2: 1$, it is transferred to the auxiliary evaporating tank where the condensation is completed. This transfer is not necessary, but is resorted to solely as a convenience, in order to continue treatment of the reduced bulk of material in a smaller tank and leave the larger tank free for treating a fresh batch of milk, and, further, because there are no obstructing coils in the auxiliary tank, interfering with the drawing off of the finished and thick condensed milk. In this process, as now used, the milk is usually first separated and the skim milk only is condensed. The cream is subsequently added to the condensed skim milk.

Advantages and Disadvantages of Campbell Process.-The initial cost of installing the necessary machincry is much less than where vacuum evaporation is practiced. The low heat applied makes it possible for the finished product to retain the properties of raw milk, leaving the albumenoids and lime salts in their original and easily digestible form.

This process is applicable only in the manufacture of unsweetened condensed milk. Unless subsequently sterilized, the product will keep for a short time only. This process has at the present time only very limited use. It can hardly be considered as an important branch of the condensed milk inclustry.

\section{CHAP'TER XV}

\section{CONDENSED BUTTERIMILK}

The value of buttermilk as a chicken feed is rapilly gaining recognition. Buttermilk, similar to skim milk and whole milk, is a highly satisfactory feel for fattening chickens. Its value is enhanced by the superior quality of the meat from buttermilk-fed chickens. 
Since the great bulk of butter is manufactured during the summer season the main supply of buttermilk is confined to the summer months. In summer the output of buttermilk far exceeds the demand for this product and much of it goes to waste for lack of a suitable market for it. In winter, on the other hand, the output of buttermilk is small and insufficient to supply the demand.

In order to stop this waste of buttermilk in summer, to utilize it economically and profitably and to equalize the supply throughout the year, some of the large creameries of the country have found it practicable and profitable to condense the surplus buttermilk. Information from chicken feeders shows that, when re-diluted to the consistency of the original buttermilk, this condensed buttermilk gives equally' as satisfactory results as the fresh buttermilk.

Manufacture.-Buttermilk is condensed in vacuo in the same manner as plain condensed bulk milk, or in open vats by passing a current of hot air through it, similar as in the case of concentrated milk. The latter process has the advantage, because it involves but little additional equipment by the creamery and can readily be operated by the ustual creamery personnel. The ratio of concentration is about + to $5 \cdot 5: 1$; i. e., from four to five and five-tenths parts of buttermilk are condensed to one part of condensed buttermilk.

The Use of Neutralizers in the Manufacture of ConDENSED BUTTERMILK.-The condensed buttermilk has a grainy body. This is due to the action of acid and heat on the casein, contracting the curd and making it hard, dry and grainy. If the acid in the buttermilk is neutralized by an alkali the body of the condensed buttermilk is smooth and homogeneous.

The most common alkalies used for this purpose are sodium bi-carbonate and milk of lime. These adulterants are easily detected by the chemist. In order to more successfully hide the use and presence of alkalies in condensed buttermilk, ammonium hydroxide and ammonium carbonate are frequently employed instead.

Since the lactic acid in the buttermilk is one of the desirable ingredients, enhancing its wholesomeness and dietetic value, it is obvious that, by neutralizing this acid, the manufacturer is robbing his product of one of the chief virtues for which it is valuable.

Furthermore, while, with the possible exception of milk of lime, these alkalies add nothing to the milk that can be of any benefit 
to the product as a food, the addition of caustic alkalies in quantities sufficient to neutralize most of the acid in buttermilk is detrimental to the wholesomeness of the finished product.

Finally, there is no good reason, why the grainy condensed buttermilk should be less acceptable to the consumer or the chicken feeder than a paste-like product with a smooth body.

Chemical Composition of Condensed Buttermilk.-The composition of condensed buttermilk naturally varies with the composition of the original buttermilk and the degree of concentration. Since these two factors are not constant, the composition of the finished product may vary within comparatively wide limits.

The following analyses show the composition of two samples of condensed buttermilk:

Composition of Conclensed Buttermilk

Not Partly neutralized by
neutralized ammonium lydroxide

Total solids

Moisture

Ash

Curd

Lactose

Lactic acid

Ammonium hydroxide

Total

$$
\begin{array}{r}
51.48 \\
48.52 \\
3.93 \\
18.93 \\
26.30 \\
3.60 \\
.00 \\
\hline 101.28
\end{array}
$$

$$
\begin{array}{r}
40.90 \\
59.10 \\
3.70 \\
15.38 \\
15.76 \\
2.52 \\
.88 \\
\hline 97.34
\end{array}
$$

Uses of Condensed Buttermilk.-Most of the conclensed buttermilk is sold to chicken feeders. It brings from four to six cents per pound.

Condensed buttermilk has also found a limited demand as human food. It is claimed to be a most wholesome, readily digestible, nutritious and palatable food. Its wholesomeness and digestibility are attributed to its high lactic acid content. It is best put on the market in glass bottles. Its keeping quality is enhanced by the high per cent. of lactic acid it contains. 


\section{CONDENSED WHEY, MYSEOST, OR PRIMOST}

The condensing of whey is a practice which originated in Scandinavia. The original process consisted of straining the whey into a kettle or large open pan over a fire. "The albuminous material that precipitates and rises to the surface is skimmed off." The whey is evaporated as rapidly as possible with constant and thorough stirring. When it has reached about one-fourth of its original volume the albumin previously skimmed off is returned and stirred thoroughly to break up all possible lumps. When the whey has attained the consistency of thickened milk it is poured quickly into a wooden trough and stirred with a paddle until cool, to prevent the formation of large sugar crystals. It can then be molded into the desired form for market.

A more rapid method of making primost is to evaporate the whey in the vacuum pan. When the syrup has reached the desired density it is drawn off, allowed to cool and pressed into bricks. The product has a yellowish brown color, gritty texture and sweetish taste.

The evaporation of whey in vacuo is as yet a rare practice and the demand for the finished product is very limited.

\footnotetext{
${ }^{1}$ United States Department of Agriculture, Bureau of Animal Industry, Bulletin No. 105
} 


\title{
PA R T I V \\ FROM FACTORY TO CONSUMER
}

\author{
CHAP'TER X'TI
}

\section{STAMPING}

Every well regulated condensing factory, selling condensed milk in hermetically sealed tin cans, employs some system of marking the cans. This is important for future reference.

When defective condensed milk is returned to the factory, the marks on the cans tell the manufacturer the date of manufacture, and his own record on file in the factory shows the conditions under which the defective milk was made. In this way defects can usually be traced to their causes and the recurrence of similar trouble can be avoided.

In some factories the batches of condensed milk are numbered from one up, and the cans are stamped with the respective batch number. This method is simple but may prove undesirable, since it informs the competitors also of the date of manufacture of competing brands. In most factories a colle of letters and figures is used, designating the factory, the date and the number of the batch of each day. Thus for instance: a concern has three factories, A, I) and C. X stands for the current year, the letters E, F, G, H, I, J, K, L, I, N, O, P indicate the twelve months of the year, respectively, the figures $1,2,3,4$, etc., represent the day of the month and also the batches of condensed milk made in one dlay.

Example: A can of condensed milk belongs to the second batch made April 9, 1913, at factory B. The can would be stamped as follows: $\mathrm{B} 9 \mathrm{H}^{\mathrm{N}} 2$.

The cans are usually stamped on the bottom, that is, on the end which carries the cap. The stamping is lone by the sealer. Small interchangeable rubber letters and figures are used. The stamping ink should contain a drier and be waterproof. In small factories the stamping is done by hand. It can be done very rapidly. 
In large factorics an automatic stamping outfit is attached to the filling, sealing or labeling machine and the cans are stamped automatically while they are being filled, sealed, or labeled.

\section{INSPECTING}

The sealed and stamped cans are placed, with caps down, in wooden trays holding twenty-four medium sized cans. All trays of one batch are stacked together. A card indicating number and date of batch and number of cans in the batch is attached to the stack and a copy of the same is filed in the office. The cans are placed with their caps down in order to detect "leakers" (cans with defective seals). Before labeling, the trays should be taken down, the cans turned over and examined for leaky seals. Unless the factory is behind in filling orders the cans will have been in stock at least twenty-four hours or usually longer. In the case of sweetened condensed milk, if any seals are defective, a little condensed milk will have oozed out by that time. Inexperienced sealers are prone to cause a high percentage of leaky cans. A careful sealer may reduce the number of leakers to .I per cent.

Checking the Work of the Sealers.-In order to regulate and improve the work of the sealers and to locate those doing poor work, it is advisable to number the sealers and supply each with small tin tags bearing his or her respective number. Each sealer drops one tag into each tray of cans sealed by him. The inspectors record the number of leakers found in each tray. Thus each sealer is charged up with the leakers he made.

Disposition of Leaky Cans.-Small leaks, in the case of sweetened condensed milk, can usually be soldered over successfully and the mended cans are returned to their respective batches. In the case of very defective seals, attempts at mending generally cause the milk in the can to burn, forming a brown crust on the cap, which spoils the can for the market. The contents have a burnt taste and smell, and upon stirring, brown and black specks of burnt milk appear. It is best to cut bad leakers open and pour the contents into the succeeding batch of milk.

Importance of Inspection.-The above description of inspection refers to sweetened condensed milk. This work is neglected in 
many factories, though it is very important. It may save labels and boxes, as well as much unnecessary labor in umpacking cases with leaky cans, and washing, relabeling and repacking them in new. clean cases.

In the case of evaporated milk ( unsweetened, sterilized) all cans coming from the incubating room should be individually shaken by hand. All cans showing no signs of bulging, and the contents of which shake with the characteristic sound and behavior of a liquid, pass inspection. If the ends of the cans are bulging or the contents do not respond to the shaking with the characteristic sound of normal milk, they are rejected, as the evaporated milk in them has either undergone gaseous or curdling fermentation, and is spoiled.

\section{LABELING}

Labeling Machines.-In the early days of the milk condensing inclustry, the labeling of the cans was done by hand, involving much

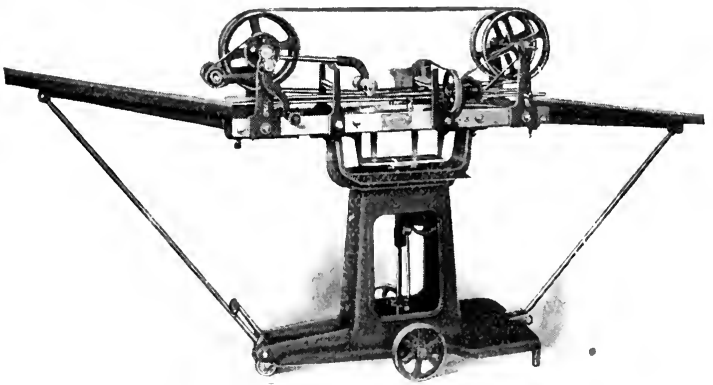

Fig. 47. I very satisfactory labeling machine Courtesy of Burt Machine Co.

time and considerable expense. Today, especially constructed labeling machines are almost exclusively used for this purpose. The efficiency of these machines is such, that they have become a permanent fixture in practically every condensery selling canned goods. They are adjustable to varions sizes of cans and can be operated by hand, motor or belt power.

Principle of Labeling Machines.-The cans are place1 into a chute from which they roll into the machine by gravity. They are caught by two endless belts which draw them through the machine. 
They first pass over the paste box, which contains an automatically revolving wheel covered with a thick layer of felt. The felt is saturated with paste or glue from the paste box. Each can comes in contact with the paste wheel and receives a touch of paste. Then the cans pass over the label box containing a stack of labels, face down. Each can picks up one label which is automatically wrapped around the can as it runs through the machine. The label box is equipped with an automatic feeder which pushes the labels up as fast as they are being used. The labeled cans leave the machine over a chute which slants from it. As they are removed they are packed directly into cases.

Wrinkles and Rust Spots on Labels.-The attractiveness of the package depends, largely, on the neatness of the label. The use of too thin, too thick, or too much paste causes the labels to wrinkle on the cans. The paste should have the consistency of heavy dough and the paste wheel should be so adjusted that it barely touches the passing cans.

Frequently the labels of the cans show stains and spots. This is especially true in the case of old goods, and is due either to a poor quality of paper, the use of sour paste or the storing of the labeled goods in damp places. Sour paste corrodes the cans and causes them to rust. The rust penetrates the label and spoils the appearance of the package. Trouble of this kind can be avoided by preparing fresh paste every day. Paste saved from the previous day is prone to sour and should not be used. The storing of the labeled goods in damp places also often causes rust spots as well as moulds on the labels. Thin and soft paper labels more easily than thick, stiff and glossy paper. In the latest types of labeling machines the use of ordinary paste has been largely superseded by that of specially preparerl glue, which removes most of the objectionable features of the ordinary paste, does not damage the label and makes a neater package.

\section{PACKING}

The labeled cans are packed in cases holding from six to ninetysix cans, according to the size of the cans. (One case holds six 1-gallon cans; forty-eight 14-, 15-, 16-, and 20-ounce cans; or seventy-two to ninety-six 8-ounce cans). 
The sides, bottom and top of the cases should be of material about three-eighths of an inch to one-half inch thick, the ends three-fourths of an inch to seven-eighths of an inch thick. The cases are usually bought in the "knock-down" shape and are made up in the factory. Sixpenny cement-coated wire nails are most suitable for this purpose. The cases are most economically nailed by the use of nailing machines, which nail one entire side or one side and one end simultaneously. The cans are usually placed into the cases direct from the labeling machine. In some factories, packing machines, which pack twenty-four medium-size cans' in one operation, are used.

Marking the Cases.-Qne end of each case is stenciled with the number of the batch; over the other end is pasted a case label, representing, enlarged, the brand of the label on the cans within. In the place of the case label, the respective brand may be printed on or burnt into the wood. The burnt stencilling is usually done by the manufacturer of the shooks. One side of each case is unully marked "Condensed Milk" or "Evaporated Milk," as the case may be; the other "Keep in cool, dry place." If sweetened condensed milk is exposed to excessive heat for a considerable length of time, as is often the case in storehouses or in the hold of steamers, where the cases may be stowed against the boiler room, it becomes brown, thickens rapidly and develops a stałe flavor. Evaporated milk also darkens when exposed to heat and depreciates in flavor. It should, therefore, be kept in a cool place. The humidity of the storage room has no effect on the condensed milk proper, the cans being hermetically sealed. Prolonged exposure to dampness, however, will moisten the paste under the labels. This causes the labels to wrinkle and the paste to become sour and musty. 'The sour paste corrodes the cans and rust spots penetrate the labels. Such cans also may soon become coated with mildew.

Packing Condensed Milk for Export.-In the case of condensed milk bought by the Lnited States Government, the cans are dipped in a solution of shellac before they are labeled. Cans for export trate and in many instances for the home market, are wrapped into heavy, soft paper, bearing on the ontside a copy of the respective brand. This wrapping paper takes up the space between the cans and prevents the cans from being damaged on their 
long journey and by rough usage. 'This wrapping is usually done by hand. Some makes of labeling machines, however, have an attachment for wrapping the cans so that when the cans leave the machine they are wrapped as well as labeled. The cases are reinforced with a band of strap iron around each end. Where the cases have to be loaded and unloaded numerous times, as is the case with export shipments, they are in danger of being torn to pieces, unless such special precautions are taken.

\section{CHAP'TER XV'II}

\section{STORAGE}

Purpose of Storing.-The purpose of storing condensed milk is largely the same as that of storing butter and other produce, namely, to keep the product from the time of large supply and low prices, to the time of small supply and high prices. In summer time, the market is usually flooded with condensed milk throughout the country, the demand for it is at ebb tide and the prices are low. In winter, there is usually a great shortage of condensed milk, the demand far exceeds the supply and prices soar high. The storing of summer milk may be necessary, also, in order to enable the manufacturer to fill his contracts and supply his trade in winter. This is especially true where the factories of a concern are located in new territories where the patrons produce an excessively small amount of winter milk.

Plain condensed milk and concentrated milk which are not sterile and contain no cane sugar to preserve them, keep but a few days at ordinary temperatures and should, therefore, be sold and used as soon as possible after manufacture. If their storage is unavoidlable, they should be held as near the freezing point as possible. For prolonged storage it might be advantageous to freeze them. However, reliable data on this phase of the industry are lacking.

Evaporated milk, sold in hermetically sealed cans, is supposed to be entirely sterile, and, if made properly, will keep indefinitely. There is a constant tendency, however, for the fat to separate out, which naturally is augmented by prolonged storage. Again, the lactic acid in the evaporated milk gradually acts on the can, causing 
the tinplate to become dull and the contents to acquire a disagreeable metallic flavor. When stored for an excessively long time this chemical action may be sufficient to cause the evolution of considerable quantities of hydrogen gas, swelling the cans.

Sweetened condensed milk which is preserved by about to per cent. of sucrose, will keep apparently unchanged for a considerable length of time. It is best, however, when fresh. Bacteriological examinations have shown that, while moderate age does not change the outward appearance of this condensed milk, the bacteria in it gradually increase and the milk gradually develops a stale flavor. White and yellow "buttons," lumps, or nodules of a cheesy texture and flavor, probably due to some fungus growth, are also prone to appear in the condensed milk. Age, also, causes it to become darker in color. These defects are especially apparent in old milk which has not been kept at a low temperature. Again, sweetened condensed milk made in May and June has a strong tendency to thicken with age and to become entirely solid.

In some cases a part of the sweetened condensed milk made during the summer months is stored in large cylindrical wooden or iron tanks sunk into the ground, or installed in the basement of the factory, where the condensed milk remains at an even temperature. As the demand for the product increases and the supply of fresh milk decreases, condensed milk is drawn from these tanks to fill the increasing orders.

Effect of Storage Temperature--Most, if not all the changes which condensed milk is prone to undergo in storage are retarded, if not entirely prevented, when stored at the proper temperature. Temperatures of 60 degrees $\mathrm{F}$. or above are too high for satisfactory storage for a prolonged period of time and the higher the temperature the greater the resulting defect.

Temperatures below the freezing point of water are also undesirable. The evaporated milk freezes and while so doing it expands sufficiently to swell the cans. Although this swelling disappears when the contents of the cans dissolve again, yet the swelling action tends to weaken the cans and may give rise to subsequent leakers. Again the melted evaporated milk is prone to be grainy as the result of freezing. This is due to the fact that when freezing, the watery portion separates from the curd and the latter contracts. 
When the milk thaws up the curd remains contracted and fails to form a smooth enulsion with the remainder of the milk.

The sweetened condensed milk does not freeze, because it contains so concentrated a sugar solution that its freezing point is

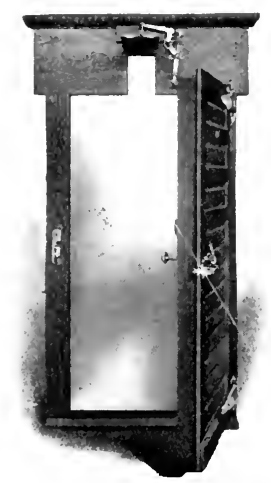

Fig. 48. The stevenson bor Courtesy of Stevenson Co. usually far below the refrigerating temperature. If it is packed in solder-sealed cans there is usually no bad effect from cold storage. However, when packed in cans sealed with the friction cap or the burr cap, difficulties may arise. These seals are not air-tight. Excessively low storage temperatures cause the contents to shrink appreciably. Suction is formed and air is drawn in through the seal. When these cans again warm up, the viscous milk in the cans seals the microscopic openings, the air and the liquid expand but the air finds no exit. This causes the cans to swell. While the quality of the milk in these cans is not impaired in the least, the swelled cans suggest gaseous fermentation, which means spoiled milk and which is invariably rejected on the market.

The temperatures at which condensed milk can be stored with the least objectionable results, range between 32 and 50 degrees $F$.

Advisability of Storing.-A heavy stock of condensed milk is a severe drain on the working capital of the condensery, involving the cost of the fresh milk, cane sugar, timplate, boxes, solder, labels, coal and labor.

Unless the manufacturer has successfully overcome and mastered all of the principal condensed milk defects, and, unless his experience justifies him in believing that his goods will stand the trials of storage, he will find it advisable not to manufacture more than he can promptly dispose of. Even at best, the condensed milk will be from three to six months old before it is all consumed, and, if it is at all subject to deterioration, the sooner it is consumed the better.

But even if the condensed milk comes out 'of storage in good 
condition, the condition of the market may be such that the goods cannot be sold at a profit, and if the market happens to take a demoralizing slump, at the time the goods are ready to leave the storage, the manufacturer may suffer heavy loss. This condition has occurred repeatedly within the last ten years.

\section{TRANSPORTATION}

The plain condensed bulk milk and concentrated milk are highly perishable products. If shipped considerable distances they should be placed in refrigerator cars.

The evaporated milk and sweetened condensed milk in hermetically sealed cans, and the latter also in barrels, can safely be shipped in ordinary box cars. The cases weigh from fifty to sixty-five pounds, and the barrels from three hundred to seven hundred pounds. Care should be taken that the cars used for this purpose are clean and dicl not previously carry goods with strong and obnoxious odors, sucl as fertilizers, as these odors are prone to follow the condensed milk to its destination. Strong box cars, in good repair only, should be used. Even at best, the cases and cans suffer more or less damage in transportation. Cars with leaky roofs should be condemned, as transportation in them may cause the package to suffer in appearance. If shipped on steamboats, it should be specified to stow the cases away from the boiler room, as prolonged exposure to high temperatures causes the condensed milk to cleteriorate.

\section{CHAPTER XVIII}

\section{MARKETS}

A large proportion of the canned condensed milk, both sweetcned and unsweetened, supplies localities, territories and countries where the lairy industry is yet in its infancy, or where gengraphic and climatic conditions bar the profitable husbandry of the dairy cow. Thus, we find some of the best conclensed milk markets in the tropics, in the arctic regions, in the army and navy, on ocean liners and in mining and lumber camps. In these markets condensed milk has, in many cases, becomé as great a necessity as fresh milk is to the inhabitants within the temperate zone. The consumption 
of canned condensed milk in our home markets has, also, been increasing rapidly within recent years, and is today assuming astonishing proportions. The rapid growth of the ice cream industry has further developed a splendid and ever increasing market for plain condensed bulk milk.

It is estimated that the canned condensed milk is from three to six months old before it reaches the consumer. It is usually sold through the medium of a jobber or broker and not direct from manufacturer to consumer. In its transit to the distant markets, it is subjected to many delays; first. by its storage in the factory, then the time in transportation, next, the delay in the warehouse of the jobber, broker or wholesale dealer. From there it gradually finds its way to the shelves of the retailer, where there is again considerable delay before it reaches the pantry of the consumer.

Market Prices of Condensed Milk.-The price of condensed milk is not controlled by the general market of dairy products, nor by any board of trade: there is no consistent uniformity of price throughout the country as is the case of butter and cheese. The price of condensed milk does not necessarily follow the rise and fall of the butter and cheese markets, but in the long run it is usually affected by abrupt fluctuations of the prices of these other dairy products, largely on account of the influence of such fluctuations on the supply to the condensery of fresh milk. It is chiefly governed by local conditions of supply and demand, composition of product and reputation of the individual brand. Condensed milk is sold under hundreds of different brands or labels. While one and the same concern may sell scores of different brands, the brand itself has very little, if anything, to do with the quality or composition of the contents of the can. Each brand usually sells at its own special price, although the various brands put on the market by the same concern often contain the same quality of milk and may be filled with condensed milk from one and the same batch. It is customary in most factories to fill the cans before they are labeled and the orders for different brands of condensed milk are filled from the same general stock. The brands serve largely as an instrument to increase the sales and to "dodge" competitors.

Sweetened condensed milk, packed in hermetically sealed cans, sells from about $\$ 3.25$ to $\$ 5$ per case of 48 sixteen-ounce cans and 
the cans retail at from 5 to 20 cents each, according to the size of the cans and market conditions.

Evaporated milk, unsweetened condensed milk in hermetically sealed cans, sells from $\$ 2.25$ to $\$ 4.00$ per case, according to the size of the cans and market conditions.

Bulk milk, both sweetened and unsweetened, goes direct from the manufacturer to the purchaser who uses it at prices agreed upon by the contracting parties. The sweetened condensed milk is sold in barrels holding from three hundred to seven hundred pounds (usually about six hundred pounds) to candy and caramel factories, bakeries and confectioners. The price varies from four to ten cents per pound according to the per cent. of fat, demand and supply. When there is a general "epidemic" of bad canned condensed milk, as is the case in years when the price of sugar is high, due to failure of the sugar cane crop, and many manufacturers are tempted to use inferior cane sugar, which they buy at a comparatively low cost, this spoiled condensed milk is usually turned into candy shops and bakeries, where it is sold for "a song." This condition has always a depressing influence on the price of sweetened condensed bulk milk, which, during such seasons, may have to be sold at a loss. Some milk condensing concerns operate their own candy shops which take care of the condensed milk that is rejected on the market.

Plain or unsweetened condensed milk is sold in I-gallon to Io-gallon cans to ice cream factories, the price varying from twentyfive to ninety cents per gallon, according to fat content, concentration and market conditions. The market for this class of goods is not very constant, but the profits are generally high. It reaches ebbtide in winter when the demand for ice cream is small. Limited Grantities of plain condensed bulk milk are also sold in milk and cream bottles for direct consumption. The concentrated milk finds the same markets as the plain condensed bulk milk.

Exports and Imports.-Canned condensed milk only need be considered here.

The United States Bureau of Statistics reports the following imports and exports of condensed milk for the year $1911^{1}$

${ }^{1}$ United states Department of Commerce and Labor, Bureau of Statistics, Report for 1912 
Exports and Imports of Condensed Milk in the United States in I9I I

\begin{tabular}{|c|c|c|c|}
\hline \multirow{2}{*}{$\begin{array}{l}\text { Exports and imports } \\
\text { in } 1,11\end{array}$} & \multicolumn{3}{|c|}{ Condensed milk } \\
\hline & Pounds & Dollars & Duty dollars \\
\hline Exports & I $2,180,+45$ & $93^{6,105.00}$ & \\
\hline Imports & 630,308 & +6.088 .00 & I 2,606.00 \\
\hline
\end{tabular}

The United States export condensed milk chiefly to North America, ()ceanica, and Asia, small quantities are also exported to South America, Africa and Europe. About 60 per cent. of all the export condensed milk goes to comntries of the North American Continent, Canada and Panama being the leading markets. Of late years our exports to Canada have fallen off very rapidly. In I9II, the total exports to Canada amounted to only about is per cent. of the total exports to the same country in igos. The rapid development of the milk condensing industry in Canada within the last few years is largely responsible for this condition. The total exports of the United States are decreasing every year. In I907, they amounted to $\$ 2.191,000$ as against $\$ 936.105$ in I9I 1 .

The imports of condensed milk in the United States are very limited. Condensed milk can be manufactured in this country practically as cheaply as anywhere else. The availability of large quantities of cane sugar, which can be purchased practically as cheaply and in many cases more cheaply than stucrose in foreign lands, the fact that prices of fresh milk in America compare very favorably with those elsewhere, and that the higher cost of American labor is largely offset by the more general use of labor-saving machinery, put the cost of manufacture of American condensed milk practically on a par with that of other countries. The high protective tariff on imported condensed milk is an additional effective agent to exclude foreign brands from American markets. The duty on imported condensed milk is two cents per pound or \$1.oo per case. ${ }^{1}$

Another cause of the limited imports lies in the fact that the agreement under which the leading European milk condensing company, the Anglo-Swiss Condensed Milk Company, which consolidated with the Nestle Condensed Milk Company, in igot, and sold

1 In 1913 the [niter States by Act of Congress removed the tariff from eondensed milk, so that foreign brands of con lensed milk may now be imported free from duty 
its American factories and business to Borden's Condensed Milk Company, contains a clause barring that company from American markets.

\section{CH.AP'ER XIX}

\section{CHEMICAL COMPOSITION OF CONDENSED MILK}

Sweetened Condensed Milk.-Sweetened condensed milk contains all the constituents of fresh milk and considerable but varying quantities of sucrose. Its composition, therefore, depends on such factors as: composition of the fresh milk from which it is made; the degree of condensation and per cent. of cane sugar added. As all of these factors vary in milk from different localities, and in milk of the same factory at different seasons of the year, no hard and fast rule can be given. The following figures merely show the average composition of sweetened condensed milk as obtained from the results of analyses of a large number of different brands.

\section{AVERAGE COMPOSITION OF SWEETENED CONDENSED MILK}

IVater

Nilk solids $\left\{\begin{array}{l}\text { fat } \\ \text { proteicls } \\ \text { milk sugar } \\ \text { ash }\end{array}\right.$

Cane sugar
26.5 per cent.

$$
\left.\begin{array}{r}
9.0 \text { per cent. } \\
8.5 \text { per cent. } \\
13.3 \text { per cent. } \\
\text { I.8 per cent. }
\end{array}\right\}
$$

32.6 per cent.

to.9 per cent.

\section{Total}

Joo.o per cent.

MITER.-The water content is largely governed by the degree of condensation and the per cent. of cane sugar. American brands average from $2+$ per cent. to 28 per cent. water. In exceptional cases milk has been found to contain as low as $2 \mathrm{I}$ per cent. and as high as $3+$ per cent. water.

Milk Solids.- The per cent. of milk solids is largely governed by the per cent. of milk solids in fresh milk and the degree of condensation. In the majority of brands the solids fluctuate between 30 and $3+$ per cent.; in extreme cases analyses have shown as low as 28 per cent. and as high as to per cent. milk solicls. The relative proportion in which the various solid constituents are present is the same as that in the fresh milk from which the condensed milk is 
made, provided that the fresh milk was not skimmed previous to condensing.

BUTTERF $\backslash T$.-The butter fat in sweetened condensed whole milk fluctuates from about 8 to 2 per cent., according to locality, season of year and degree of condensation. Sweetened condensed milk sold in barrels is usually partly or wholly skimmed and is, therefore, low in fat. It has been suggested that a small portion of the milk fat is lost during the process of condensation, and this theory is frequently resorted to by condensed milk men to explain why their milk is low in fat. It has been claimed by some that the volatile fats (volatile fatty acids ) are lost during the process of condensation. This claim is not well founded, since repeated experiments ${ }^{1}$ have conclusively demonstrated that condensed milk contains the normal amount of volatile fatty acids. It has further been experimentally proven that the condensed milk, when made properly and from whole milk, contains fat equal in amount to that found in the fresh milk used. A reasonable allowance should be made, however, for loss of milk due to spilling and wasting in pipes and retainers. Experience has shown that this loss amounts to about fifty to one hundred pounds of milk per average batch under normal conditions.

PRoTEIDS.-The per cent. of proteids in condensed milk varies with the per cent. of proteids in the original milk and the degree of concentration. It fluctuates usually between 7.5 and 9 per cent. The heating previous to condensing coagulates a portion of the milk albumin and alters the casein to the extent that it is not precipitated in the normal way, when rennet is added to the diluted condensed milk. In early spring when the majority of the cows supplying the condensery freshen, there is a tendency of the jacket and coils in the vacuum pan to become coated more or less heavily with a layer of semi-solid milk. This very probably is due to the relatively high per cent. of albumin which sticks to the heating surface. This thickened milk, when mixed with and stirred in water, usually redissolves without much difficulty. See also "Defects of Sweetened Condensed Milk," page I 5 I.

While, in most analyses of sweetened condensed milk, the per cent. of proteids nearly equals that found in the fresh milk multiplied by the degree of concentration, there is a tendency toward a

1 Hunziker and Spitzer, Indiana Agrieultural Experiment Station Bulletin No. 134, 1909 
slight loss of this constituent due to precipitation in the forewarmers.

MILK SUg.ıR.- Sweetened condensed milk contains from about I 2.5 to 15 per cent. of milk sugar, the amount varying according to the degree of concentration and per cent. of milk sugar in the fresh milk. The milk sugar is not known to unclergo any material changes as the result of the condensing process. If condensed milk is recondensed, it assumes a darker color which is largely due to the caramelizing of a part of the milk sugar, caused by the action of prolonged exposure to heat. The milk sugar in conclensed milk crystallizes very readily and causes the condensed milk to become sandy and settled. Chemical analyses of this sugar sediment show that it consists principally of milk sugar. The primary cause of this property lics in the fact that sweetened condensed milk contains so little water (about 26.5 per cent.) that the milk sugar is present in the form of a supersaturated solution; therefore, any condition which favors sugar crystallization will tend to produce this defect. ${ }^{1}$ Milk sugar requires from five to six times its weight of water at ordinary temperatures for complete solution. In sweetened condensed milk the milk sugar has access to only about twice its weight of water ( I 2.5 to I 5 per cent. lactose to 25 to 27 per cent. water).

Asn.-The per cent. of ash is largely dependent on the degree of condensation. It usually varies from I.5 to 2 per cent. It is quite constant in fresh milk (normal fresh milk contains uniformly about .7 per cent. ash). The per cent. of ash in sweetened condensed milk may serve, therefore, as a reasonably reliable factor in determining the degree of condensation. The heating of milk, before condensing, precipitates and renders insoluble a portion of the mineral solids, principally the lime salts.

Sucrose.-The purpose of the presence of sucrose in this product is to preserve it. Most of the sweetened condensed milk on the market contains from 37 to +3 per cent. sucrose, or cane sugar. Wider variations, however, are not infrequent. In some cases analyses showed as low as 30 per cent. and in others as high as 48 per cent. cane sugar. Cane sugar dissolves in one half its weight of water, so that under normal conditions there is sufficient water in the condensed milk to keep the sucrose in solution. The

1 For further details on causes of settled sweetened condensed milk see Chapter XXIII, page 146 
amount of sucrose in milk does not appreciably affect the power of the milk to dissolve milk sugar, nor does the per cent. of lactose present materially affect the power of the milk to dissolve sucrose.

SPECIFIC GRAITr:-The specific gravity of sweetened condensed milk falls within the limits of 1.24 to 1.35 . Foreign brands ¿! verage higher in specific gravity than American brands. The sperific gravity of sweetened condensed milk is controlled by the degree of condensation, the per cent. of fat and the per cent. of cane sugar. Milk condensed at the ratio of about 2.5 parts of fresh milk to $I$ part of condensed milk and containing about 9 per cent, fat and to per cent. cane sugar, has a specific gravity of from 1.28 to 1.29. The specific gravity of sweetened condensed skim milk may go as high as 1.35 , and, if it contains an excess of cane sugar, it may be still higher.

Chemical Analyses of Sweetened Condensed Milk of Eighteen Different Brands

\begin{tabular}{|c|c|c|c|c|c|c|c|}
\hline Brand & $\begin{array}{c}\text { Milk } \\
\text { solids } \\
\text { per } \\
\text { cent. }\end{array}$ & $\begin{array}{l}\text { Water } \\
\text { per } \\
\text { cent. }\end{array}$ & $\begin{array}{l}\text { Fat } \\
\text { per } \\
\text { cent. }\end{array}$ & $\begin{array}{l}\text { Pro- } \\
\text { teids } \\
\text { per } \\
\text { cent. }\end{array}$ & $\begin{array}{c}\text { Lae- } \\
\text { tose } \\
\text { per } \\
\text { cent. }\end{array}$ & $\begin{array}{l}\text { Ash } \\
\text { per } \\
\text { cent. }\end{array}$ & $\begin{array}{l}\text { Sucrose } \\
\text { per } \\
\text { cent. }\end{array}$ \\
\hline $\begin{array}{c}1 \text { "silver spoon" } \\
\text { Hires" Condensel Hilk Co.... } \\
3 \text { "Fagle" }\end{array}$ & 31.90 & 28.68 & 8.40 & 9.12 & 12.56 & 1.91 & 40.38 \\
\hline Borden's Condensed Milk Co. & 31.08 & 25.99 & 8.72 & 8.15 & 12.35 & 1.86 & 42.93 \\
\hline $\begin{array}{r}\text { Truro Condensed } \\
3 \text { ".Tip ' }\end{array}$ & 31.23 & 27.33 & 9.56 & 8.32 & 13.4 .2 & 180 & 4144 \\
\hline $\begin{array}{r}\text { Bordens" Condensed } \\
3 \text { "Challen: }\end{array}$ & 36.57 & 21.67 & 10.07 & 9.35 & 15.00 & 2.15 & 41.76 \\
\hline Borten's Conde & 31.74 & 24.84 & 8.23 & 8.51 & 13.12 & 1.92 & 43.42 \\
\hline Mohawk Comilen & 32.84 & 24.07 & 9.31 & 8.71 & 12.95 & 1.87 & 43.09 \\
\hline Wiseonsin Conde & 31.15 & 26.83 & 8.10 & 8.49 & 12.87 & 1.79 & 42.02 \\
\hline $\begin{array}{l}\text { American Contensed Milk ('o. } \\
\text { " "Reil Cross"" }\end{array}$ & 35.56 & 26.50 & 9.31 & 9.50 & 14.80 & 1.95 & 37.94 \\
\hline $\begin{array}{c}\text { Mohawk Conclensed Milk co...... } \\
3 \text { "Rose" }\end{array}$ & 34.78 & 27.14 & 11.07 & 7.92 & 14.13 & 1.76 & 3856 \\
\hline $\begin{array}{c}\text { Borden"s Condensed Milk Co....... } \\
\text { " "Magnolia" }\end{array}$ & 30.82 & 24.76 & 8.88 & 8.06 & 12.07 & 1.81 & 4297 \\
\hline Borden's conflens & 31.98 & 26.32 & 864 & 7.84 & 13.50 & 2.100 & $+2(x)$ \\
\hline $\begin{array}{l}\text { Michigan Condensed Milk Co..... } \\
2 \text { "Milk Maid" }\end{array}$ & 30.00 & 27.63 & 8.60 & 7.07 & 12.60 & 1.73 & $41 .(x)$ \\
\hline $\begin{array}{r}\text { Anglo-swiss Condensed Milk c'o.- } \\
\text { " "dullee" }\end{array}$ & 35.69 & 25.65 & 9.6 .3 & 8.78 & 15.17 & 200 & 3866 \\
\hline The Manitola Dai & 29.40 & 32.15 & 9.62 & 8.61 & 11.30 & $1.8 \%$ & 35.45 \\
\hline Ballwin conclense & 32.24 & 26.69 & 11.50 & 850 & 12.35 & 1.81 & 41.67 \\
\hline $\begin{array}{c}\text { Canada Milk Condensing Co... } \\
\text { " "Nestle" }\end{array}$ & 31.61 & 30.84 & 10.61 & 8.47 & 12.40 & 1.81 & 37.5 .5 \\
\hline Henry Nestle "Tpper Ten" & 32.91 & 28.04 & 8.06 & 7.68 & 15.23 & 1.94 & 39.05 \\
\hline C. S. Condensed Milk Co.. & 33.65 & 27.88 & 8.811 & 8.34 & 14.66 & 1.85 & 3847 \\
\hline
\end{tabular}

1 Spitzer, Indiana Agrieultural Experiment station, 1910

2 McGill, Inland Rev. Dept., Ottawa, Bulletin No. 14, 1948

3 Coehran, special Report of Analysis of C'ordensed Milks and Infants' Fools, Pennsylvania Department of Agriculture, 1905 
Evaporated Milk.-The same factors which control the chemical composition of sweetened condensed milk, also govern that of the unsweetened product, with the exception that the cane sugar is absent.

The following figures represent, in round numbers, the average composition of evaporated milk as obtained from analyses of a large number of American brands.

\section{AVERAGE COMPOSITION OF EVAPORATED MILK}

Water

73 per cent.

Milk solids $\left\{\begin{array}{ll}\text { fat } & 8.3 \text { per cent. } \\ \text { proteids } & 7.5 \text { per cent. } \\ \text { lactose } & 9.7 \text { per cent. } \\ \text { ash } & 1.5 \text { per cent. }\end{array}\right\} 27$ per cent.

IOO per cent.

The chemical and physical properties of the various ingredients in unsweetened condensed milk are affected to a greater extent than in the case of sweetened condensed milk. This is largely due to exposure of the evaporated milk to high temperatures in the sterilizer.

IVATER AND SOLIDS are governed by the degree of concentration and the relative per cent. of the same constituents in the fresh milk. The per cent. of solids admissible in evaporated milk is largely dependent on the chemical and physical properties of the milk and the sterilizing temperatures employed. Excess in solids in this product jeopardizes its marketable properties, owing to the tendency of the proteids to form hard lumps of curd during the sterilizing process. Evaporated milk very low in solids tends toward the separation of its butter fat in storage. Analyses show a range of from 23 to $3 \mathrm{I}$ per cent. solids. Since the per cent. of solids necessary and possible to be contained in marketable evaporated milk, largely depends on the properties of milk, and, since these properties again are principally controlled by locality, season of year, crop, feed and weather conditions and the quality of the fresh milk, the solids in milk from any given factory and at any given season of the year may vary very considerably. In some localities and at certain times of the year the best results may be obtained with evaporated milk containing 28 per cent. solids. In other localities it may be impossible at 
certain seasons of the year, to incorporate more than 24 per cent. solids without injuring or destroying the marketable properties of the product ${ }^{1}$.

BuTTERFAT.- The fat varies with the per cent. of fat in the fresh milk and with the degree of concentration. No fat is lost during the process of condensing and sterilizing. ${ }^{2}$ It has been claimed by some that in the process of manufacture, the volatile fatty acids escape and that the evaporated milk therefore contains less fat than the fresh milk from which it is made, times the legree of concentration. If this were true the loss of fat in the evaporated milk would not exceed .25 of I per cent. But analyses show that the fat in the evaporated milk is entirely normal in composition and contains the same proportion of volatile fatty acids as the fat in the fresh milk.

The Composition of Milk Fats in Evaporated Milk :

\begin{tabular}{l|c|c|c|c|c}
\hline $\begin{array}{c}\text { Date of } \\
\text { Manufacture }\end{array}$ & $\begin{array}{c}\text { Reichert } \\
\text { Meissl } \\
\text { number }\end{array}$ & $\begin{array}{c}\text { Iodine } \\
\text { number }\end{array}$ & $\begin{array}{c}\text { Melting point of } \\
\text { mixed fats }\end{array}$ & $\begin{array}{c}\text { Melting point of } \\
\text { insoluble } \\
\text { fatty acids }\end{array}$ \\
\hline August, 1908 - & 28.48 & 33.64 & 33.3 degrees C. & 41.0 degrees C. \\
November, 1908 - & 29.52 & 33.60 & 33.4 degrees C. & 41.2 degrees C. \\
\hline
\end{tabular}

In the evaporated milk there is a strong tendency for the fat to separate out during storage and to churn in transportation. This is largely avoided by the proper adjustment of the sterilizing process and by ase of the homogenizer.

PRoTeIDs.-The proteids vary with the per cent. of total proteids in the fresh milk and the degree of concentration. Similar to the case of sweetened condensed milk there is a tendency of a slight loss of proteids in evaporated milk due to mechanical adhesion of a part of the precipitated curd to the heating surfaces in the forewarmers and in the vacumm pan.

Most of the coagulable milk albumin is precipitated. Fresh milk contains about . 6 per cent. of albumin that is not coagulable by heat. ${ }^{3}$ The relation of soluble and insoluble curd is shown in the following table which represents analyses of different brands of evaporated milk.

${ }^{1}$ Hunziker, Indiana Agricultural Experiment Station, Twenty-first Annual Report, 1908, pages $67-68$

${ }_{2}^{2}$ Hunziker anol Spitzer, Indiana Agricultural Experiment station, Bul'etin No. 134

3 Hunkizer, Indiana Agrieultural Experiment Station, Bulletin No. 143 
Soluble and Insoluble Curd in Evaporated Milk ${ }^{1}$

\begin{tabular}{|c|c|c|c|}
\hline Brand & $\begin{array}{c}\text { Insoluble } \\
\text { curd } \\
\text { per cent. }\end{array}$ & $\begin{array}{l}\text { Soluble } \\
\text { albumin } \\
\text { per cent. }\end{array}$ & $\begin{array}{c}\text { Total } \\
\text { proteids } \\
\text { per cent. }\end{array}$ \\
\hline Gold Milk . . . . . & 8.14 & .46 & 8.90 \\
\hline Columbine - & 7.41 & .49 & 7.90 \\
\hline Every Day -..-_- & 7.54 & .46 & 8.0 \\
\hline Gold Milk _- & 7.37 & .33 & 7.70 \\
\hline Star & 7.86 & .30 & 8.16 \\
\hline Morning Glory & 8.28 & .34 & 8,62 \\
\hline Carnation - & 6.49 & .52 & 6.91 \\
\hline Beauty - & 8.39 & .39 & 8.78 \\
\hline Van ciamp's _- & 7.52 & .42 & 7.94 \\
\hline Monareh _- & 6.77 & .52 & 7.29 \\
\hline Diadem _.. & 7.116 & .42 & 7.48 \\
\hline Reindeer & 6.88 & .52 & 7.40 \\
\hline Wilson's - - & 6.89 & .49 & 7.38 \\
\hline Iounder -...-- & 7.21 & .44 & 7.65 \\
\hline Average -... & 7.436 & $.4 \div 9$ & 7.86 .5 \\
\hline
\end{tabular}

The above figures show that, in the evaporated milk, practically all of the coagulable albumin is changed to insoluble curd. The brands analyzed contained evaporated milk condensed at the ratio of 2 to 2.4 parts of fresh milk to I part of evaporated milk. The soluble albumin found corresponds with the albumin not coagulable by heat, normally found in fresh milk, times the ratio of concentration.

The casein is largely precipitated by the sterilizing heat, but is present in the form of very finely divided particles. This is due to the mechanical shaking to which the evaporated milk is subjected in the sterilizer and in the shaker. In many batches of evaporated milk the precipitation of the casein during sterilization is so fine that the product is perfectly smooth without shaking. The casein in evaporated milk does not respond to the action of remet as does the casein in fresh milk.

Milk Sugar.-The milk sugar is present in per cent. corresponding with that of the original milk, times the degree of concentration. A portion of it has undergone oxilation (caramelization) due to the high sterilizing temperatures. It gives to the evaporated milk a yellow to light brown color. The higher the sterilizing temperature and the longer the exposure of the evaporated milk to this heat, the darker is its color.

${ }^{1}$ Hunziker, Indiana Agrieultural Fxperiment Station, Bulletins No. 134 and 143

2 Hunziker, Indiana Agricultural Experiment Station, Twenty-fifth Annual Report, ]9:8 
AsH.-The mineral constituents also are present in nearly the same proportion to the other solids, as in fresh milk. They are largely rendered insoluble by the sterilizing process. The lime constituents frequently are found in the bottom of the cans in the form of hard, whitish, insoluble granules.

Since the ash in normal fresh milk is practically constant, averaging about .7o per cent., the per cent. of ash in the evaporated milk is frequently used as a factor in determining the degree of concentration. The results may, however, be very misleading, since, when the ash is precipitated in the form of granules, it is practically impossible to mix it back into the milk in order to obtain a representative sample for analysis.

The Specific Gratity ranges from 1.05 to 1.08 , according to the degree of concentration and the specific gravity of the original milk. It averages about 1.065 .

Plain condensed bulk milk is of very varying composition, depending largely on the degree of concentration and the per cent. of fat present. It is usually made from partly or wholly skimmed milk and is condensed at the ratio of 3 to 4 parts of fresh milk to I part of condensed milk. The same fact applies to the composition of concentrated milk. 
Chemical Analyses of 'Twenty-four Different Brands of Evaporated Milk $^{-1}$

\begin{tabular}{|c|c|c|c|c|c|c|c|}
\hline Brand & Solids & Water & Fat & Curd & Lactose & Ash & Total \\
\hline Gold Milk & 29.25 & 70.75 & 9.42 & 8.44 & 9.75 & 1.54 & 99.80 \\
\hline Columbine & 24.63 & 75.37 & 7.45 & 7.41 & 8.56 & 1.36 & 99.98 \\
\hline Every Day & 26.20 & 73.80 & 8.07 & 7.54 & 9.10 & 1.47 & 100.15 \\
\hline Gold Milk - & 27.18 & 72.82 & 9.07 & 7.39 & 9.23 & 1.49 & 100.00 \\
\hline Star & 29.04 & 70.90 & 8.35 & 7.86 & 10.37 & 1.62 & 99.16 \\
\hline Morning Glory & 31.08 & 68.92 & 10.48 & 8.26 & 10.47 & 1.67 & 99.82 \\
\hline Carnation & 23.81 & 76.19 & 8.05 & 6.49 & 7.55 & 1.24 & 99.49 \\
\hline Beauty -... & 28.38 & 71.62 & 8.47 & 8.39 & 9.94 & 1.56 & 99.98 \\
\hline Van Camp's & 27.89 & 72.11 & 8.69 & 7.52 & 9.66 & 1.54 & 99.52 \\
\hline Wilson's -.. & 25.23 & 74.77 & 8.70 & 6.53 & 8.68 & 1.37 & 100.05 \\
\hline Monareh - & 26.70 & 73.30 & 8.09 & 6.77 & 10.35 & 1.44 & 99.95 \\
\hline Diaden -.. & 24.96 & 75.04 & 8.16 & 7.06 & 7.92 & 1.33 & 99.51 \\
\hline Reindeer & 26.66 & 73.34 & 8.08 & 6.88 & 10.21 & 1.45 & 99.96 \\
\hline Dundee & 27.04 & 72.96 & 8.73 & 7.21 & 9.36 & 1.48 & 99.74 \\
\hline Sundry samples & & & & & & & \\
\hline $1 \ldots$ & 28.02 & 71.98 & 8.93 & 7.68 & 9.86 & 1.61 & 100.06 \\
\hline & 31.99 & 68.01 & 9.68 & 8.49 & 11.88 & 1.69 & 99.75 \\
\hline & 26.01 & 73.99 & 8.18 & 6.77 & 9.24 & 1.46 & 99.64 \\
\hline & 27.33 & 72.67 & 9.04 & 6.93 & 9.42 & 1.51 & 99.57 \\
\hline & 29.37 & 70.63 & $9 . \pi 1$ & 7.34 & 10.52 & 1.56 & 99.76 \\
\hline & 21.12 & 78.88 & 7.30 & 5.78 & 6.78 & 1.12 & 99.86 \\
\hline & 23.25 & 76.75 & 7.98 & 6.19 & 7.96 & 1.25 & 100.13 \\
\hline 0 & 25.48 & 74.52 & 8.68 & 6.34 & 8.67 & 1.35 & 99.56 \\
\hline $9_{-\ldots}-$ & 26.62 & 73.38 & 9.20 & 7.00 & 9.18 & 1.37 & 100.13 \\
\hline
\end{tabular}

${ }^{1}$ Hunziker and Spitzer, Indiana Agricultural Experiment Station, Bulletin No. 13t, 1909

\section{CHAP'TER XX}

\section{SANITARY PURITY AND DIETETIC VALUE OF CONDENSED MILK}

Sanitary Purity.-From the point of view of freedom from pathogenic and other harmful micro-organisns, all forms of condensed milk are superior to the average market milk. In the first place, the manufacture of a marketable condensed milk makes essential eternal vigilance in the control of the quality of the fresh milk. It is safe to state that in no milk plants does the quality of the fresh milk accepted, receive as careful attention and average as high as in the milk condensery. The foundation of the condensed product, the fresh milk, therefore, is of a relatively high standard of purity. 
Again, the temperature to which the milk is subjected is sufficiently high to destroy the germs of practically all milk-borne diseases: so that, unless the condensed milk becomes infected with pathogenic germs after condensing and before the tin cans are hermetically sealed, practically all danger from disease germs is eliminated. In the case of evaporated milk the marketable product is free from all forms of germ life. The only exception to this rule would apply to concentrated milk, in the manufacture of which the milk is not heated to temperatures detrimental to the life of bacteria.

Dietetic Value.-The dietetic value of condensed milk is largely dependent on the effect of heated milk on its nutritive value and on digestion. As far as condensed milk is concerned, there are no available data that would throw any light on this subject. The results of feeding experiments with heated, pasteurized, or sterilized milk vs. raw milk, however, may furnish a logical guide as to the dietetic effect of condensed milk. Milk pasteurized at high temperatures, or sterilized, may be considered comparable, as far as the effect of heat is concerned, to condensed milk.

Doane and Price $^{1}$ report the following experimental results: "Raw milk is more easily digested when fed to calves than either pasteurized, or cooked milk. Contrary to theory, cooked milk, when fed to the calves used in these experiments, caused violent scouring in the majority of trials. A majority of physicians in charge of children's hospitals corresponded with, favored the use of raw milk for infants, when the milk is known to be in perfect condition, but favored pasteurized milk under ordinary conditions. With one exception all the physicians corresponded with, discouraged the use of cooked, or sterilized milk for infant feeding."

Rosenat ${ }^{2}$ states that "Comparative observations upon infants under the same conditions show that they flourish quite as well upon heated milk as upon raw milk. Laboratory experiments as well as chemical observations coincide with the view, that heated milk is quite as digestible as raw milk. In fact it is now claimed to be more so. Metabolism experiments indicate that the utilization of calcium and iron in the body is more complete in children fed upon boiled cow's milk, than in those fed upon raw cow's milk."

\footnotetext{
${ }^{1}$ Doane and Price, Maryland Agricultural Experiment Station, Bulletin No. 77, 1901

2 Rosenau, United States Defiartment of Agriculture, Bureau of Animal Industry, Circular No. 153,1910
} 
Stutzer ${ }^{1}$ who conducted experiments of artificial digestion reports in favor of boiled milk, while similar investigations made by Ellenberger and Hofmeister ${ }^{2}$ showed no difference in the digestibility between raw and cooked milk.

Rodet" who experimented with dogs noticed a slight difference in favor of boiled milk. Bruning ${ }^{4}$ fed dogs, pigs, rabbits, and guinea pigs with raw and sterilized milk and reports that all results were in favor of the sterilized milk. Bruckler's ${ }^{5}$ experiments with dogs showed that the animals gained more in weight on sterilized milk than on raw milk, but that their general health, vigor and vitality was better when fed raw milk. Variot ${ }^{6}$ observed no difference in the effect on infants between raw and boiled milk.

Peiper and Eichloff made post mortem examinations on numerous dogs which had been fed for prolonged periods on raw and boiled milk, respectively. In the dogs fed on boiled milk the marrow of the bones was highly anamic, the articulation of the bony structure looser, the ash content of the bones and the blood lower, and there was more sodium chloride and less fibrin in the blood than in the case of the dogs fed on raw milk.

Storck $^{-}$and others attribute such infantile diseases as rickets and scurvy to the feeding of boiled milk.

It is generally assumed that, because the lime and phosphoric acid of milk become largely insoluble when milk is heated to sterilizing temperatures, these elements in sterilized milk are not sufficiently available to supply the needs of the growing organism. In experiments with dogs Aron and Frese found that the utilization of the lime is not affected by heating the milk and that, as far as the assimilation of the lime by the growing organism is concerned, it is immaterial in what form the lime is present. Even when fed in difficultly soluble form, as tertiary lime phosphate, the lime was utilized as well as the lime of normal raw milk.

The fact that the phosphorus (phosphoric acid), needed for the building up of the bony structure, and which is present in milk

1 Stutzer, Landw. Versnehs-Stationen, 40, p. 307

2 Ellenberger \& Hofmeister, Bericht veher das Veterinarwesen Koenigreich Saehsen, 1890

3 Rodet, Compt, rent. soe biol., 48, p. 5ix

4 Bruning. Muenehner Mediz... Wochensehrift. No. 8, 1405

4 Bruning, Zeitschrift fuer Tiermed, $10, \mathrm{p}$. 110, 196

5 Bruckler. Jahrbuch fuer Kinderheilk. 66, p. 343, 196

Gariot, Comp. rend., 139, 1. 1002, 194

: Storck, zit. n. Knukel, Studien neber die sog. sterilisierte Milch des Handels. Diss., Luzern, tins

8 Aron and Frese, Grimmer Chemie 11. Physiologie der Mileh, 1910 
largely in organic combination as casein and as lecithin, is changed by heat to inorganic combinations, the lecithin phosphorus by saponification, and the casein phosphorus by changes in the casein molecule, suggests a poorer retention of the inorganic phosphorus by the animal body. Cronheim and Mueller ${ }^{1}$ who studied this phase of nutrition could detect no appreciable difference as to the assimilation of phosphorus by feeding sterilized and raw milk, respectively. Their results were rather in favor of sterilized milk.

Grimmer ${ }^{2}$ holds that digestive and intestinal disorders in infants are possibly largely due to biological disturbances, modifying the bacterial flora of the intestines, and to the absence of lecithin and unorganized ferments in heated milk. He reports that the addition to boiled milk of substances rich in lecithin, such as the yolk of egg, also ferments, such as pepsin, trypsin, and emulsin produce a marked improvement in such cases.

The foregoing citations suggest that our knowledge of the dietetic effect of heated or boiled milk is exceedingly limited and that the results obtained and conclusions drawn by the various investigators are at variance. In experiments with the living organism, and confined to so few specimen as seems to have been the case in the work reported, the factors of individuality and environment are a constant stumbling block, magnifying the limit of experimental error and weakening the conclusiveness of the results. On the basis of our present knowledge it seems reasonable to conclude that, as far as the digestibility of its inherent ingredients is concerned, condensed milk, when consumed in properly diluted form, varies but little, if any, from raw milk. The absence in condensed milk of ferments, such as enzymes, which are destroyed in the process and which may assist digestion, may be considered the most important defect of condensed milk from the dietetic point of view.

In the case of sweetened condensed milk, however, the nutritive ratio of the normal milk is decisively disturbed by the presence of large quantities of sucrose. Even when diluted to far beyond the composition of normal and original fluid milk, the per cent. of cane sugar is still high, causing the nutritive ratio of such milk to be abnormally wide and unbalanced. The carbohydrates are present far in excess of the protein, fat and ash. If fed to infants exclu-

1 Cronhein and Mueller, Jahrbuch fuer Kinderheilk, 57, p. 45, 1903

2 Grimmer, Chemie and Physiologie der Mileh, 1910 
sively and for a prolonged period of time, the growing organism is bound to suffer from malnutrition and at the expense of muscular development.

Furthermore, it is conceded by the medical profession that sucrose is not a suitable form of carbohydrates for infants. It is not as digestible as lactose, it changes the bacterial flora of the intestines, enhancing the development of butyric acid and other gas forming and putrefactive germs at the expense of Bacillus bifidus, which is the natural inhabitant of the intestine in normal, milkfed babies.

Sweetened condensed milk is generally highly advertised by the manufacturer as a suitable food for babies; it is frequently recommended by physicians and in some instances, it is claimed to have agreed with babies who were unable to take care of milk in any other form. It is not improbable that in these extremely isolated cases of baby feeding, when all other feeds failed, the true virtue attributed to the sweetened condensed milk, lay in the fact that the mothers carefully followed the directions on the label for dilution. The directions specify that the condensed milk be diluted with ten to sixteen parts of water. The majority of cases of digestive disorders in bottle-fed babies are undoubtedly the result of the natural tendency of the mother to feed her child too much milk or too rich milk. When we consider that the ratio of concentration in sweetened condensed milk is only about 2.5 to $I$, it is obvious that a dilution of 10 or 16 to $\mathrm{I}$ is a great relief to the over-taxed digestive organs of infants, previously fed on milk too rich for normal digestion. The immediate change of the health and disposition of these babies for the better, as the result of turning from a prolonged siege of too rich food to the very dilute condensed milk, is therefore not surprising.

The manufacturer of sweetened condensed milk in this country is inclined to load his product excessively with sucrose. He does this largely in an effort to increase the keeping quality and to guard against the development of fermentations in the finished article that ruin the goods for the market. While a certain amount of sucrose is necessary to preserve this milk, yet, if the product is manufactured from a good quality of fresh milk, as it should be, and when the proper sanitary conditions are maintained in all departments of the 
factory, sixteen pounds of cane sugar per one hundred pounds of fresh milk is entirely sufficient. He should bear in mind that sweetened condensed milk is used and accepted by the consumer as a substitute for market milk, and it is the manufacturer's moral duty to retain in this substitute the normal properties and composition of the product which it is supposed to replace, as nearly as is consistent with the production of a wholesome and marketable product.

\section{CHAPTER XXI}

\section{CONDENSED MILK STANDARDS AND LAWS}

The Federal Food and Drugs Act, passed June, I906, and which went in force Jannary I, I907, has raised the standard of excellence of condensed milk to no small degree. It has served as a purifier of the entire industry, putting a premium on the product of the honest manufacturer and insuring the public against condensed milk of inferior food value.

Prior to the enforcement of this act, three states only had definite standards and laws regulating the composition of condensed milk. In the absence of a federal law, car loads of condensed skim milk were unloaded and sold as condensed milk in states and cities which had no laws or ordinances prohibiting the sale of condensed skim milk, labeled condensed milk. The Federal Food and Drugs Act, executed through the offices of the Interstate Commerce Department, put a stop to this fraud, protecting the public from these inferior goods, eliminating the manufacture, traffic and competition of an unlawful product, enhancing the business of legitimate manufacture and raising the standard and integrity of the industry.

Federal Standards. ${ }^{1}$-The Federal Standards for sweetened condensed milk and evaporated milk which went into force January I, I907, are as follows:

"SWEETENED CONDENSED MILK is milk from which a considerable portion of water has been evaporated and to which sugar (sucrose) has been added and contains not less than 28 (twentyeight) per cent. of milk solids, of which not less than 27.5 (twentyseven and five-tenths) per cent. is milk fat."

1 United States Department of Agriculture, Circular No. 19; also Indiana Agricultural Experiment Station Bulletin No. 143 
This standard is reasonable, just, adequate and attainable under all normal conditions. Sweetened condensed milk in hermetically sealed tin cans averages about 32 per cent. milk solids, and the per cent. of milk solids can be increased considerably above this average without injuring the marketable properties of the product. Manufacturers of swectened condensed milk well know from costly experience, that it would not do to drop the per cent. of milk solids to or below 28 per cent. Such milk would be too thin to hold the sugar in suspension, the sugar would tend to settle to the bottom of the cans, rendering the product unsalable, though not necessarily unwholesome. Again, this thin milk does not keep well, it is prone to undergo fermentation. The manufacture of a good quality of salable sweetened condensed milk requires that the fresh milk be condensed at the ratio of about $2 \frac{\mathrm{T} / 2}{\mathrm{I}} \mathrm{I}$. With this ratio of concentration it is obvious that it is not difficult to incorporate 28 per cent., or over, of milk solids in sweetened condensed milk at all times.

"ETAPORATFD MILK is milk from which a considerable portion of water has been evaporated and contains not less than 28 (twentyeight) per cent. milk solids, of which not less than 27.5 (twentyseven and five-tenths ) per cent. is milk fat."

Unfortunately, for the moral effect of the law and for the progress of the condensing industry, the standard of evaporated milk was made so high, evaporated milk shall contain 28 per cent. solids, that it was found to be beyond the reach of the manufacturer to comply with it under most conditions without impairing the marketable properties of the product. The results of this error have confronted many an honest manufacturer with unsurmountable difficulties. He was compelled to choose between two equally unsatisfactory alternatives, i. c., either to manufacture a profluct below standard, violating the law, or to close his factory.

Modified Eraporated Wi!k Standard.-The unreasonableness of the Federal Standard for evaporated milk was experimentally demonstrated by results of investigations conducted at the Indiana Agricultural Experiment Station. ${ }^{1} \quad$ Further extensive investigations were made by the United States Bureau of Chemistry. ${ }^{2}$ Finally. in March, I9I ${ }^{3}$ the standard was morlified to read as follows:

\footnotetext{
${ }^{1}$ Hunziker, Indiana Agrieultural Fxperiment Station Bulletin No. 143, 1910

2 Results not nublished

${ }^{3}$ Cnited states Department of Agriculture, Food Inspection Decisi n No. 131, 1911
} 
“I. Evaporated milk should be prepared by evaporating fresh, pure whole milk of healthy cows, obtained by complete milking and exclucling all milkings within fifteen days before calving and seven days after calving, provided that at the end of this seven day period the animals are in a perfectly normal condition.

"2. It should contain such percentages of total solids and of fat that the sum of the two shall be not less than $3+.3$ and the percentage of fat shall be not less than 7.8 per cent.

"3. It should contain no added butter or butter oil incorporated either with whole milk or skimmed milk or with the evaporated milk at any stage of manufacture."

This modified standard was an improvement over the original standard which it superseded. However, the requirements of solids were still too high.

Difficultics of Mccting Thesc Standards for Ecraporated Milk. - While these standards can be complied with in some localities and under certain favorable conditions, they are beyond the reach of the manufacturer in other localities and under less favorable conditions. The manufacturer is compelled, in order to produce a marketable product, to use sufficiently high temperatures in the sterilizer to render the milk absolutely sterile. This he must accomplish without causing the product to become curdy.

The degree of concentration of the evaporated milk directly controls its curdling properties. The higher the degree of concentration, the greater is the danger of a curdy product. Unfortunately, the agents which regulate the ease with which milk curdles, are not under the control of the operator. They have to do with breed, period of lactation, condition, care and feed of the cows, season of year, climatic and weather conditions and the care and chemical, physical and physiological properties of the milk on the farm. It so happens that in localities, where dairying has not as yet reached a high state of development, where cows are exposed to inclement weather, or in the southern tier of the dairy belt, where the cows suffer from the sweltering heat of the summer months and are pestered with flies, and where the available water for cooling the milk on the farm is not very cold, the milk is more prone to curdle, than in highly developed dairy countries, or in localities of the cooler regions of the dairy belt, etc.

The properties of milk to curdle, whatever the agents causing them may be, are intensified by the degree of concentration. It is, 
therefore, necessary for the successful manufacture of a salable product to regulate this.

A further objection to both, the original and the modified standard for evaporated milk is that, where milk is bought and paid for on the basis of butterfat contained therein, as it should be, the factory receiving high-testing milk, labors financially under a distinct disadvantage. The reason for this is that in high-testing milk, such as Jersey and Guernsey milk, the butterfat constitutes about 34 per cent. of the total solids, while in low-testing milk, such as Holstein milk, the butterfat constitutes only about 28 per cent. of the total solids. In order to meet the requirements for milk solids, more butterfat has to be put into the evaporated milk per case, where high-testing milk is condensed than in the case of lowtesting milk. Consequently, the cost per case, of the manufacture of such milk is greater than that of low-testing milk. These standards, therefore, discriminate in favor of manufacturers and breeds of low-testing milk, such as milk from Holsteins and Ayrshires, and against manufacturers and breeds of high-testing milk, such as milk from Jerseys and Guernseys.

Putting the Composition of the Eraporated Milk on the Label. - As the result of these difficulties, numerous manufacturers protested against these stanclards and succeeded in obtaining from the Government temporary concessions to the effect that "there would be no violation of the Food and Drugs Act if the percentage composition of the goods was plainly stated on the label in connection with the name of the substance, although this might be lower than that required by Food Inspection Decision No. I3I." This information was issued by the Government to the condenseries in the form of a circular letter.

As the result of this concession, many condenseries, which experienced difficulties in complying with the original standard, adopted individual standards of composition in accordance with their local conditions and they stated on the label, in more or less legible type, the percentages of solids and fat below which their goods would not drop.

Subsequent investigations by the Government, however, seemed to indicate that this form of labeling was misleading to the public and would, therefore, be in violation of the Food and Drugs Act. 
Consequently, the concession of permitting individual standards was then withdrawn.

The Federal Board of Food Inspection is further considering the advisability of modifying the evaporated milk standard, but until a decision is reached, the standard proclaimed in Food Inspection Decision No. I 3 I is valid.

Condensed Skim Milk.-The Federal Standard for condensed skin milk is as follows:

"Condensed skim milk is skim milk from which a considerable portion of water has been evaporated."

To this class of condensed milk belongs all condensed milk made from wholly or partly skimmed milk.

\section{CHAP'TER XXII}

\section{COST OF MANUFACTURE}

General Discussion.--The cost of manufacture varies, in a general way, with the organization and size of the factory, capacity of machinery and the amount of the output. These variations are further modified by the cost of available labor, the price of milk, cane sugar, tin cans, box shooks, coal and other supplies, etc.

In a properly organized plant the cost of manufacture per case of finished product decreases with the increase of the output, provided that the capacity of the machinery is sufficient to take care of such increase. When the plant is forced beyond its capacity, the factory operates at a disadvantage, and the extra labor and possible waste and losses tend to increase the cost per case. When the output drops below ioo to I 50 cases per day, profitable manufacture becomes difficult, the overhead expense is out of proportion with the business, the factory cannot take advantage of rebates in the purchase of supplies, the factory labor is relatively high, because skilled men have to do manual labor, and occasional losses due to spoiled goods devour the profits of a comparatively large portion of the entire output.

The price of milk fluctuates with season and proxinity and strength of competing markets. The fluctuations embrace a range of from $\$$ I.OO to $\$ 2.00$ per one hundred pounds of fluid milk, or twenty-five cents to fifty cents per pound of butter fat. 
Cane sugar varies in price largely with the season and with the success or failure of the sugar cane crop. Sugar prices usually reach their climax in fall and their minimum price in late winter or early spring. The variations usually fall within the limits of $\$ 4.00$ and $\$ 6.50$ per one hundred pounds of sugar.

Tin cans vary in price with style of can and whether made in the condensery or bought from a can-making concern. Some factories are paying more or less heavy royalties for the privilege of using certain patents of cans. Cans intencled to be sealed without the use of solder, but which are guaranteed to make a hermetical seal, are generally higher in price than those in the sealing of which solder is used. 'This difference in price, however, is offset, in part at least, by the cost of the solder and gasoline. Cans purchased from can-making concerns usually are more expensive than cans manufactured in the condensery. This holds true only where the tin-shop of the condensery is properly equipped and efficiently manned. The cost of cans bought from can-making concerns is about fifty-five cents per case, varying somewhat with size and style of can: when made in the condensery the price may be lowered from Io to 20 per cent.

The cost of coal varies with quality and locality. Under average conditions, the condensing and packing of one pound of fluid milk requires about three-tenths of a pound of coal or thirty to forty pounds per case. A good quality of "mine run" can be laid down at the factory in states near the coal region, like Indiana and Illinois for about $\$ 2.50$ per ton, or in northern states, like IVisconsin, for about $\$ 3 \cdot 3$ o per ton. The cost of coal per case, therefore, may vary from about three and eight-tenths cents to six and a half cents per case. Where natural gas or refuse from lumber mills are available, the cost of fuel may be reduced materially by the use of these substitutes for coal.

Solder and gasoline for sealing the cans average about three and a half cents per case. The price of solder is about twenty-seven cents per pound and the solder used per case of forty-eight cans amounts to about one-tenth of a pound.

The labels vary in price according to quality of paper, and elaborateness of printing. The average cost of labels is about four cents per case. 
The box shooks and nails per case cost about eight to ten cents.

The labor, including factory labor, the office personnel and the manager's salary is about twenty-five cents per case, varying obviously with the organization and output of the factory.

The interest on the investment and insurance amount to about two and a half to three cents per case. A factory manufacturing two hundred cases of condensed milk per day requires an investment of about $\$ 25,000$ for building and equipment and about $\$ 10,000$ for operating capital.

The expense of freight and other transportation ranges from about five to twenty cents per case, according to distance. It may average about twelve cents per case.

The selling expense varies considerably with the organization of the sales department and the type and extent of advertising done. Under favorable conditions it may be held down to twenty-five to thirty cents per case. If premiums are awarded the cost is about ten cents extra. The introduction of new brands often incurs an expense as high as $\$$ I.OO per case. The average sales expense may be consistently placed at thirty to forty cents per case.

For convenience sake the cost per case may be grouped as follows : 


\section{SWEETENED CONDENSED MILK}

Cost per Case of Forty-eight Cans Containing About Forty Pounds of Condensed Milk

Ioo pounds milk@\$r.50 ....................5o

I6 pounds cane sugar@\$5.00 per Ioo pounds..... .90

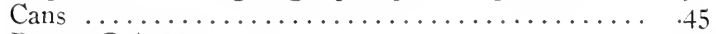

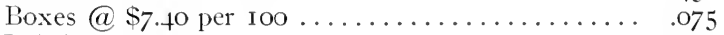

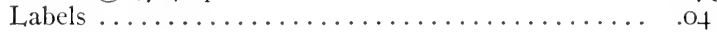

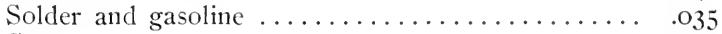

Coal .........................

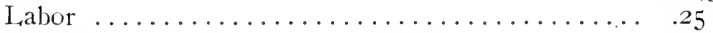

Interest on investment and insurance.......... .03

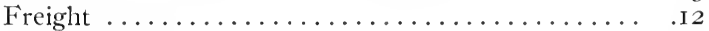

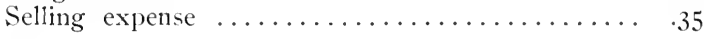

Total cost of manufacture and sale of one case of sweetened condensed milk ........... \$3.795

\section{EVAPORATED MILK}

Cost per Case of Forty-eight Tall-size Cans Containing Fifty-four Pounds of Evaporated Milk

I Io poundsmilk@\$I.50 per hundred pounds.....\$I.65

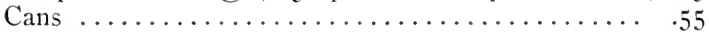

Boxes ............................. . 55

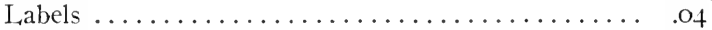

Solder and gasoline $\ldots \ldots \ldots \ldots \ldots \ldots \ldots \ldots \ldots . .035$

Coal ............................... 045

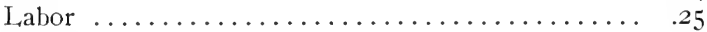

Interest on investment and insurance........... .03

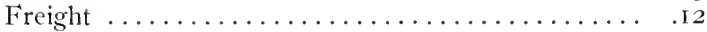

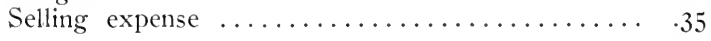

Total cost of manufacture and sale of one case of tall-size cans of evaporated milk.........\$3.I45 



\section{PA RT VI \\ CONDENSED MILK DEFECTS, THEIR CAUSES AND PREVENTIONS}

\section{CHAPTER XXIII \\ CLASSIFICATION OF DEFECTS}

If we recognize in fresh cow's milk an article of food, highly complex in composition, subject to many and complex changes and to rapid deterioration unless handled carefully and skillfully, then the successful manufacture of condensed milk, a product more complex in it composition and exposed to more diverse, more varying and, in most cases, more unfavorable conditions than fresh milk, must involve a knowledge that extends beyond the mere mechanical knack of heating, adding sugar, evaporating, sterilizing, cooling, filling, sealing and packing.

The simplicity of the process tends to belittle and hide the complexity of the product. Anybody can acquire the routine knowledge of condensing milk, but few can make a uniformly good quality of condensed milk. It, therefore, happens that defective condensed milk is made now and then in most, if not all condenseries, and that the output of a poor quality of condensed milk is not necessarily the exception, but quite often the rule.

Nany are the defects which cause condensed milk to be rejected on the market and numerous are the aventues that may lead to the manufacture of defective milk. The milk faults may be of mechanical, physical, chemical, or bacteriological origin, or they may be due to a combination of two or more of these forces. In some instances the defects can be detected in milk during, or immediately after the process, in which case they may be remedied, or their recurrence prevented. But more often, several weeks may pass before abnormalities develop and before the manufacturer realizes that something is wrong with the milk. In the meantime, the conditions which originally produced the milk defect may have so changed, that it is exceedingly difficult to locate the seat of the original trouble. 


\section{DEFECTIVE SWEETENED CONDENSED MILK}

The following are the chief and most common defects of swectened condensed milk:

I. Sandy, rough or gritty

2. Settled

3. Thickened and cheesy

4. Lumpy, white or yellow buttons

5. Blown or fermented

6. Rancid

7. Putrid

8. Brown

\section{Sandy, Rough or Gritty Sweetened Condensed Milk}

GENERAL Description.-This is condensed milk in which a portion of the milk sugar has been precipitated in the form of crystals, the size of the crystals depending on the conditions causing crystallization. First-class sweetened condensed milk is smooth and velvety. Such milk is not entirely free from sugar crystals, but they are so minute in size that they do not rob the condensed milk of its natural smoothness. In sandy or gritty condensed milk the crystals are very numerous and large enough to grind between the teeth, similar to salt crystals in gritty butter. The presence of these crystals is also noticeable to the naked eye; the milk looks candied.

Causes and Prenention.-The sugar crystals which render the condensed milk rough and sandy consist largely of milk sugar. The solubility of milk sugar is relatively low. Milk sugar requires about six times its weight of water at ordinary temperature for complete solution. Condensed milk contains from 12.5 to i 5 per cent. milk sugar and only about 26.5 per cent water. The ratio of milk sugar to water in sweetened condensed milk, therefore, is $1: 2$, while for complete solution it should be $\mathrm{I}: 6$. The milk sugar in this product is present in a supersaturated solution and any condition which favors sugar crystallization strongly tends to precipitate this milk sugar, because there is more of it present in the milk than the available water is capable of readily keeping in solution. The chief factor that prevents the milk sugar from precipitating very badly is the great viscosity of the condensed milk. This is largely due to the caseous matter and the cane sugar. 
Cane Sugar Content.-It has been argued that the large amount of sucrose which sweetened condensed milk contains, is the principal cause of sandy milk and of sugar sediment in the bottom of the tin cans, and that a reduction in the amount of sucrose lessens the tendency of the sugar to crystallize and the milk to become sandy. This line of reasoning is erroneous. The presence, in water, of sucrose in solution does not materially lessen the power of the water to dissolve milk sugar, provided that the sucrose solution is not a saturated one. Sweetened condensed milk, contains about 35 to 45 per cent. sucrose and 24 to 28 per cent. water. Sucrose dissolves in one half its weight of water. The sweetened condensed milk does not, therefore, contain a saturated solution of sucrose.

The chief factors causing milk sugar crystallization and sandy condensed milk are: incomplete solution of the sucrose, excessive chilling in the vacutum pan, superheating in the vacuum pan, improper cooling, excessive stirring, and warming up too cold condensed milk with the help of agitation.

Incomplete Solution of Sucrose.-If the finished product is to be smooth and free from sandiness, it is essential that the sucrose which is added to the hot, fresh milk be thoroughly dissolved before the mixture reaches the vacuum pan. Undissolved sugar crystals in a medium as highly concentrated as sweetened condensed milk have much the same effect in a physical way, as have bacteria in fresh milk in a biological way; they multiply rapidly. Therefore, if all the sugar added to the fluid milk is not completely dissolved, the undissolved sugar crystals give rise to wholesale precipitation of the milk sugar in this product after manufacture. Complete solution of the cane sugar can best be accomplished by heating the liquid, milk or water, in which the sugar is to be dissolved, to the boiling point and by boiling the mixture for several minutes; or by placing the sugar on a large wire mesh strainer (about eighty meshes to the inch) which stretches across the sugar well and allows hot milk to run over this sugar into the well below. In this way the sugar crystals must dissolve before they can reach the sugar well.

One of the safest methods of insuring complete solution of the cane sugar is to dissolve it in a separate kettle in a sufficient quantity of boiling water (preferably distilled water) and boiling the syrup for five to fifteen minutes. If the syrup thus made is given 
a few minutes rest it should become perfectly clear; by its clearness, the purity of the sugar can also be observed. If a scum forms at the top it should be removed; then the hot sugar syrup is drawn into the pan. Care should be taken that the milk already condensing in the pan has not become too concentrated, otherwise sugar crystallization may set in. It is advisable to inject the sugar syrup gradually, rather than to wait until nearly all the milk is in the pan.

E.rcessize Chilling in the Pan.-The cause of grittiness of con(lensed milk may lie in the pan itself. Where the water used for condensing is very cold, and where one end of the spray pipe in the condenser is very close to the goose neck of the pan, as is the case with most of the vacuum pans in use, the chilling of the vapors and of the spray of milk rising from the pan is so sudden, that sugar crystals are prone to form in the spray and along the walls of the pan. These crystals either stick to the side of the pan, or fall back into the milk where they later multiply and cause the milk to become sugary. Trouble from this source can be avoided by either raising the temperature of the water that goes to the condenser which is, however, not practical under most conditions, or by closing the holes in that portion of the spray pipe which is nearest the pan. This can easily be done by wrapping a piece of galvanized iron or tinplate around the portion of the spray pipe to be closed, or by filling the holes with solder, or by replacing the old spray pipe by a new and shorter one, properly constructed.

Superheating at End of Batch.-Sometimes the manufacturer is persistently troubled with the appearance of crystals in the condensed milk of monstrons size, as large as rice kernels: this condition arrives usually very gradually. During the first few days after manufacture, only a few of these large crystals may appear in some of the cans. In the course of a few weeks, all of the cans may contain specimen of these "rice crystals" which increase in number until the entire contents of the cans are one mass of "rice crystals," rendering the milk unsalable. The direct causes of this particular kind of sugar crystallization are excessive concentration of the condensed milk, the use of too much steam pressure in the coils and jacket when condensation is near completion, delay in the drawing off of the condensed milk from the pan, and leaky steam valves in the pipes leading to jacket and coils.

Toward the end of the condensing process the milk becomes 
heavy, thick and syrupy, and boils with much less violence. If, at this stage of the process, excessive steam pressure is used in the jacket and coils, the milk is superheated, often causing the precipitation of "rice crystals." Again, where the finished condensed milk is drawn from the pan very slowly, either owing to too small an outlet in the bottom of the pan, or because the milk is forced to run through a strainer attached to the outlet, or because the finished condensed milk is retained in the pan as the result of an accident, in all of these cases there is langer of superheating, and therefore, of the production of these large crystals. This danger is especially great, where the valves of the steam pipes leading to the jacket and coils are leaking, as is often the case. The avoidance of excessive concentration and the removal of any conditions that tend to expose the finished condensed milk to excessive heat will usually prevent further trouble of this sort.

Improper Cooling.-The method used for cooling the sweetened condensed milk after it leaves the vacuum pan is another important factor determining the smoothness or grittiness of the finished product. The chief principles involved here are the rapidity and extent of cooling and the amount of agitation to which the condensed milk is subjected.

In order to fully appreciate the importance of strict attention to details in the cooling process of sweetened condensed milk, it should be understood, that the formation of sugar crystals in concentrated solutions is enhanced by sudden chilling and by excessive agitation of these solutions. The sudden and irregular chilling of a part or all of the sweetened condensed milk in the cooling cans is the result of the use of badly dented cans, poorly fitting paddles, a warped condition of the pivots on which the $\operatorname{cog}$ wheels in the bottom of the cooling vat revolve, too cold water, and the application of too much cold water.

The paddles must scrape all parts of the sides of the cans, from top to bottom. This is possible only when the cans are intact and their sides are smooth and free from indentations. The paddles must be adjusted properly so that their edges fit snugly against the sicles of the cans, they must be firmly fastened to the cross bars and forced against the sides of the cans by springs. In order that the cans may run true they must properly fit into the rim of the cog wheels in the bottom of the cooling vat and the pivots on which the 
$\operatorname{cog}$ wheels revolve must be perpendicular. If the pivots are warped, the $\operatorname{cog}$ wheels cannot run true and the cans wobble; this causes uneven and incomplete scraping of the sides of the cans by the paddles.

The water in the cooling vat should not be cold, but have a temperature of about 90 degrees $\mathrm{F}$. when the cans, filled with the hot condensed milk, are set into the vat. The cold water should flow into the vat slowly and be evenly distributed throughout the vat. This is best accomplished by the installation of a perforated pipe running the entire length of the vat. The cooling must be gradual. It should occupy about two hours.

Excessive Stirring.-The cans should revolve slowly. Rapid revolution causes excessive agitation of the condensed milk, which stimulates the formation of crystals. About five revolutions per minute is satisfactory. In order to make more effective the proper scraping of the cans by the paddles when the cans revolve slowly, it is advisable to install two paddles in each can, touching the periphery of the can on opposite sides.

When the milk has been cooled to between 60 and 70 degrees F., the water should be drawn from the cooling vat, or the cans should be removed at once.

Warming Up of Too Cold Condensed Milk.-Finally, if the condensed milk is cooled to too low a temperature, either by mistake, or as the result of the cans of cooled milk standing in a very cold room over night, so that the condensed milk is too thick to run through the filling machine, it is best to warm it up by simply allowing it to stand in a warm room. The practice of setting the cans back into the cooling tank and revolving them in warm water is objectionable, since this stirring of the milk, while it is warming, seems invariably to produce wholesale sugar crystallization, and therefore, causes the condensed milk to become very gritty.

\section{Settled Sweetened Condensed Milk}

General Description.-By the term "settled milk" the condensed milk man refers to condensed milk which has precipitated and thrown down a portion of its sugar, forming a deposit of sugar crystals in the bottom of the can or barrel. This deposit may vary in amount from a very thin layer to a layer an inch deep or more, according to the character and age of the milk. The na- 
ture of this sediment also differs in different cases of settled milk. It may be soft, and upon stirring may mix in and dissolve readily, or it may be very dry and hard, in which case it sticks to the bottom of the can with great tenacity, and can be removed and mixed into the milk with difficulty only. Like gritty milk, settled milk is a very common condensed milk defect. Though it does not render the product less wholesome, it is an undesirable characteristic. Such milk is usually rejected on the market and results in a partial loss to the manufacturer.

Causes and Prevention.-It is obvious, for reasons above referred to, that the conditions leading up to the production of settled milk, are closely related to those that cause milk to become gritty. Condensed milk cannot drop its milk sugar, unless the latter is present in the form of crystals. The absence of crystals then, means that condensed milk will not settle; but experience has shown that it is a practical impossibility to manufacture sweetened condensed milk which contains no sugar crystals. Sugar crystals are always present in it, and the fact that the milk is not sandy or gritty, does not necessarily mean that it will not settle. Nevertheless, the removal of conditions conducive of sandy or gritty milk, diminishes the tendency of the formation of sugar sediment. The successful and uniform production of condensed milk that does not settle, however, involves additional conditions that are not controlled by the factors causing gritty milk.

Effect of Density on Sugar Sediment.-One of the chief of these conditions is the density of the condensed milk. The thinner the condensed milk, the greater the difference between the specific gravity of the liquid portion and that of the sugar crystals; therefore, the more readily will the crystals sink to the bottom. The viscosity of thin condensed milk, also, is less than that of thick milk, offering less resistance to the force of gravity of the crystals. In the manufacture of sweetened condensed milk that has the proper density, about 2.5 to 2.8 parts of fresh milk are condensed into one part of condensed milk. If the evaporation is stopped sooner, so that the ratio is much less than 2.5 to $\mathrm{I}$, the condensed milk is usually too thin to hold its sugar crystals in suspension.

Effect of Fat Content on Sugar Sediment.-The per cent. of fat in milk, also, influences the specific gravity of the condensed milk, and therefore, has some effect on the settling of the sugar crystals, 
although to a relatively slight degree. Nevertheless, sweetened condensed skimmed milk will settle less readily than sweetened condensed whole milk.

Eiffect of Cane Sugar Content on Sugar Sediment.-The per cent. of cane sugar materially influences the specific gravity and viscosity of the condensed milk. Milk with a high per cent. of sucrose is heavier, more viscous and drops its sugar crystals less rapidly than milk with a low per cent. of sucrose.

Turning the Cans to Prezent Sugar Sediment.--Concerns who have been continually troubled with settled milk often resort to the practice of turning their cases daily, or at other regular intervals. This keeps the precipitated crystals in motion, but it does not prevent the settling entirely. Moreover, milk destined to settle, as the result of defects in the process, cannot be prevented from dropping its crystals after it leaves the factory. Some concerns have stooped to printing on their labels statements similar to the following: "A sediment in the bottom of this can indicates that this condensed milk is absolutely pure and free from harmful ingredients." Advice of the above denomination is obviously ridiculous as well as untrue.

\section{Thickened and Cheesy Sweetened Condensed Milk}

General Description.-The term "thickened and cheesy" condensed milk applies to condensed milk that has become thick and in some cases solid. This is a very common trouble with milk manufactured in late spring and early summer. The milk thickens soon after its manufacture and continues thickening until it assumes the consistency of soft cheese, without the development of acid. In this condition it usually has a peculiar stale and cheesy flavor, disagreeable to the palate of the consumer. Such milk is invariably rejected on the market.

Causes and Prevention: Effect of Colostrum on Thickening. -It has been suggested that this spontaneous thickening is due to the presence in the fresh milk of colostrum milk, because this defect appears at a time when the majority of the cows supplying the condensery freshen. This explanation can hardly be considered correct and there is no experimental evidence available substantiating it. If the presence of colostrum milk were the cause of it, the thickening would take place during the process, as the result of the action of heat on the albumenoids. This is not the case. This thickening be- 
gins some days and often some weeks after manufacture and increases as the milk grows older.

Effect of Cow's Feed.on Thickening.-Again, the cause of this defect has been attributed to the change in feed, the cows being turned from dry to succulent feed at the time when this tendency of the condensed milk to thicken occurs. There is no reliable evidence, however, of how the succulent pasture grasses on which the cows feed can bring about this thickening action in the condensed milk.

Effect of Bacteria on Thickening.-A third and far more reasonable explanation is that this thickening is the result of a fermentation process. It is quite probable that the thickening of sweetened condensed milk is closely related to the sweet-curdling fermentation in fresh milk. The sweet-curdling of fresh milk is a fermentation characteristic of, and frequent during late spring and summer. It is caused by certain species of bacteria which are capable of producing a rennet-like enzyme, which has the power to curdle milk in the sweet state. These bacteria are known to be closely associated with dirt and filth, especially from the feces, and gain access to the milk usually on the farms where the production and handling of milk is not accomplished under most sanitary conditions.

It is further known, as the result of analyses that, in spite of the large per cent. of cane sugar which sweetened condensed milk contains, the bacteria in it increase with the age of the milk. The thickening of the sweetened condensed milk in early summer, therefore, very probably is the result of a slow curdling of its casein, caused by enzymes which are produced by bacteria. It has further been demonstrated that condensed skim milk thickens more readily than condensed whole milk, which may be explained by the fact that condensed milk without butter fat represents a more favorable medium for bacterial growth. Furthermore, it has been conclusively demonstrated by the writer and others that the addition of cane sugar to condensed milk, in excess of that present in normal condensed milk, greatly retards thickening. This fact suggests that the higher per cent. of sucrose has an inhibiting effect on the enzyme-producing bacteria, and perhaps, on the action of the enzyme itself. This condensed milk defect can be prevented entirely by using, during the summer months, eighteen pounds of sucrose per one hundred 
pounds of fresh milk, so that the condensed milk contains about 45 per cent. sucrose.

Owing to the poor keeping quality of the summer condensed milk, it is advisable not to store any milk made during these months, but to sell it, even at a small margin, as fast as it is manufactured.

Effect of Finishing in Pan I'ith High Steam Pressure on Thickening.-Abnormally thick condensed milk is also the result of overheating the condensed milk in the vacuum pan toward the close of the process. The batch should be finished with low steam pressure in the jacket and coils, not to exceed five pounds of pressure, and the milk should be drawn from the pan at once after condensation is completed.

Effect of Age on Thickening.-Finally, all sweetened condensed milk has a tendency to thicken with age. Exposure to high storage temperature (summer heat) hastens this action. The rapidity of thickening in storage increases with the increase in temperature. This tendency is very much reduced, therefore, by protecting the goods from high temperatures and by storing them below 60 degrees F. (See Chapter on "Storage," page I I2).

\section{Lumpy Sweetened Condensed Milk}

General Description.-Lumps of varying denominations are not infrequently found in sweetened condensed milk. They may be soft and permeate the contents of the can throughout, or may appear especially in the form of a "smear" along the seams of the can; or again, they may float on the surface, in which case they are usually hard and cheesy, and either white or yellow in color. Their presence gives the contents of the can an unsightly appearance at best. and in many cases, they spoil its flavor. They naturally suggest to the consumer that something is wrong with the condensed milk, and cause him to reject the whole package.

Causes and Prevention.-The chief causes of lumpy condensed milk are: poor quality of fresh milk, unclean pipes in factory, milk from fresh cows, acid flux in tin cans, and unclean and contaminated tin cans.

Poor Quality of Fresh Milk and Unclean Factory Conditions.Upon opening the can of condensed milk, even shortly after it is filled, the lid is covered with large and small lumps and specks stick- 
ing to the tin, presenting a very uninviting appearance. This condition can usually be traced back to a poor quality of fresh milk, containing too much acid. Very often, too, the cause lies in the factory itself, where it is due to lack of cleanliness. A thorough inspection of milk tanks, milk pipes and pumps generally shows accumulations of remnants of milk which get into the milk of the succeeding batch. Where this condition exists, it is noticeable that the first batch of the day contains more specks and lumps than the succeeding ones. These lumps do not, as a rule, grow larger in size nor increase in number with the age of the condensed milk, but they injure its appearance to the eye, and certainly cannot add to the wholesomeness of the milk. They might easily become the cause of the formation of ptomains. A more rigid inspection of all the fresh milk as it arrives at the factory and a thorough scouring of all milk tanks and milk pumps, pipes and conveyors usually prevents the recurrence of this defect.

Milk From Fresh Cocis.-During early spring there is a strong tendency of the jacket and coils in the vacuum pan to becone coated with a thick layer of gelatinous and lumpy milk. This is probably due to the fact that milk during these months comes largely from freshened cows and may contain some colostrum milk which coagulates when subjected to heat, or that the proteids of milk from these fresh cows are abnormally sensitive to heat. This thickened material usually does not leave the pan until most of the condensed milk has been drawn off. It, therefore, appears in the last one or two cooling cans. If the milk in these cans is mixed with the rest of the condensed milk, the lumps will appear again in the tin cans. The last cans drawn from the pan should, therefore, be kept separate. The contents of these remnant cans may be redissolved in hot water and should be recondensed in a succeeding batch. In this way the manufacturer sustains practically no loss. In order to prevent these lumps from getting into the cooling cans, some factories attach a strainer to the outlet of the pan. This practice is as unnecessary, as it is damaging to the milk in the pan. The straining greatly retards the removal of the milk from the pan, and the milk is held in the hot pan so long, as to cause partial superheating which is otherwise detrimental to its quality. 


\section{COMPARATIVE COMPOSITION OF GELATINOUS COATING OF THE JACKET AND COILS AND OF NORMAL CONDENSED MILK OF THE SAME BATCH, MADE APRIL 23, 1908}

Coating of jacket and coils

Moisture

Lactose

Fat

Curd

Ash

Acid

Sucrose
24.76 per cent.

I3. 12

$9 \cdot 5^{0}$

8.14

I. 42

.33

$+1 \cdot 36$

98.63 per cent.
Normal condensed milk

30.34 per cent. 13.16 "

$\begin{array}{rc}7.44 & \text { “ } \\ 7.30 & \text { “ } \\ 1.80 & \text { “ } \\ .40 & \text { “ } \\ 40.02 & \text { “ }\end{array}$

Ioo. 46 per cent.

The above analyses were made in order to determine the difference in chemical composition between that part of the batch which, in the spring of the year, forms a gelatinous coating on the jacket and coils and that part which remains normal. The figures do not show as great a difference, as the physical comparison of the two products would suggest. Possibly the most significant point these analyses show is that, while the proteicls in the coating are higher, the ash is lower than in the normal condensed milk.

A large portion of the ash of milk is present in chemical combination with the casein, which does not curdle by heat, while the albumin, which is coagulated by heat, contains only a very small amount of ash. Therefore, the fact that an increase in the proteids of this gelatinous coating is accompanied by a decrease in the ash content, would suggest that the proteids of the coating of the jacket and coils consist of more albumin and less casein than the proteids of the normal condensed milk of the same batch. Since this coating of the jacket and coils occurs only in the spring of the year, when most of the cows freshen, it is reasonable to assume that this coating is the result of the acceptance at the factory of milk too soon after calving and which contains excessive quantities of proteids and other substances which are highly sensitive to heat, such as albumin, colostrum, etc.

E.rcess of Acid in Condensed Milk and Acid Flur in Tin Cans. -The presence in the condensed milk of organic and mineral acids, 
in excess of the amount which normal fresh milk contains, is conducive of the formation of lumps.

Excessive amounts of acid in condensed milk may be the result of fermentations, ustually due to a poor quality of sugar, or of the use of acid flux in the making and sealing of the tin cans. Condensed milk that shows acid or gaseous fermentation usually contains lumps. The acid which it develops as the result of the fermentation, curdles the casein with which it comes in contact.

One of the most common channels through which condensed milk may become contaminated with acid mechanically, is the use

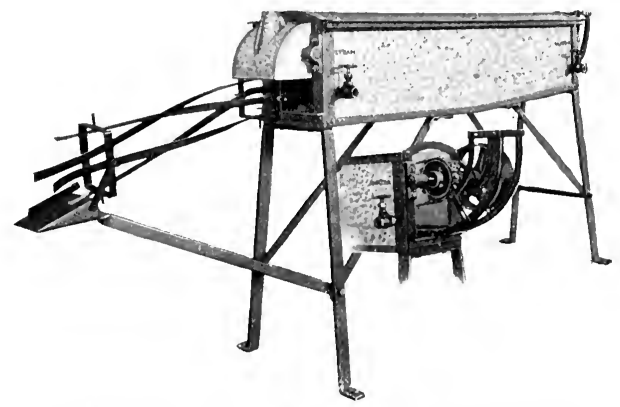

Fig. 49. Machine for rinsing and sterilizing the tin rans Courtesy of The Sprague Canning Machinery co.

of cans, in the manufacture of which acid flux was used. The acid flux generally used contains zinc chloride. The flux precedes the solder and some of it is bound to sweat through the seams into the interior of the cans. Zine chloricle is a highly poisonous product and its use in the manufacture of tin cans, which are intended for receptacles of human food, should be prohibited by law. Aside from its injurious effect on the health and life of the consumer, its presence, even in small quantities in condensed milk, is a detriment to its market value. In such cans there accumulate, usually along the seams, lumps and smeary substances which have been found to consist of casinate of zinc.

Nost commercial soldering fluxes consist largely of zinc chloride and are highly acicl, although many of these are advertised as acid-free fluxes. In order to avoid condensed milk containing 
lumps from this source, cans should be used, in the manufacture of which a strictly acid-free flux is used and which are sealed with acid-free flux. Dry, powdered resin or resin dissolved in alcohol or gasoline are harmless in this respect and are just as effective fluxes, as acid flux.

Unclean and Contaminated Tin Cans.-Finally, there frequently appear in sweetened condensed milk, species of lumps which are firm and cheesy and which usually float on top of the milk in the can. These are called buttons. Some are white, others are yellow. These buttons appear in old milk more frequently than in milk that has been in storage for a short time only. They grow in size and sometimes one "button" covers the entire surface of the condensed milk in the can. Their origin is not well understood, but they are supposed to be the result of fungus growth. It is not improbable that they are produced by molds, the spores of which gain access to the condensed milk in the factory, or to the cans before they are filled. These "buttons" appear in the canned goods and in the barrel goods. Their occurrence can be minimized by protecting the condensed milk and the empty cans from dust and other impurities or by sterilizing the cans immediately before use, and by paraffining and thoroughly steaming the barrels before filling.

\section{Blown, or Fermented Sweetened Condensed Milk}

Generat, Description.-One of the most disastrous troubles in the manufacture of sweetened condensed milk is the appearance of "swell heads." This term is applied to cans of condensed milk, the contents of which have undergone gaseous fermentation, the resulting pressure causing the encls of the cans to bulge or swell, and frequently to burst open the seams. In the case of barrel goods, the pressure may cause the barrel head to blow out. This gaseous fermentation is usually, though not always, accompanied by the development of acid and the formation of lumps.

This fermented milk is worthless for any purpose and means a total loss to the manufacturer. The loss is generally angmented by the fact that this trouble does not become noticeable at once; its development requires several weeks, so that large quantities of condensed milk may have been manufactured before it is apparent that the milk is defective. Some of the goods may have reached the market before the cans begin to swell, in which case the repu- 
tation of the respective brand is jeopardized. In some instances entire batches show this defect, while in others only a few cans or cases of each batch are blown.

Causes and Prenention.-This defect may be brought about through various channels. In most cases it is lue to contamination of the milk, on the farm or in the factory, with specific microorganisms which are capable of fermenting one or more of its ingredients, in spite of the preservative action of the sucrose; or the condensed milk may contain highly fermentable substances such as glucose or invert sugar, so that the germs normally present in the condlensed milk become active and produce gas; or the milk may not be condensed to a sufficient degree of concentration, or may not contain adequate quantities of sucrose, to render it immune to the bacteria normally present. The cans may also bulge without bacterial action, as the result of exposure to a wille range of temperatures, causing mechanical contraction and expansion of the contents.

Contamination IVith Specific, Gas-Producing Bacteria and $Y$ cast.-This is by far the most common cause of blown milk. While the micro-organisms which, under normally sanitary production of milk and factory conditions, gain access to the condensed milk, are largely inhibited and to not ferment the sweetened condensed milk, there are certain specific forms of bacteria and yeast whose growth is not retarded by the concentrated sugar solution of this product. Contamination of the condenser milk with these specific organisms is usually the result of highly unsanitary conditions in the handling of the condensed milk.

The products of fermentation depend on the particular type and species of micro-organisms involved. In most cases the sucrose is the chief constituent attacked, but the lactose, also, is capable of gaseous fermentation, though instances of lactose fermentation in sweetened condensed milk are not common.

The gaseous fermentation of lactose is largely caused by bacteria, yeast and molds which contain the lactose-splitting enzyme "lactase," which has the power of hydrolyzing the lactose. While the species of organisms which cause lactic acid fermentation from lactose are very numerous, those containing the enzyme lactase and thereby causing gaseous fermentation from lactose, are less frequent, at least, as far as their access to milk and condensed milk is 
concerned. It is generally understood, though not experimentally proven, that species of micro-organisms which do not contain the enzyme lactase have no gas-producing action on lactose.

The great majority of cases of gaseous fermentation of sweetened condensed milk are the result of the action of micro-organisms on the sucrose, especially those which contain the enzyme "invertase." The majority of yeasts secrete invertase and ferment sucrose. producing alcohol and carbon dioxide to the same extent as in the case of glucose fermentations. The process is considerably slower, however, especially at the start, owing to the fact that inversion of the sucrose must precede fermentation. For this reason gaseous fermentations of sweetened condensed milk do not become noticeable until the product is one or several weeks old.

Contamination I'ith Ycast on the Farm.-In most cases of yeast fermentations of sweetened condensed milk, the source of contamination lies in the factory. While such contamination may and often does occur on the farm, the yeast cells, though they may be spore-bearing, are destroyed by the heat to which the fresh milk is subjected in the forewarmers and before it reaches the vacuum pan. The thermal death point of all forms of yeast which have come to the attention of the writer in connection with a vast number of investigations of fermented condensed milk was below i 80 degrees $\mathrm{F}$. If all the milk is properly heated in the forewarmers to Igo degrees $\mathrm{F}$. or over, there is, therefore, little danger of fermented milk, caused by contamination of the fresh milk on the farm with yeast. If, however, the heating is incomplete, or if some of the milk passes into the vacuum pan without having been properly heated, there is danger of milk, contaminated with these yeasts, to result in fermented condensed milk.

Contamination with Ycast in the Factory--As previously stated, yeast fermentation of condensed milk can almost invariably be traced back to contamination in the factory. After the milk leaves the forewarmers, or hot wells, it is never again heated to temperatures high enough to destroy these destructive yeast cells. The channels through which yeast contamination may occur in the factory are many.

Contaminated Sugar.-The sucrose itself may be contaminated with yeast. This is frequently the case and especially so if the sugar 
is exposed to dampness, and if flies, bees, ants or cockroaches have access to it.

Again, the sugar may reach the milk through a sugar chute. The lower end of the chute is usually located directly over the steaming milk in the hot well. The vapors arising from below may be condensed in the chute, causing its inside walls to become damp, and sugar will adhere to the damp surface, forming a crust. If the crust is not removed daily, its contamination with yeast and other dangerous micro-organisms is almost inevitable and whenever this crust peels off and drops into the milk, the contamination may be carried into the finished product, giving rise to gaseous fermentation.

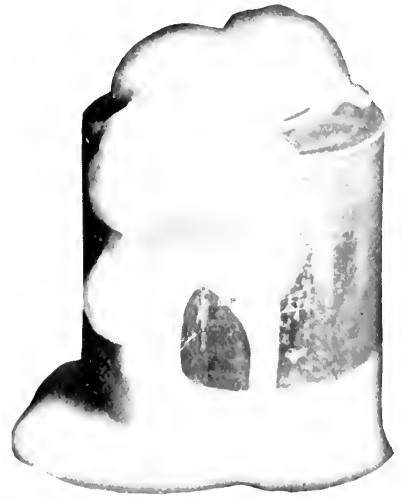

Fig. 50. Gaseous fermentation in sweetened condensed milk

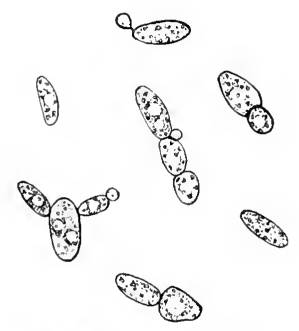

Fig. 31. Veast cells causing gaseous fermentation

This species is capable of fermenting sugar solutions containing $85 \%$ sucrose

Contaminated Machinery and Milk Cone'cyors.--Remnants of milk may lodge in the condenser, in the vacuum pan, in the pipes conveying the milk and conclensed milk, in the cooling cans or coils, in the supply tank of the filling machine, or the filling machine itself. These remnants are all subject to contamination and nay become the source of fermented condensed milk. The strictest attention to scrupulous cleanliness and continuous inspection of all parts of conveyors and apparatus which come in contact with the milk are the only consistent safeguards against trouble from this source.

Contamination Through "Cut-opens". - It is customary to empty the contents of sample cans which are cut open for any purpose, 
back into the condensed milk of succeeding batches. If these samples happen to be contaminated with the fermenting germs, the defect is naturally propagated from batch to batch and it is exceedingly difficult to locate the source of the trouble. It is obvious that all suspicious "cut-opens" should be rejectec and that all "cut-opens" that are utilized should be emptied into the hot well where their contents are boiled up again.

Dangerous Effect of Poor Quality of Sugar.- Sweetened condensed milk is not sterile. There is no part of the process that would render it sterile and, from the time it leaves the vacum pan to the time when the tin cans are hermetically sealed, it is exposed to ,contamination with microbes, even though the factory observes the most rigid attention to scrupulous sanitation and cleanliness. Most of these microbes are harmless and their growth is inhibited by the preservative action of the cane sugar. If, however, a poor quality of sucrose is used, which may contain traces of invert sugar, or acid, etc., many of these common species of micro-organisms, harmless in normal condensed milk, find an opportunity to develop and cause gaseous fermentation. The presence of invert sugar makes unnecessary the action of invertase in order to start fermentation; thus, microbes which do not secrete invertase and are otherwise harmless, may become detrimental in the presence of invert sugar, added to the milk in the form of a poor quality of cane sugar. In a similar way the use in condensed milk of commercial glucose, as a substitute of a part of the cane sugar, and in order to reduce the cost of manufacture, is bound to cause disastrous results. Nothing but the best refined, granulated sucrose should be used, the best is the cheapest.

Dangerous Effect of High Acid in Milk.-Acids have the power of inverting sucrose. The inversion by acid is especially active in the presence of heat. The milk in the vacuum pan is condensing at I30 to ${ }^{5} 50$ degrees $F$. These temperatures are most favorable to inversion of a portion of the sucrose in the presence of acid. The higher the acid content of the milk, the more active is the inversion. Since invert sugar is the very ingredient necessary to cause bacterial action in the finished product, it is essential that the acidity of the milk to be condensed, should be held down to the minimum in order to avoid trouble from this source. 
Contamination with Butyric Acid Bactcria.-Frequently the troublesome microbe is not a yeast, but belongs to a species of bacteria highly resistent to heat, and which fail to be destroyed by heating the milk to the boiling point. In this case, the contamination usually originates on the farm. Organisms of this kind, which infest the milk on the farm in this connection, largely belong to the butyric acid group. The most prominent among them are Granulobacillus saccharo-butyricus mobilis or Bacillus saccharobutyricus, Bacillus esterificans, Bacillus dimorphobutyricus. The putrefactive forms of butyric acid organisms, such as Bacillus putrificus, Plectridium foetidum, Plectridium novum, etc., do not seem to thrive in sweetened condensed milk.

The contamination may occur from dust of hay and other fodder, grain, bedding, or the unclean coat of the udder and surrounding portions of the animal, or from milking with wet and unclean hands, or from remnants of milk in unclean utensils.

It is noticeable that the great majority of cases of blown milk appear during late summer and early fall, when the crops are harvested and the air in the barn is frequently loaded with dust from the incoming crops. Gelatin plates exposed in the stable before and during the filling of silos showed an enormous increase of colonies on the plates exposed during the filling of the silos. Milk drawn under such conditions is naturally subjected to excessive contamination, unless special precautions are observed.

A very common source of these butyric acid organisms also is remnants of milk in pails, strainers, coolers, cans and any other utensils with which the milk may come in contact, also polluted water used for rinsing the utensils. The cheese-cloth strainer, owing to the fact that it is difficult to thoroughly clean and that it is very seldom really clean, is a very serious menace in this respect. Under average farm conditions, unless a new cloth strainer is used at each milking, it is safe to condemn it entirely and to recommend the use of a fine wire mesh strainer containing about eighty meshes to the inch. On some farms the milk is held in a set of old cans which are kept on the farm and which never reach the can washer at the factory. Just before hauling time these cans are emptied into the clean cans from the factory. These old cans are often not washed properly and sometimes not at all. The remnants of milk in these cans breed these undesirable germs and contaminate the 
fresh milk. It is obvious that such a practice is bound to jeopardize the quality and life of the finished product and may constitute a continuous cause of blown milk.

Effect of Amount of Sucrosc.-Since the sucrose contained in sweetened condensed milk is the chief agent preserving it, it is obvious that enough of it must be added to insure adequate preservative action. Experience has shown that about 39 to 40 per cent. of sucrose is required to preserve the condensed milk under average conditions. A higher per cent. of sucrose would naturally intensify the preservative action and inhibit the growth of the bacteria normally present more completely; but if enough sugar were added to also inhibit the growth of and make harmless those violent gas producing butyric acid bacteria and yeast cells, which thrive in sweetened condensed milk containing 40 per cent. sucrose, the product would be objectionable from the consumer's point of view. The logical avoidance of "swell heads" as the result of these undesirable germs, therefore, must ever lie in prevention, rather than cure. The sanitary standard of production on the farm and of the process in the factory must be raised to and maintained on a level where the milk is protected from contamination with these microorganisms.

The writer ${ }^{1}$ has isolated yeast from fermented sweetened condensed milk that produced vigorous gas formation in media containing as high as 85 per cent. sucrose (600 grams sucrose in 100 c.c. whey bouillon).

Effect of Too Thin Condensed Milk.-Condensed milk that is too thin is, also, prone to start fermenting, since it is deficient in the chief preserving agents, i. e., density and per cent. of sucrose. It is not safe to put goods on the market, with a ratio of concentration much less than $2.5: \mathrm{I}$.

Effect of Exccssizely Low Tcmpcratures.-The cans of sweetened condensed milk may also bulge in the case of cans with nonhermetical seals, exposed successively to excessive cold and to room temperature. In this case, the condensed milk is entirely normal and unaffected, and the bulging is the result of mechanical contraction and expansion by cold and heat. This is possible only where the seal of the cans is not entirely hermetical. In the case of

\footnotetext{
${ }^{2}$ Hunziker, Results not published
} 
the Gebee seal with the burr cap, and the McDonald seal with the friction cap, the seal is not absolutely air-tight. While the pores between cap and can are microscopic in size, and not large enough to permit the contents from leaking out, they are sufficient to admit air. The cans are usually filled with the condensed milk at a temperature of about 70 degrees F. If the filled and sealed cans are exposed to a very low temperature, as may be the case in winter, in store houses or in transit, the milk and the air in the cans contract. This contraction is intensified by the fact that the sweetened condensed milk does not freeze. Its concentration is so great that its freezing point is usually below the most extreme cold storage temperature. This contraction of milk and air in the cans produces a partial vacuum, causing air to be drawn into the cans through the microscopic openings of the seal. When the cans are subsequently moved into places with a more moderate temperature, the milk and the air in the cans expand, but the milk on the inside of the cans forms a seal preventing the escape of the surplus air. The result is that the ends of the cans bulge. This phenomenon has been experimentally determined by the author. ${ }^{1}$ While the contents of such cans are perfectly normal, the package suggests fermented milk and may be rejected on the market.

It is evident, from the above data, that the swelling of the cans, as the result of exposure to excessively low temperatures, can readily be avoided, either by protecting the cans against excessive cold, or by using cans that are sealed with solder. The solderseals are hermetical so that no air can be drawn into the cans when a partial vacuum is formed in their interior as the result of the contraction of air and milk.

\section{Rancid Sweetened Condensed Milk}

Gener.il Description.-Sweetened condensed milk may develop a distinctly rancid flavor and odor, a defect which renders it unmarketable.

Causes and Prevention. - While the exact causes of the development of rancidity in lairy products are as yet not well understood, it has been demonstrated experimentally that rancidity as well as other allied off-flavors, such as oiliness, tallowiness, fishiness, etc., are closely associated with the decomposition of some of

\footnotetext{
${ }^{2}$ Hunziker, Results not published
} 
the milk fats. Formerly these lefects were attributed to the breaking down of the glycerides of the volatile fatty acids, but more recent experimental lata indicate that the olein is the most unstable fat, owing to the ease with which it yields to oxidation, and that the splitting up of the glycerides of oleic acid in all probability is largely responsible for the different shades of rancidity which develop in dairy products under certain combinations of conditions.

According to the best authorities, there are many agents which may be active in the production of rancidity. The fact that in rancid butter are usually found to predominate certain species of organisms, such as the fungi of Penicilium Glaucum, Penicilium Roqueforti, Cladosporium butyri, Oidium lactis, Actinomycoces odorifora, yeast and various bacterial species, such as Bacterium fluorescens, Bacterium prodigiosum, Bacillus mesentericus, etc, and that these species are capable of making butter rancid, has led to the conclusion that they may be the cause of rancidity, either by direct action, or by the secretion of fat-splitting enzymes. It is, therefore, quite possible that some of these species, or similar groups of species, may be instrumental in developing rancidity in sweetened condensed milk. It has been further found that the milk products from certain individual cows, or cows under certain physiological conditions are more prone to develop a rancid flavor, than milk products from other cows or cows under other conditions.

Other agents capable of decomposing the glycerides of the various fatty acids, and especially of oleic acid, are heat, air and light. Thus, sweetened condensed milk, similar to butter, when exposed at room temperature to light and air will assume a tallowy and rancid flavor very readily. In cold storage this development is retarded. In the dark, it is very slow and the absence of air also hinders this development.

Relation of Polluted II'ater to Rancidity--Polluted and filthy water is usually contaminated with fungi and bacteria belonging to the species enumerated above and which have been found to be able to produce rancidity. It is, therefore, not improbable, where such water is used in the factory in the washing of cans, conveyors. kettles, pipes, etc., in the condenser of the vacuum pan and in the cooling tanks, as is frequently the case, that the contamination of milk with it may result in the development of rancidity. 
Relation of Adulterants to Rancidity.-It has also been experimentally demonstrated that the use, in the process of manufacture, of artificial fats, or commercial glucose developed a distinctly rancid flavor in the finished product.

Relation of Climate to Rancidity.-It is frequently claimed that condensed whole milk shipped to the tropics turns rancid. owing to exposure of this milk, rich in fat, to a warm climate. Advantage is sometimes taken of this argument, to justify violations of the law by skimming all, or a part of the milk before condensing. This matter has been thoroughly investigated. All experimental results show that sweetened condensed milk, made properly and in conformance with the law, and containing all the butter fat of the original whole milk, does not turn rancid at any temperature. The available evidence goes to show that sieges of rancid condensed milk are usually the result of the addition to the product of adulterants. When, in the manufacture, nothing but pure milk from healthy cows and the best refined granulated sucrose are used and due attention is given to reasonable cleanliness in the factory, the product is not in danger of becoming rancicl.

\section{Putrid Sweetened Condensed Milk}

GeNer.l Description.-Sweetened condensed milk is best when fresh. With age it gradually develops a stale flavor which frequently develops into a putrid odor and flavor.

Causes and Prenention.-The purer the fresh milk and the cane sugar, and the more careful the processor, the longer will the condensed milk retain its pleasant flavor, provided that it is stored at a reasonably low temperature. Age, howerer, will cause the best sweetened condensed milk to become stale. The appearance of the stale flavor is usually hastened when heating the fresh milk with direct steam; also, where the fresh milk is not heaterl to a sufficiently high temperature (below I76 degrees F.) the condensed milk will break down rapidly with age, usually developing a putricl flavor and odor. This defect rarely appears where the fresh milk is heated to I 80 degrees $F$. or above. This phenomenon is probably due to the presence in milk of active enzymes, such as galactase, gradlually decomposing the proteids. The action of most of these enzymes is destroyed when the milk is heated to I 76 degrees F. or above. 


\section{Brown Sweetened Condensed Milk}

GenNeral Description.-Some of the sweetened condensed milk on the market has a brown color, suggesting chocolate pudding. In this condition it is usually rejected by the consumer.

Causes and PRerention.-All sweetened condensed milk not held at a low temperature grows darker in color with age. If manufactured properly and not exposed to unfavorable conditions, this brown color appears very gradually and not until the condensed milk is many months old. If exposed to high temperature in storage or transportation, when stowed against the boiler room in the hold of the steamer, or laying on the shelves of the warm grocery store or drug store, etc., it turns brown rapidly. Condensed milk in cold storage retains its natural color indefinitely. Where milk is recondensed (the condensed milk is redissolved either in water or in fresh milk and condensed a second time), the product is always darker in color. This brown color is due to the oxidizing action of heat on both, the lactose and the sucrose, a portion of the sugar caramelizing. Experience has shown that the sugar is more sensitive to the oxidizing action of the heat of recondensing, than when condensed the first time.

\section{CHAPTER XXIV}

\section{DEFECTIVE EVAPORATED MILK AND PLAIN CONDENSED BULK MILK}

The following are the chief defects of unsweetened condensed milk: curdy, grainy, separated and churned, blown or fermented, brown, gritty.

\section{Curdy, Plain Condensed Milk and Evaporated Milk}

General Description.-Curdy, unsweetened condensed milk is a term used for milk in which a part of the casein is precipitated in the form of lumps of various sizes. The appearance of lumps of curd in this product is a defect that may render the goods unsalable.

Causes and Prevention.-Lumps are usually due to a poor quality of fresh milk, the use of excessive heat in the sterilizing process and too high a degree of concentration. 
Lumps in Plain Condensed Bulk Milk.-Lumps are prone to appear in plain condensed bulk milk, as this class of goods is usually made from fresh milk that may be slightly sour, as is the case in creameries and in milk plants where the surplus and the returned milk is often manufactured into plain condensed bulk milk. This defect can be avoided by neutralizing the milk before heating, with an alkali (sodium bicarbonate or lime water), heating less intensely, by not carrying the condensing process quite so far, or by overcondensing before superheating and then diluting with distilled water to the proper density, after superheating. If the plain condensed bulk milk comes from the pan in lumpy condition, it can usually be reduced to a smooth body by passing it through an ice cream freezer at ordinary temperatures.

Lumps of Curd in Ez'aporated Milk.-The danger of lumpiness, or curdiness in evaporated milk is greatly augmented by the fact that, in addition to the causes named under plain condensed bulk milk, the sterilizing process must be dealt with. The high sterilizing temperature used, tends to precipitate the proteids of milk, and the temperature cannot be reduced below certain limits without impairing the keeping quality of the product. Nost of the evaporated milk, after sterilization, is subjected to the shaking process in which the coagulum in the cans is reduced to a homogeneous creamy fluid, provided that the curd is not too hard. A curd will form in the sterilizer in the majority of cases. If it is soft enough, so that it can be completely broken up, no harm is done. If it is so firm that mechanical shaking fails to cause it to disappear, then the evaporated milk will reach the market in lumpy condition and is difficult to sell.

Effect of Quality of Fresh Milk.-The quality of fresh milk is all important in preventing lumpy evaporated milk. The milk must come from healthy cows in good, normal physical condition. It must not contain colostrum milk nor be stripper milk and it must receive the best of care on the farm and reach the factory perfectly sweet. Milk that is not of high quality in every respect should not be received at the factory. ${ }^{1}$

Effect of Concentration.-The more concentrated the evaporated milk, the greater the danger of lumpiness. All the conditions causing lumpiness are intensified by the degree of concentration. The manufacturer must, therefore, study the behavior of his product at

1 For detailed discussion of relation of quality of fresh milk to curdine:s of evaporated milk see Chapter VIII on "Manufacture of Evaporated Milk," "Quality of Fresh Milk," p. 81 
different degrees of concentration, and then decide how much evaporation it will stand without developing subsequently a permanent curd in the sterilizer. ${ }^{1}$

Effect of Stcrilization.-The coagulum is formed in the sterilizer. The higher the temperature, other conditions being the same, the firmer the curd. The lowest temperature that will efficiently sterilize the evaporated milk should, therefore, be used. Since the sterilizing temperature to be maintained cannot be modified below certain limits, it is necessary, when the milk is very sensitive to the heat, to lower the degree of concentration. In some factories fractional sterilization is resorted to with batches of milk that are suspicious. By so doing, lower temperatures can be used effectively, but this process calls for much more labor, increases the cost of manufacture and decreases the capacity of the factory.

Effect of Fractional Curdling.-Experience has shown that, if the proteids in evaporated milk are partly precipitated by heat before the milk reaches the sterilizer, the curd, or lumps formed in the sterilizer are less firm and can be shaken out more readily. It is, therefore, advisable to heat the milk in the forewarmers to as near the boiling point as possible and to hold it at that temperature for at least five minutes before it is drawn into the pan. The superheating of the evaporated milk before it leaves the pan is an additional safeguard against the formation of excessive curd in the sterilizer.

Effect of Homogcnizing Ez'aporated Milk.-Excessive pressure in the homogenizer tends to so change the physical properties of the casein as to render it more sensitive to the sterilizing process. Evaporated milk, homogenized under excessive pressure almost invariably forms a firm, unshakable curd in the sterilizer. The homogenizing pressure should be kept down to one thousand pounds or below. ${ }^{2}$

Acid Flux in the Cans Causcs Lumps.-Sinilar as in the case of the sweetened condensed milk, the presence of acid flux in the cans of evaporated milk causes lumpiness. The acid that reaches the interior of the cans causes the milk coming in contact with the seams to curdle. Only acid-free flux should be used in the manufacture and sealing of the cans.

1 For detailed discussion of relation of concentration to curdiness of evaporated milk see Chapter IX on "Manufacture of Evaporated Hilk," "Striking," p. 83

2 For detailed discussion of the effect of homogenizing on curdiness see Chapter $\mathrm{X}$ on "Homogenizing" and Chapter XXIV on "Separated and Churned Fvaporated Milk," p. 167 


\section{Grainy Evaporated Milk}

General Description.-This term is sometimes applied to lumpy milk, in which case it means the same. By grainy milk, however, is generally understood milk which contains a sediment of a white granular appearance, which is insoluble.

Causes and Prevention.-This granular sediment is largely found in the hermetically sealed cans after the sterilizing process. It is due to excessively high sterilizing temperatures or too long exposure of the milk to the process. It consists largely of the mineral matter of milk, rendered insoluble and precipitated by heat. Sometimes as much as a teaspoonful is found in a r6-ounce can. The use of lower sterilizing temperatures or the shortening of the period of sterilization will help to avoid this defect.

\section{Separated and Churned Evaporated Milk}

General Description. -This is a very common defect. A portion of the butter fat of the contents of the hermetically sealed cans, has separated and appears in the form of lumps of cream or of churned butter, on top of the evaporated milk. While this separated evaporated milk is normal in quality and wholesomeness, its appearance condemns it.

Causes and Prevention.-As explained in Chapter $\mathrm{X}$ on "Homogenizing," p. 85, the fundamental cause of separated and churned evaporated milk lies in the difference of the specific gravity between the butter fat and the rest of the milk constituents. The fat globules, being lighter than the serum, tend to rise to the surface, forming a layer of thick cream. When this separated evaporated milk is subjecterl to agitation, as is the case in transportation, this cream churns into lumps of butter. This tendency of the fat to separate in storage and churn in transportation. increases with the increase of the size of the fat globules, because the larger the gloiules, the larger is their cubic content in proportion to their surface. This fact is based on the well known physical law, that the surfaces of two spheres are to each other as the squares of their diameters. and the cubic contents of two spheres are to each other as the cubes of their diameters. The cubic contents determine the gravity force, or buoyancy. while the surfaces control the resistance force. Therefore, the larger the fat globules the greater is their buoyancy and 
the weaker is the relative resistance which they must overcome in their upward passage.

Effect of Locality and Season.-Since the predominating size of fat globules in milk, varies with breed and period of lactation of the cows, ${ }^{1}$ the ease with which evaporated milk separates and the difficulty of overcoming this defect, differ greatly with locality and season of year. The fat globules in milk from the Channel Island breeds, average two to three times as large as those in milk from the Holsteins and Ayrshires. Therefore, factories located in Holstein and Ayrshire territories are not troubled nearly as much with fat separation in evaporated milk, as factories in localities where Jerseys and Guernseys predominate.

Again, the fat globules are largest at the beginning of the period of lactation and decrease in size as the period of lactation advances.

Relation of Breed and Period of Lactation to Size of Fat Globules ${ }^{1}$

\begin{tabular}{|c|c|c|c|c|c|c|c|c|}
\hline \multirow{2}{*}{\multicolumn{3}{|c|}{$\begin{array}{l}\text { Months of period } \\
\text { of lactation }\end{array}$}} & \multicolumn{6}{|c|}{ Breeds of dairy cows } \\
\hline & & & Jersey & Guernsey & Holstein & Ayrshire & Holderness & Devon \\
\hline \multicolumn{3}{|c|}{ 1st month } & 1104 & 928 & & 687 & & 546 \\
\hline 2nd & 4 & - & 1098 & 1063 & 640 & 580 & 661 & 585 \\
\hline $3 \mathrm{rd}$ & “ & - & 1228 & 954 & 576 & 624 & 67 & $4 \% 0$ \\
\hline & “، & - & 1097 & 659 & 256 & 426 & 501 & 547 \\
\hline 5 th & “ & (1) & 1149 & 839 & 396 & 384 & 397 & 319 \\
\hline $6 \mathrm{th}$ & “ & - & 846 & 737 & 595 & 399 & 324 & 353 \\
\hline 7 th & $"$ & - & 1017 & 584 & 340 & 322 & 329 & 270 \\
\hline & “ & - & 733 & 568 & 310 & 298 & 379 & 201 \\
\hline & “ & $-2-1$ & 715 & 408 & 384 & $2+1$ & 315 & 250 \\
\hline 10th & $" ،$ & 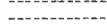 & 571 & 426 & 281 & 248 & 336 & 298 \\
\hline \multicolumn{3}{|c|}{ Average for year.... } & 955.8 & 716.6 & 420.1 & 420.9 & 427.6 & 375 \\
\hline
\end{tabular}

1Hunziker, Mills and Spitzer, "Moisture Control of Butter." Indiana Agricultural Experiment Station, Bulletin No. 159, 1912, pp. 330-334

In order to equalize the output of evaporated milk throughout the year, condensing concerns make every effort to induce their patrons to time the breeding of their cows in such a way that the fresh cows are distributed throughout the year. The result of this practice is, that the milk supply of these factories represents at all times a mixture of milk from cows at all stages of their period of lactation. This naturally equalizes the behavior of the finished product as far as separation of the fat is concerned, facilitating the control of this separation. On the other hand, in localities of fac- 
tories, newly established, summer milk is largely produced and the majority of cows freshen in the spring. This causes a marked increase of the size of the average fat globules in early summer, rendering the manufacture of evaporated milk, that does not separate its fat, more difficult.

Effect of Degree of Concentration.-Other conditions being the same, the more concentrated the product the less the danger of fat separation in the finished product. The reason for this lies in the fact that with the concentration the viscosity and the resistance force of the evaporated milk increase, hindering the fat globules in their upwar'd passage. This is partly offset by the increase in the specific gravity of the product, but the increase of the resistance force exerts a stronger influence against separation of the fat, than the increase of the gravity force exerts in favor of fat separation.

However, as the concentration increases, the evaporated milk becomes more sensitive to the sterilizing process and beyond certain limits it would be necessary to reduce the temperature or the length of exposure to heat, or both, in order to prevent the more highly concentrated milk from becoming permanently curdy. If, in order to increase the viscosity, the degree of concentration is carried so far that the sterilizing process has to be shortened, nothing is gained but much may be lost. It is obvious, therefore, that the degree of concentration does not furnish a practical basis for controlling fat separation.

Effect of the Stcrilizing Process.-Prolonged exposure of the evaporated milk to the sterilizing heat tends to so change the physical properties of the albuminoids, as to render the product more viscous. Within the limits of the necessary sterilizing heat, long exposure to moderate heat is more effective in this respect than short exposure to a high degree of heat. Since the greater viscosity tends to keep the fat globules from rising, the use of a prolonged sterilizing process, in which the heat is applied slowly, is more effective in preventing fat separation in the evaporated milk than a rapid, short process, in which the temperature used is very high.

It should be understood from the discussion in previous chapters that, in regulating the process of sterilization, the processor should be governed by the condition and behavior of the milk and that on the one hand the degree and duration of heat should always be suf- 
ficient to insure absolute sterility of the product, while on the other he must guard against the formation of an unshakable curd. ${ }^{1}$

Effect of Supcrheating.-The viscosity of the evaporated milk may also be slightly increased and its sensitiveness towards the sterilizing heat lessened by superheating it in the vacuum pan.

Turning the Cans in Storage.-Many manufacturers, in an effort to avoid fat separation, have adopted the practice of turning their goods in storage at regular intervals. This operation naturally interferes with and retards the rising of the fat to the surface, as long as the goods remain in the factory. After they leave the factory this control must of necessity cease and if the evaporated milk, owing to the process of manufacture and the condition of the product, is destined to separate its fat, the turning of the cases, while at the factory, cannot permanently prevent separation. IVhere the goods are consumed immediately after they leave the factory. this practice may serve the purpose; but, since the large bulk of evaporated milk manufactured, is exposed to prolonged storage, its advantage is very limited.

Effect of Homogenizing.-Under average conditions careful attention to the precautions above discussed will greatly minimize and often prevent fat separation. At best, however, much of the evaporated milk on the market shows signs of separation after sixty to ninety days and some of it even after two weeks, for the fundamental cause of separation, the difference in gravity between the fat globules and the rest of the milk constituents, is still present; then again, under less favorable conditions, even the above precautions may not prove adequate to keep the fat from separating.

The introduction of any agent or process, therefore, capable of permanently removing this fundamental cause, must prove a lasting benefit to the manufacturer of evaporated milk. This agent has been found in the homogenizer. The homogenizer makes it possible to divide the fat globules so finely, that their buoyancy or gravity force is not great enough to overcome the resistance of the surrounding liquid. They are unable to rise to the surface, but remain in homogeneous emulsion.

The chief objection to the use of the homogenizer is its effect on the casein of the milk. Beyond certain limits of pressure it so

\footnotetext{
1 For detailed discussion see Chapter XII on "Sterilizing," p. 93
} 
affects the casein, that the latter is more prone to curdle in the sterilizer. However, experience has amply shown that the maximum pressure required to prevent fat separation in the finished product, is not great enough to seriously affect the behavior of the casein during sterilization. Hence, the proper regulation of the pressure and the intelligent use of the homogenizer, furnish a satisfactory and reliable means to prevent fat separation. Under average conditions, the use of sufficient pressure to reduce the fat globules to one-third of their original size, practically destroys the power of the fat globules to rise to the surface. A pressure of approximately one thousand pounds per square inch, makes possible this reduction of the size of the fat globules. ${ }^{1}$

\section{Fermented Evaporated Milk}

General Description.-Fermented evaporated milk is evaporated milk, which after sterilization, has undergone fermentation. The type of fermentations found in this product varies with locality, season of year and factory conditions. The contents of the cans may have soured with curd formation, or a curd may have formed without acid development, or the fermentation may be gaseous, in which case the cans bulge, and these gaseous fermentations may be accompanied by acid formation or by putrefactive products. In all cases of fermented milk the product is entirely worthless. These defects are usually, though not always, detected during the period of incubation.

Fermented evaporated milk is the result, either of incomplete sterilization, or of leaky cans. The causes of fermented evaporated milk differ with the specific type of fermentations produced; they will be discussed separately and as relating to the respective types of fermentations.

\section{Acid Fermentation, Sour, Curdled, Evaporated Milk}

General Description.- Upon opening the cans the contents are found to be sour and curdy.

Catses ANd PREvention.-This condition is the result of the presence of acid producing species of micro-organisms, usually of the lactic acid type, which sour the milk, and the acid produced curdles the casein. Since the majority of the lactic acid bacteria

\footnotetext{
${ }^{1}$ For details on the use of homogenizer see Chapter $\mathrm{X}$ on "Homogenizing," p. 83
} 
are not resistant to heat and are destroyed at relatively low heat, this defect is not usually caused by incomplete sterilization. The temperature of sterilization, though it might be insufficient to kill spore forms, is high enough to make it impossible for lactic acid bacteria to pass the process alive.

The only way in which this defect can occur is through subsequent contamination of the contents of the cans with these germs, and the only possible channel, through which this subsequent contamination may occur, is leaky cans, or leaky seals. A careful examination of the cans of sour, curdled evaporated milk usually shows faulty cans or faulty seals.

\section{Bitter Curd}

GENERAL DEscription.-When the cans are opened the contents present a solid coagulum, generally noticeably white in color and very bitter to the taste, similar to the bitterness of dandelions. 'There is a separation of practically clear whey, the curd does not break down readily upon shaking and the acid reaction of the mixture of curd and whey is about .35 to .fo per cent., which is normal for evaporated milk.

Causes and PReVEntion.-Microscopic examinations under high magnification of cultures in sterile milk show the presence of very small bacilli. The milk forms a firm coagulum in five to seven days and when over one week old the curd has the same strong, bitter taste as that in the cans. The bitterness increases with age. These bacilli grow best at 90 degrees $\mathrm{F}$. They are facultative anaerobes, developing both, in aerobic and anaerobic media, but prefer anaerobic conditions.

In the cases under observation no spores were detected and exposure for fifteen minutes to $2 \mathrm{I} 2$ degrees $\mathrm{F}$. destroyed these germs. The above findings do not exclude the possibility of spore formation under conditions very unfavorable to growth and life.

The presence of this species of bitter curd organisms suggests incomplete sterilization of the evaporated milk. The striking whiteness of the curd in all cases that have come to the writer's attention. is further proof of the correctness of this deduction. It indicates that these cans received relatively little heat in the sterilizer, otherwise the curd would have a darker color. This defect usually does not show up in all the cans of one and the same batch, but only in a 
limited portion of each batch. This fact suggests that the distribution of heat in the sterilizer is not uniform, some cans getting less heat than others.

This defect occurs generally in summer, a fact which may be due to one or both of the following conditions:

While it is well known that there is a variety of species of bacteria, yeast and torula that are capable of producing a bitter curd, either direct, or through the secretion of casein-curdling enzymes, and while these different species of micro-organisms come from a variety of sources, the most common sources are, the soil, pasture. water and the udder itself. It is a noteworthy fact that this defect is most commonly found in milk and milk products when the cows are on pasture. It is, therefore, probable that, in most cases, this troublesome germ is carried into the milk on the farm.

Again, in summer, at a time when this defect generally occurs, the effect on the cows of the summer heat and flies, and the tendency toward high acid in milk, render the milk most sensitive to the sterilizing heat. The operator finds it difficult to avoid the formation of a disastrous curd in the sterilizer. In order to guard against this trouble he is tempted to either lower the temperature, or shorten the duration of the sterilizing process. This tends towards incomplete sterilization. A very frequent result of this incomplete sterilization in the early summer months, is the formation of a bitter curd. When the processor returns to the proper sterilizing process, the occurrence of bitter curd in the cans disappears and the product is normal.

A further safeguard against the recurrence of this trouble lies in providing for uniform distribution of heat in the sterilizer. If the cans liave to be stacked in deep tiers, which is undesirable and should be avoided, slats of wood or iron should be placed over the top of every second row of cans. This will make possible the free access of steam to at least one end of each can. If the circulation of steam in the sterilizer is poor, the uniform distribution of heat can be facilitated by filling the sterilizer about one-third full of water so that, with every revolution of the frame-work, the cans have to pass through this water once. The water reaches every nook in the interior of the sterilizer, distributing the heat much more uniformly 
than the steam. If these precautions fail to remedy the trouble, then the entire process is inadequate and either more heat, or longer exposure to the same heat is necessary.

It is obviously imperative that the fresh milk, as it arrives at the factory, be subjected to the most rigid inspection on the platform, in order to guard against the processing of unduly contaminated milk.

\section{Blown Evaporated Milk (Gaseous Fermentation)}

General, Description.-The ends of the cans bulge out very noticeably, frequently so much so that the seams of the cans burst open. This is due to gaseous fermentation causing ligh pressure in the cans. The pressure is often so great, that upon opening the cans, most of the contents are blown out with tremendous force. In some cases of blown evaporated milk, the contents have an acid odor, pleasant and aromatic. In most instances, however, they give off very foul odors and suggesting hydrogen sulfide, not unlike aggravated cases of Limburger cheese. These odors are exceedingly penetrating and difficult to remove from anything they come in contact with.

Causes and Prevention.-The bacteria causing gaseous fermentations in evaporated milk usually belong to the anaerobic group of butyric acid species and in most cases, though not always, the putrefactive types prevail, such as Bacillus putrificus. Plectridium novum and Plectridium foetidum, especially the latter, because of its cxtraordinary power of resistance to heat. Plectridium foetidum is an obligatory anaerobe and it absolutely refuses to grow under aerobic conditions. It is an actively motile, medium-sized organism with flagella and spores. At one end it has an Indian club-like enlargenent, in which appears the spore. The bacillus resembles a kettle-drum stick similar to B. tetani. Under strictly anaerohic conditions, and incubated at go degrees F., it ferments milk in four days. The milk first curdles, then gradually the curd dissolves (digests) completely, leaving a clear yellow liquicl, similar in appearance to butter oil. The fermentation is accompanied by the evolution of a penetrating foul odor. This organism survives exposure for I5 $_{5}$ minutes to 245 degrees $F$. Its thermal death point lies between 245 and $25^{\circ}$ degrees $\mathrm{F}$. 
Plectridium foetidum, as well as most of the other species of anaerobic, spore bearing butyric acid bacilli and bacteria, is present abundantly in cultivated soil, in field crops and even on the kernels of the grain. Since this type of evaporated milk defect is characteristic, especially, of the product manufactured during the late summer and early fall months, it is very probable that the dust incident to the harvesting of the field crops, furnishes the chief source of contamination of the milk.

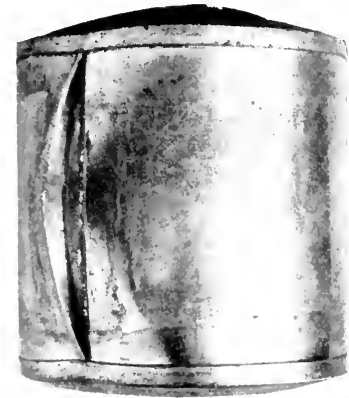

Fig. 52. The result of gaseous fermentation

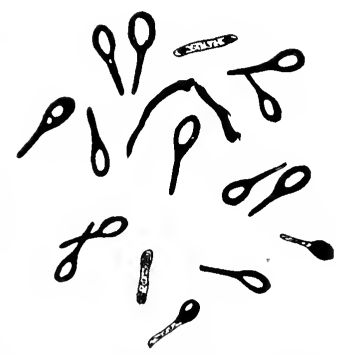

Fig. 53. Plectridinm foetidum, a highly resistant species of anaerobic microorganisms, causing "swell heads" of evaporated milk

In order to avoid the occurrence of blown, fermented, evaporated milk, therefore, it is necessary to employ the highest sterilizing temperatures, or the longest exposure to the sterilizing heat, or both, consistent with freedom of the milk from curdiness. Experience has shown that the use of the formula for sterilizing, given under Chapter XII on "Sterilizing," guards effectively against this defect.

Blow'n Eraporated Milk Duc to Frecaing.-If the evaporated milk is exposed to storage temperatures below the freezing point of water, the contents of the cans will freeze. While freezing, the contents expand sufficiently to cause the ends of the cans to bulge. When the cans are subsequently transferred to warmer temperatures, so that their contents melt again, the milk contracts and the cans resume their normal shape.

While the wholesomeness and flavor of the product are not affected by the freezing process, the remelted evaporated milk is usually less smooth and often slightly grainy. This is due to the fact 
that, during the process of freezing, there is a partial separation of the watery portion from the caseous material. The casein contracts and the watery portion freezes. When melted, the emulsion is less complete than it was before freezing. The casein remains in its contracted form and robs the product of its original smoothness.

Bloz'n Ez'aporated Milk Due to Chemical Action.-While properly processed evaporated milk is perfectly sterile, and from the biological point of view, keeps indefinitely, the cans of very old, evaporated milk may bulge, as the result of the action of the acid in the milk on the container. Evaporated milk contains from .35 to .50 per cent. acid (calculated as lactic acid). When the tin cans are filled with the evaporated milk, the timplate is bright and untarnished, both, inside and out. After the sterilizing process, the inside surface of the cans is dark and dull. This is caused by the combined action of acid and heat, which seems to weaken the tinplate. This phenomenon is further illustrated by the fact that where creameries pasteurize their skimmilk and return it to the patrons in the milk cans hot, the milk cans are short-lived; they soon corrode and begin to leak.

The acid in the evaporated milk continues to act on the tinplate of the can after manufacture and in the case of very old evaporated milk, the acid may decompose a considerable part of the iron. This action is accompanied by the evolution of hydrogen gas, which causes the cans to bulge. This action is hastened by continued exposure of the goods to high temperatures (summer heat). This fact was experimentally demonstrated, ${ }^{1}$ also, by scratching the bottom of tin cans on the inside with a file, then filling the cans with a 4 per cent. solution of lactic acid and acetic acid, respectively. After sealing, the cans were sterilised in the autoclave, so as to avoid any possibility of bacterial action. After cooling, these sterilized cans were incubated for some time at 90 degrees $\mathrm{F}$. The cans containing the dilute acid began to swell, while the check cans, containing distilled water only, remained normal.

\section{Brown Evaporated Milk}

General Description.-It is the aim of the processor to so govern the sterilizing process as to give the evaporated milk a rich,

${ }^{1}$ Hunziker and Wright, Indiana Agricultural Experiment Station. Results not published 
yellow, creamy color. Frequently, this color limit is overstepped to the extent of imparting to the evaporated milk a brown color, suggesting coffee with milk in it. In this condition evaporated milk fails to appeal to the consumer.

Causes and Prevention.-The dark color in evaporated milk is due to the oxidizing action of excessive heat on the milk sugar, causing the milk sugar to caramelize. This can be avoided by reducing the sterilizing temperature, or shortening the sterilizing process, or both. The storing of evaporated milk at high temperatures (summer heat) also tends to deepen its color with age.

\section{Gritty Plain Condensed Bulk Milk}

Gener.IL Description.-Grittiness in the unsweetened goods appears usually only in the plain condensed bulk milk. It is a defect which renders the product undesirable for ice cream making.

CaUses AND PREVENTION.-The chief cause of this defect is too great concentration. Plain condensed bulk milk which is not condensed over 3.5 parts of fresh milk to I part of condensed milk does not become gritty. When the concentration exceeds $t: I$, the milk sugar begins to crystallize out, making the product gritty. Milk sugar requires about six times its weight of water for complete solution in cold water. When condensed at the ratio of $t$ :I or over, the plain condensed bulk milk contains considerably less than five parts, by weight, of water to one part of milk sugar. This high concentration, together with the practice of storing this product at refrigerating temperatures in order to preserve it, is responsible for the grittiness. This trouble can, therefore, easily be prevented by not condensing to quite as high a degree of concentration.

\section{CHAPTER XXV}

\section{ADULTERATIONS OF CONDENSED MILK}

It is the sense of the Federal Pure Food Act that the addition to condensed milk of any substance except sucrose, and the abstraction of any substance from milk except water, is an adulteration.

Skimming.-Condensed milk made from partly or wholly skimmed milk must be labeled and sold as condensed skimmed milk 
in order to comply with the Pure Food regulations. However, it is possible for condenseries receiving fresh milk, rich in butter fat, to skim a part of that milk and have their product still conform with the food standards.

Skimmed sweetened condensed milk can readily be detected by its whitish color, while condensed whole milk has normally a rich yellow color. When diluted, to the consistency of ordinary milk, skimmed condensed milk, both the sweetened and the unsweetened, foams very profusely when shaken, while diluted condensed whole milk behaves similar to ordinary whole milk. ${ }^{1}$

Addition of Artificial Fats.-In order to lower the cost of manufacture, attempts have occasionally been made to skim the fresh milk and substitute the abstracted fat by artificial fats of animal or vegetable origin. If the punishment for such violations of the law and the protection of the consumer had to solely depend on the findings of food chemists, justice would indeed be dealt out very slowly, for condensed milk is analyzed for the kinds of fat it contains in but very rare cases, and the detection of artificial fat by chemical analysis is a difficult process. Fortunately for the consumer, there are easier and simpler means to detect "filled" conclensed milk. The presence of foreign fats in condensed milk, whether animal or vegetable, give the product a peculiar flavor and odor, not present in the unadulterated milk. This unnatural flavor and odor is especially noticeable when a teaspoonful of the condensed milk is dissolved in half of a cupful of hot water or coffee.

The addition to condensed milk of artificial fats produces an inferior quality of condensed milk and decreases its keeping quality. The milk is prone to become rancid. Condenseries are known to have lost their output of an entire season as the result of the adulteration of their product with artificial fats. The practice of a tulterating condensed milk with foreign fats is now an exceedingly rare occurrence.

Addition of Commercial Glucose.-Commercial glucose belongs to a group of starch products in which dextrose is the leading constituent. It is manufactured by the action of dilute acids on starch and starchy matter, or occasionally woody fiber. In this country it is almost wholly made from maize starch.

1 For chemical tests of butterfat in eondensed milk, see Chapter XXVII 
Starch glucose occurs in commerce in several forms, varying from the condition of pure anhydrous dextrose, through inferior kinds of solid sugar, to the condition of a thick syrupy liquid, colorless and transparent, resembling molasses in consistency and glycerine in appearance; it contains a large proportion of lextrin. In connection with the manufacture of condensed milk the term "glucose" refers to this thick, syrupy liquicl. It is added to the condensed milk with a view of substituting a portion of the sucrose and thus reducing the cost of manufacture. It has also been suggested that the presence of commercial glucose in condensed milk prevents the precipitation of sugar crystals. Experiments have shown, however, that condensed milk containing varying amounts of glucose, will become sandy just as readily as normal condensed milk.

That glucose cannot be used as a substitute for sucrose, is obvious from the fact that its presence defeats the very object for which sucrose is added. Instead of serving as a preservative, as is the case with the best refined, granulated cane sugar, glucose acts as a most effective fermentative. It has been explained that the presence in sucrose of traces of invert sugar, or levulose and glucose, causes condensed milk to ferment. Glucose belongs to the monosaccharides. Its chenical formula, like that of levulose, is $\mathrm{C}_{6} \mathrm{H}_{12} \mathrm{O}_{6}$, it oxidizes readily and uncler the influence of yeast and other micro-organisms it ferments, yielding mainly alcohol and carbon dioxide. Its presence in condensed milk, therefore, is prone to start fermentation, and the manufacturer who uses it with a view of lessening the cost of manufacture of condensed milk is, indeed, practicing poor economy. There is no adulteration of sweetened condensed milk, that will produce such inevitable disaster, as the addition to it of glucose. Aside from this fact, the law prohibits the acldition of anything except sucrose.

Addition of Bi-Carbonate of Soda, Ammonium Hydroxide, Lime Water and Other Alkali.-These alkalies are frequently added to a poor quality of fresh milk, for the purpose of neutralizing the excess of acid and preventing the milk from curdling when exposed to heat. If used in reasonable quantities, they interfere in no way with the quality and healthfulness of the product, and may in exceptional cases, prevent great loss. If used in excess, the milk 
will foam very badly in the vacuum pan, which renders the process of condensing a difficult one and the finislred product has a bitter flavor. Under ordinary conditions, their use is entirely unnecessary and simply means additional labor and expense. The above agents and also viscogen, are sometimes used with the view of thickening the product and increasing the output. Experimental results, ${ }^{1}$ however, showed that these agents cannot be used in large enough quantities to produce the above results without materially lowering the quality of the product.

Addition of Cream of Tartar.-Cream of tartar is used extensively in the manufacture of candies and caramels. Its purpose is to make the sugar in these products precipitate in the form of very fine and soft crystals. Condenseries, which have been continually troubled with sugar crystallization and sugar sediment, have tried to overcome this defect by adding cream of tartar to the sweetened milk in the vacuum pan. Cream of tartar is an acid salt (acid potassium tartrate, KH. $\mathrm{C}_{4} \mathrm{H}_{4} \mathrm{O}_{6}$ ), and it is this acid, which in the manufacture of candy, causes the fine and soft grain of the sugar. It is obvious, that if enough cream of tartar were added to condensed milk, to produce the desired effect on the sugar, the acid present would curdle the milk. Its use is of no value to the manufacturer of condensed milk.

Addition of Starch.-The pasty and thick consistency of sweetened condensed milk frequently suggests to the public that it contains starch. This is erroneous, for it is doubtful if condensed milk is ever adulterated with starch. There would be absolutely nothing gained by so doing, and the presence of starch in condensed milk could be readlily detected with iodine. Iodine gives the starch cells a deep blue color.

\footnotetext{
1 Hunziker. Experiments not published
} 


\section{PA R T VI I}

\section{MANUFACTURE OF MILK POWDER}

\section{CHAP'TER XXVI}

\section{DEFINITION}

Milk powder, dry milk, pulverized milk, dehydrated milk, desiccated milk, is made from cow's whole milk, or partly or wholly skimmed milk, to which sugar, or alkalies, or both may, or may not have been added, and which has been evaporated to dryness, either under atmospheric pressure, or in vacuo.

\section{KINDS}

The milk powders on the market vary chiefly in their solubility and fat content. The bulk of the milk powders is produced from wholly or partly skimmed milk. Most of the milk powders of the early days of this industry, contained added cane sugar and alkalies. The purpose of the addition of alkalies was to lend greater solubility to the proteids.

The process of manufacture, however, has been improved to the extent to where the solubility of the proteids can be preserved without the admixture of alkalies. Most of the milk powders put on the market in this country are free from admixture of any substances foreign to normal milk.

\section{HISTORY AND DEVELOPMENT OF INDUSTRY}

The origin and history of the milk powder industry are very closely related and intimately connected with that of the condensed milk industry. The fundamental purpose of the two products is one and the same, i. e., to preserve milk as nearly as possible in its natural condition, and to reduce its bulk to the minimum, so as to make possible its economical transportation to all parts of the world. 
The difference between milk powder and condensed milk, is mainly one of degree of concentration. It is not surprising, therefore, that the inventions of processes of manufacture of the two products date back to about the same period, the middle of last century, and in most cases, the inventors of the one product had also in mind and gave due consideration to the possibilities of the other.

The first commercially usable process was invented by Grimwade who secured the English patent in 1855 . His process consisted briefly of first adding carbonate of soda or potash to the fresh milk, then evaporating in open jacketed pans and with constant agitation, until a dough-like substance was obtained; then adding cane sugar; the mixture was then pressed between rollers into ribbons, further dried and then pulverized. The alkali, in the form of carbonate of soda or potash, was added in order to render the casein more soluble, and the purpose of the admixture of the sugar was to produce granulation of the dough toward the end of the process. The evaporation in open pans was later superceded by the use of the vacuum pan. The Grimwade process of manufacturing milk powder was in practice for some years.

The introduction and rapid development of the condensed milk industry and the difficulty of the economic manufacture of a marketable milk powder of good keeping quality, had a retarding effect on the development of the milk powder industry. While occasional new processes were invented and new patents granted, the commercial development of the industry dates back only about fifteen to twenty years. Within the last decade the industry in this country and in Europe has been growing rapidly. Today there are in operation in the United States some thirty milk powder factories.

The bulk of the milk powder manufactured now is made from skimmed milk. The manufacture of whole milk powder is as yet very limited and is confined to the filling of specific orders for the same, because of its low keeping quality. The fact that whole milk powder becomes rancid under similar conditions, as is the case with butter, and that it must be refrigerated in order to keep, is overshadowing the many and distinct advantages of this concentrated product. Until this obstacle is removed and the manufacturer is able to put on the market a whole milk powder that has the desired keeping properties, the development of this industry cannot reach 
the proportions justifiable by the great usefulness of this valuable product and comparable with the manufacture of other forms of preserved milk and dairy products.

\section{QUALITY OF FRESH MILK}

What has been stated concerning the necessity of a high quality of fresh milk in the successful manufacture of condensed milk, is equally true in the manufacture of milk powder. The fresh milk must be normal in its properties. It must be produced under strictly sanitary conditions and receive the proper care on the farm. It is especially essential that it arrive at the factory perfectly sweet, since acidity tends to lower the solubility of the finished product.

\section{DESCRIPTION OF THE PRINCIPAL PROCESSES OF MANUFACTURE}

Numerous processes for the manufacture of milk powder have been invented and patented in this country and in Europe. Many of these processes differ but slightly from one another. For convenience sake these processes are herein classified in accordance with the fundamental principles of evaporation involved:

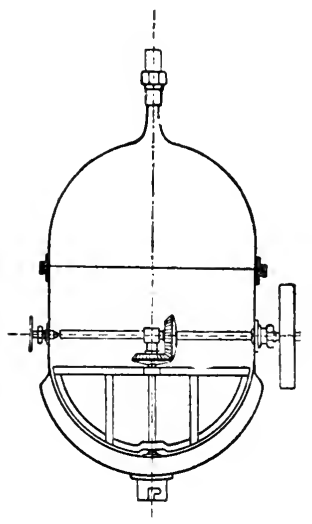

Fig. 54. The Wimmer milk powder machine

1. The Wimmer Process.-The milk is boiled in a vacuum pan similar to that used in the manufacture of condensed milk. The racuum pan has a deep steam jacket for heating, but in the place of the usual coils, the pan is equipped with a mechanical stirrer. The milk is condensed at a relatively low temperature and the stirerer revolves until the water content of the milk is reduced to about 30 per cent. and the milk has become porous and crumbly, though it still forms a compact mass. The drying is then completed in the open air and without additional heating. The product is then ground to a powder. This is the process invented by Ole Bull Wimmer of Copenhagen, Denmark. 
2. The Just-Hatmaker Process.-The milk sprays in a thin film over two steam heated cylinders or drums, about sixty inches long and twenty-four inches in diameter. The cylinders are about one-eighth of one inch apart and revolve in opposite directions. The milk reaches the drums from a supply tank located in the center above the drums. In order to insure a continuous and uniform supply of milk, a constant level of about four inches of milk is maintained in the supply tank. This process was invented by J. R. Hatmaker of London, and was patented in I902. Its objectionable fea-

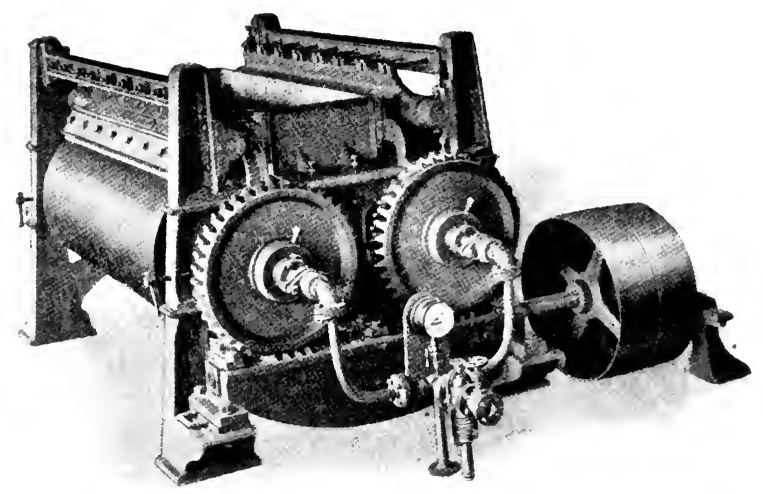

Fig. 55. The Just-Hatmaker milk drier

ture lies in the fact that the excessive heat at which the milk is evaporated impairs the solubility of the product. The cylinders are charged with two to three atmospheres of steam pressure, causing the heating surface to have a temperature of about 250 to 280 degrees $\mathrm{F}$.

3. The Eckenburg and Passburg Processes.-In the Eckenburg process the milk is exposed in a thin layer on the surface of a revolving metal cylinder or drum, which is enclosed in a vacuum chamber. The cylinder is heated by passing hot water or steam through it. The fact that the evaporation takes place in a vacuum chamber makes it possible to accomplish the drying at a relatively 
low temperature, although the film of drying milk is naturally exposed for a brief time to the direct heat of the cylinder. The cylinder revolves at the rate of about one revolution per minute, the film of dried milk is scraped off the cylinder by a stationary, adjustable knife and the desiccated milk discharged into a receiver. T'he fresh milk enters the vacuum chamber at the bottom and the revolving cylinder is so adjusted that it automatically picks up a thin film of milk. 'This process was invented by Dr. Martin Eckenburg, of Sweden.

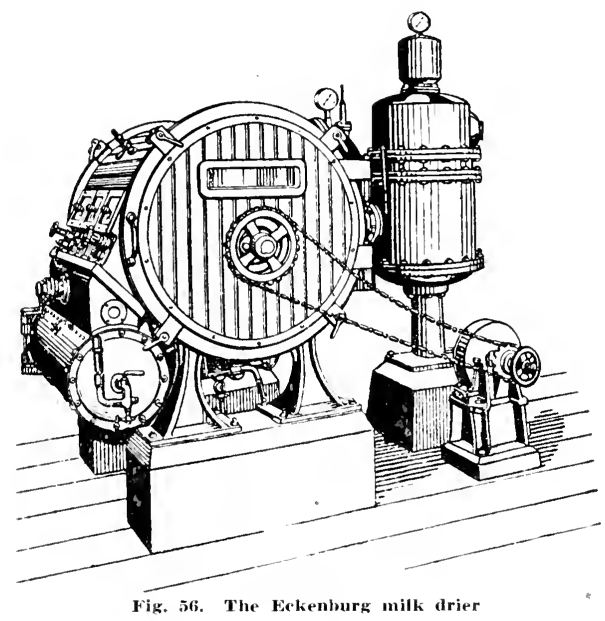

A similar apparatus and process was invented and patented by Emil Passburg of Rerlin, Germany. This inventor recommends the evaporation of the milk in the vacuum pan to about one-fourth its volume before it enters the dryer. The dryer has a similar arrangement as that of Eckenburg but is equipped with an additional device for the purpose of insuring a film of uniform thickness of the condensed milk. In some of these dryers the milk is sprayed against the drum and a properly set knife regulates the thickness of the film. The fact that the milk is partly condensed before reaching the drum, greatly hastens the process of drying and increases the 
capacity of the apparatus, but it also involves a more expensive equipment.

In this, as in all other processes, where the desiccation is accomplished by evaporation on a revolving, steam-heated drum, the rapidity and completeness of evaporation are regulated by the temperature and speed of the drum.

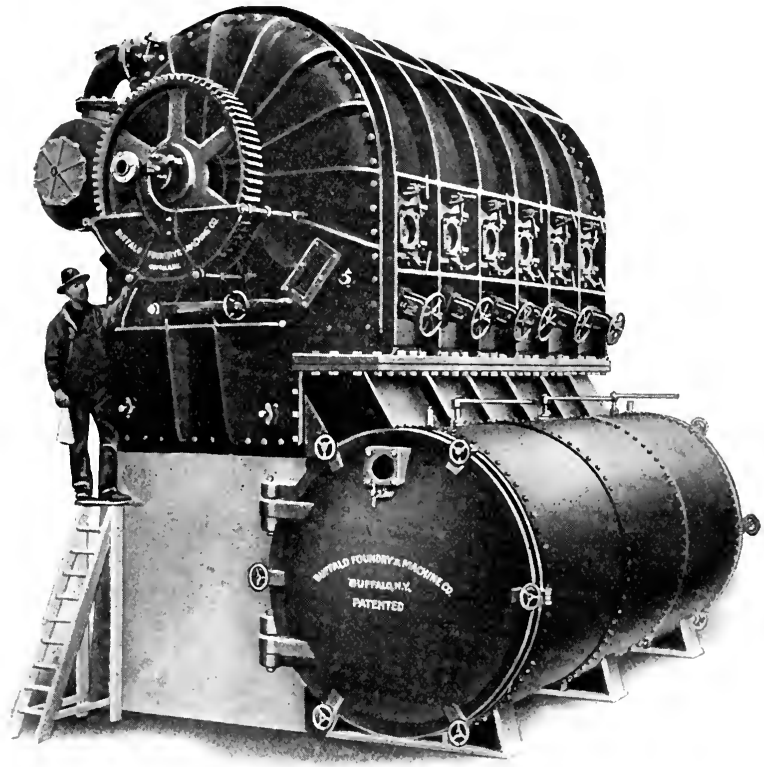

Fig. 57. The Passburg milk drier Courtesy of the Buffalo Foundry \& Machine Co.

4. The Campbell Process.-A current of warm air passes through the milk upward until the milk has become thick. The remainder of the drying is accomplished by exposure to heated air. The dried milk is then ground to a powder. This is the Campbell process, invented in 1900 and patented by J. H. Camplell of New York in 1902. 


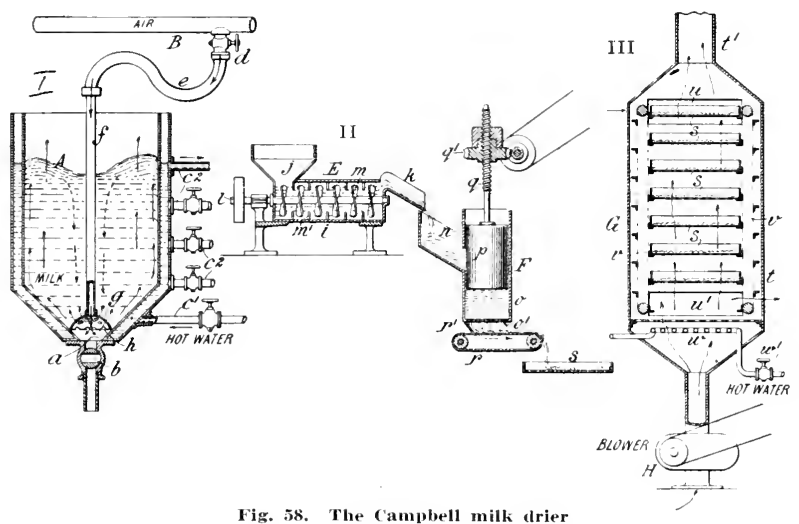

I A concentrating vessel, a outlet, b valve, c hot water jacket, $\mathrm{c}^{1}$ hot water pipe, $\mathrm{c}^{2}$ discharge of jacket, $\mathrm{B}$ air pipe, e connecting hose, f stand pipe, $g$ air-distributing disc, $t$ air chamber.-II E pug mill, i cylinder, $j$ hopper, $\mathrm{k}$ chute, $\mathrm{l}$ horizontal shaft, $\mathrm{m}$ blades for stirring, $\mathrm{m}^{\prime}$ projections for scraping blades, $\mathrm{F}$ Vermicelli-machine, $\mathrm{n}$ hopper, o cylindrical chamber, p piston, q spiral screw, $q^{\prime}$ worm-wheel, $o^{\prime}$ small holes, $r$ endless traveling apron, s tray with perforated bottom.-III G drier, $t$ body of drier, $H$ blower, $t^{\prime}$ flue, $u$ opening to insert trays, $u^{\prime}$ opening for removing trays, vv endless chains with projections for supporting trays, w coil heater, $w^{\prime}$ pipe circulating hot water.

5. The Merrell-Gere Process.-The milk is condensed in the vacuum pan to about one third to one fourth its volume. The condensed but still fluid milk is forced under pressure through a fine jet, causing it to be atomized and sprayed into a current of hot air, in an evaporating chamber. This atomized liquid forming a mist, offers the maximum surface for evaporation of its water. The hot air absorbs the moisture of the milk almost instantly and the milk drops to the bottom of the chamber in the form of a snow-like powder. No grinding is necessary. This process was invented by L. C. and I. S. Merrell and W. B. Gere, assignors to Merrell-Soule Co., of Syracuse, N. Y., and patented July 23, 1907. The following are the claims of the patentees: 


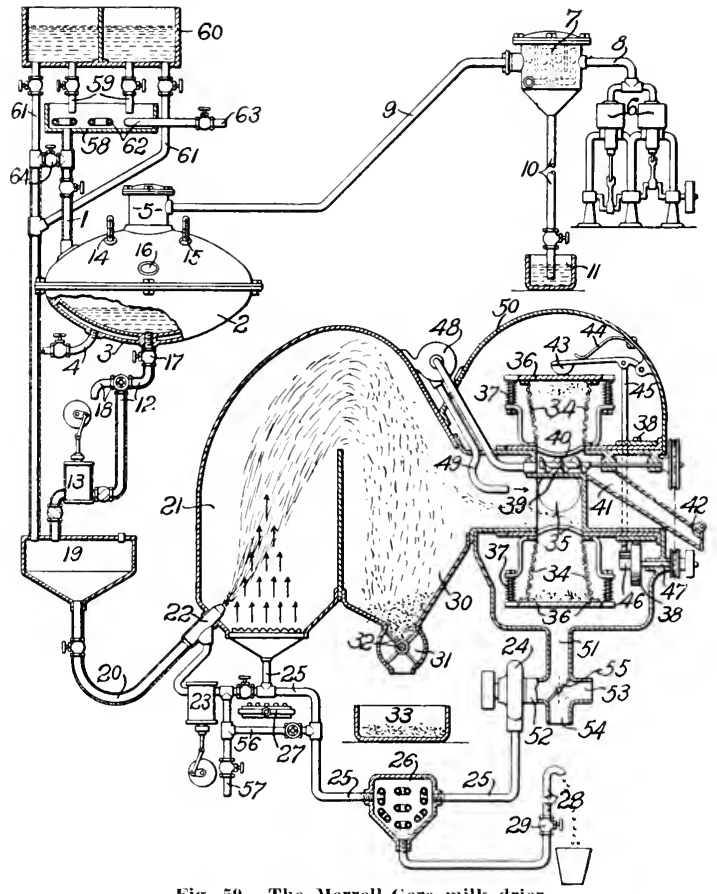

Fig. 59. The Ilerrell-(iere milk drier

1 intake of milk, 2 vacuum pan, 3 jacket, 4 steam intake into jacket, 5 dome of pan, 6 vacuum pumps, 7 condenser, 10 water column, 11 overflow cistern for dry vacuum system, 12 discharge pipe of pan, 13 pump, 14 pressure gauge, 15 thermometer, 16 sight-glass, 17 regulating valve, 18 two-way draw-off cock for sampling, 19 reservoir, 21 desiccating chamber, 22 spray jet, 23 force pump, 24 air pump, 25 compressed air, 26 air drying chamber, 27 air heater, 28 stand-pipe, 29 drip valve, 30 depository of part of powder, 31 outlet of powder, 32 rotary gate, 33 receptacle, 34 rotary dust collector consisting of tubular screen partitions, 35 openings connecting with desiccating chamber, 36 head closing tubular screen, 37 springs, 38 gear for rotating dust collector, 39 receptacle, 40 screw conveyor removing powder into 41 which is a chute, 42 automatic discharge valve, 43 beater to remove adhering powder, 44 spring of beater, 45 rod, 46 toothed rack, 47 driving shaft, 48 suction pump to facilitate removal of 
powder, 49 conduit, 50 casing inclosing dust collector, 51 discharge of casing, 52, 53 and 54 terminal branches, 55 rotary valve, 36 auxiliary valved conduit, 57 supplementary valveú conduit, 58, 59, 61, 62, 63 and 64 equipment for treating either colloids or crystalloids separately.

\section{"Clainis:}

I. "The process of obtaining the solid constituents of liquids and semi-liquids, in the form of powder, which process consists in concentrating the substance by removing a large percentage of the water therefrom, converting the concentrated mass into a fine spray, bringing such spray into a current of dry air or gas having an avidity for moisture so that substantially all the remaining liquid constituents are separated thereby, conveying the dry powder into a suitable collecting space away from the air or gas current, and discharging the air or gas separately from the dry powder.

2. "The process of obtaining the solid constituents of liquids and semi-liquids, in the form of powder, which process consists in concentrating the substance by removing a large percentage of water therefrom, converting the concentrated mass into a spray, bringing such spray into a current of dry heated air or gas having an avidity for the moisture of the substance treated, retaining the atoms momentarily in said current so that substantially all the remaining moisture is converted into vapor and the product is prevented by the cooling effect of such evaporation from undergoing chemical change, conveying the dry nowder into a suitable collecting space away from the vaporizing current, and discharging the air or gas separately from the dry powder.

'In witness whereof we have hereunto set our hands this 7 th day of August, Igo6."

Witnesses:

H. E. Chase, Howard P. DFinison."
LEWIS C. MFRRELL.

IRVING S. Merrell.

William B. Gere. 
The product of the Merrell and Gere process is without question superior to any milk powder manufactured by the various processes herein mentioned. It embodies the three all important characteristics of a desirable and successful milk powder; namely, it contains less than the minimum amount of moisture which permits of bacterial action, its butterfat is retained in the globular form and does therefore mix with water readily, forming a complete emulsion, and its albumen is present in its natural, non-coagulated and soluble form, insuring complete solubility of this dried milk in water.

In the above classification of processes, only those processes have been discussed which produce true milk powders without the admixture of alkalies or sugar and which are commercially practical. Numerous other processes have been patented, especially in European countries. Most of these require the addition to the milk of either alkalies, or sugar, or both, or else their commercial application has not been found commercially successful. 


\section{CHAP'TER XXVII}

\section{PACKING FOR THE MARKET}

The dried milk, reduced to a fine powder, is put on the market in packages of various types and sizes. Small packages are usually put up in tin or fibre cans holding from eight ounces to ten pounds of milk powder. These cans are closed with a friction cap. The bulk of dried nilk is put up in barrels which are lined with parchment paper similar to the lining of sugar barrels. Nilk powder should be stored in a dry atmosphere. When exposed to dampness it is prone to absorb moisture. In this condition its life is shortenerl, as it becomes monldy and spoils.

\section{COMPOSITION OF MILK POWDER}

Nilk powder is made from whole milk, partly skimmed milk and skim milk. The following figures show the composition of milk powders manufactured by the several different processes.

Composition of Milk Powders Manufactured by Different Processes

\begin{tabular}{|c|c|c|c|c|c|c|}
\hline Process & $\begin{array}{c}\text { Fat } \\
\text { per } \\
\text { cent. }\end{array}$ & $\begin{array}{l}\text { Proteids } \\
\text { per } \\
\text { cent. }\end{array}$ & $\begin{array}{c}\text { Lactose } \\
\text { per } \\
\text { cent. }\end{array}$ & $\begin{array}{l}\text { Sucrose } \\
\text { per } \\
\text { cent. }\end{array}$ & $\begin{array}{l}\text { Ash } \\
\text { per } \\
\text { cent. }\end{array}$ & $\begin{array}{l}\text { Water } \\
\text { per } \\
\text { cent. }\end{array}$ \\
\hline Whole milk & & & & & & \\
\hline${ }^{1}$ Merrell and Gere & 29.20 & 26.92 & $36 \cdot 4^{8}$ & & 6.00 & $\mathrm{I} \cdot 40$ \\
\hline ?J. R. Hatmaker & $2 \mathrm{I} \cdot 7 \mathrm{O}$ & 28.70 & $35 \cdot 10$ & & 6.50 & 8.00 \\
\hline :E. Passburg & $22 \cdot 5^{6}$ & 20.83 & 20.87 & 28.77 & 5.90 & 4.04 \\
\hline Half skimmed & & & & & & \\
\hline${ }^{1}$ Merrell and Gere & 15.10 & $33 \cdot 30$ & 39.70 & & 6.90 & 5.00 \\
\hline I. R. Hatmaker & 13.00 & 30.57 & 48.85 & & 7.28 & 8.30 \\
\hline${ }^{3}$ Process not known & I 5.80 & $37 \cdot 45$ & 33 . I I & & $7 \cdot 34$ & 6.30 \\
\hline Skimmed & & & & & & \\
\hline${ }^{3}$ Merrell and Gere & I. OO & 37.00 & 47.00 & & 8.00 & 7.00 \\
\hline${ }^{3}$ J. R. Hatmaker & I. 02 & $37 \cdot 28$ & $4^{6} \cdot 30^{\circ}$ & & 8.00 & $7 \cdot 40$ \\
\hline
\end{tabular}

1 Larsen and White, Milk Technology

2 C. Huyge, La poudre du lait, Revue generale du lait, Vol. 3, No. 14, 1904

3 .J. Mayrhofer, Ueber einige Erzeugnisse der Milch, Zeitschr. f. d. Vol. vii, No. 11, 1904. Landw. Versuchswesen in Oesterreich 


\section{DEFECTS OF MILK POWDERS}

High Water Content.-In order to insure keeping quality, milk [owders must be as free from moisture as possible. Milk powders are not sterile, nor are they supposed to contain preservatives such as sucrose and chemicals. Their only safeguard against bacterial fermentation and spoiling is their comparative freedom from water. Unless the process fulfills this requirement, milk powders will not keep and their chief virtue, which renders them most valuable, is forfeited.

Insoluble Milk Powders.-If milk powders are to take the place of fresh milk or condensed milk on the table of the consumer, they nust be readily soluble. One of the greatest obstacles in the progress of the milk powder industry, has been that the dried milk of most of the processes failed to be readily and completely soluble. Earlier processes prescribed the admixture to the milk of alkalies in order to preserve the solubility of the proteids, which otherwise were rendered insqluble by the high heat of the respective processes. It is obvious that a dried milk, the solubility of which can be retained only by the adinixture of alkalies, is a poor substitute for $m$ ilk, and the very principle of adding chemicals to a food product like milk, is contrary to our ideal of honest and successful manufacture of high quality of product. In the most approved processes now in use, the milk is never exposed to temperatures high enough to render the proteids of the resulting milk powder insoluble, and in their applications the use of solvents is unnecessary.

Non-miscible Milk Powders.-The miscibility of the dried milk with water depends, aside from its solubility, on the physical condition of its butter fat and the casein. If the process employed is such as to destroy the globular form of the fat globules, it is impossible to reduce the dried milk to a homogeneous fluid, similar to normal fresh milk. The fat in such milk will rise to the surface quickly, similar to the fat in a mixture of oil and water.

In fresh and normal milk the casein is present, not in solution, but in suspension. The particles of casein are very minute and form an intimate mechanical union with the water. In this condition they are present in the form of a homogeneous emulsion with the other ingredients of the milk. When the milk is desiccated at 
high temperatures, the particles of casein lose their property of emulsifying and when the desiccated milk is redissolved, the casein fails to be miscible, dropping to the bottom in the form of finely divided, insoluble curd. In order to produce milk powder which is miscible in water, the process and heat used must be such, as to permit the casein to pass into the finished product in its natural state.

Both of these requirements of miscible milk powder, the globular state of the fat globules and the natural emulsifying properties of the casein, seem to be adequately met and complied with in the product of the Merrell and Gere process.

Rancid Milk Powder.--From the biological point of view, milk powder, properly made and with a minimum moisture content, cannot decompose. Unfortunately, one of the constituents of dried milk, the butterfat, is prone to undergo chemical changes upon exposure to light, heat and air. The less stable fatty acids, especially the oleic acid, the glycericle of which is an unsaturated fat, oxiclize readily, giving the product a rancid or tallowy flavor. Even the most experienced manufacturers of milk powiler, using the most perfected processes now known, admit that milk powder made from whole milk, or partly skimmed milk, will become rancid when exposed to air, light and orchinary temperatures.

Experience has amply demonstrated that whole milk powder will deteriorate and become rancid very much under the same conditions as butter. In order to prevent whole milk powder from becoming rancil, it must be stored in the coll.

\section{MARKETS}

Owing to its relatively poor keeping (quality, the markets for whole milk powder are limited. It is a most ideal substitute for fresh milk or condensed milk, if used when fresh or whenever, in its storage and transportation, it can be protected by cold. This requirement, however, is a serious obstacle to its omniusefulness and will remain a hinderance to its introduction in the pantry of the consumer, until the manufacturer succeeds in correcting this defect.

Skim milk powder, on the other hand, is free from this drawback, and when properly made and kept dry, it keeps indefinitely. 
It has become a most valuable dairy product and its uses are manifold. It is used in the consumer's kitchen, in bakeries and confectioners' establishments, in the manufacture of ice cream, fermented milk beverages, and starters for cream ripening where milk and skim milk are not available: in the preparation of baking powder, of pure lactic acid cultures for creameries and cheese factories, of drugs, choice toilet soaps, etc. In European countries, the chocolate factories purchase vast quantities of skim milk powder in the manufacture of milk chocolate and allied products, and manufacturers of diverse prepared food products such as cereals, soups, noodles, and vegetables, furnish additional markets for this new dairy product.

\section{CHAPTER XXVIII}

\section{DRIED BUTTERMILK AND DRIED WHEY}

These by-products of the creamery and cheese factory can be reduced to a powder in a similar way and by the same processes and machinery, as are used in the manufacture of dried milk and aried skim milk.

Dried buttermilk makes a splendid chicken feed, both for egg production and for fattening chickens. It is best diluted to about the original buttermilk (one part powder in ten parts water) and mixed with the grain feed into a mush. Like fresh buttermilk, so is cried buttermilk a wholesome, nutritious and easily digested food and recommends itself especially to persons with weak digestion. When properly made, buttermilk powder keeps indefinitely and may, therefore, be available for immediate use at all times.

the following analyses show the composition of buttermilk powder and of the fresh buttermilk from which it was made. 


\section{COMPOSITION OF BUTTERMILK POWDER}

\begin{tabular}{lrr} 
& Fresh buttermilk & Buttermilk powder \\
Butter fat & I.I7 per cent. & I I.70 per cent. \\
Proteids & 3.00 per cent. & 36.24 per cent. \\
Lactose & 2.97 per cent. & 35.50 per cent. \\
Ash & .85 per cent. & 8.25 per cent. \\
Acidity & .60 per cent. & 6.00 per cent. \\
Iron $\left(\mathrm{Fe}_{2} \mathrm{O}_{3}\right)$ & .00 per cent. & I.92 per cent. \\
Water & $9 \mathrm{I} .63$ per cent. & 4.32 per cent. \\
\cline { 2 - 3 } & Total &
\end{tabular}

${ }^{1}$ The buttermilk of which the composition is shown in the above table was made at the plant of the Buffalo Foundry and Nachine Company, Buffalo, N. Y., under the supervision of the writer. The machine used was of the Passburg type. The buttermilk was furnished by Schlosser Bros., of Frankfort, Indiana. This batch of buttermilk happened to be abnormally high in butterfat; therefore the large butterfat content of the finished product. The iron found in the dried buttermilk is probably due to the fact that the drying drum of the desiccator was of iron and was acted upon by the high per cent. of lactic acid. About thirty pounds of steam pressure were used in the drying drum, the temperature in the vacuum chamber was i 25 degrees $F$. and the vacuum twenty-five to twentysix inches of the mercury column.

This buttermilk powder had a nice, clean, acid taste, it was much relished by all who sampled it and, when fed to chickens for fattening, produced satisfactory gains in weight.

Whey powder is manufactured in a similar manner. Its chief value lies in its usefulness in the diet of infants and invalids, with whom the consumption of casein produces digestive disturbances. Since fresh whey is often not obtainable, the whey powvler, the good keeping quality of which permits of keeping it on hand, furnishes an admirable substitute.

The chief objection to these desiccated dairy by-products, such as dried skim milk, dried buttermilk, and dried whey, is that the cost of reducing them to dryness is somewhat out of proportion

${ }^{1}$ Hunziker, Indiana Agricultural Experiment Station, Twenty-sixth Annual Report, 1913 
with their actual value, as compared with the raw or condensed product. Dried skim milk, for instance, sells at thirteen to fourteen cents per pound. When diluted to the consistency of the raw skim milk, one pound of powder yields about ten or eleven pounds of skim milk, costing between $\$$ I.25 to $\$ 1.40$ per hundred pounds, which is almost the price of fresh whole milk. It is obvious, that the average creamery cannot afford to make starter at the rate of $\$ 1.25$ to $\$$ I.4O per hundred pounds.

For the same reason the demand for dried buttermilk and dried whey is as yet very limited. These products, in their natural state, contain too small a proportion of the valuable ingredients, and they are too cheap to justify the high cost of manufacture, in order to place them on the market in the dry form. This, of course, does not apply to the use of dried skim milk for the many industrial purposes mentioned, where properties, other than the mere food value. determine the real merits, value and usefulness of the product. 


\title{
PA RT VI I I
}

\section{TESTS AND ANALYSES OF MILK, CONDENSED MILK AND MILK POWDER}

\author{
CHAPTER XXIX
}

\section{PRACTICAL METHODS OF SYSTEMATIC EXAMINATION OF PRODUCT FOR MARKETABLE PROPERTIES}

The manufacturer should know at all times the quality and keeping quality of his product. He should have a systematic check, not only on his product stored in the factory, but also on the goods in transit and on the market, in order to promptly detect goods that show signs of deterioration. This will enable him to investigate the cause of the defect, to prevent its recurrence and to avoid spoiled goods from reaching the consumer. The following simple method of systematic examination has been found effective in keeping a reliable check on each batch until the product is old enough to have proved its immunity from the usual specific defects.

Number of Samples Needed.-Five cans of every batch of condensed milk or evaporated milk, bearing the corresponding batch number, are reserved for this purpose. For convenience's sake these sample cans are best stored on shelves about fifteen inches widle and five inches apart. These dimensions are sufficient to conveniently accommodate five I6-ounce cans of one and the same batch and placed in a row, one behind the other. These shelves should be installed in a place, preferably the office, where the cans may be exposed to similar changes and extremes of temperature, as is the case in transit and in the retail store. The cans of sweetened condensed milk should be placed on these shelves bottom-side up. The cans of evaporated milk should be placed on the shelves right-side up. 
Frequency of Examination.-Every day one can of condensed milk or other product, one, three, ten, thirty and sixty days old, respectively, is opened and the contents are carefully examined for thickness, smoothness, sugar sediment, curdiness, fat separation, color, flavor, fermentation-changes, etc.

Technique of Examination.--Since the temperature of the product influences its apparent thickness, it is desirable to examine the condensed milk at a uniform temperature, preferably 60 or 70 degrees $\mathrm{F}$. This is best accomplished by the use of a water-tight tray of galvanized iron or tin, about twelve inches long, nine inches wide, and three and a half inches deep, with an overflow about two and a half inches above the bottom. Every day, at a regular hour, the samples of the ages above stated, are placed into this tray, containing water at the desired temperature (6o to 70 degrees F.), about thirty minutes before the cans are opened. All cans should be placed in the tray right-side up.

Upon opening the cans, the coating on the lid shows the presence of sugar sediment and of lumps of curd in the case of sweetened condensed milk, and a layer of thick and buttery cream in the case of evaporated milk. A perfectly clear lid, without any coating, indicates the freedom of the product from these defects. In the case of fermented milk the ends of the cans are usually bulged. Upon opening, a part of the contents is forced out. The thickness is estimated by inserting a spatula, or spoon, or by pouring, and the flavor and smoothness are determined by tasting.

The observations should be carefully recorded in a book reserved for this purpose, and any changes observed, as the milk advances in age, should be noted.

Interpretation of Results.-Most of the physical and mechanical defects appear in milk from one to ten days old. Defects resulting from fermentation processes generally become noticeable two to three weeks after manufacture.

Fluctuations in the thickness, from batch to batch, indicate lack of proper attention on the part of the pan-man to the "striking" of the batches. Sugar sediment shows the need of closer attention to the solution of sucrose and the cooling of the condensed milk. I.umps and buttons suggest the acceptance of a poor quality of 
fresh milk, or unsanitary condition of milk cans, vats, pipes and conveyors in the factory, or unclean tin cans. Fat separation and curdiness of evaporated milk suggest a faulty process. Fermentation of sweetened condensed milk urges investigation of the quality and condition of the sugar and of the sanitary condition. of all apparatus and conveyors of milk, condensed milk and sugar, from the forewarmers to the sealing machine. Fermented evaporated milk points to incomplete sterilization or leaky tin cans, etc.

\section{Systematic Examination a Necessary Feature of Economic} Manufacture.-Manufacturers who neglect to conduct a systematic examination of their product, similar to that outlined above, frequently argue that they cannot afford to waste five cans out of every batch.

This is indeed a mistaken conception of economy. IVith the exception of fermented milk, the "cut-opens" can be emptied into the succeeding batch, so that all that is lost is the tin cans. Fermented goods cannot be utilized anyway, neither on the market, nor elsewhere. Their loss, therefore, will occur whether in the form of "cut-opens," or cans intended for the trade.

The slight waste incurred by cutting open cans with sound contents is insignificant as compared with the incalculable savings which this practice may make possible, by the early detection of faulty goods and the prevention of their recurrence, by enabling the manufacturer to withdraw suspicious goods from the market before they have ruined the reputation of the respective brands, and by furnishing a reliable check on the work of the employees, whose knowledge, that their product is subjected to, and must pass a rigid examination, acts as a moral stimulus for high quality, skill and carefulness. 


\section{CHAPTER XXX}

\section{CHEMICAL TESTS AND ANALYSES OF MILK, SWEETENED CONDENSED MILK, EVAPORATED MILK AND MILK POWDERS}

In assembling these methods of analysis, preference has been given the "Official and Provisional Methods of Analysis," published by the American Association of Agricultural Chemists. ${ }^{1}$ The official methods have been modified and supplemented by other methods in numerous cases, wherever, in the judgment of the writer and others, such modifications and substitutions are better adapted for analysis of these special products. A special effort has further been made to include in this chapter modifications and abbreviations of tests and analyses, adapted for the use of the factory operator. whose knowledge, skill, facilities and time are too limited to enable him to successfully follow the directions of the official methods, or to execute delicate and difficult chemical analyses.

For practical factory tests of fresh milk on the receiving platform, determining its fitness for condensing, the reader is referred to Chapter III, "Factory Tests for Purity," pp. 29 to 34.

\section{MILK}

\section{SPECIFIC GRAVITY}

Aeronetric Method, by Menss of The QUenenNe LactomETER.-Use an accurate Quevenne lactometer with thermometer attachment, and a lactometer cylinder about ten inches high and one and a half inches wide. Fill the cylinder with milk at a temperature between 55 and 65 degrees $\mathrm{F}$. Insert the lactometer and when it has found its equilibrium, note the point on the scale at the surface of the milk. The correct temperature is 60 degrees F. For every degree Fahrenheit above 60 add one tenth point to the observed reading, and for every degree Fahrenheit below 60 deduct one tenth point from the observed reading. This rule holds good

\footnotetext{
${ }^{1}$ United States Department of Agrieulture, Bureau of Chemistry, Bulletin No. 107, 1912
} 
only, when the range of temperature is within the limits of 55 degrees and 65 degrees $\mathrm{F}$.

The specific gravity is calculated by adding Iooo to the lactometer reading and dividing the sum by Iooo. Example: Lactometer reading is $3 \mathrm{I}$ at 65 degrees $\mathrm{F}$. Corrected reading is $3 \mathrm{I} .5$;

$$
\text { specific gravity is } \frac{3^{\mathrm{I}} \cdot 5+1000}{1000}=1.03{ }^{1} 5 \text {. }
$$

Gravimetric Determin.tion.-This consists of the filling of a perfectly dry picnometer or other graduated flask of known measure, with milk at the standard temperature $(60$ degrees $\mathrm{F}$., or I 5.5 degrees C.) and weighing the flask and contents. The weight of the flask is then deducted from the weight of the flask plus contents and the difference is divided by the weight of an equal volume of water at standard temperature. The result is the specific gravity of the milk.

The Westphal balance method furnishes another accurate means of determining the specific gravity. Both, the gravimetric method and the Westphal balance method, while accurate when operated by the skillful chemist, require consiclerable time. Experimental comparisons have demonstrated that, for all practical purposes, the Quevenne hydrometer, when accurately graduated, yields correct results, and the simplicity and rapidity of its operation render its use in the determination of the specific gravity of milk highly advantageous and satisfactory.

\section{TOTAL SOLIDS}

BY MFANS OF TIIF B.\BCOCK FORMUL.1.-For rapid and reasonably accurate work the total solids of milk are best determined by the use of the Babcock formula, which is as follows:

$$
\text { Total solids }=\frac{\mathrm{L}}{4}+\mathrm{I} .2 \times \mathrm{f} .
$$

$\mathrm{L}=$ Quevenne lactometer reading.

$\mathrm{f}=$ per cent. of fat.

Example: Lactometer reading is 32 ; per cent. fat is 4 .

$$
\text { Total solids }=\frac{32}{4}+\mathrm{I} .2 \times+=12.8 \text { per cent. }
$$


Gravinetric Method.- - Heat from three to five grams of milk at the temperature of boiling water until it ceases to lose weight, using a tared flat dish of not less than 5 c.c. diameter. If desired, from fifteen to twenty grams of pure, dry sand may be previously placed in the dish. Cool in a desiccator and weigh rapidly to avoid absorption of hygroscopic moisture."

\section{ASH}

"Weigh about twenty grams of milk in a weighed dish, add 6 c.c. of nitric acid, evaporate to dryness, and ignite at a temperature just below redness until the ash is free from carbon."

\section{TOTAL NITROGEN}

Place about five grams of milk in a Kjeldahl digestion flask and proceed, without evaporation, as described under "Gunning Method" for the determination of nitrogen. Multiply the percentage of nitrogen by 6.38 to obtain nitrogen compounds.

\section{Gunning Method}

\section{APPARATCS}

"(a) Kjoldahl flasks for both digestion and distillation.-These are flasks having a total capacity of about $55^{\circ}$ c.c. made of hard, moderately thick, and well-annealed glass. When used for distillation the flasks are fitted with rubber stoppers and bulb tubes, as given under distillation flasks.

(b) Kjcldahl digestion flasks.-These are pear-shape, roundbottomed flasks, made of hard, moderately thick, well-annealed glass, having a total capacity of about 250 c.c. They are $22 \mathrm{c.m}$. long and have a maximum diameter of $6 \mathrm{c} . \mathrm{m}$.. tapering gradually to a long neck, which is $2 \mathrm{c.m}$. in diameter at the narrowest part and flared a little at the edge.

(c) Distillation flasks.-For distillation a flask of ordinary shape, of about $55^{\circ}$ c.c. capacity, may be used. It is fitted with a rubber stopper and with a bulb tube above to prevent the possibility of sodium hydrate being carried over mechanically during distillation. The bulbs may be about $3 \mathrm{~cm}$. in diameter, the tubes being of the same diameter as the condenser and cut off obliquely at the lower end, which is fastened to the condenser by a rubber tube." 


\section{PREPARATION OF REAGENTS}

"(a) Potassium sulphate.-This reagent should be pulverized before using.

(b) Sulphuric acid.-The sulphuric acid should have a specific gravity of $1.8_{4}$. It should be C. P. containing no nitrates nor anmonium sulphate.

(c) Sulphuric acid.- $-\mathrm{N}$-Io solution.

(d) Standard alkali solution.-The strength of this solution relative to the acid must be accurately determined, N-Io solution.

(c) Mctallic mercury or mercuric oxid.--If mercuric oxid is used, it should be prepared in the wet way, but not from mercuric nitrate.

(f) Granulated sinc or pumice stone.-One of these reagents is added to the contents of the distillation flasks, when found necessary, in order to prevent bumping.

(g) Potassium sulphid solution.-A solution of forty grams of commercial potassium sulphid in one liter of water.

(h) Sodium hydroxid solution.-A saturated solution of sodium hydroxid free from nitrates.

(i) Indicator.-A solution of cochineal is prepared by digesting and frequently agitating three grams of pulverized cochineal in a mixture of 50 c.c. of strong alcohol and 200 c.c. of distilled water for a day or two at ordinary temperatures. The filtered solution is employed as inclicator."

\section{DETERUINATION}

Place the substance to be analyzed in a digestion flask, employing from 0.7 to 3.5 grams, according to its proportion of nitrogen. Add ten grams of powdered potassium sulphate and from $\mathrm{I}_{5}$ to 25 c.c. (ordinarily about 20 c.c.) of sulphuric acid. Conduct the digestion by starting with a temperature below boiling point and increasing the heat gradually until frothing ceases. Digest for a time after the mixture is colorless or nearly so, or until oxidation is complete. Do not add either potassium permanganate or potassium sulphid. Dilute, neutralize, distil, and titrate with standard alkali. In neutralizing, it is convenient to add a few drops of phenolphthalein indicator, by which one can tell, when the acid is completely neutralized, remembering that the pink color, which indicates 
an alkaline reaction, is destroyed by a considerable excess of strong fixed alkali.

\section{CASEIN AND ALBUMIN}

"(a) Castin.-The determination should be made when the milk is fresh, or nearly so. When it is not practicable to make this determination within twenty-four hours, add one part of formaldehyde to twenty-five hundred parts of milk, and keep in a cool place. Place about ten grams of milk in a beaker with about go c.c. of water at 40 degrees to 42 degrees C., and add at once I.5 c.c. of a Io per cent. acetic acid solution. Stir with a glass rod and let stand from three to five minutes longer. Then decant or filter, wash two or three times with cold water by decantation, and transfer precipitate completely to filter. Wash once or twice on filter. The filtrate should be clear, or nearly so. If it be not clear when it first runs through, it can generally be made so by two or three repeated filtrations, after which the washing of the precipitate can be completed. Determine nitrogen in the washed precipitate and filter by the Gunning method. To calculate the equivalent amount of casein from the nitrogen multiply by 6.38 .

In working with milk which has been kept with preservatives, the acetic acid should be added.in small proportions, a few drops at a time, with stirring, and the addition continued until the liquid above the precipitate becomes clear or very nearly so.

(b) Albumin.--Exactly neutralize with caustic alkali the filtrate obtained in the preceding operation (a), add o.3 c.c. of a 10 per cent. solution of acetic acid and heat the liquid to the temperature of boiling water until the albumin is completely precipitated, collect the precipitate on a filter, wash, and determine the nitrogen therein. Nitrogen multiplied by 6.38 equals albumin."

In the place of the above method the per cent. of albumin may be determined by subtracting the per cent. of casein from the per cent. of total nitrogen.

\section{MILK SUGAR (LACTOSE)}

OP'TICAL METHOD

PREPARATION OF REAGENTS

"(a) Acid mercuric nitrate-Dissolve mercury in double its weight of nitric acid, specific gravity I.42, and dilute with an equal 
volume of water. One cubic centimeter of this reagent is sufficient for the quantities of milk mentioned below. Larger quantities may be used without affecting the results of polarization.

(b) Mercuric iodid aith acetic acid.-Mix 33.2 grams of potassium iodid, 13.5 grams of mercuric chlorid, 20 c.c. of glacial acetic acid, and 6 to c.c. of water."

\section{DETERIIXATIOX}

The milk should be at a constant temperature, and its specific gravity determined with a delicate hydrometer. When greater accuracy is required, a pycnometer is used.

The quantities of the milk measured for polarization vary with the specific gravity of the milk as well as with the polariscope used. The quantity to be measured in any case will be found in the following table.

"Determination of Volume of Milk Sample

\begin{tabular}{|c|c|c|}
\hline \multirow[b]{2}{*}{$\begin{array}{l}\text { Specifle } \\
\text { gravity }\end{array}$} & \multicolumn{2}{|c|}{ Volume of milk to be used } \\
\hline & $\begin{array}{c}\text { For polariscopes of which the } \\
\text { sucrose normal weight is } \\
16.19 \text { grams } \\
\text { Cubie centimeters }\end{array}$ & $\begin{array}{c}\text { For polariscopes of which the } \\
\text { suerose normal weight is } \\
26.048 \text { grams } \\
\text { Cubie centimeters }\end{array}$ \\
\hline I. .024 & 60.0 & $64 \cdot 4$ \\
\hline I. 026 & $59 \cdot 9$ & $64 \cdot 3$ \\
\hline I. 028 & 59.8 & $64 \cdot 15$ \\
\hline I. 030 & $59 \cdot 7$ & $64 \cdot 0$ \\
\hline I . O32 & $59 \cdot 6$ & 63.9 \\
\hline I. O34 & $59 \cdot 5$ & 63.8 \\
\hline I. 035 & $59 \cdot 35$ & $63 \cdot 7$ \\
\hline
\end{tabular}

Place the quantity of milk indicated in the table, in a flask graduated at I02.+ c.c. for a Laurent or I02.6 c.c. for a Ventzke polariscope (Mohr c.c.). Add I c.c. of mercuric nitrate solution or 30 c.c. of mercuric iodid solution (an excess of these reagents (loes no harm), fill to the mark, agitate, filter through a dry filter, and polarize. It is not necessary to heat before polarizing. In case a $200 \mathrm{~mm}$. tube is used, divide the polariscope reading by 3 when the sucrose normal weight for the instrument is 16.19 grams, or by 2 when the normal weight for the instrument is 26.048. When a 
$400 \mathrm{~mm}$. tube is used, these divisors become 6 and 4 , respectively. For the calculation of the above table the specific rotary power of lactose is taken as 52.53 degrees, and the corresponding number of sucrose as 66.5 degrees. The lactose normal weight to read ioo degrees on the sugar scale for Laurent instruments is 20.496 grams, and for Ventzke instruments, 32.975 grams. In case metric flasks are used the weights here mentioned must be reduced to i6.i6o and 26.000 grams, respectively."

\section{Low's Volumetric Metiod, Modified}

\section{PREPARATION OF REAGEXTS}

"(a) Copper sulphatc solution.--Dissolve 34.639 grams of $\mathrm{CuSO}_{4} \cdot{ }_{5} \mathrm{H}_{2} \mathrm{O}$ in water and dilute to 500 c.c.

(b) Alkaline tartrate solution.-Dissolve 173 grams of Rochelle salts and 50 grams of sodium hydroxid in water and dilute to 500 c.c.

(c) Mired solution.-Mix equal volumes of solutions (a) and (b) immediately before use.

(d) Standardization of the thiosulphatc solution.-Prepare a solution of sodium thiosulphate, dissolving 24.659 grams of pure crystals to Iooo c.c. Weigh 6.36 grams copper foil. Dissolve by warming in minimum amount of nitric acid and water required. Boil to expel the red fumes, add i 60 c.c. strong bromine water and boil until the bromine is thoroughly expelled. Remove from the heat and add a slight excess of strong ammonium hydroxid: 223 c.c. is about the right amount. Again boil until the excess of ammonia is expelled, as shown by a change of color of the liquid, and partial precipitation. Now add a slight excess of strong acetic acid ( IOO to I3O c.c. of 80 per cent. acid) and boil for a minute. Cool to room temperature and dilute to 1000 c.c. Titrate a known amount ( 10 to I5 c.c.) of the copper solution, to which ro c.c. of a 25 per cent. solution of pure potassium iodid has been added, with the thiosulphate solution until the brown tinge has become weak, then add sufficient starch liquor to produce a marked blue coloration. Continue the titration cautiously until the color clue to free iodin has entirely vanished. The blue color changes toward the end to a faint lilac. If at this point the thiosulphate be added drop by drop and a little time be allowed for complete reaction after each addition, 
there is no difficulty in determining the end point within a single drop. One cubic centimeter of the thiosulphate solution will be found to correspond to .00636 grams of copper."

\section{DETERMIXATIOY OF COPPER}

"After washing the precipitated cuprous oxid, cover the gooch with a watch glass and dissolve the oxid by means of 5 c.c. of warm nitric acid (1:I) poured under the watch glass with a pipette. Catch the filtrate in a flask of 250 c.c. capacity, wash watch glass and gooch free of copper; 50 c.c. of water will be sufficient. Boil to expel red fumes, add 5 c.c. of bromin water, boil off the bromin, and proceed exactly as in stanlardizing the thiosulphate."

\section{DETERUINATION OF LACTOSE}

Place 50 c.c. of the mixed copper reagent in a beaker and heat to the boiling point. While boiling briskly add roo c.c. of the lactose solution containing not more than 0.300 gram of lactose and boil for six minutes. Filter immediately through asbestos and wash. Obtain the weight of lactose equivalent to the weight of copper found from the following table. 
"Table for the Determination of Lactose (Soxhlet-IVein)"

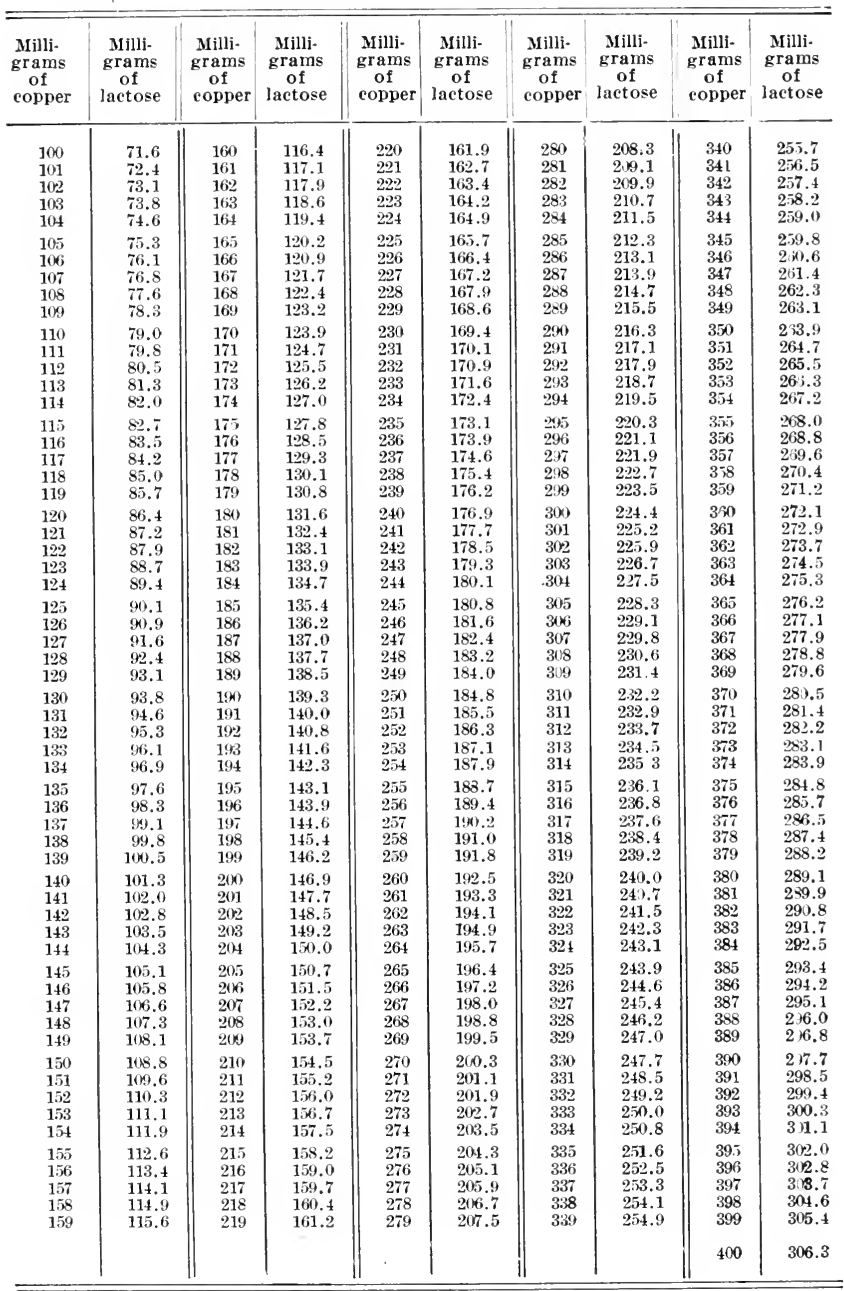




\section{BUTTER FAT}

\section{The Babcock Test}

STAXIARI) (ILANSWARE 1

(a) Standard milk test bottles, graduated to 8 per cent. and with sub-divisions of .I per cent.

(b) Pipette graduated to 17.6 c.c.

(c) Acid measure graduated to 17.5 c.c.

(d) Centrifuge-Babcock tester

(e) Water bath for reading at I 35 to I fo legrees F.

(f) Calipers for measuring fat column

(g) Sulphuric acid, specific gravity I $_{82}$ to $\mathrm{I}_{83}$

\section{IETER.MIX.ATIOX}

Pipette 17.6 c.c. of the properly mixed sample of milk into the milk test bottle. Add 17.5 c.c. of acid and shake until all the curd is completely dissolved. Both milk and acid should have a temperature of 55 to 70 degrees F. If milk and acil are too warm, set the sample bottles and the acid jar into a trough or tub of water at 55 to 70 degrees $F$. for thirty minutes before testing. The test bottles containing the mixture of milk and acid are then whirled in the Babcock tester for five minutes at about one thousand revolutions per minute, in the case of a tester with a twelve inch diameter wheel. Fill the test bottles to the bottom of the neck with hot water. The water should be soft, preferably rain water or distilled water. If hard tap water is used it should be boiled to precipitate the carbonates, otherwise the test will be difficult to read, owing to the presence of bubbles of gas on top of the fat columm. Revolve again at full speed for two minutes, fill the test bottles to near the top of the graduation with hot water. Whirl in the centrifuge for one minute. Now set the test bottles in the water bath at I35 to I fo legrees $\mathrm{F}$. for five minutes. The test is now ready to be rearl. The figures on the test bottles represent per cent. In the case of the 8 per cent. standard milk test bottle the sub-divisions represent tenths per cent. Read from the bottom of the lower curve to the top of upper curve of the fat column, including the meniscus in the reading."

${ }^{1}$ Hunziker, Indiana Agricultural Experiment station, Cireulars 41 and $\$ 2,1914$

2 For correct rearling see page 2:1 
GRAIIIETRIC HETHOJ-I'APER COIL

"Make coils of thick filter paper, cut into strips 6.25 by 62.5 c.m., and thoroughly extract with ether and alcohol, or correct the weight of the extract by a constant obtained for the paper. From a weighing bottle or weighing pipette, transfer about 5 grams of milk to the coil, care being taken to keep the end of the coil held in the fingers, dry. Dry the coil, dry end down, on a piece of glass at the temperature of boiling water; transfer to an extraction apparatus, and extract with absolute ether or petroleum ether boiling at about 45 degrees C.; dry the extracted fat and weigh."

\section{SWEETENED CONDENSED MILK}

\section{PREPARATION OF SAMPLE}

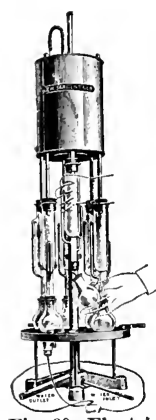

Fig. 60. Electric

fat extractor

Courtesy of

E. H. Sargent \& Co.

Pour the contents of the can into a bowl or on a glass plate. Scrape out the can thoroughly, removing all the sugar sediment from the top and bottom of the can. Mix thoroughly with pestle or spatula until a homogenous emulsion is secured. This is important, as it is exceedingly difficult to secure a representative sample otherwise.

If it is desired to use a 40 per cent. solution as directed in the determination of the individual ingredients, weigh accurately 40 grams of the properly mixed contents of the can into a IOO c.c. graduated flask. Add 60 c.c. of water. The sweetened condensed milk mixes somewhat difficultly with the water. Complete solution is facilitated by adding the water in several installments, shaking after each addition until condensed milk sediment adheres no longer to the bottom and sides of the flask.

\section{SPECIFIC GRAVITY}

Aerometric Méthod, by Means of Beaumé Hydrometer

\section{APPARATLS}

Bcaumć Hydroncter.-Use a specially constructed Beaumé hydrometer with mercury bulb, and a scale of 30 to 37 degrees B., graduated to tenths degrees. Length over all, twelve inches; length of spindel, six inches; length of empty bulb, four and one-quarter 
inches; width of empty bulb, thirteen-sixteenths of one inch.

Hydrometer Jar.-Use a glass or tin cylinder with substantial base, minimum length twelve inches, minimum width one and a half inches.

\section{DETERMINATION}

The Beaume hydrometer is graduated to read correctly at 60 degrees F. (15.5 degrees C.). At this temperature the sweetened condensed milk is too viscous for rapid and accurate work. Warm the condensed milk to Ioo degrees F. or above and correct the Beaumé reading by adding to the observed reading .025 points for every degree Fahrenheit above 60. At a temperature of 100 degrees F. or above, the reading can be made in fifteen minutes or less, after the hydrometer is inserted in the milk.

The specific gravity is determined by the use of the following formula :

$$
\text { Specific gravity }=\frac{\mathrm{I} 44 \cdot 3}{\mathrm{I}+4 \cdot 3-\mathrm{B}}
$$

$\mathrm{B}=$ Beaumé reading at 60 degrees $\mathrm{F}$.

Example: Observed Beaumé reading at 120 is 31.6

Corrected reading $=31.6+[(120-60) \times .025]=33.1$

$$
\text { Specific gravity }=\frac{\mathrm{I}+4 \cdot 3}{\mathrm{I} 44 \cdot 3-33 \cdot \mathrm{I}}=\mathrm{I} .2977
$$

The following table shows the specific gravity of sweetenerl conclensed milk when the Beaumé reading is known. 
Comparison of Degrees Beaumé With Specific Gravity

\begin{tabular}{|c|c|c|c|c|c|}
\hline Beaumé & $\begin{array}{l}\text { Speeific } \\
\text { gravity }\end{array}$ & Beaume & $\begin{array}{l}\text { Specifle } \\
\text { gravity }\end{array}$ & Beaumé & $\begin{array}{l}\text { Specifle } \\
\text { gravity }\end{array}$ \\
\hline 0 & 1.000 & 16.5 & 1.130 & 29.7 & 1.260 \\
\hline 0.7 & 1.005 & 17.1 & 1.135 & 30.2 & 1.265 \\
\hline 1.4 & 1.010 & 1.77 & 1.140 & 30.6 & 1.270 \\
\hline 2.1 & 1.015 & 18.3 & 1.145 & 31.1 & 1.275 \\
\hline 2.7 & 1.020 & 18.8 & 1.150 & 31.5 & 1.280 \\
\hline 3.4 & 1.025 & 19.3 & 1.155 & 32.0 & 1.285 \\
\hline 4.1 & 1.030 & 19.8 & 1.160 & 32.4 & 1.290 \\
\hline 4.7 & 1.035 & 20.3 & 1.165 & 32.8 & 1.295 \\
\hline 5.4 & 1.040 & 20.9 & 1.170 & 33.3 & 1.300 \\
\hline 6.0 & 1.045 & 21.4 & 1.175 & 33.7 & 1.305 \\
\hline 6.7 & 1.050 & 22.0 & 1.180 & 34.2 & 1.310 \\
\hline 7.4 & 1.055 & 22.5 & 1.185 & 34.6 & 1.315 \\
\hline 8.0 & 1.6660 & 23.0 & 1.190 & 35.0 & 1.320 \\
\hline 8.7 & 1.065 & 23.5 & 1.195 & 35.4 & 1.325 \\
\hline 9.4 & 1.070 & 24.0 & 1.200 & 35.8 & 1.330 \\
\hline 10.0 & 1.075 & 24.5 & 1.205 & 36.2 & 1.335 \\
\hline 10.6 & 1.080 & 25.0 & 1.210 & 36.6 & 1.340 \\
\hline 11.2 & 1.085 & 25.5 & 1.215 & 37.0 & 1.345 \\
\hline 11.9 & 1.090 & 26.0 & 1.220 & 37.4 & 1.350 \\
\hline 12.4 & 1.09 .5 & 26.4 & 1.225 & 37.8 & 1.355 \\
\hline 13.0 & 1.100 & 26.9 & 1.230 & 38.2 & 1.360 \\
\hline 13.6 & 1.105 & 27.4 & 1.235 & 38.6 & 1.365 \\
\hline 14.2 & 1.110 & 27.9 & 1.240 & 39.0 & 1.370 \\
\hline 14.9 & 1.115 & 28.4 & 1.245 & 39.4 & 1.375 \\
\hline 15.4 & 1.120 & 28.8 & 1.250 & 39.8 & 1.380 \\
\hline 16.0 & 1.125 & 29.3 & 1.255 & 40.1 & 1.395 \\
\hline
\end{tabular}

Gratimetric Determination

Dilute a measured portion of a to per cent. solution with an equal volume of water, use 5 c.c. of the diluted mixture, corresponding to I gram of the condensed milk and proceed as directed under "Milk," page 20 I.

\section{TOTAL SOLIDS}

Dilute a measured portion of a to per cent. solution with an equal volume of water, measure 5 c.c. of the diluted mixture, corresponding to I gram of the condensed milk into an evaporating dish containing 15 to 20 grams of pure dry sand and proceed as directed under "Milk," page 202.

\section{ASH}

Ignite the total solids at very low redness, cool, and weigh. See "Milk," page 202. 


\section{PROTEIDS}

Determine nitrogen in 5 c.c. of the to per cent. solution according to the Gunning method, see "Milk," page 202, and multiply the results by 6.38 .

\section{LACTOSE}

Dilute five grams of a to per cent. solution to about fo c.c. and add .6 c.c. of Fehling's copper solution. Nearly neutralize with sodium hydroxide, make up to roo c.c., filter through dry filter and determine lactose in an aliquot as directed under "Milk-Determination of Lactose," page 204.

\section{FAT}

\section{MODIFIED B.IBCOCK TES'T}

Weigh eighteen grams, or measure i6. I c.c. of the to per cent. solution into a standard Babcock milk test bottle. Add + c.c. of commercial sulphuric acid, specific gravity 1.82 to 1.83 . Shake immediately until acid is thoroughly mixed with the milk. Whirl in Babcock tester for six minutes at full speed. The centrifuge must run smoothly. Stop the tester gradually and remove the bottles carefully so as not to break the layer of floating curcl. Decant the clear whey by slowly inclining the bottle. Now adcl two-thirds of a 17.6 c.c. pipette full of water. After thoroughly shaking to emulsify the curd and to wash it free of sucrose, add + c.c. sulphuric acid, shake, whirl and decant as before. Then add one iz.6 c.c. pipette full of water, 17.5 c.c. of sulphuric acid and complete the liabcock test in the usual way as directed under "Nilk," page 209. Multiply the reading by 2.5 .

This method yields very satisfactory results with sweetened condensed milk containing not less than + to 5 per cent. fat. With condensed milk of a lower fat content the decanting of the clear whey is difficult, since the curd in the partly skimmed product is too heavy to float in the form of a firm cheese.

\section{The, Roese GotTlien Method}

As practicel in the Dairy Laboratory, Bureau of Chemistry, Department of Agriculture

"Weigh out 4 to 5 grams of the homogeneous sample of condensed milk into a Rohrig tube (Zeit. Lnters Nahr. u. Genussm, 
1905. 9:531) or some similar apparatus and dilute with water in the tube to about 10.5 c.c.- or, if preferred, weigh into the tube ro to I I grams of a to per cent. solution of the substance-add I $1 / 4$ c.c. of concentrated ammonium hydroxic ( 2 c.c. if the sample be sour)

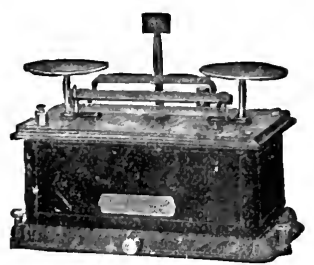

1700

Fig. (11. Balance for weighing sweetened condensed milk Courtesy of

The Torsion Balance Co.

and mix thoroughly with the milk. Add ro c.c. of 95 per cent. alcohol and mix well. Then add 25 c.c. of washed ethyl ether and shake rigorously for half a minute, then add 25 c.c. of petroleum ether (redistilled slowly at a temperature below 60 (legress C. preferably) and shake again for half a minute. Let stand 20 minutes or until the upper liquid is practically clear and its own lower level constant. Draw off of the ether solution as much as possible-usually 0.5 to 0.8 c.c. will be left-into a weighed flask through a diminutive quick acting filter, of selected paper. The flask should always be weighed with a similar one as counterpoise.

"Re-extract the liquid remaining in the tube, this time with only is c.c. of each ether, shaking vigorously half a minute with each, and allow to settle.

"Draw off the clear solution through the small filter into the same flask as before and wash the tip of the spigot, the funnel and the filter with a few c.c. of a mixture of the two ethers in equal parts (previonsly mixed and free from deposited water).

"For perfectly exact results the re-extraction must be repeated. This extraction yields usually not more than about a milligram of fat, if the previous ether-fat-solutions have been drawn off closely -an amount averaging about .O2 per cent. on a 4 gram charge.

"Evaporate the ether slowly on a steam bath, then dry the fat in a boiling water oven until loss of weight ceases.

"Prove the purity of the fat by dissolving in a little petroleum ether. Should a residue remain, wash the fat out completely with petroleum ether, dry the residue, weigh, and deduct the weight. ('This should not often be necessary.)

"Finally deduct the weight obtained by blank determination on the chemicals used.

"By this method practically absolnte results can be obtained." 


\section{SUCROSE}

Determine by difference, deducting the milk solids (ash plus proteids plus lactose plus fat) from the total solids, or invert the sucrose, determine the total invert sugar, deduct from this the lactose calculated as invert sugar and calculate the difference is sucrose.

\section{MILK SOLIDS}

Deduct the per cent. sucrose from the percent. total solids. The difference represents the per cent. milk solids.

\section{EVAPORATED MILK}

\section{PREPARATION OF SAMPLE}

Shake the can of evaporated milk vigorously before opening. If, upon opening the can, separated cream or small lumps of butter are found to adhere to the seams and around the junction of the ends and the body, set the can in a water bath at $\mathrm{z} 30$ degrees F. for ten minutes or until all fat is completely dissolved. Then pour the entire contents into a beaker and pour back and forth several times until a homogeneous mixture is secured. If it is known before opening the can that the contents are separated, submerge the whole can in a water bath at $\mathrm{I} 30$ degrees $\mathrm{F}$. for ten minutes, then shake. open and proceed as above.

If it is desired to use a to per cent. solution, as directed under the determination of the individual ingredients, weigh accurately 40 grams of the properly mixed contents of the can into a roo c.c. graduated flask. Add 6o c.c. water and mix thoroughly by shaking or stirring.

\section{SPECIFIC GRAVITY}

\section{AEROMETRIC METHOD}

\section{APPARATLS}

Bcaumé hydrometer.-Use a special Beaumé hydrometer with a scale ranging from five to twelve points, graduated to tenths degrees and mercury-weighted. Length over all eleven inches, length of spindel six inches, length of empty bulb four inches and width of empty bulb seven-eighths inch.

Hydrometer jar.-Use a glass or tin cylinder with substantial base. Minimum height ten inches and minimum width one and a half inches. 


\section{IOETERHIXATIOS}

The Beaumé hydrometer is graduated to read correctly at 60 degrees F. (I5.5 degrees C). For every degree Fahrenheit above 60 add .03I 3 points to the observed reading. For every degree Fahrenheit below 60 , deduct .03 I 3 points from the observed reading.

The specific gravity is determined by the use of the following formula :

$$
\text { Specific gravity }=\frac{\mathrm{I}+5 \cdot 5}{\mathrm{I}+5 \cdot 5-\mathrm{B}}
$$

$\mathrm{B}=$ Corrected Beaumé reading

Example: Beaumé reading at 80 degrees F. is 7.8

Corrected reading $=7.8+\left[(80-60) \times .03{ }^{1} 3\right]=8.43$

$$
\text { Specific gravity }=\frac{\mathrm{I}+5 \cdot 5}{\mathrm{I}+5 \cdot 5-8.43}=\mathrm{I}_{\mathrm{i}} .06 \mathrm{I} 5
$$

Equally good results may be obtained by diluting the evaporated milk with an equal weight of water. Then take the Quevenne lactometer reading at 60 degrees $\mathrm{F}$. Multiply the reading by 2 , add 1000 , and divide by 1000 .

\section{Gravimetric Determination}

Dilute the evaporated milk with four times its weight of water and proceed as directed under "Milk," page 20 I.

\section{TOTAL SOLIDS}

By Means of Specific Gravity and Babcock Formula

Determine the specific gravity as above directed. Multiply by IOOO and subtract Iooo. Then use the following formula:

$$
\frac{\mathrm{L}}{4}+1.2 \times \mathrm{f}
$$

$\mathrm{L}=$ The figure derived from the specific gravity by above calculations

$\mathrm{f}=$ per cent. fat

Example: Evaporated milk tests 7.8 per cent. fat and has a specific gravity of 1.06 I 5

$\mathrm{L}=(\mathrm{1} .0615 \times 1000)-\mathrm{I000}=61.5$

Total solids $=\frac{6 \mathrm{I} .5}{4}+\mathrm{I} .2 \times 7.8=24.74$ per cent. 
For rapid determination of the total solids of evaporated milk the factory operator is referred to the following tables from which the per cent. total solids may be read at a glance when the Beaumé reading at 60 degrees $\mathrm{F}$. and the per cent. fat are known.

\section{PER, CENT. SOLIDS OF EVAPORATED MILK}

The Beaumé Degrees at 60 Degrees F. are Indicated in the Horizontal Line at the Top. The Per Cent. of Fat is Shown in the Vertical Column at the Left

Beaumé reading at 60 degrees Fahrenheit

\begin{tabular}{|c|c|c|c|c|c|c|c|c|c|c|}
\hline & 8.0 & 8.1 & 8.2 & 8.3 & 8.4 & 8.5 & 8.6 & 8.7 & 8.8 & 8.9 \\
\hline $\begin{array}{c}\text { PER } \\
\text { CENT }\end{array}$ & $\begin{array}{c}\text { Solids } \\
\text { per } \\
\text { cent. }\end{array}$ & $\begin{array}{c}\text { Solids } \\
\text { per } \\
\text { cent. }\end{array}$ & $\begin{array}{c}\text { Solids } \\
\text { per } \\
\text { cent. }\end{array}$ & $\begin{array}{c}\text { Solids } \\
\text { per } \\
\text { cent. }\end{array}$ & $\begin{array}{c}\text { Solids } \\
\text { per } \\
\text { cent. }\end{array}$ & $\begin{array}{c}\text { Solids } \\
\text { per } \\
\text { cent. }\end{array}$ & $\begin{array}{c}\text { Solids } \\
\text { per } \\
\text { cent. }\end{array}$ & $\begin{array}{c}\text { Solids } \\
\text { per } \\
\text { cent. }\end{array}$ & $\begin{array}{c}\text { Solids } \\
\text { per } \\
\text { cent. }\end{array}$ & $\begin{array}{l}\text { Solids } \\
\text { per } \\
\text { cent. }\end{array}$ \\
\hline 6.0 & 21.7 & 21.94 & 22.13 & 22.32 & 22.52 & 22.71 & 22.90 & 23.10 & 23.29 & 23.49 \\
\hline 6.2 & 21.99 & 22.18 & 22.37 & 22.56 & 22.76 & 22.95 & 23.14 & 23.34 & 23.53 & 23.73 \\
\hline 6.4 & 22.23 & 22.42 & 2.61 & 2.80 & 23.00 & 23.19 & 23.38 & 2358 & 23.77 & 23.97 \\
\hline 6.6 & 20.47 & 22.66 & 2.85 & 23.04 & 23.24 & 23.43 & 23.62 & 23.82 & 24.01 & 24.21 \\
\hline 6.8 & 22.71 & 22.90 & 23.119 & 23.28 & 23.48 & 23.67 & 23.86 & 24.06 & 24.25 & 24.45 \\
\hline 7.0 & 22.95 & 23.14 & 23. & 23.52 & 23.72 & 23.91 & 24.10 & 24,30 & 4.49 & 24.69 \\
\hline 2 & 23.19 & $2: 3.38$ & 23.57 & 23.76 & 23.96 & 24.15 & 24.34 & 24.54 & 24.73 & 24.93 \\
\hline 7 & 23.43 & 23.62 & 23.81 & 24.00 & 24.20 & 24.39 & 24.58 & 24.78 & 24.97 & 25.17 \\
\hline 7.6 & 23.67 & 23.86 & 24.05 & 24.24 & 24.44 & 24.63 & 24.82 & 25.02 & 25.21 & 25.41 \\
\hline 7.8 & 23.91 & 24.111 & 24.29 & 24.48 & 24.158 & 24.87 & 25.06 & 25.26 & 25.45 & 25.61 .5 \\
\hline 8.11 & 24.15 & 24.34 & 24.53 & 24.72 & 24.92 & 25.11 & 25.30 & 25.50 & 25.69 & 25.89 \\
\hline 8.2 & 24.39 & 24.58 & 24.77 & 24.96 & 25.16 & 25.35 & 25.54 & 25.74 & 25.93 & 26.13 \\
\hline 8.4 & $24.6 i 3$ & $24.8^{\circ}$ & 25.01 & 25.20 & 25.411 & 25.59 & 25.78 & 25.98 & 26.17 & 6.37 \\
\hline 8.6 & 24.87 & 25.06 & 25.35 & 25.44 & 25.64 & 25.83 & 20.192 & $2(6.22)$ & 26.41 & 26.61 \\
\hline 8.8 & 25.11 & 25.30 & 25.49 & 25.68 & 25.88 & 26.07 & 26.26 & 26.46 & 26.65 & 26.85 \\
\hline 9.0 & 25.35 & 25.54 & 25.73 & 25.92 & 26.12 & $26 ., 31$ & 26.50 & 26.70 & 26.89 & 27.09 \\
\hline 9.2 & 25.59 & 25.78 & 25.97 & 26.16 & 21.36 & 26.55 & 26.74 & (1) & 27.13 & 27.33 \\
\hline 9.4 & 25.83 & 26.02 & 26.21 & 26.40 & 26.60 & 26.79 & 26.98 & 27.18 & 27.37 & 27.57 \\
\hline 9.6 & 26.07 & $26.26 \mathrm{i}$ & 26.45 & 26.64 & 26.84 & 27.03 & 27.22 & 27.42 & 27.61 & 27.81 \\
\hline 9.8 & 26.31 & $2(i .50$ & 26.69 & 26.88 & 27.188 & 27.27 & 27.46 & 27.66 & 27.85 & 28.05 \\
\hline 10.0 & 26.55 & 26.74 & 26.93 & 27.12 & 27.32 & 27.51 & 27.70 & 27.90 & 28,09 & 28.29 \\
\hline$\therefore$ & 26.79 & 26.98 & 27.17 & $27.31 \mathrm{i}$ & 27.56 & 27.75 & 27.94 & 28.14 & 28.33 & 28.53 \\
\hline 10.4 & 27.03 & 27.22 & 27.41 & 27.60 & 27.89 & 27.99 & 28.18 & 2838 & 28.57 & 28.77 \\
\hline 10.6 & 27.27 & 27.46 & 27.65 & 27.84 & 28.04 & 28.23 & 28.42 & 28.62 & 28.81 & 29.01 \\
\hline 10.8 & 27.51 & 27.70 & 27.89 & 28.08 & 28.28 & 28.47 & 28.66 & 28.86 & 29.175 & 29.25 \\
\hline 11.0 & 27.7 & 27.94 & 28.13 & 28.32 & 28.52 & 28.71 & 28.90 & 29.10 & 29.29 & 29.49 \\
\hline & 27.99 & 28.18 & 28.37 & 28.56 & 28.76 & 28.95 & 29.14 & 29.34 & 29.53 & 29.73 \\
\hline & 28.23 & 28.42 & 28.61 & 28.80 & $29 .(1) 1$ & 29.19 & 29.38 & 29.58 & 29.77 & 29.97 \\
\hline $11.6 \mathrm{i}$ & 28. & 28.660 & 28.85 & 29.04 & 29.24 & 29.43 & 29.62 & 29 & 30.01 & 30.21 \\
\hline 11.8 & 28.71 & 28.90 & 29.09 & 29.28 & 29.48 & 29.67 & 29.86 & 30.06 & 30.25 & 30.45 \\
\hline
\end{tabular}


PER CENT. SOLIDS OF EVAPORATED MILK (Continued)

The Beaumé Degrees at 60 Degrees F. are Indicated in the Horizontal Line at the Top. The Per Cent. of Fat is Shown in the Vertical Column at the Left

Beaume reading at 60 degrees Fahrenheit

\begin{tabular}{|c|c|c|c|c|c|c|c|c|c|c|}
\hline & 9.0 & 9.1 & 9.2 & 9.3 & 9.4 & 9.5 & 9.6 & 9.7 & 9.8 & 9.9 \\
\hline $\begin{array}{c}\text { PER } \\
\text { CENT }\end{array}$ & $\begin{array}{c}\text { Solicls } \\
\text { per } \\
\text { cent. }\end{array}$ & $\begin{array}{l}\text { Solids } \\
\text { per } \\
\text { cent. }\end{array}$ & $\begin{array}{l}\text { Solids } \\
\text { per } \\
\text { cent. }\end{array}$ & $\begin{array}{c}\text { Solids } \\
\text { per } \\
\text { cent. }\end{array}$ & $\begin{array}{l}\text { Solids } \\
\text { per } \\
\text { cent. }\end{array}$ & $\begin{array}{c}\text { Solids } \\
\text { per } \\
\text { cent. }\end{array}$ & $\begin{array}{c}\text { Solids } \\
\text { per } \\
\text { cent. }\end{array}$ & $\begin{array}{l}\text { Solids } \\
\text { per } \\
\text { cent. }\end{array}$ & $\begin{array}{l}\text { rolids } \\
\text { per } \\
\text { cent. }\end{array}$ & $\begin{array}{l}\text { Solids } \\
\text { per } \\
\text { cent. }\end{array}$ \\
\hline 6.0 & 23.68 & 23.88 & 24.08 & 24.27 & 24.47 & 24.66 & 24.86 & 25.06 & 25.26 & 25.45 \\
\hline 6.2 & 23.92 & 24.12 & 24.32 & 24.51 & 24.71 & 24.90 & 25.10 & 25.30 & & 25.69 \\
\hline 6.4 & 24.16 & 24.36 & 24.56 & 24.75 & 24.95 & 25.14 & 25.34 & $25.5 \mathrm{t}$ & 25.74 & 25.93 \\
\hline 6.6 & 24.40 & 24.60 & 24.80 & 24.99 & 25.19 & 25.38 & 25.58 & 25.78 & 25.98 & 26.17 \\
\hline 6.8 & 24.64 & 24.84 & 25.04 & 25.23 & 25.43 & 25.62 & $25.8^{\circ}$ & 26.012 & 2 & 26.41 \\
\hline 7.0 & 24.88 & 25.08 & 25.28 & 25.47 & $25.6 \bar{\tau}$ & 25.86 & 26.06 & 26.26 & 26.46 & 26.65 \\
\hline 7.2 & 25.12 & 25.32 & 25.52 & 25.71 & 25.91 & 26.10 & 26.30 & 26.511 & 26.70 & 26.89 \\
\hline 7.4 & 25.36 & 25.56 & 25.76 & 25.95 & 26.15 & 26.34 & 26.54 & 26.74 & 26.94 & 27.13 \\
\hline 7.6 & 25.60 & 25.80 & 26.00 & 26.19 & 2 & 88 & 26.78 & 26.98 & & 27.37 \\
\hline 7.8 & 25.84 & 26.04 & 26.24 & 26.43 & $26.6: 3$ & 26.82 & 27.02 & 2722 & 27.42 & 27.61 \\
\hline 8.0 & 26.08 & 26.28 & 26.48 & 26.67 & 26.87 & 27.06 & 27.26 & .46 & & 27.85 \\
\hline 8.2 & 26.32 & 26.52 & 26.72 & 26.91 & 27. & 27.30 & 27.50 & $\div .70$ & 60 & 28.09 \\
\hline 8.4 & 26.56 & 26.76 & 26.96 & 27.15 & 27.35 & 27.54 & 27.74 & 27.94 & & 28.33 \\
\hline 8.6 & 26.80 & 27.00 & 27.20 & 27.39 & 27.59 & 27.78 & 27.98 & 28.18 & & 28.57 \\
\hline 8.8 & 27.04 & 27.24 & 27.44 & 27.63 & 27.83 & 28.02 & 28.22 & 2842 & 28.62 & 28.81 \\
\hline 9.0 & 27.28 & 27.48 & 27.68 & 27.87 & 2 & 28 & 28 & 28 & & 9.15 \\
\hline 9.2 & 27.52 & 27.72 & 27.92 & 28.11 & 28.31 & 28.50 & 28.70 & 28.90 & & 29.29 \\
\hline 9.4 & 27.76 & 27.96 & 28.16 & 28.35 & 28.55 & 28.74 & 28.84 & 29.14 & 29.34 & 29.53 \\
\hline 9.6 & 28.00 & 28.20 & 28.40 & 28.59 & 28.79 & 28.98 & 29.18 & 9.58 & 29.53 & 29.77 \\
\hline 9.8 & 28.24 & 28.44 & 28.64 & 28.83 & 29.03 & 2922 & 29.42 & 29.62 & 29.82 & 30.01 \\
\hline 10.0 & 28.48 & 28.68 & 28.88 & 29.07 & 29. & 29.46 & 29.66 & 29.86 & & 30.25 \\
\hline 10.2 & 28.72 & 28.92 & 29.12 & 29.31 & 29.51 & 29.70 & 29.911 & 30.10 & $\therefore$ & 50.49 \\
\hline 10.4 & 28.96 & 29.16 & 29.36 & 29.55 & 29.75 & 29.94 & 30.14 & 30.34 & & 30.73 \\
\hline 10.6 & 29.20 & 29.40 & 29.611 & 29.79 & 29.99 & 30.18 & 30.33 & 3058 & 30 & 30.97 \\
\hline 111.8 & 29.44 & 29.64 & 29.84 & 30.03 & 30.23 & 30.42 & 20.622 & 311.2 & $31.0^{\circ}=$ & 31.21 \\
\hline 11.0 & 29.68 & 29.88 & 30.08 & 30.27 & 30.47 & 30.66 & 80.86 & 31 & & 31.45 \\
\hline & 29.92 & 30.12 & 30.32 & 30.51 & 30.71 & 30.90 & 31.10 & 31.30 & & 31.69 \\
\hline 11 & 30.16 & 30.36 & $30.51 \%$ & 30.75 & 30.95 & 31.14 & 3134 & 31.54 & 31.74 & 31.93 \\
\hline 11.6 & 30.40 & 30.60 & 30.80 & 30.99 & 31.19 & 31.88 & 3158 & 31.78 & 31.98 & 32.17 \\
\hline 11.8 & 311.64 & 30.84 & 31.04 & 31.23 & 31.43 & 31.62 & 31.82 & 32.02 & 3222 & 2241 \\
\hline
\end{tabular}




\section{PER CENT. SOLIDS OF EVAPORATED MILK (Continued)}

The Beaumé Degrees at 60 Degrees F. are Indicated in the Horizontal Line at the Top. The Per Cent. of Fat is Shown in the Vertical Column at the Left

\section{Beaumé reading at 60 degrees Fahrenheit}

\begin{tabular}{|c|c|c|c|c|c|c|c|c|c|c|}
\hline \multirow{2}{*}{$\begin{array}{r}\text { FAT } \\
\text { PER } \\
\text { CENT }\end{array}$} & 10.0 & 10.1 & 10.2 & 10.3 & 10.4 & 10.5 & 10.6 & 10.7 & 10.8 & 10.9 \\
\hline & $\begin{array}{l}\text { Solids } \\
\text { per } \\
\text { cent. }\end{array}$ & $\begin{array}{l}\text { Solids } \\
\text { per } \\
\text { cent. }\end{array}$ & $\begin{array}{c}\text { Solids } \\
\text { per } \\
\text { cent. }\end{array}$ & $\begin{array}{l}\text { Solids } \\
\text { per } \\
\text { cent. }\end{array}$ & $\begin{array}{l}\text { Solids } \\
\text { per } \\
\text { cent. }\end{array}$ & $\begin{array}{l}\text { Solids } \\
\text { per } \\
\text { cent. }\end{array}$ & $\begin{array}{l}\text { Solids } \\
\text { per } \\
\text { cent. }\end{array}$ & $\begin{array}{c}\text { Solids } \\
\text { per } \\
\text { cent. }\end{array}$ & $\begin{array}{l}\text { Solids } \\
\text { per } \\
\text { cent. }\end{array}$ & $\begin{array}{c}\text { Solids } \\
\text { per } \\
\text { cent. }\end{array}$ \\
\hline 6.0 & 25.65 & 25.85 & 26.05 & 26.25 & 26.45 & 26.65 & 26.85 & 27.05 & 27.25 & 27.45 \\
\hline 6.2 & 25.89 & 26.09 & 26.29 & 26.49 & 26.69 & 26.89 & 27.09 & 27.29 & 27.49 & 27.69 \\
\hline 6.4 & 26,13 & 26.33 & 26.53 & 26.73 & 26.93 & 27.13 & 27.33 & 27.53 & 27.73 & 27.93 \\
\hline 6.6 & 26.37 & 26.57 & 26.77 & 26.97 & 27.17 & 27.37 & 27.57 & 27.77 & 27.97 & 28.17 \\
\hline 6.8 & 26.61 & 26.81 & 27.01 & 27.21 & $2 \pi .41$ & 27.61 & 27.81 & 28.01 & 28.21 & 28.41 \\
\hline 7.0 & 26.85 & 27.05 & 27.25 & 27.45 & 27.65 & 27.85 & 28.05 & 28.25 & 28.45 & 28.65 \\
\hline .2 & 27.09 & 27.29 & 27.49 & 27.69 & 27.89 & 28.09 & 23.29 & 28.49 & 28.69 & 28.89 \\
\hline 7.4 & 27.33 & 27.53 & 27.73 & 27.93 & 28.13 & 28.33 & 28.53 & 28.73 & 28.93 & 29.13 \\
\hline 7.6 & 27.57 & 27.77 & 27.97 & 28.17 & 28.37 & 28.57 & 28.77 & 28.97 & 29.17 & 29.37 \\
\hline 7.8 & 27.81 & 28.01 & 28.21 & 28.41 & 28.61 & 28.81 & 29.01 & 29.21 & 29.41 & 29.61 \\
\hline 8.0 & 28.05 & 28.25 & 28.45 & 28.65 & 28.85 & 29.05 & 29.25 & 29.45 & 9.65 & 29.85 \\
\hline 8.2 & 28.29 & 28.49 & 28.69 & 28.89 & 29.09 & 29.29 & 29.49 & 29.69 & 29.89 & 30.09 \\
\hline 8.4 & 28.53 & 28.73 & 28.93 & 29.13 & 29.33 & 29.53 & 29.73 & 29.93 & 30.13 & 30.33 \\
\hline 8.6 & 28.77 & 28.97 & 29.17 & 29.37 & 29.57 & 29.77 & 29.97 & 30.17 & 30.37 & 30.57 \\
\hline 8.8 & 29.01 & 29.21 & 29.41 & 29.61 & 29.81 & 30.01 & 30.21 & 30.41 & 30.61 & 30.81 \\
\hline 9.0 & 29.25 & 29.45 & 29.65 & 29.85 & 30.05 & 30.25 & 30.45 & 30.65 & 30.85 & 31.05 \\
\hline 9.2 & 29.49 & 29.69 & 29.89 & 30.09 & 30.29 & 30.49 & 30.69 & 30.89 & 31.09 & 31.29 \\
\hline 9.4 & 29.73 & 29.93 & 30.13 & 30.33 & 30.53 & 30.73 & 30.93 & 31.13 & 31.33 & 31.53 \\
\hline 9.6 & 29.97 & 30.17 & 30.37 & 30.57 & 30.77 & 30.97 & 31.17 & 31.37 & 31.57 & 31.77 \\
\hline 9.8 & 30.21 & 30.41 & 30.61 & 30.81 & 31.01 & 31.21 & 31.41 & 31.61 & 31.81 & 32.01 \\
\hline 10.0 & 30.45 & 30.65 & 30.85 & 31.05 & 31.25 & 31.45 & 31.65 & 31.85 & 32.05 & 32.25 \\
\hline 10.2 & 30.69 & 30.89 & 31.09 & 31.29 & 31.49 & 31.69 & 31.89 & 32.09 & 32.29 & 32.49 \\
\hline 10.4 & 30.93 & 31.13 & 31.33 & 31.53 & 31.73 & 31.93 & 32.13 & 32.33 & 32.53 & 32.73 \\
\hline 10.6 & 31.17 & 31.37 & 31.57 & 31.77 & 31.97 & 32.17 & 32.37 & 32.57 & 32.77 & 32.97 \\
\hline 10.8 & 31.41 & 31.61 & 31.81 & 32.01 & 32.21 & 32.41 & 32.61 & 32.81 & 33.01 & 33.21 \\
\hline 11.0 & 31.65 & 31.85 & 32.05 & 32.25 & 32.45 & 32.65 & 32.85 & 33.05 & 33.25 & 33.45 \\
\hline $11 \%$ & 31.89 & 32.09 & 32.29 & 32.49 & 32.69 & 32.89 & 33.09 & 33.29 & 33.49 & 33.69 \\
\hline 11.4 & 32.13 & 32.33 & 32.53 & 32.73 & 32.93 & 33.13 & 33.33 & 33.53 & 33.73 & 33.93 \\
\hline 11. & 32.37 & 32.57 & 32.77 & 32.97 & 33.17 & .33 .37 & 33.57 & 33.77 & 33.97 & 34.17 \\
\hline 11.8 & 32.61 & 32.81 & 33.01 & 33.21 & 33.41 & 33.61 & 33.81 & 34.01 & 34.21 & 34.41 \\
\hline
\end{tabular}




\section{Gravimetric DetTermination}

Dilute a measured portion of a to per cent. solution with an equal volume of water, use 5 c.c. of the diluted mixture, corresponding to I gram of the eraporated milk and proceed as directed under "Milk," page 202.

\section{$\mathrm{ASH}$}

Ignite the total solids at very low redness, cool, and weigh, see "Milk," page 202.

\section{PROTEIDS}

Use 5 c.c. of a to per cent. solution, determine nitrogen according to the Gunning Method as directed under "Milk," page 202, and multiply result by 6.38 .

\section{LACTOSE}

Dilute Io grams of a 40 per cent. solution to about fo c.c. and add .6 c.c. of Fehling's copper solution; nearly neutralize with sodium hydroxide, make up to Ioo c.c., filter through dry filter, and determine lactose in an aliquot as directed under "Milk," page 204.

\section{FAT}

\section{THE MODIFIFd Babceck Métiod ${ }^{1}$}

Carefully weigh 4.5 grams of well-mixed evaporated milk into the 8 per cent. test bottle. Add one 17.6 pipetteful of water. Add 17.5 c.c. of sulphuric acid and shake until the curd in the test bottle is completely dissolved. IVhirl at usual speed (one thousand revolutions per minute) for five minutes. Mix equal portions of water and sulphuric acid in glass beaker. For one or two tests, one pipetteful of water and one acid measure full of acill are sufficient. Fill test bottle to slightly below the bottom of the neck with the hot diluted acid. Whirl for two minutes. If the fat collected at the base of the neck is not clear, shake the bottles until all the curdy matter is completely dissolved, fill bottle to about the 8 per cent. mark with hot water, whirl for one minute and read the test at 140 degrees $F$. The fat column must be read from the top of the upper meniscus to the bottom of the lower meniscus. Nuttiply the reading by 4. This gives the correct per cent. of fat.

\footnotetext{
1 Hunziker and Spitzer, Indiana Agricultural Experiment Station, Bulletin No. 134, 19:9
} 
Instead of weighing 4.5 grams into the test bottle, a 4.3 c.c. pipette may be used. After emptying the pipette into the bottle it

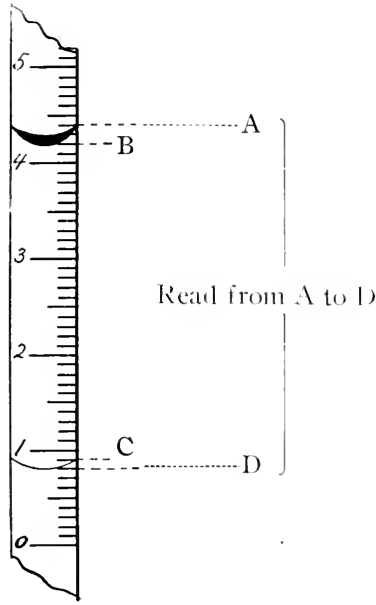

liig. 6\%.

keading the babconk tont should be rinsed twice, and the rinsings discharged into the test bottle.

For making numerous tests from the same sample it is advisable to dilute the evaporated milk with equal parts of water, by weiglit: then weigh nine grams of this dilution into the test bottles and add one-half pipetteful of water.

The Rofse Gotthte Method

Proceed as directed under "Sweetened Condensed Milk," page 213.

\section{MILK POWDER} TOTAL SOLIDS

Neigh 5 grams of the milk powder in a drying bottle or evaporating dish and place in drying oven at roo to to5 degrees C. until constant weight is secured.

ASH

Weigh two grams of the milk powiler in a weighed platinum dish and proceed as directed under "Milk," page 202.

\section{PROTEIDS}

Use 5 grams of the milk powder and proceed as clirected under "Milk," page $2 \mathrm{O} 2$.

\section{MILK SUGAR (LACTOSE)}

Dissolve 10 grams of milk powder in go c.c. of water. Warm and stir until a satisfactory solution is effected and proceed as directed under "Nilk," page 204. and multiply result by ro.

\section{SUCROSE}

For the determination of sucrose proceed as directed under "Sweetened Condensed Milk," page 21 5. 
The Babcock Trst Mlitiod.-Dissolve 10 grams of milk powder in go c.c. of water. Warm and mix until a complete solution is effected. Then proceed as directed under "Milk," page 209. and multiply the result by 10.

"Roes: GotThin: Mlornow.-Weigh I gram of the powder in a 30 c.c. lipped beaker. Liub up with 9 c.c. of water and 2 c.c. of concentrated ammonium hydroxid, digest on steam bath until the casein is well softened and the whole resembles milk. Cool, transfer to Rohrig tube or similar apparatus, using 10 c.c. of 95 per cent. alcohol for rinsing, followed, after shaking contents of tube, by 25 c.c. of washed ethyl ether. Shake vigoronsly for one-half minute, and proceed as in the determination of fat in sweetened condensed milk."

\section{CHAPTER XXXI}

\section{DETECTION OF ADULTERANTS AND PRESERVATIVES IN MILK}

\section{Addition of Water and Skim Milk and the Removal of Cream}

Friouency of Aduteritun.-Experience has shown that where milk is received from a large number of patrons, as is the case in most milk condensing factories, some of the milk may be and frequently is being tampered with before it reaches the factory. In the case of condenseries buying and paying for the milk on the butter fat basis, neither the watering nor the skimming of the milk results in any material direct loss to the factory. Excessive skimming, however, does reduce the yield of the finished product somewhat, inasmuch as a small amount of solids is removed with the cream. Excessive watering necessitates the expenditure of slightly more fuel to remove the extraneous water in the process of evaporation.

Where the condensery buys and pays for its milk by the humdred weight, however, it is obviously essential that such adulterations be guarded against ly eternal vigilence.

TAKing and PrisirRving ol THE Sampres-In order to minimize the work of testing without interfering with the effectiveness 
of the control, it is alvisable to take composite samples. Use pint jars with tight lids; label the jars with the number of the respective jatron and place them in numerical order on conveniently located shelves on the receiving platform. In the case of the route systens of receiving milk, the samples of milk from each route should be stored together. Use a dipper holding one ounce of milk : by pouring a dipperful of milk of each patron each day into the respective jars, enough milk is collected in each jar at the end of two weeks to test with the lactometer and the Babcock test every two weeks.

In order to preserve the samples in proper condition drop at large corrosive sublimate tablet into each enpty jar and after each addition of milk, mix the corrosive sublinate with the milk by giving the jar a rotary motion. Add one dipperful of each patron's milk daily into the jars.

Testing the Composite SAmples.--At the end of every two weeks test the samples with the (unevenne lactometer and the Babcock test. The samples should have a temperature of 55 to 65 degrees F. In summer and at any other time when the temperature naturally is much higher or lower, place the sample jars into a tank or tub of water at the desired temperature, from one half hour to an hour before testing. For directions for the use of the lactometer and the labcock tester, see Chapter XXX, "Milk," page 200. If the milk contans corrosive sublimate, derluct one-lialf point from the lactometer reading for each tablet in one pint of sample.

INTERPRETATION OF RFSUL'S.-The lactometer reading and the per cent. fat alone furnish a pretty safe inclex to the freelom from, or presence of adulteration of the milk. From these two factors other guides, such as the specific gravity, per cent. of total solids and per cent. of solids not fat of milk, and specific gravity of the milk solids may be calculated. These are of alditional assistance to the inspector. All of these factors vary considerably with the individuality, breed, period of lactation and feed of the cows, so that considerable latitule must be allowed in determining whether or not any given sample of milk has been alulterated. 'These variations are greatest between inclividual cows and between different breeds, but they also are quite striking in milk of the same cows from day to lay and at different stages of the period of lactation. In mixed herd milk, such as the condensery largely reccives, the composition is 
comparatively uniform on consecutive days. Whenever possible, in the case of suspicious milk received at the factory, samples should be secured direct from the stable for comparison.

The following may be considered reasonable limits of composition beyond which normal milk seldom trespasses, and milk not falling within these linits may be regarcled with suspicion.

\section{Minimum Maximum Average}

Fat 2.5 per cent.

4 per cent.

Specific gravity of milk r.o2g

I.034

I.032

Per cent. total solicls II.5O

I 2.3

Per cent. solids not fat 7.75

9.25

8.5

Specific gravity of milk

solids

$1.25 \quad 1.36$

I.33

These factors are affected by the skimming and watering of milk as follows:

Cream removed or $\left\{\begin{array}{l}\text { Fat low } \\ \text { Specific gravity of milk high } \\ \text { Total solids low } \\ \text { Solids not fat high } \\ \text { Specific gravity of milk solids high }\end{array}\right.$

Water arlded $\left\{\begin{array}{l}\text { Fat normal or low } \\ \text { Specific gravity of milk loa } \\ \text { Total solids low } \\ \text { Solids not fat low } \\ \text { Specific gravity of nilk solids normal }\end{array}\right.$

Cream removed water adled $\left\{\begin{array}{l}\text { Fat low } \\ \text { Specific gravity of milk normal } \\ \text { Total solids loa' } \\ \text { Solicls not fat loa or normal } \\ \text { Specific gravity of milk solicls normal or high }\end{array}\right.$

The total solirls are determined by the formula 
The solids not fat are cletermined by the formula

$$
\frac{\mathrm{L}}{4}+.2 \times \mathrm{f}
$$

The specific gravity of the milk solids is determined by the formula

$$
t-\frac{t}{\frac{I O O S-I 0 O}{s}}
$$

$\mathrm{L}=$ Quevenne lactometer rearling at 60 degrees $\mathrm{F} . ; \mathrm{f}=$ per cent. fat; $\mathrm{t}=$ total solids; $\mathrm{s}=$ specific gravity of milk.

Example of milk that is normal.-Quevenne lactometer reading at 60 legrees F. 32, fat 4 per cent.

Answer:

Specific gravity of the milk $=1.032$

Total solids $\frac{32}{4}+\mathrm{r} .2 \times 4=\mathrm{I} 2.8$ per cent.

Solicls not fat $\frac{32}{t}+.2 \times 4=8.8$ per cent.

Specific gravity of milk solids

$$
12.48-\frac{12.48}{\frac{100}{\frac{1.032}{1.0 .32}}}=1.300
$$

E.rample of milk to which ater has been added.-Onevenne lactometer reading at 60 degrees $F$. 26 , fat 3.8 per cent.

Answer:

Specific gravity of milk $=1.026$

Total solids $\begin{gathered}26 \\ 4\end{gathered}+\mathrm{I} .2 \times 3.8=$ I I.of per cent.

Solicls not fat $\frac{26}{4}+.2 \times 3.8=7.26$ per cent.

Specific gravity of milk solids

$$
\begin{array}{ll}
11.06)-\frac{11.06}{100} & \begin{array}{l}
1.026-100 \\
1.026
\end{array}
\end{array}
$$


E.rample of milk from which cream was remozed or to which skimmed milk aras added.-Quevenne lactometer reading at to degrees F. 35, fat 2 per cent.

Answer:

Specific gravity of milk $=1.035$

Total solirls $\frac{35}{4}+$ I.2 $\times 2=$ I I. I 5 per cent.

Solids not fat $-\frac{35}{4}+.2 \times 2=9.15$ per cent.

Specific gravity of milk solids

$$
\text { II.I } 5-\frac{\text { II.I } 5}{\frac{100 \times 1.035-100}{1.035}}=1 .+f^{6}
$$

Example of milk from which cream a'as romored and to ahich water was added.-Quevenne lactometer reading at 60 degrees $\mathrm{F}$. 32, fat 2 per cent.

Answer:

Specific gravity of milk $=1.032$

Total solirls $\frac{3^{2}}{4} \cdot+\mathrm{r} .2 \times 2=$ I0.4 per cent.

Solids not fat $\frac{32}{4}+.2 \times 2=8.4$ per cent.

Specific gravity of milk solirls

$$
\frac{\mathrm{IO} .4}{\mathrm{I} 0.4-\frac{100 \times 1.032-\mathrm{IOO}}{\mathrm{I} .032}}=\mathrm{I} .425 \text { per cent. }
$$




\section{DETECTION OF ARTIFICIAL COLORING ${ }^{1}$}

\section{LEACH'S METHOD}

"Warm about 150 c.c. of nilk in a casserole over the flame and add about 5 c.c. of acetic acid, after which slowly continue the heating nearly to the boiling point while stirring. Gather the curd, when possible, into one mass by the stirring rod, and pour off the whey. If the curd breaks up into small flakes separate from the whey by straining through a sieve or colander. Press the curd free from allhering liquill, transfer to a small flask, and macerate for several hours (preferably over night) in about 50 c.c. of ether, the Hask being tightly corked and shaken at intervals.

\section{1. "DETECTION OF ANNATTO (IN THE ETHER EXTRACT)}

"Decant the ether extract as obtained above into an evaporating dish, place on the water bath, and evaporate the ether. Nake the fatty residue alkaline with sodium hydroxid, and pour upon a very small wet filter while still warm. Ifter the solution has passed through, wash the fat from the filter with a stream of water and dry the paper. If, after lrying. the paper is colored orange, the presence of annatto is indicated. Confirm by applying a drop of stamons chlorid solntion, which, in presence of annatto, produces a characteristic pink on the vrange-colored paper.

\section{2. "DETECTION OF ANILIN ORANGE (IN THE CURD)}

"The curd of an uncolored milk is perfectly white after complete extraction with ether, as is also that of a milk colored with annatto.

"If the extracted fat-free curd is distinctly dyed an orange or yellowish color, anilin orange is indicated. To confirm the presence of this color, treat a lump of the fat-free curd in a test tube with a little strong lyclrochloric acid. If the curd immediately turns pink. the presence of anilin orange is assured.

${ }^{1}$ Cnited States Department of Agrieulture, Bureau of Chemistry, Bulletin No. 107 


\section{3. "DETECTION OF CARAMEL (IN THE CURD)}

"If the fat-free curd is colored a dull brown, caramel is to be suspected. Shake a lump of the curd, as in (2), with strong hylrochloric acid in a test tube and heat gently. In the presence of caramel the acid solution will gradually turn a deep blue, as will also the white, fat-free curd of an uncolored milk, while the curd itself does not change color. It is only when this blue coloration of the acid occurs in connection with a brown colored curd, which itself does not change color, that caramel is to be suspected, as distinguished from the pink coloration produced at once under similar conditions by anilin orange."

\section{4. "LYTHGOE'S TEST FOR ANILIN ORANGE}

"'Treat about so c.c. of the milk with an equal volume of hydrochloric acid (sp. gr. 1.20) in a porcelain casserole and give the dish a slight rotary-motion. If an appreciable amount of anilin orange is present, a pink color will at once be imparted to the curd particles as they separate."

\section{DETECTION OF SUCROSE IN MILK TO WHICH SUCRATE OF LIME ${ }^{1}$ (VISCOGEN) HAS BEEN ADDED}

25 c.c. of milk or cream are shaken in a small E.rlenmeyer flask with Io c.c. of a 5 per cent. solution of uranium acetate, allowed to stand for five minutes and filtered through a folled filter. If the filtrate is not clear, pour through filter again until clear. To Io c.c. of the filtrate 2 c.c. of a cold saturated solution of ammonium molybdate and 8 c.c. of lydrochloric acid (one part of 25 per cent. acid to seven parts of water) are added. The mixture is shaken and placerl in a water bath at 80 degrees C. for five minutes. In the case of the presence of sucrose the solution becomes more or less blue according to amount of sucrose present. Upon standing in the water bath for a longer time the blue color becomes deeper. It the end of ten minutes it is deep blue, while in the absence of sucrose at the end of five minutes the color is faintly green, which deepens, but never acquires a blue shade. By means of this method as little as .05 per cent. sucrose can be detected.

\footnotetext{
${ }^{1}$ Barthel, Milk and Dairy Produets
} 


\section{DETECTION OF LIME IN MILK ${ }^{1}$}

Shake 250 c.c. of milk at 15 degrees C. with io c.c. of a io per cent. solution of hyllochloric acicl. Let stand at room temperature for half an hour. Filter, returning the first portion of filtrate to the filter. Cover filter to prevent evaporation.

Pour Iof c.c. of the filtrate (equal to 100 c.c. of milk) into a 200 c.c. flask, add 10 c.c. of a 10 per cent. solution of ammonia and fill the flask to the mark with water at 15 degrees C. Let stand for thirty minutes. Filter through folded filter, pouring back on the filter the first portion of the filtrate. Test 100 c.c. of filtrate (equivalent to 50 c.c. of milk) with ro c.c. of 5 per cent. ammonium oxalate solution and proceed with the determination of the lime in the ustal way, but without warming the liquid.

According to Baier and Neumann and corroborated by Luhrig. in normal milk the lime in the serum is present to the extent of thirteen to eighteen milligrams per Ioo c.c. In milk to which sucrate of lime has been added the results are correspondingly higher.

\section{DETECTION OF GELATIN :}

. Prepare an acid solution of mercuric nitrate by dissolving mercury in twice its weight of nitric acirl of 1.42 specific gravity, and diluting this solution to twenty-five times its bulk with water. To Io c.c. of the milk or crean to be examined, add an equal volume of the acid mercuric nitrate solution, shake the mixture, add 20 c.c. of water, shake again, allow to stand five minutes, and filter. If much gelatin is present the filtrate will be opalescent and cannot be obtained quite clear. To a portion of the filtrate contained in a test tube, add an equal volume of a saturated aqueous solution of picric acid. A yellow precipitate will be produced in presence of any considerable amount of gelatin, while smaller amounts will be indicated by a cloudiness. In the absence of gelatin the filtrate obtained will remain perfectly clear."

\section{DETECTION OF PRESERVATIVES}

CARBONATE OR BICARBONATE OF SODA ${ }^{1}$ (HILGER'S METHOD)

Dilute 50 c.c. of milk with 250 c.c. of water. Heat and precipitate with a small quantity of alcohol. Filter, evaporate the filtrate

\footnotetext{
${ }^{1}$ Barthel, Milk and Dairy Products

${ }^{2}$ Cnited States Department of Agriculture, Bureau of Chemistry, Bulletin 107, 1912
} 
to one-half its original volume and test with litmus for an alkaline carbonate.

\section{FORMALDEHYDE (HEHNER'S METHOD)}

Dilute the milk with an equal volume of water. Fill a test tube one-half full. Add commercial sulphuric acid, specific gravity i.82I.84. The acid should be allowed to flow down the side of the tube so as to aroid excessive mixing of acid and milk. If formaldehyde is present a violet ring forms at the junction of milk and acid. By this test the presence of one part of formaldehyde in two hundred thousand parts of milk can be detected. When more than .05 per cent. formaldehyde is present the violet color does not appear.

The same color reaction is obtained when the acid is added to the milk in the Babcock test.

Farrington and Woll $^{1}$ recommend the following method: Measure 5 c.c. of milk in a white porcelain dish, add 5 c.c. of water, and Io c.c. of hydrochloric acid containing a trace of ferric chloride $\left(\mathrm{Fe}_{2} \mathrm{Cl}_{6}\right)$. Heat the mixture. If formaldehyde is present a violet color appears.

\section{BORIC ACID AND BORATES ?}

"Render decidedly" alkaline with lime water about 25 grams of the sample and evaporate to dryness on a water bath. Ignite the residue to destroy organic matter. Digest with about is c.c. of water, add hydrochloric acid, drop by drop, until all is dissolved, and add I c.c. in excess. Moisten a piece of delicate turmeric paper with the solution; if borax or boric acid is present, the paper on drying will acquire a peculiar red color, which is changed by ammonium hydroxid to a dark blue-green, but is restored by acid.

A preliminary test may be made by immersing a strip of turmeric paper in about Ioo c.c. of liquid foods, to which about 7 c.c. of concentrated hydrochloric acid has been added. Solid and pasty goods may be heated with enough water to make them thoroughly fluid, hydrochloric acid added in about the proportion of $I$ to 13 , and tested in the same manner."

\section{BENZOIC ACID ?}

"Add 5 c.c. of dilute hydrochloric acid to 50 c.c. of the milk in a flask and shake to curdle. Then add I 50 c.c. of ether, cork the

${ }^{1}$ Farrington \& Woll, Testing Milk and its Products

2 [nited States Department of Agriculture, Bureau of Chemistry, Bulletin 107, 1912 
flask and shake well. Break up the emulsion which forms by aid of a centrifuge, or if the latter is not available extract the curdled nilk by gently shaking with successive portions of ether, avoiding the formation of an emulsion. Transfer the ether extract (evaporated to small volume if large in bulk) to a separatory funnel and separate the benzoic acid from the fat by shaking out with dilute ammonium hydroxid, which takes out the former as ammonium benzoate. Evaporate the ammoniacal solution in a dish over the water bath till all free ammonia has disappeared, but before dryness is reached, add a few drops of ferric chlorid reagent. The characteristic flesh-colored precipitate indicates benzoic acid. Care should be taken not to add the ferric chlorid until all the ammonia has been driven off, otherwise a precipitate of ferric hydrate is formed."

\section{SALICYLIC ACID ${ }^{2}$}

Acidulate 20 c.c. of milk with sulphuric acid and shake with ether. Evaporate the ether solution and treat the residue with alcohol and a little iron-chloride solution; a deep violet color indicates the presence of salicylic acid.

\section{HYDROGEN PEROXIDE* \\ (Wilkinson and Peters' Method)}

Add four drops of an alcoholic solution of + per cent. benzidine (paradiamidodephenyl) and 2 (lrops of acetic acid to Io c.c. of milk. If hydrogen peroxide is present the milk assumes a blue color. 005 grams of hydrogen peroxide in IoO c.c. of milk can be (tetected by this method.

\section{CHAP'TER XXYII}

\section{BACTERIOLOGICAL ANALYSIS}

It is not the purpose of this volume to discuss in detail the technique of bacteriological analyses of the milk products described herein. The methods and technique of determining the bacteriological flora, quantitatively and qualitatively, are identical to those used in the bacteriological study of milk and other food products, and which are fully described in manuals on bacteriology. 
As a guide to those who are not familiar with the peculiarities of bacterial fermentations of condensed milk, it may suffice to state that, in the case of sweetened condensed milk, the destructive biological agents are largely confined to yeast, which grow best in media containing a high per cent. of sucrose.

In the case of evaporated milk the direct cause of fermeniation usually lies in the presence in such milk of very resistant, sporebearing bacteria, usually of the butyric acid type and often belonging to the putrefactive species. In the majority of cases these organisms demand anaerobic cultural conditions. 
*Legal Standards for Dairy Products

\begin{tabular}{|c|c|c|c|c|c|c|c|c|c|c|c|}
\hline \multirow{2}{*}{ States } & \multicolumn{3}{|c|}{ Milk } & \multirow{2}{*}{$\begin{array}{l}\begin{array}{c}\text { Skim } \\
\text { milk }\end{array} \\
\begin{array}{l}\text { Total } \\
\text { solids }\end{array}\end{array}$} & \multirow{2}{*}{$\begin{array}{l}\text { Cream } \\
\text { Fat }\end{array}$} & \multirow{2}{*}{$\begin{array}{c}\begin{array}{c}\text { But- } \\
\text { ter }\end{array} \\
\text { Fat }\end{array}$} & \multirow{2}{*}{$\begin{array}{c}\begin{array}{c}\text { Whole } \\
\text { milk } \\
\text { cheese }\end{array} \\
\text { Fat }\end{array}$} & \multicolumn{2}{|c|}{$\begin{array}{l}\text { Condensed } \\
\text { milk }\end{array}$} & \multirow{2}{*}{$\begin{array}{c}\text { Ice } \\
\text { cream } \\
\text { (plain) }\end{array}$} & \multirow{2}{*}{$\begin{array}{l}\text { lce } \\
\text { cream } \\
\text { (fruit } \\
\text { and } \\
\text { nut) } \\
\text { Fat }\end{array}$} \\
\hline & $\begin{array}{l}\text { Total } \\
\text { solids }\end{array}$ & $\begin{array}{c}\text { Solids } \\
\text { not } \\
\text { fat }\end{array}$ & Fat & & & & & $\begin{array}{l}\text { Total } \\
\text { solids }\end{array}$ & Fat & & \\
\hline $\begin{array}{l}\text { Alabama } \\
\text { Arizona } \\
\text { Arkansas } \\
\text { California }\end{array}$ & Pr. ct. & Pr. et. & Pr.ct. & Pr.ct. & $\begin{array}{r}\text { Pr.et. } \\
\text { No } \\
\text { Ferle } \\
18.0\end{array}$ & $\begin{array}{l}\text { Pr. ct. } \\
\text { State: } \\
\text { State } \\
\text { ral rulit } \\
89.0\end{array}$ & $\begin{array}{l}\text { Pr.et. } \\
\text { tandard? } \\
\text { tandard } \\
\text { gs adop }\end{array}$ & $\begin{array}{l}\text { Pr. et. } \\
\mathrm{s} \\
\mathrm{s} \\
\mathrm{ted}\end{array}$ & Pr. et. & Pr. et. & Pr. $\cdot \mathrm{t}$. \\
\hline $\begin{array}{l}\text { California } \\
\text { Colorado }\end{array}$ & 11.5 & 0.3 & 3.0 & 0.0 & $\begin{array}{r}316.0 \\
16.0\end{array}$ & 80.0 & 150 & & $(2)$ & 12 & 12 \\
\hline $\begin{array}{l}\text { Connecticut } \\
\text { Delaware } \\
\text { District of } \\
\text { Columbia }\end{array}$ & 11.75 & 8.5 & 3.5 & 9.3 & 16.0 & State & tanilard & & & & \\
\hline Florida & 11.7 .5 & 8.5 & 3.25 & 9.25 & 18.0 & 82.5 & 150 & 428.0 & 47.7 & 19 & \\
\hline $\begin{array}{l}\text { Gicorgia } \\
\text { Hawaii }\end{array}$ & $\begin{array}{l}11.75 \\
11.5\end{array}$ & $\begin{array}{l}8.5 \\
8.5\end{array}$ & $\begin{array}{l}3.25 \\
3.0\end{array}$ & 9.25 & 18.0 & 82.5 & 150 & $\begin{array}{l}28.0 \\
28.0\end{array}$ & $\begin{array}{c}1.766 \\
7.7\end{array}$ & 14 & 12 \\
\hline Jllaho & 11.2 & 8.0 & 3.2 & 9.3 & 18.0 & 8.25 & 30 & $(2)$ & $(2)$ & 14 & 12 \\
\hline Illinois _....... & 11.5 & 8.5 & 3.0 & 9.25 & 18.0 & $8 \geq .5$ & 150 & (2) & $(2)$ & 8 & \\
\hline Indiana _..... & $x-1$ & 8.5 & 3.25 & 9.26 & 18.0 & 83.5 & 1 (5) & 28.0 & 127.5 & 8 & \\
\hline $\begin{array}{l}\text { Iowa } \\
\text { Kansas }\end{array}$ & $\begin{array}{l}12.0 \\
11.75\end{array}$ & 8.5 & $\begin{array}{l}3.0 \\
3.95\end{array}$ & 9,0 & 16.0 & $\left.{ }^{6} 80.1\right)$ & & & & 12 & \\
\hline & $\begin{array}{l}11.75 \\
12.5\end{array}$ & $\begin{array}{l}8.5 \\
8.5\end{array}$ & $\begin{array}{l}3.25 \\
3.25\end{array}$ & $\begin{array}{l}9.2 .3 \\
9.26\end{array}$ & ${ }^{3} 18.0$ & 80.0 & $\begin{array}{ll}1 & 50 \\
1 & 50\end{array}$ & $(2)$ & $\left({ }^{2}\right)$ & $1 t$ & 12 \\
\hline $\begin{array}{l}\text { Kentucky } \\
\text { Lotisiana }\end{array}$ & 12.5 & $\begin{array}{l}8.5 \\
8.5\end{array}$ & $\begin{array}{l}3.25 \\
3.5\end{array}$ & $\begin{array}{l}9.26 \\
8.0\end{array}$ & $\begin{array}{l}18.0 \\
18.0\end{array}$ & 83.5 & & $\begin{array}{l}29.0 \\
(2)\end{array}$ & $\begin{array}{c}126.765 \\
(2)\end{array}$ & 14 & 12 \\
\hline - & 11.75 & 8.5 & 3.25 & & $\begin{array}{l}18.0 \\
18.0\end{array}$ & & & & & & \\
\hline Mlarylane & 12.5 & -1 & 3.5 & 9.25 & 18.0 & & - & $(2)$ & $(2)$ & 4 & 6 \\
\hline Massachusetts - & 12.15 & $\cdots$ & 3.25 & 9.3 & 15.0 & $\cdots$ & $-\cdots$ & 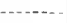 & & & - \\
\hline $\begin{array}{l}\text { Michigan } \\
\text { Mlinnesota }\end{array}$ & $\begin{array}{l}13.5 \\
13.0\end{array}$ & 9.75 & $\begin{array}{l}3.0 \\
3.25\end{array}$ & & 30,0 & - & 145 & $(\because)$ & $(2)$ & 12 & -- \\
\hline $\begin{array}{l}\text { Minnesota } \\
\text { Mississippi }\end{array}$ & 13.0 & & $3.2: 3$ & & & State: & tanilari? & $(")$ & $(\stackrel{2}{)})$ & 12 & - \\
\hline Missouri & 12.0 & 8.75 & 3.25 & 9.25 & 18.0 & 8.2 .5 & $1, \ldots$ & 28.0 & 27.76 & 14 & \\
\hline Montana & 11.75 & 8.5 & 3.25 & ; & 20.0 & 8.25 & $15 y$ & & & 14 & \\
\hline Nebraska ... & $\ldots$ & $-\cdots$ & 3.0 & & 18.0 & & . & & & 14 & $1 \%$ \\
\hline New Hampsuire & 12.0 & & $\cdots$ & 8.5 & 18.0 & 811.0 & & & & $\pi 14$ & $\ldots$ \\
\hline $\begin{array}{l}\text { New Jersey } \\
\text { New Mexico... }\end{array}$ & 11.5 & & 3.0 & & $\begin{array}{l}16.0 \\
\mathrm{Xi}\end{array}$ & sto- & neard & & & - & - \\
\hline $\begin{array}{l}\text { New Mexico } \\
\text { New York }\end{array}$ & 11.5 & & 3.0 & & 18.0 & & & (5) & 125.0 & & \\
\hline Xevarla & 11.75 & 8.5 & 3.25 & 9.25 & 18.0 & 8.5 & 150 & 26.5 & 7.8 & 14 & \\
\hline North Carolina & 11.75 & 8.5 & 3.25 & 9.25 & 18.0 & 82.5 & $1.7 \%$ & 280 & 127.5 & 14 & 12 \\
\hline North Dakota_ & 12.0 & 9.0 & 3.0 & $\cdots$ & 15,0 & & & & & $1 t$ & \\
\hline Olio & 12.0 & & 3.0 & & & 980.0 & -- & $\left({ }^{10}\right)$ & ${ }^{1} 250$ & & \\
\hline $\begin{array}{l}\text { Oklahoma - } \\
\text { oregon - }\end{array}$ & 12.51 & $\begin{array}{l}9.5 \\
9.0\end{array}$ & $\begin{array}{l}3.0 \\
3.2\end{array}$ & $\ldots$ & $\begin{array}{l}18.0 \\
0,0\end{array}$ & 81.5 & 30.0 & (ii) & $(11)^{--}$ & 14 & \\
\hline $\begin{array}{l}\text { Oregon - } \\
\text { Pennsylvania.- }\end{array}$ & 12.0 & 9.0 & $\begin{array}{l}3.2 \\
3.25\end{array}$ & & $\begin{array}{l}20.0 \\
18.0\end{array}$ & (n) & 32.0 & & & 12 & $-\overline{6}$ \\
\hline Porto Rico & 12.0 & 9.0 & 3.0 & & 0.0 & & -...- & & & & \\
\hline Rhode Island -- & 12.0 & & 2.5 & & & & & & & & \\
\hline $\begin{array}{l}\text { South Carolina } \\
\text { South Dakota }\end{array}$ & & & & & & States & nelarel & & & & \\
\hline $\begin{array}{l}\text { South Dakota-- } \\
\text { Tennessee }\end{array}$ & $\ldots$ & $\begin{array}{l}8.5 \\
8.5\end{array}$ & $\begin{array}{l}3.25 \\
3.25\end{array}$ & 9.25 & 18.0 & 80.0 & $\begin{array}{l}150 \\
5\end{array}$ & 29.0 & 1.27 .5 & 11 & 12 \\
\hline $\begin{array}{l}\text { Tennessee } \\
\text { 'Texas }\end{array}$ & $-\cdots$ & 8.5 & $\begin{array}{l}3.2 .3 \\
3.25\end{array}$ & 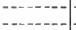 & $\cdots$ & & & th & & $\cdots$ & \\
\hline Utah & 12.0 & 9.0 & 3.2 & 9.0 & 18.0 & 80.0 & 151 & (2) & $(2)$ & 11 & 12 \\
\hline Vermont & 1212.5 & & & & & & & & & & \\
\hline $\begin{array}{l}\text { Virginia } \\
\text { Washington }\end{array}$ & $\begin{array}{l}11.75 \\
12.0\end{array}$ & 8.5 & $\begin{array}{l}3.25 \\
3.25\end{array}$ & $\begin{array}{l}9.25 \\
9.3\end{array}$ & $\begin{array}{l}18.0 \\
18.0\end{array}$ & 82.5 & & $(2)$ & $(2)$ & 8 & \\
\hline West Virginia-- & 12.0 & & & & & States & anclard & & & & \\
\hline Wisconsin .... & $\cdots$ & 8.5 & 3.0 & 9.0 & 18.0 & 82.5 & 150 & 28.0 & 8.0 & 14 & \\
\hline Wyoming _..... & & 8.5 & 3.25 & 9.25 & 18.0 & 82.5 & 1 in & 28.11 & (13) & 14 & 12 \\
\hline
\end{tabular}

1 Percentage of fat liaserl on total solids

2 Fat, 7.8 per cent.; total solids plus fat, 34.3 per cent.

3 For buttermaking, 25 per cent. fat

"'This standard for sweetened condensed milk: "Evaporated milk," solits, 24 per cent.; fat, 7.8 per cent.

${ }^{5}$ No report; 1910 standard given

6 By weight

Tot more than 0.2 per cent. "filler"

8 Iust correspond to 11.5 per cent. coliss in crude milk

9 If artiflcially colored

10 Must correspond to 12 per cent, solid in crume milk

$1123-24$ per cent. solids, 7.9 per cent. fat; $24-25$ per cent. solids, 7.8 per cent. fat; $25-26$ per cent. solids, 7.7 per cent fat; 26 per cent. solids, 7.6 per cent fat

12 In May and June, colids 12 per cent.

13 Fat, 27.5 per cent. of total solids

* United States Department of Agriculture, Bureau of Animal Industry, Circular 218, 1913 


$$
\text { . }
$$




\section{N D E X}

\section{A}

Absolute pressure

Absolute racuum

Accidents in operating pan, prevention of

Acid fermentation

Aciel flux

Acid in milk

Acid tests

Actinomyeoses odorifora

Adnlterants

detection of

Age

Agitation 112, $113,114,150,164$

Air $72,73,146$

Albumin

$105,1+5,004$

Altitude

.58, $59,60,61$

Altitude of various cities in U. S.... 60

Altitule, relation to atmospheric pressure $.58,61$

Ammonium hydroxide 179

Analyses of, eraporated milk......127, 215 milk milk powiler ...........................................29] sweetened rondensed milk........122, 210 Anglo-Siriss C'ondensed Milk Co,....... 12 Annatto, detection of ..........................227 Anilin orange, detection of........2.27, 208 Artificial coloring ................................ 207 Artificial fats $136,163,178$ Ash........121, 126, 167, 202, 212, 220, 221 Atmospheric pressure

\section{B}

Babcork test.................209, 213, 220, 220 Bacteria and other fungi,

Actinomycoses odorifora

Bicillus dimorphobutyrieus 162

Bacillus esterifieans ........................159

Bacillus mesentericus _..................162

Bacillus putrifieus ........................... 159

Bacillus sacelrarobutyrieus …….......159

Bacterium fluoreseens ……............. 162

Bacterim prodigiosum ...................162

Cladosporium butyri .........................162

Oidium lactis ..................................162

Penicilium glaucum ...........................162

Penicilimm roqueforti ......................162

Plectridium foetidum ......159, 174. 175

Plectridium novum $159,17+$
Bacteriological analyses ......................231

Barometric condenser …..................... 50

Barometrie reading at different altitudes ...................................... 59

Barrels, condensed milk ................ 73,154

6. Basis of buying milk .......................... 27

Beaume lyddrometer

$\ldots 68,69,70,84,85,86,165,210,215$

Beet sugar ................................. 41

Benzoic acid, detection of ................230

Bicarbonate of soda.............179, 152, 229

Bitter curd in evaporated milk....... $172,173,174$

Blow-down valve, or vaceum breaker.. 49

Body, or vapor belt ............................ 47

Boiling test …..................................... 31

Borden's Condensed Milk Co............. 12

Borden, Gail ...........................10,11, 12

Boric acid and borates, detection of..230

Box shooks …….......................111, 138

Brands .................................................. 116

Brown evaporated milk........125, 176, 177

\section{C}

Camplell process

$11 \%, 103$

Cane sugar ............................t0, 150, 155

amount of ……...................43, 155,160

determination of .................215, 221, 228

effect on color ................................ 164

effect on digestibility..43, 130, 131, 132

effect on sugar sediment ..........143, 148

effect on thickening ....................44, 149

incomplete solution of ...................143

mixing of $\ldots \ldots .44,45,121,122,143,157$

preservative properties of ...........40, 44

price of ...............................44, 137

quality of .................2. 15.5, 156, 158

solubility of ..........................121, 1 22

solution of ..................................... ? 43

Caramel, detection of ............................2.

Carbonate of soda, detection of ..........229

Care of milk utensils ..................29, 159

Casein …...................... 120, 124, 12.), 204

Casinate of zine .......................... 79,753

Catch-all, or milk trap ........................ 53

Checking work of sealers ....................108

Classification of condensed milk de-

Coal

Coating on jacket and coils.................120

coils in vacuum pan ........................... 47 
Colostrum, effect of

148

Commercial glucose

Composition of,

concentrated milk

condensed buttermilk

evaporated milk

fat in condensed milk ...................124

milk powder .................................. 189

plain condensed bulk milk...............126

sweetened conrlensed milk ................119

Concentrated milk

102

Concentration, ratio of.

$66,101,104,147,160$

Condensed buttermilk ..........................104

Condensed milk factories .................. 16

drainage of ....................................... 20

economic arrangement of machinery 26 equipment, list of ................24, 25. 26 essentials of suitable location of... 16 factory sanitation ..............35, 150, 157 floor plan of factory ...........21, 22, 23 milk supply $21,22, \frac{23}{16}$ sanitary arrangement of machinery

26,157

sewage disposal

19

tin shop ...................................... 23

transportation facilities ................... 18

water supply ...........................17, 162

Condenser milk industry ................. 9

Condensed skim milk .........................136

Condensed whey, primost, myseost.....106

Condensery regulations....................28, 29

Condenser discharge .................53, 63, 64

Condensers ............................................. 50

Barometric .......................................... 50

capacity of .................................. 62

care of ............................................. 52

suriace ................................................ 50

wet-vacuum spray ............................ 51

Condensing evaporated milk ........83, 170

Condensing plain rondensed bulk milk.. 101

Condensing sweetened condensed milk

$45,64,65,66,150$

Contaminated machinery .......26, 36,157

Contaminated sugar...40, 41, 42, 155, 166

Contamination of milk in factory......156

Contamination of milk on farm....... $27,28,150,151,156$

Control of quality of fresh milk....... 28

Cooling ....................................29, 89, 102

Cooling in sterilizer ....................96, 166

Cooling sweetened condensed milk,

agitation $.72,73,146$ effect on sugar erystallization... 72,145 equipment for ............................... 72 method of 72 temperature 72,73

Cost of manufacture 136

Cream of tartar
Curdy evaporated milk, caused by

acid flux in cans.......................92, 166

concentration .................84, 8.5, 134, 165

fractional ('urdling ....................97, 166

fractional sterilization ..................... 97

homogenizing ............................... \$., 166 quajity of fresl milk..27, 2s, $81,8 \%, 165$ sterilizing heat ...................95, 96,166 shaking ................................ $97,98,99$

Curdy plain condensed bulk milk, effect of quality of fresh milk. $27,28,100,164,165$ neutralizing the acid 165

\section{D}

Decomposition of,

lactose ...........................................

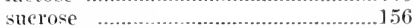

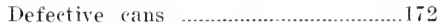

Defective evaporated milk..................164

Defective milk powder ..........................192

Defective sweetened condenserl milk.. 1+1

Delyydrated milk ....................................181

Desiccated milk .....................................181

Detection of beet sugar ................... 42

Difficulties in meeting evaported milk standards

Digestibility of condenser milk.......

............................ 128, $130,131,132$

Digestion experiments ........125, 129,130

Dilutien of condensed milk ................131

Distribution of factories in $[$. S.... $] 5$

Distrilution of heat in sterilizer ..... 94

Dome ...................................................... 49

Drawing off condensed milk ................ 71

Drips from jacket and coils ............... 48

Dried buttermilk ...........................195, 196

Dried whey .................................195, 196

Duration of sterilizing process.

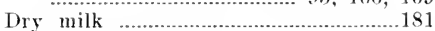

Dry-vacuum pump ............................. 54

\section{E}

Economic arrangement of machinery 26 Effect of heat on ash of milk...126, 127 Efficieney of shakers............................ 99

Efficiency of racum pan .................... 46

Efficiency of vacuum pump ............. 55

Enzymes in condensed milk................130

Equipment of condensery.........24, 25, 26

Eraporated milk.......13, 81, 123, 164, 215

Evaporated milk standards ........133, 134

Evaporation, affected by..................... 12 ratio of steam and water .............. 64 steam pressure in jacket and coils 61 temperature of condenser discharge $61,62,63$ 
temperature in pan ...............61, 62, 63 vacuum in pan ......................61, 62,63 water in condenser ...............61, 62, 63

Excessive chilling in pan ..................14t

Excessive stirring of sweetened condensed milk $72,73,146$

Exports of condensed milk ........117,118

\section{F}

Factory sanitation $26,35,36,150,151,157$

Fat globules, size of ....................124, 168

Fat in condensed milk. $120,124,147,168,209,210,220,221$ 220

Feed for dairy cows . 8,159

Fermented evaporated milk........109, 171 Fermented sweetened condensed milk..154

Fermentation tests

Filling, in barrels 73, 154 in cans 74,91

Filling machines .7., 90

Finishing the batch, (see striking)

Flux for soldering..................79, 152, 153

Food value of condensed milk...........131

Food inspection deeision No. $131 \ldots \ldots . .136$

Forewarmers, heat in...37, $38,39,40,1.56$

Formaldehyde, detertion of ...............230

Fractional sterilization

$.97,166$

\section{G}

Gaseous fermentation in evaporated milk 174,175

Gas generators ….................................. 80

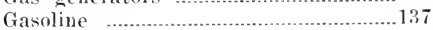

Gas sup ply ……................................... 79

Gehee seal …......................................... 76

Gelatin, retection of ..........................209

Glueose ………............. 40, 158, 163, 17

Grainy evaporated milk $\ldots \ldots \ldots . .126,167$

Gritty plain condensed bulk milk, caused by,

erystallization of milk sigar $121,142,143,144,145,177$ degree of concentration

Gunning methor 202

\section{H}

Hanid sealing 77

Health of cows 28

Heating the fresh milk,

method of purpose of $38,39,40,169$ temperature $37,82,83,100,163$ Homogenizers $38,100,156,163$ $87,88,166$
Homogenizing,

effect on curdiness ................... \&s, 166

effect on fat separation $86, s 7,8 s, 170$ purpose ....................................... 86,170

principle .......................................... 87

How to keep factory in sanitary condition ….............. $6,36,150,151,157$

Iydrogen peroxide, detection of ........231

\section{I}

Improrts of condensed milk.......117, 118 Improper cooling ……............ 2 , 73, 145 Incomplete solution of cane sugar.... $44,45,121,122,143$

Incomplete sterilization ….................172

Ineubation .................................99, 100

Individual standards ............................135

Insoluble albumin ................................125

Insprection of cans ....................... 108, 171

Interest on investment..........................138

Invention of condensed milk process 9

Invertase …….......................... 156, 158

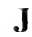

Iacket in racum pan 47

\section{$\mathbf{L}$}

Labeling .................................................. 109

Labeling machines ...............................109

Labels, eost of ...................................137

quality of ......................................... 110

rust spots and wrinkles ...................110

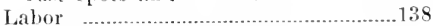

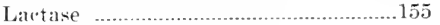

Lactose, (see milk sugar)

Leach 's method, detertion of coloring ................................................ 227

Leaky cans, disposition of ...................108

Lime, detection of ..............................229

Loading the sterilizer …................... 94

Low's volumetric methori.......................206

Lumpy sweetened condlensed milk, caused by,

aeid flux in tin (ans........... $79,152,153$

easinate of zine .........................79, 153

contaminated barrels ..................73, 154

milk from fresh cows

$27,28,29,151,152$

poor quality of fresh milk...27, 28, 150 unclean factory conditions .............. $26,35,36.150,151$

unclean tin eans ...............................154

white and yellow buttons .................154 


\section{I}

MeDonald seal 76

Market prices

Markets of condensed milk .116

Marking the cases

116

$152,155,158,159,164,165,179$ control of quality

Milk draw pipe

Vilkers and milking 29

Milk of lime...............104, 105, 165,179

Milk powder ........................................181 analysis of ............................... 191, 221

Campluell process ....................186, 187

composition ........................................19]

Eckenlurg process ...........................184

history and development of industry

181

Just-IIatmaker process ....................184

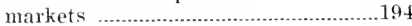

Merrell-Gere process..........187, 185, 191

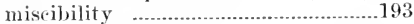

packing for market

191

Passburg process .....................184, 185

quality of fresh milk ......................183

raneidity .......................................... 194

solubility ...................................191, 192

water content ................................192

Wimmer process ..................................189

Milk strainers .............................29, 159

Milk sugar, lactose

caramelizing action

121,125

color $125,164,177$

crystallization $121,143,144,145,146$, 177

decomposition

.155

determination

$204,213,220,221$

solubility

121,142

Milk tests for purity,

acid tests

30

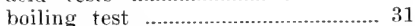

sediment test .................................. 32

sense of smell and taste .................. 29

temperature test .............................. 30

Milk trap ............................................ 53

\section{$\mathbf{N}$}

Neutralizers

104,179

Neutralizing

.165

New York Condensed Milk Co.......... 12

Nitrogen ...............................................202

Nutritive ratio in sweetened condensed milk

\section{$\mathbf{0}$}

Oleic acid

Old cans on the farm
Operation of, homogenizer................... 88 vacuum pan ...................................64, 65 vacuum pumps .................................55

Output of condensed milk in U. S.... 14 Oxidation of olein ..........................162

\section{$\mathbf{P}$}

Packing

111

Packing for export ..............................111

Peroxide of hydrogen, detection of ....231

Plain condensed bulk milk...11,100, 164

Polluted water ...............................17, 162

Poor quality of, fresh milk......27, 28, 150 sugar ............................42, 155, 156, 158

Practical methods of systematic examination of condensed nuilk for marketable properties....197, 19s, 199

Premiums, cost of .................................138

Preservatives, detection of ...............229

Pressure, atmospheric ....................58, 61 in lomogenizer ........................... 166 steam ..........................61, 64, 66, 150

Primost ................................................ 106

Proteids $120,124,125,202,213,220,221$

Putrid sweetened condenser milk, $38,39,40,113,163$

\section{Q}

Qualifications of processor...........96, 166 Quality of, fresh milk, 27, 28, s1, s2, 100 $150,164,165,183$

sugar ...........................42, 155, 156, 158

Quevenne lactometer ..........................201

\section{$\mathbf{R}$}

Rancid sweetened conlensed milk, affected by,

air, light, heat ...........................162 artificial fats ....................136, 163, 178

bacteria, yeast, molds.......................162 glucose ................................................. 178 oleic acid ..........................................162 polluted water ..............................17, 162 tropical climates ................................163

Rapidity of cooling in sterilizer....96, 166

Relation of steam pressure to boiling point .......................................56, 57

Roese-Gottlieb method........212, 2.21, 222

Rust spots on labels ..........................110

\section{$\mathbf{S}$}

Salicylie acid, detection of .231

Sampling of batch ............................. 71

Sampling devices ................................. 71

Sandy sweetened condensed milk.........142 caused by, cane sugar content 143,148 
ehilling in pan

144

cooling, improper.

$72,73,145$

incomplete solution of eane sugar $44,45,121,122,143$

stirring, excessive ............. $72,73,146$ superheating in pan...................66, 144 warming up too cool condensed milk 146

Sanitary can …...............................74, 76

Sanitary purity of condensed milk....127

Sealing eans …......................... $76,92,166$

Sealing machines ..............................7 $\overline{7}, 92$

Sediment test ........................................ 32

Selling expense ....................................138

Separation of fat in evaporated milk, afiected by,

concentration

169

fat globules, size of ...............124, 168

homogenizing .................86, si, s8, 170

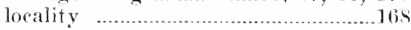

period of lactation ...........................16

season …......................................164

sterilizing process ................93, 9.5, 169

superheating in pan ...................83, 170

turning cans in storage ..................... 170

Settled sweetened condensed milk...... 146 affected $\mathrm{l}, \mathrm{y}$,

cane sugar content .....................44, 14 s

density of condensed milk ..............147

fat content ….................................14

turning cans in storage ................... 1ts

Sewage disposal ................................. 19

Shakers ……................................ 98,99

Shaking …............................97, 98, 99

Sight glass ........................................ 49

Skimming, detection of $220,204,225,206$

Solder, 78 ; cost of, 137 ; seals with... 76

Solids in, evaporaterl milk...123, 216, 217 $218,219,220$

milk

milk powder .....................................

sweetened condensed milk

$119,212,215$

Solids not fat..................224, 225, 226

specifie gravity 122, 126, $1+7,200,201$, $210,211,212,215,216,224,225,226$

Stables $.29,159$

Standardizing vat ................................. 8.5

Standards of, condensel skim milk

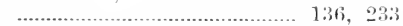

evaporated milk ...............133, 134, 233

sweetened condensed milk.......132, 2.83

individual …....................................135

by states ...................................................

Starch in condensed milk .................... $\mathrm{s} \theta$ )

Starting the pan ................................ 64

Steam necestary for evaporation....... 64

Sterilizers …......................................... 93
Sterilizing, distribution of heat......... 94

duration …................................ 166,169

temperature..........................95, 96, 166

Storage, advisability of........114, 150, 176

duration ............................113, 150, 164

purpose ............................................112

temperature.......113, $160,161,164,175$

turning cans in .........................148, 170

Straining …..................................29, 159

Strainers …...................................71, 144

Striking or finishing, evaported milk 83 plain condensed bulk milk................101 sweetened condensed milk......66, 67, 68

Sucrate of lime, detection of......228, 229

Sucrose, (see cane sugar)

Sugar chute

45,157

Superheating ….....................................101

Swelled cans due to, ehemical action 176 low temperature ......................113, 175

Sweetened condensed milk, 11, 13, 37, 107 $119,131,139,141,164,177,210$

Sweetened condensed milk for baby food

\section{$\mathbf{T}$}

Temperature of condenser discharge 64 Tests and analyses of milk, condensed milk, and milk powder ................197

Tests for fat ................................... 34

Thermometer in varum pran............... 49

Tin cans, eost of ...............................137

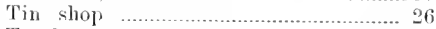

Total cost per rase .............................139

Transportation, 115: cost of', 138, faeilities for

\section{V}

Tacuo, science and pratice of evaporation in, 5.5, 56, 57, $58,59,60,61$, $62,63,64$

Vacuum pan …..............5, 46, 47, 48, 49

Vacuum pump ………....................54, 5.5

Venthole cans ....................................... 91

Venthole fillers .................................... 91

\section{W}

Warming up too cold sweetened condensed milk .................................146

Water, detection of in milk $224,225,226$

in condenser …....................61, 62, 63

in evaporated milk ..........................123

in sweetened condensed milk ...........119

supply …................................17, 162

Westphal halance ................................201

Wet-vacuum spray rondenser ……........ 51

Yeast

156,159 


\section{INDEX TO ADVERTISERS}

Page

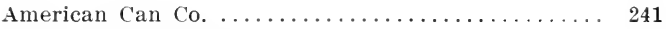

Barber Creamery Supply Co., A. H. .......... 242

Bausch and Lomb Optical Co. ............. 242

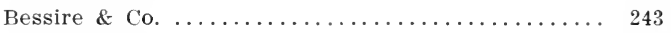

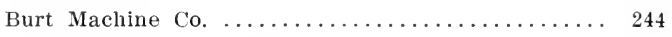

Dairy Machinery and Construction Co. ......... 247

De Laval Separator Co. .................. 245

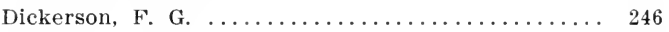

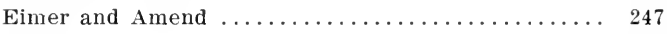

Ford \& Co., J. B. . . . . . . . . . . . . . 248

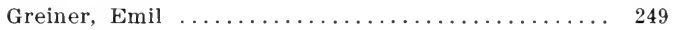

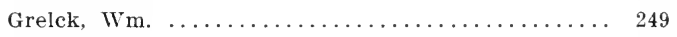

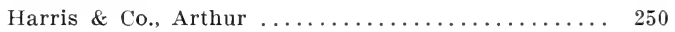

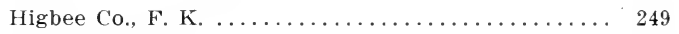

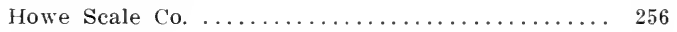

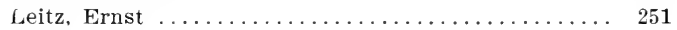

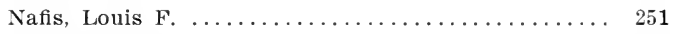

Sargent \& Co., E. H. . . . . . . . . . . . . . . 256

Schaefer Manufacturing Co. ............... 252

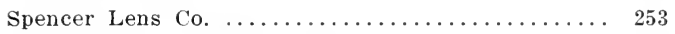

Sprague Canning Machinery Co. ............. 254

Stevenson Cold Storage Door Co. ........... 255

Stier Manufacturing and Engineering Co., Herman... 256

Sturges \& Burn Manufacturing Co. ........... 260

Tagliabue Manufacturing Co., C. J. ........... 257

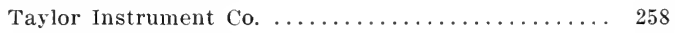

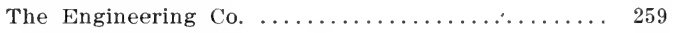

The Preservaline Manufacturing Co. .......... 262

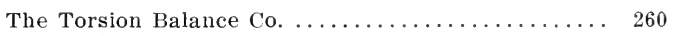

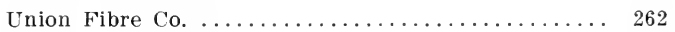

Wagner Glass Works .................. 261 

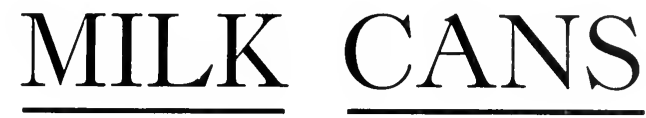

\title{
REGULAR
}

and SANITARY Style

\author{
made in \\ sizes to suit all trade \\ requirements
}

Uniform Quality

Prompt Service

Shipments made from nearest factory saving delays and freight charges.

American Can Co. NEW YORK

Chicago

Montreal
San Francisco Portland, Ore.

WITH OFFICES IN ALL LARGE CITIES 
Be sure to get the General Catalogue of the A. H. Barber Creamery Supply Co.

\section{CHICAGO, ILLINOIS}

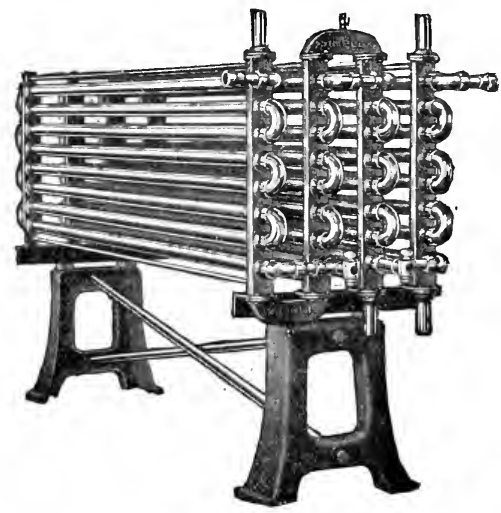

\section{Simplex Internal} Tube Heaiers and Coolers

And other things must interest yout.

The internat Tube system does away with the danger of contamination from outside sources.

The Internal Tube system saves loss from evaporation as the milk during both the heating and eooling processes is not subject to atmospherie conditions.

The Internal Tube system gives the greatest effieiency in heating and eooling as the sections can be connected up on the regenerative principle.

The Internal Tube system is sanitary to the last degree as every ineh ean be thoronghly brushed and then sterilized with live steam.

The Internal Tube System requires less floor space per thousand pounds of milk than any other system yet derised.

The Internal Tube System will bear the elosest investigation if you are building a new or remodeling an old plant.

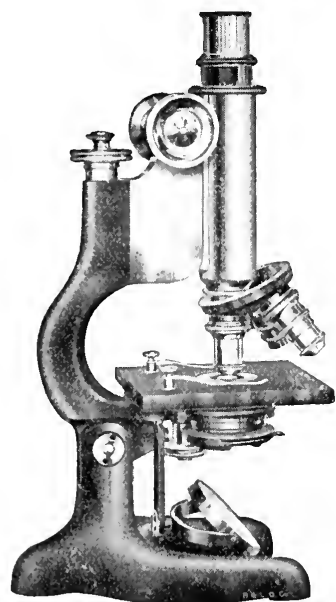

\section{Bausch \&. Lomb Microscopes}

\section{are standards of optical and mechanical efficiency}

FF-8 is one of several models especially designed for bacteriological work. It has all necessary adjustments, two iris diaplurugms and an optical equipment of three objectives, incinding an oil immersion, two eyepieces and an Abhe Condenser in guick acting serew substage.

The number of magnifiontions obtuinable ranges from 50 to 1260. Send for catalog describing this and other models. 


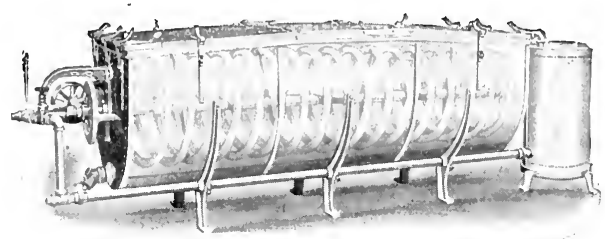

\section{RAPID AND UNIFORM GOOLING OF CONDENSED MILK}

At a large saving of time, a cory large saving of expense, and an ENORHOUS saving of labor by the use of the

\section{CELEBRATED “JENSEN” COIL SYSTEM}

Circulating well water, hydrant water, ice water or brine Automatically. No pumps, no trouble, no lifting of cans in and out of tanks. Saves room as well.

\section{INVESTIGATE}

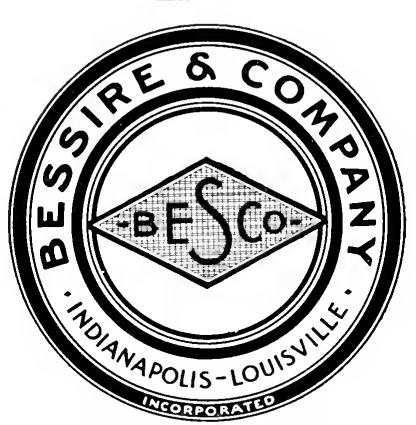

DAIRY AND CREAMERY SUPPLIES 


\section{This Machine Plays an Im- portant Part in Milk Canning}

It labels as many cans a day as you require.

Orders are filled promptly and storage facilities never overtaxed.

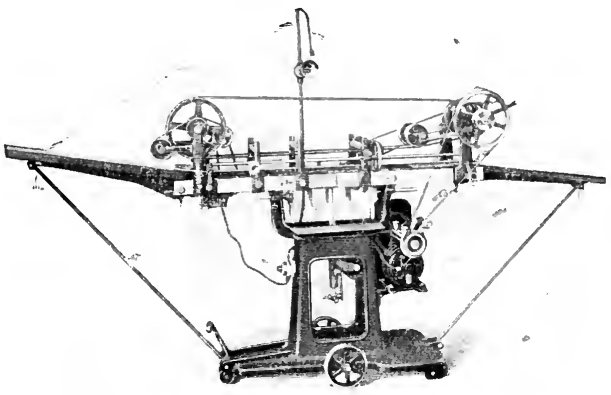

\section{THE BURT LABELING MACHINE}

Is used in the small as well as the largest plants because there is no other way to label cans so fast, neat and cheap.

It applies the label with a hot moisture-proof cement which sets instantly, thus preventing the label from slipping while being wrapped around the can and ensuring it always being applied tight and matched evenly at lap. No paste is put on the can, so there's no possibility of the label discoloring-it always looks as though just from the printer-that increases the sales value of goods.

Let us tell you more about the Burt Labeler-what it does and why you should not be without it. Just state size of cans used.

\section{BURT MACHINE COMPANY}

Labeling, Wrapping and Lacquering Machines

BALTIMORE, MD. 


\section{THIS IS THE MACHINE}

which is being installed in the most modern and up-to-date milk plants the country over

Makes milk more marketable because it removes from the milk contaminations such as broken-down tissue and other undesirable milk conditions which for the most part have their origin in the cow's udder before the milk is drawn into the pail.

This is the result you can achieve with a DE LAVAL MILK CLARIFIER, a machine which is destined to play as important a part in the whole milk industry as the cream separator has in the production of more and better cream.

These machines are rapidly being installed by the largest and most progressive milk concerns in the country and an investigation will surely convince you that you can accomplish immeasurably better results with a De Laval Milk Clarifier than with any other so-called method of straining and filtration, and with less labor and expense.

Machines can be furnished in various capacities from 12,000 to 100 pounds per hour in either turbine, beltdriven or hand driven styles.

The power required for driving the largest capacity machine is only $5 / 8$ of one horse power.

Immediate installations can be made. Catalog and other information mailed upon request.

THE DE LAVAL SEPARATOR COMPANY, New York Chicago San Francisco Seattle 


\section{USE THE DICKERSON VENT FILLER It affords the BEST and CHEAPEST PACKAGE}

This machine receives either soldered or sanitary cans, and the milk, by gravity. It flls rapidly, accurately, reliably. It neatly and securely seals at minimum cost.

It is simple, compact, entirely automatic, readily cleansed and sterilized, very dependable and will last a life time.

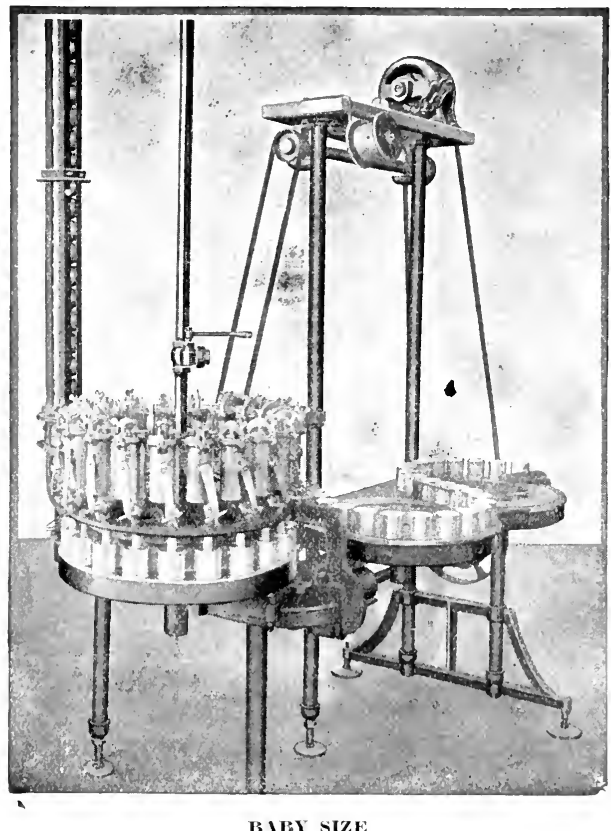

It enables the use of cans that are cheaper, more portable and cleaner. (The smaller the hole the less the dirt.)

It simplifies, systematizes and cheapens all your can handling and milk filling operations. It eliminates modesirable lahor. It avoids waste of solder, eans and milk. You can have vour sanitary cans made with hoth ends on.

The baby filler fills baby cans; the tall filler tall cans and the combination machine takes families and talls.

The machines quickly pay for themselves by their own ecouomy. Fou get all the sanitary and selling advantages gratis.

They pack a better seller at from $4 \mathrm{c}$ to $8 \mathrm{c}$ less per case.

$$
\text { "MIKE LS I'ROVE IT" }
$$

F. G. DICKERSON

541-557 W. Washington Blvd., Chicago

268 Market St., San Francisco. 308 Chestnut St., Philadelphia 


\section{TO THE MANUFACTURERS OF EVAPORATED MILK}

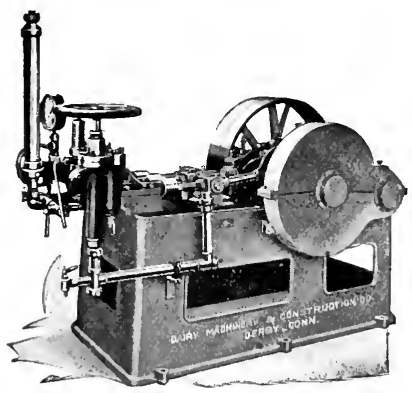

We take pleasure in recommending to you the Progress Homogen. izer for treatment of your evaporated milk. We have more Progress Homogenizers in Condensing Factories than all other manufacturers of Homogenizers in Europe and America put together. In fact, the Progress Homogenizer has proved to be the only machine that would be reliable every day, and have enough capacity to be of benefit to the Manufacturer of Evaporated Milk.

They are used in the leading factories for evaporated milk in this country. Write us for catalog and special information.

DAIRY MACHINERY \& CONSTRUCTION CO., INC. DERBY, CONN.

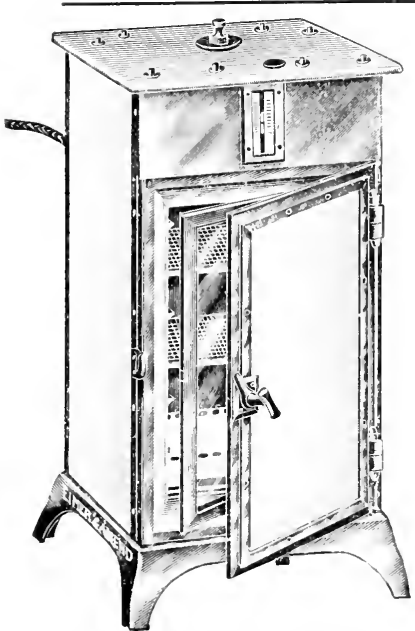

FRE.IS ELECTRIC IXCEIBATOR Iceurate to a fraction of a degree.

Ised in Many of the Largest Dairy Laboratories.
We Carry Large Stocks of

\section{LABORATORY} GLASSWARE and APPARATUS

of the most dependable quality.

HYDROMETERS

LACTOMETERS

MILK CENTRIFUGES

FERMENTATION TUBES

MILK TESTING APPARATUS

MICROSCOPES, ETC.

Large illustrated catalog sent on request

\section{Eimer \& Amend}

Established 1851

NEW YORK and PITTSBURG 


\section{The Choice of Experts}

Never for a moment does the man who thoroughly understands the making of high quality butter forget that cleanliness is one of the first considerations.

And that is the reason Dairy Experts and Authorities are unanimous in their choice of

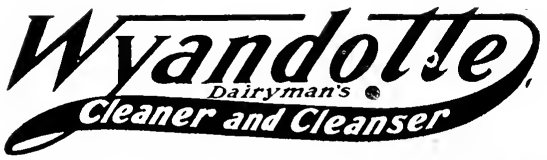

as their cleaning agent for keeping factory utensils and containers in the proper sanitary condition.

Do you wonder why these men specify Wyandotte Dairyman's Cleaner and Cleanser and what there is to Wyandotte Dairyman's Cleaner and Cleanser that makes it their choice?

Just as you or they would choose milk or cream of the highest quality for making the best butter so they for similar reasons choose Wyandotte Dairyman's Cleaner and Cleanser for cleaning. They know it does more cleaning by far than common cleaning agents. It not only cleans better but it drives away odors, staleness and impurities which other cleaners have no power to remove. And they also know it can do no harm to the milk or utensils as it is free from greases, fats, caustic, lye or anything of a harmful nature. Its purity is as important to them as its sanitary cleansing qualities.

Indian in Circle

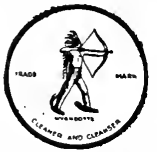

In Every Package
Eighty-five per cent of the buttermakers in the United States and Canada use Wyandotte Dairyman's Cleaner and Cleanser, but should you be one of the few who are not and do not know what this remarkable cleaner can do for cleaning dairy utensils merely write your supply man for a keg or barrel and give it a trial. It proves all claims quickly.

The J. B. FORD COMPANY, SOLE MFRS., WYANDOTTE, MICH., U. S. A.

This Cleaner has been awarded the highest prize wherever exhibited 


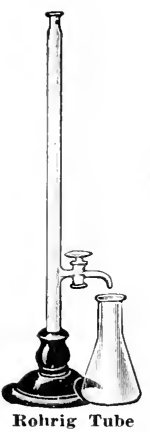

\section{The Emil Greiner Co.}

Fulton and Cliff Sts., New York City

Established 1880

Incorporated 1905

Manufacturers of Apparatus for the Testing of Milk and its Products

Hydrometers and Thermometers for Milk Condensing Plants

Special Apparatus to Order

BABCOCK TEST GLASSWARE

\section{WILLIAM GRELCK \\ Consulting Dairy Engineer}

ELGIN, ILL.

(Member American Chemical society)

Wm. Grelek is prepared to advise on all matters relating to the Milk Industry, as to correction of Defects-Formulas of Conclensing and Drying MilkMalted Milk and Infant Foods-Plant and Machinery-Fuel Economy-Homogenizing.

\section{Fred K. Higbie Company}

MANUFACTURERS AND JOBBERS

\section{Creamery and Milk Dealers Machinery and Supplies}

Send for Catalog of Refrigerating Machinery, Creamery and Milk Dealers Equipment and Supplies

\section{FRED K. HIGBIE COMPANY}
E. C. PRICE, Pres.
G. GREENLEAF, Sec'y.

1822 S. CLARK ST., CHICAGO, ILL. 


\title{
Arthur harris \& Go.
}

Established 1884

\author{
212-218 Curtis St. \\ CHICAGO, ILL.
}

Pioneer Constructors of

\section{MACHINERY FOR THE MANUFACTURE OF}

PLAIN, SUGARED, EVAPORATED AND

\section{MALTED MILK}

VACUUM PANS

FOREWARIMERS

VACUUM PUMPS

CAN COOLERS

PIPE COOLERS

RECEIVING TANKS

STORAGE TANKS

FILLING MACHINES
STERILIZERS

SHAKERS

LABELING MACHINES

RUBBER PACKED COCKS

SAMPLERS

SUPERHEATERS

COOLING COILS

WEIGH SCALE TANKS

SANITARY PIPE AND FITTINGS

SOLDERING COPPERS

PEEPHOLE GLASSES

WRITE US REGARDING YOUR NEEDS 

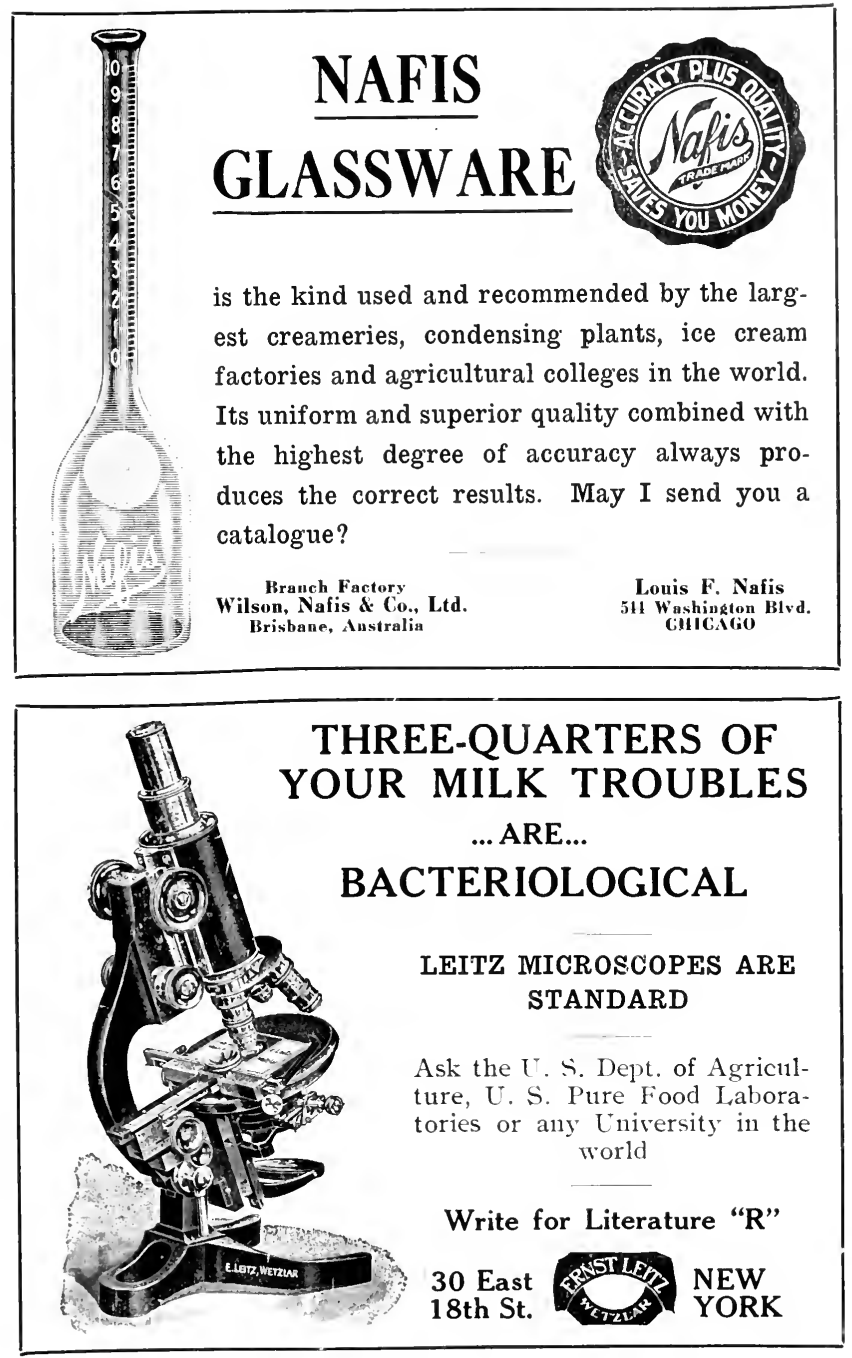


\section{Schaefer Mfg. Co.}

Manufacturing Machinists

We manufacture all iron machinery used in processing evaporated and sweetened condensed milk.

STERILIZERS ....... 2 Sizes

SHAKERS ......... 12 Sizes

CAN COOLERS....... 12 Sizes

TEST STERILIZERS. . . 1 Size

FLOOR PLATES ..... 4 Styles

STEEL TRAYS

FILLERS .......... 3 Sizes

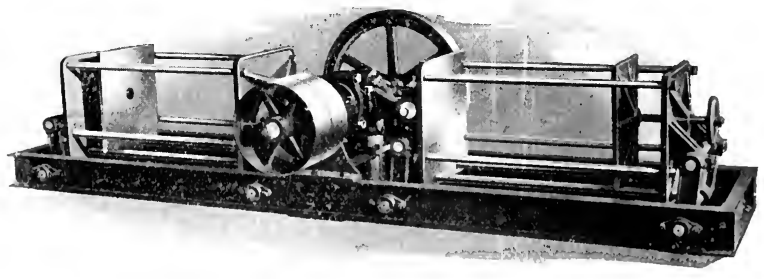

Our Shaker.

OUR SPECIALITY

Making Special Machinery to Meet Your Special Requirements

\section{SCHAEFER MFG. CO.}

FRANK D. CHAPMAN, Mgr. 


\title{
SPENCER MICROSCOPE No. $20 \mathrm{H}$.
}

The Ideal for Bactereological and Research Work.

\section{ADVANTAGES:}

Side fine adjustment- $21 / 2$ times finer than any prism or lever fine adjustment.

Drop-swing Condenser Mounting.

Black lacquered body tube, avoiding reflections of light.

Low compact construction affording maximum ease and comfort in use.

Large stage with long arm-unusual capacity.

Spencer Standard superior optick.

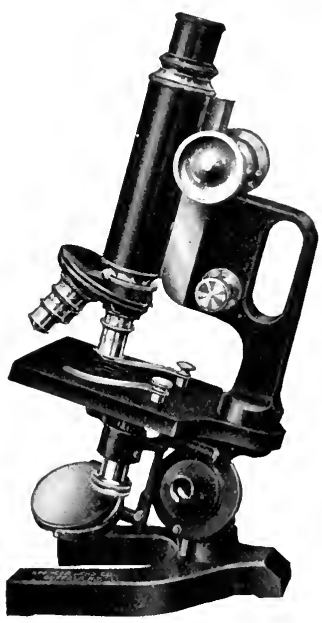

Spencer Microscope No. 20 H

\section{SPENCER MICROSCOPES}

ARE BUILT FR.OM THE

\section{Laboratory Worker's Standpoint}

There are incorporated in them many features of practical usability, features which make for convenience and comfort in use as well as efficiency and durability which others do not have.

\section{SPENCER MICROSCOPES}

I. Optical Superiority.

$$
\text { EXCELL IN }
$$

II. Mechanical Perfection.

111. Embodiment of Improvements Which Mark Them as Best Adapted to Their Purpose.

Weare the only Amerlcan manufacturers of microscopes making A pochromatic objectives. Ten years' experience in builing side-fine adjustments.

Bactereological Apparatus of All Kinds supplied.

Get Our Quotations.

\section{Spencer Lens Company}

\author{
BUFFALO. N. Y.
}




\section{SPRAGUE}

CANNING MACHINERY CO.

MANUFACTURERS OF

APPARATUS AND MACHINES

EMPLOYED IN

\section{MILK \\ CONDENSING}

AND

CANNING

\section{ESTIMATES FURNISHED ON COMPLETE PLANS}

FACTORY:

HOOPESTON, ILL.
SALES OFFICE:

CHICAGO, ILL. 


\section{DOO R S}

Doors are just a big valve and are a weak point in all Cold Storage. Their insulation is important, so is their tightness, but their quickness is vastly more so, because it affords the workman less excuse for leaving them open.

The Stevenson Doors have been developed with these features constantly in mind. The Doorframe is adjustable to conform always to the Door thus insuring perfect fit and freedom, without expense or refiting. The thick portion of the Door fits loosely in the frame and thus avoids binding.

The overlapping margin of the Door is held tightly to its seat against the face of the Doorframe by powerful elastic hinges having the largest bearings made for Doors of such weight. Its Self-Acting Roller Fastener has enormous strength, is arranged for padlock-no slackening as it latches-the soft hemp gasket in the joint is always in sight. A mere touch frees and opens it from either side.

Stevenson Doors swing entirely out of the passageway, when opened, the Doorway may hence be 6 inches narrower, an important economy in refrigeration. The jambs of the Doorframes are straight, clean, sanitary. No frail rebate strips in the Doorway.

The opening in wall as constructed in this year 1913 , should be $31 /$ inches wider and $4^{1 / 2}$ inches higher than the clear size of our Doorway. Follow construction numbered 1 and 2 .

For Overhead Track Doors this rough opening should extend $13^{1 / 2}$ inches above lower edge of track bar. Doorframes are secured with lag screws $3 / x+$ inches, inserted through front casing at $A$.

Fig. B. shows wooden bevelled threshold $13 / 4$ inches thick. Connects lower ends of Doorframe, forms a part of it and is let down into the floor. No feather edge, no jolt, no splinters. For ware-
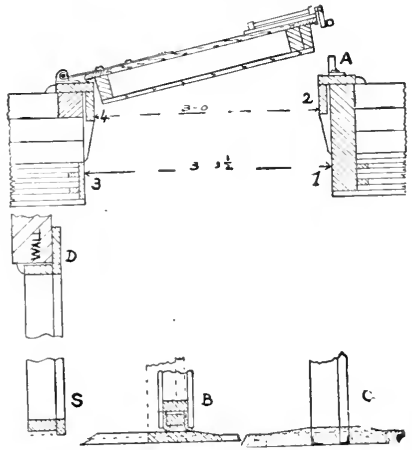

Installation Diagrams.

STOCK SIZES.

ftevensou's standard Cold Storage Doors.

Size of

Size of

Doorway

in Clear

$2-3 \times 2-0$

$2-0 \times 4-0$

$2-0 \times 5-0$

$2-0 \times 5-6$

$2-0 \times 6-0$

$2-6 \times 6-0$

$3-0 \times 6-0$

$3-6 \times 6-0$

$4-0 \times 6-0$

$3-0 \times 6-6$

$3-6 \times 6-6$

$4-0 \times 6-6$

\section{Wall Opening}

to receive our

Door Frames

$2-6^{1 / 2} \times 2-41 / 2$

$2-3^{1 / 2} \times 4-4^{1 / 2}$

$2-3^{1} 2 \times 5-416$

$2-3^{1} \times 5-10^{1 / 2}$

$2-3^{1 / 2} \times 6-4^{1 / 2}$

$2-91 / 2 \times 6-41 / 2$

$3-3^{1 / 2} \times 6-41 / 2$

$3-91 / 2 \times 6-41 / 2$

$4-31_{2} \times 6-41 / 2$

$3-31_{2} \times 6-10^{1 / 2}$

$3-91 \times 6-10 \%$

$4-3^{1 / 2} \times 6-10^{1 / 2}$
Estimated

Weight, crated

100

140

170

185

200

250

300

350

400

325

380

440

houses. Accommolates trucks.

Fig. Concrete Floors. Shows lower ends of Doorframe extending down into the floor $3^{\prime \prime}$, and connected by angle irons extending across the Doorway from one side to the other below the surface.

Fig. Shows Doorframe with full standard sill and head, used on all sizes of Doorframes. Suited only to walking through.

special Freezer Doors for Icy Doorways, on a modified plan for intermittent and perfectly free, regardiess of temperature, moisture or accumulation of ice in any degree.

Revolving Ice Cream Doors (Iron). Do not swell and bind.

Combined Self Closing Ice Door and Chute of three styles. Ice Counters.

\section{Stevenson Cold Storage Door Co. CHESTER, PENSALNANi}


FULL. JEWELED RUST PROOF No. 60 CREAM TESTING SCALB For Use in Connection with the Babcock Tests

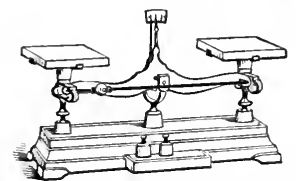

This Scale is especinliy designed for very accurnte weighing of cream. It is made rust-proof, all bearings being of agate and the weighing plates of porcelaln. It has a wide bar in front to balance the bottle, and is provided with the necessary weight. Base of scale is $10^{1 / 2}$ in. long; the porceiain plates are three in. square.

All bearings are agate, plates are porcelain. Base and under connections are galvanized, making a rust-proof seale.

Also made in larger sizes to weigh 6 and 12 bottles. We manufacture scales for all kinds of factory purposes. Write us for prices.

The Howe Scale Co. of ILl., 1315"Wabash. CHICAgo

\section{SARGENT'S ELECTRIC DRYING OVEN}

(PATENTED

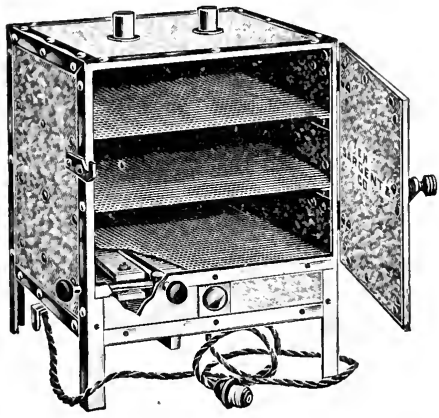

May be set for any temperature from $70^{\circ}$ C. to $150^{\circ}$ C. and will maintain that temperature indefinitely. Aimost a necessity in IIlk Product Laboratories where the maintenagce of the lowest usable temperature is imperative.

Price complete with six-foot cord, plug and thermometer, \$25.(0). Wound for 110 or 220 volt current.

Complete eatalogues furnished upon application.

\section{E. H. SARGEN' \& CO.}

Manufacturers, Importers, Dealers in Chemicals and Chemical Apparatus of High Grade only.

\section{5-127 West Lake Street - Chicago}

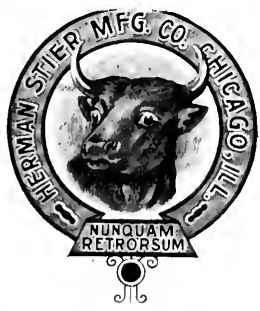

\section{HERMAN STIER Manufacturing and Engineering Co.}

\section{CHICAGO, ILL.}

Designers and builders of complete Plants and Specialities for the manufacture of Industrial Milk Products, Butter, Condensed Milk, Sugar, Cheese, Flour, Buttermilk, Casein, Albumen, Salts, Acids, etc.

High class design and work only 


\section{"TEMPERATURE CONTROL IS THE MOST IMPORTANT FACTOR IN PASTEURIZATION"}

(CIRCULAR 184-BUREAU OF ANIMAL INDUSTRY) U. S. DEPT. OF AGRICULTURE.

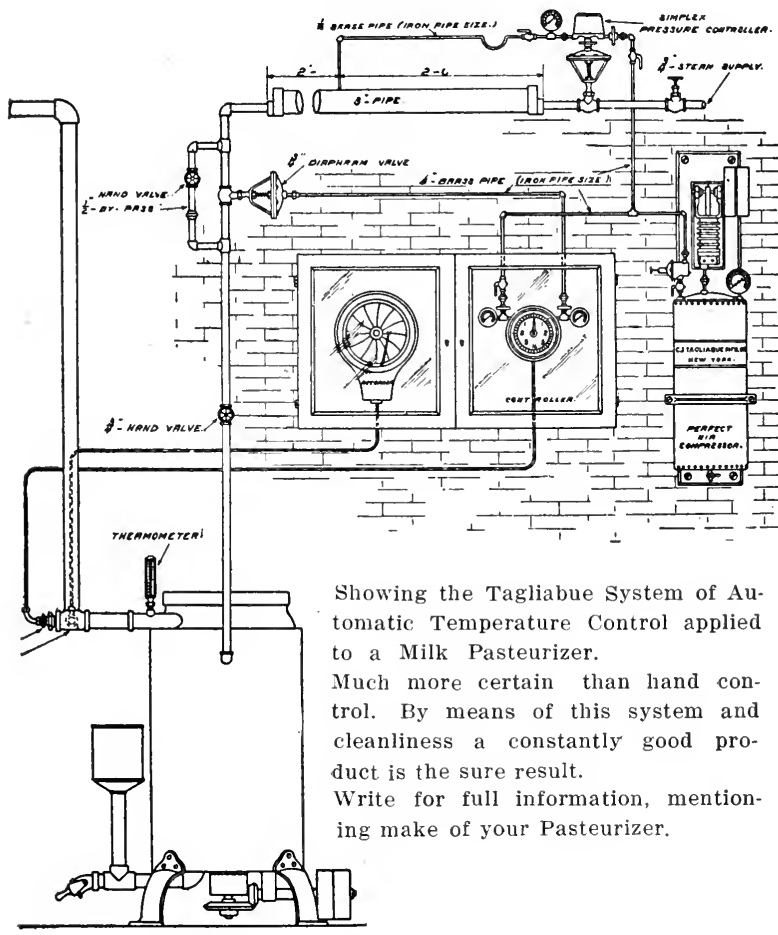

\section{J. TAGIAABE MFG. CO.}

Boston

Philadelphia

Pittsburgh Cleveland
18 to 8.5 Thirty-Third Street

BROOKLYN, NEW YORK
Chicago

St. Louis

New Orleans San Francisco 


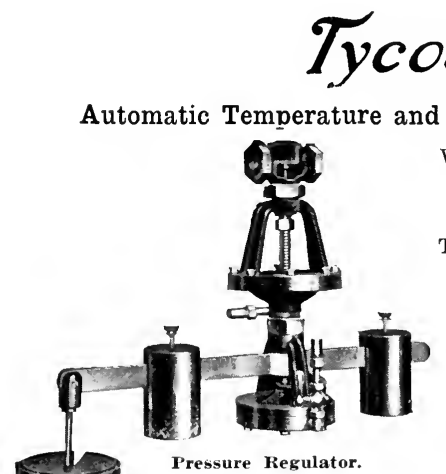

Will control Temperature in the sterilizer with neglible variation.

Thousands being used daily for many applications.

LOW COST

Practically Indestructible.

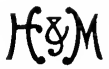

Thermometers for any and all applications. Write for catalog.

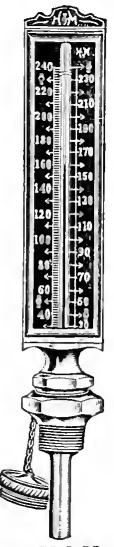

H \& M

Thermometer
ASK FOR FACTS

\section{"Tycos" Recording Thermometer.}

It will work for you every minute, every hour, every day.

If the temperature does vary it writes it all down in in $\mathrm{k}$ for you.

It is doing something every instant and you cannot get away from the truth it tells.

The Tycos Recording Thermometer is made for any application covering temperature ranges from $40^{\circ}$ below 0 to $1000^{\circ}$ above 0 .

It operates by the expansion and contraction of mercury.

\section{"Tycos" Time Valve An Automatic Cooker}

It does its work completely. Shuts off steam and opens the exhaust automatically and simultaneously at just the right moment.

\section{The H\&M Division \\ Taylor Instrument Companies}

Rochester, N.Y.

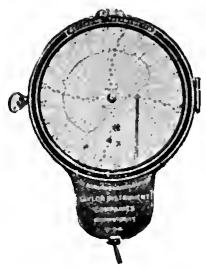

Recording Thermometer. 


\section{The Engineering Company Fort Wayne, Indiana}

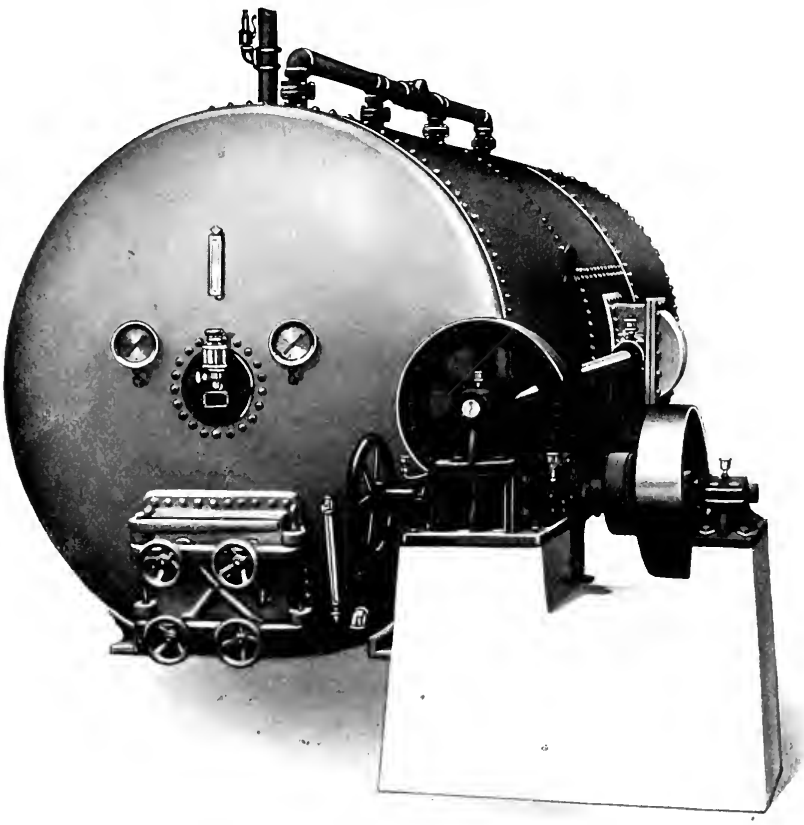

We huild sterilizers from 40 eases per charge to 270 cases per charge and all intermediate sizes. The latest scientific and merhanical ideas are embodied in this machine. It is sanitary; the distribution of heat is absolute and under full control of the operator; it reunires less operating power, water and steam than any other style of sterilizer; it saves time in loading and unloading, cannot be overbalanced, has no exposed years and runs silently. Onr shakers are constructed with a wide range of capacity and are giving excellent satisfaction.

The material used on all our machines is the very best that money can purchase, and with our organized system and our corps of first-class mechanics, we are well prepared to keef abreast of any new improvements.

\section{THE ENGINEERING CO. Fort Wayne, Indiana}




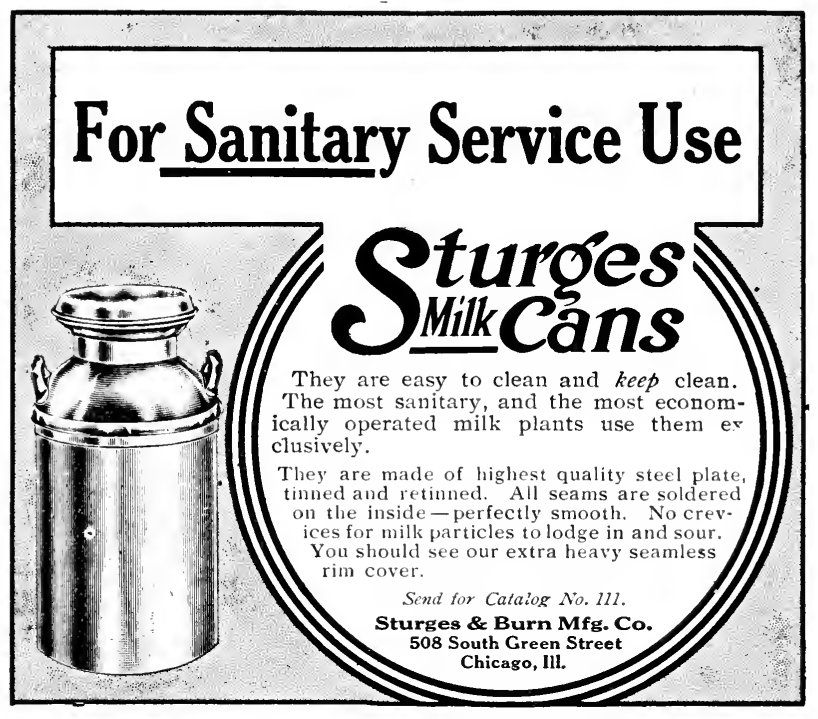

\section{TORSION BALANCE CREAMERY SCALES}

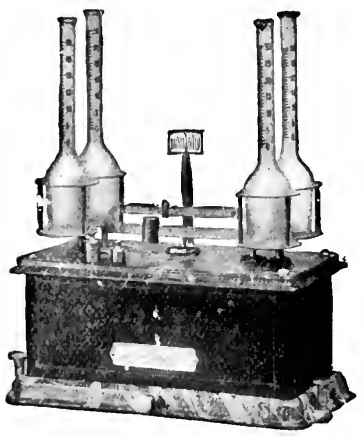

Style No. 1530.

Evaporated Milk Scale

Factory and Works:

1479 Eighth St.

Jersey City, N. J.

\section{No knife-edges-No Friction-- No Wear \\ Sensitive and Accurate}

No loose parts to shift. Working parts practically in one piece.

Torsion Balance four bottle Cream Test Scale Style 1530 is mostly used by collection stations, creameries and milk condenseries on account of its extreme accuracy.

Your profits depend on your tests as much as anything else, probably more so.

\section{The Torsion Balance Company}

Manufacturers of Special Scales for Special Purposes

Pacific Coast Branch: 50.52 California St. San Francisco, Cal.

Office:

92 Reade St., New York, N. Y. 


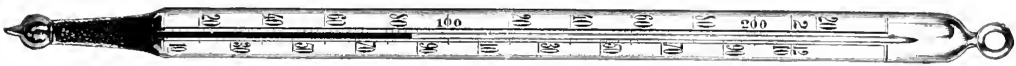
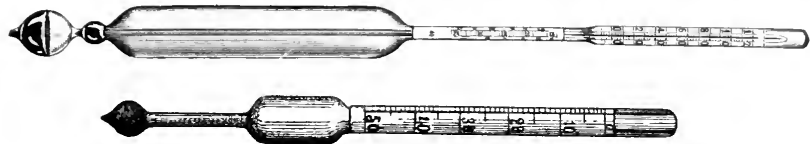

\section{THE WAGNER PRECISION BABCOCK GLASSWARE}
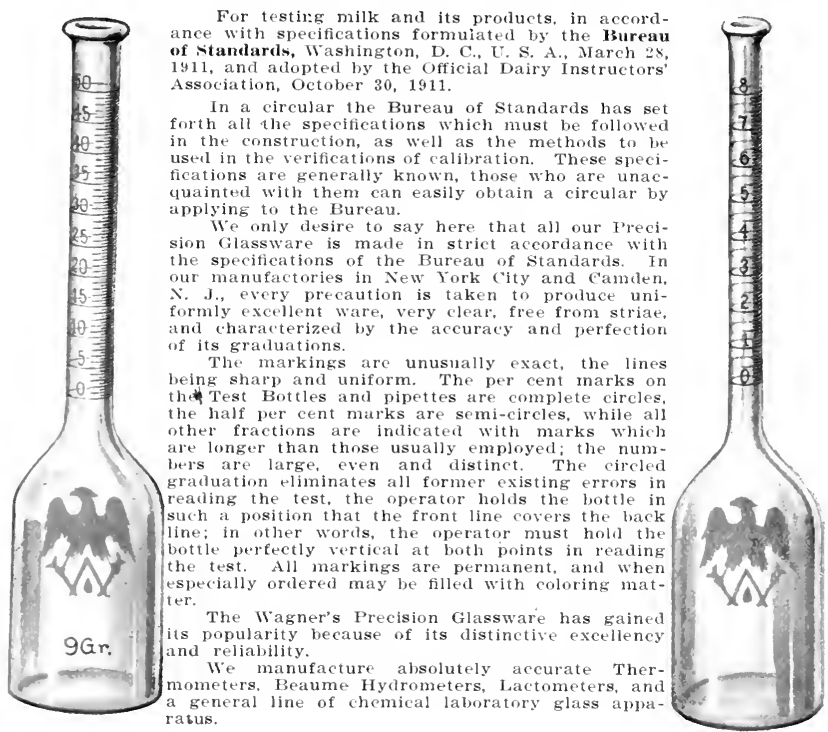

\section{THE WAGNER GLASS WORKS 695-697 E. 132d St., NEW YORK CITY}




\section{Perfection Brand Butter Color LAKTONE AND CHEESE COLOR Both Purely Vegetable}

C. T. No. 2-For preserving milk samples for composite testing. CLEARLINE-Facilitates the reading of tests. Eliminates the meniscus.

These well known creamery requisites are manufactured by THE PRESERVALINE MFG. CO. - Brooklyn, New York City.

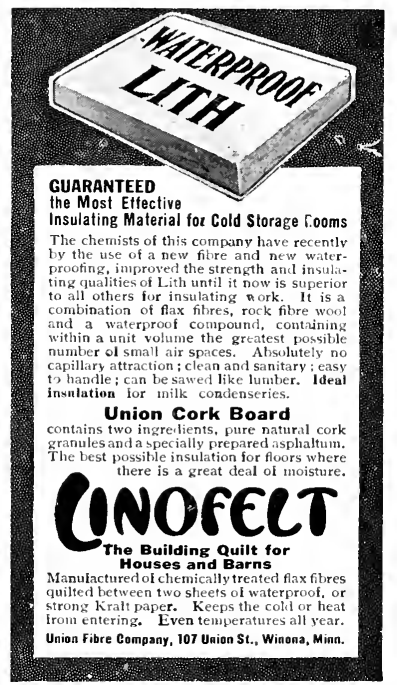




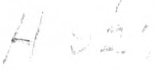



